12

\title{
Summary Report on Close-Coupled Subsurface Barrier Technology Initial Field Trials to Full-Scale Demonstration
}

\author{
John H. Heiser \\ Environmental \& Waste Technology Center \\ Brookhaven National Laboratory \\ Brian Dwyer \\ Mixed Waste Landfill Integrated Demonstration \\ Sandia National Laboratory

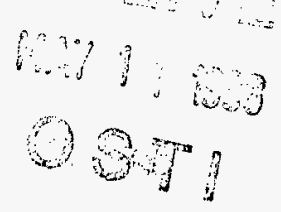

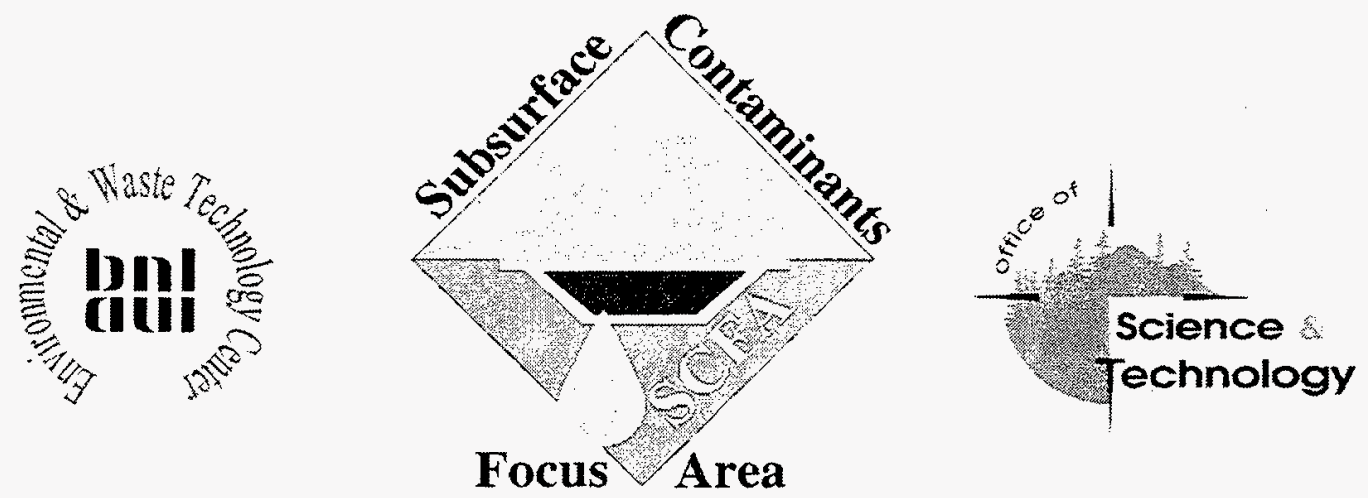
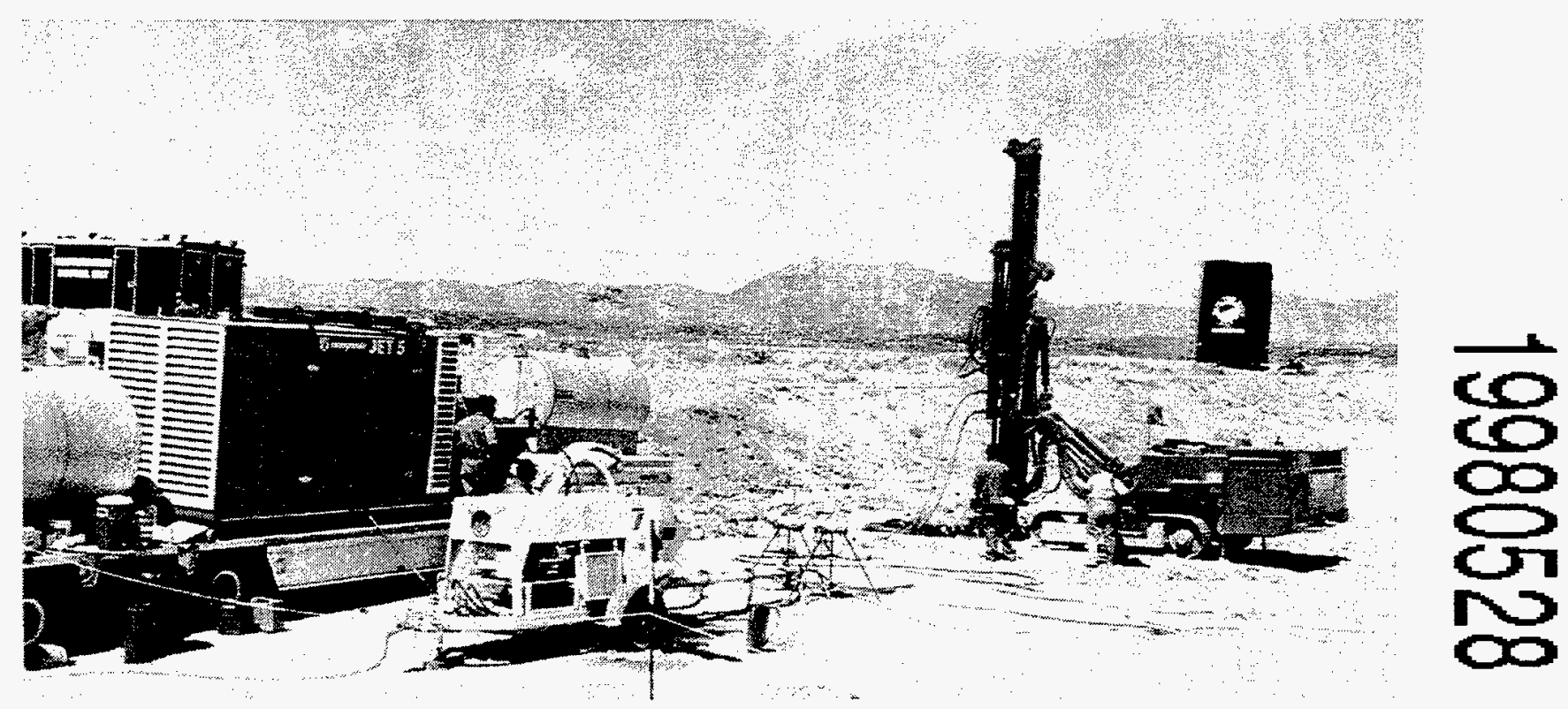

Prepared for the

United States Department of Energy

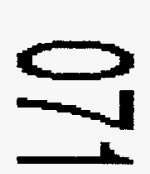

Office of Science and Technology

Environmental Management-50

Contract No. DE-AC02-76CH00016

DISTRIBUTION STATEMINT 


\section{DISCLAIMER}

This report was prepared as an account of work sponsored by an agency of the United States Government. Neither the United States Government nor any agency thereof, nor any of their employees, makes any warranty, express or implied, or assumes any legal liability or responsibility for the accuracy, completeness, or usefulness of any information, apparatus, product, or process disclosed, or represents that its use would not infringe privately owned rights. Reference herein to any specific commercial product, process, or service by trade name, trademark, manufacturer, or otherwise does not necessarily constitute or imply its endorsement, recommendation, or favoring by the United States Government or any agency thereof. The views and opinions of authors expressed herein do not necessarily state or reflect those of the United States Government or any agency thereof. 
BNL-52531

\title{
Summary Report on Close-Coupled Subsurface Barrier Technology
} Initial Field Trials to Full-Scale Demonstration

\author{
John H. Heiser \\ Environmental \& Waste Technology Center \\ Brookhaven National Laboratory \\ Brian Dwyer \\ Mixed Waste Landfill Integrated Demonstration \\ Sandia National Laboratory
}

September 1997

Contributors:

George Frost, 3M Company, Inc. Jerry Alexander, AGEC, Inc. Steve Phillips, AGEC, Inc.

Willis Stewart, AGEC, Inc. Seleste A. Williams, AGEC, Inc.
Laurence Milian, BNL

Gunnar Senum, BNL

Terry Sullivan, BNL

Richard Farnsworth, INEEL

Guy Loomis, INEEL

David Reichhardt, MSE-TA, Inc.

DISTRIBUTION OF THIS DOCUMENT IS URUMMITED

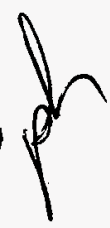

MASTER

Prepared for the

United States Department of Energy

Office of Science and Technology

Environmental Management-50

Contract No. DE-AC02-76CH00016 


\begin{abstract}
The primary objective of this project was to develop and demonstrate the installation and measure the performance of a close-coupled barrier for the containment of subsurface waste or contaminant migration. A close-coupled barrier is produced by first installing a conventional, low-cost, cement-grout containment barrier followed by a thin lining of a polymer grout. The resultant barrier is a cement-polymer composite that has economic benefits derived from the cement and performance benefits from the durable and resistant polymer layer. The technology has matured from a regulatory investigation of the issues concerning the use of polymers to laboratory compatibility and performance measurements of various polymer systems to a pilotscale, single column injection at Sandia to full-scale demonstration. The feasibility of the closecoupled barrier concept was proven in a full-scale "cold" demonstration at Hanford, Washington and then moved to the final stage with a full-scale demonstration at an actual remediation site at Brookhaven National Laboratory (BNL). At the Hanford demonstration the composite barrier was emplaced around and beneath a 20,000 liter tank. The secondary cement layer was constructed using conventional jet grouting techniques. Drilling was completed at a $45^{\circ}$ angle to the ground, forming a cone-shaped barrier. The primary barrier was placed by panel jet-grouting with a dualwall drill stem using a two part polymer grout. The polymer chosen was a high molecular weight acrylic. At the BNL demonstration a V-trough barrier was installed using a conventional cement grout for the secondary layer and an acrylic-gel polymer for the primary layer. Construction techniques were identical to the Hanford installation.
\end{abstract}

This report summarizes the technology development from pilot- to full-scale demonstrations and presents some of the performance and quality achievements attained. Use of dual-wall drill pipe to inject two-fluid, thermosetting-polymer grouts was proven to be safe and reliable. Jet grouting was proven to be capable of installing a continuous barrier without affecting the waste form. The demonstration also provided on a proof-of-concept level the ability to emplace a barrier integrity verification system at the site. Excavation, visual inspection and a falling-head permeability test provided positive evidence that the barrier was indeed fault free. All of the project objectives were met for the BNL pit G-11 close-coupled barrier. A closecoupled barrier was successfully installed that achieved all of the performance requirements with no technical complications. Both the close-coupled barrier concept and the use of dual-fluid injection of thermosetting polymers are now considered ready for commercial application. 


\section{TABLE OF CONTENTS}

ABSTRACT $\ldots \ldots \ldots \ldots \ldots \ldots \ldots \ldots \ldots \ldots \ldots \ldots \ldots \ldots$ iii

LIST OF FIGURES $\ldots \ldots \ldots \ldots \ldots \ldots \ldots \ldots \ldots \ldots$ vii

LIST OF ACRONYMS AND ABBREVIATIONS $\ldots \ldots \ldots \ldots \ldots \ldots \ldots$

EXECUTIVE SUMMARY $\ldots \ldots \ldots \ldots \ldots \ldots \ldots \ldots \ldots \ldots \ldots \ldots \ldots$

ACKNOWLEDGMENTS $\ldots \ldots \ldots \ldots \ldots \ldots \ldots \ldots \ldots \ldots \ldots \ldots \ldots \ldots$

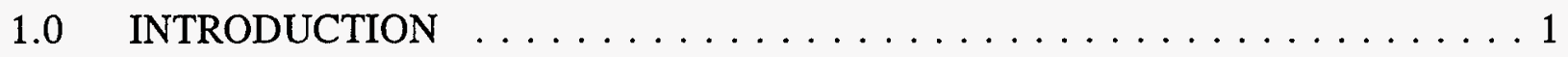

2.0 POLYMER BARRIER MATERIALS $\ldots \ldots \ldots \ldots \ldots \ldots \ldots \ldots \ldots \ldots \ldots \ldots$

3.0 CLOSE-COUPLED BARRIER CONCEPTUAL DESIGN $\ldots \ldots \ldots \ldots \ldots 7$

4.0 PILOT-SCALE FIELD TESTS $\ldots \ldots \ldots \ldots \ldots \ldots \ldots \ldots$

4.1 Single Column Injection at the Sandia Chemical Waste Landfill . . . . . . . 9

4.1 .1 Lessons learned . . . . . . . . . . . . . . . . 14

4.2 Proving the Dual-Fluid Injection Technique for Polymer Grouts . . . . . . 15

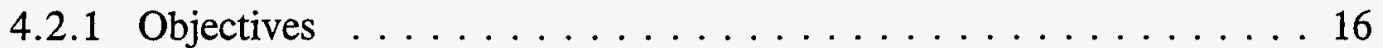

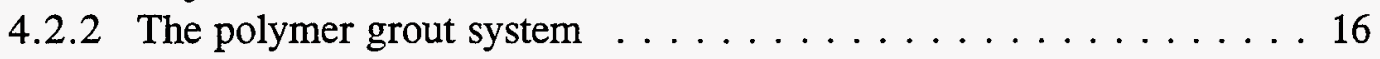

4.2.3 Modifications to the Casa Grande C-6S Jet Grouting Unit $\ldots \ldots .17$

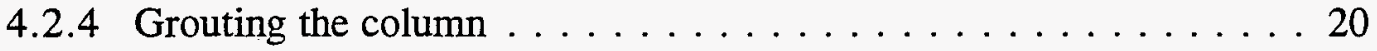

4.2.5 Results of the single-column test at INEEL . . . . . . . 30

5.0 FULL-SCALE DEMONSTRATION OF THE CLOSE-COUPLED BARRIER TECHNOLOGY AT THE DOE HANFORD SITE $\ldots \ldots \ldots \ldots \ldots \ldots \ldots$

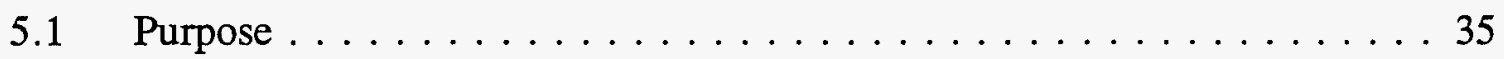

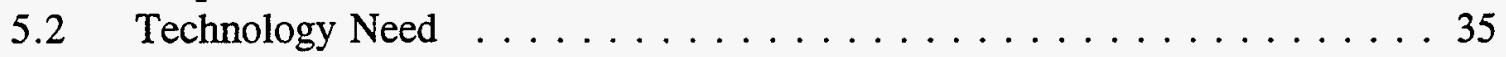

5.3 Technology Benefits . . . . . . . . . . . . . . . 36

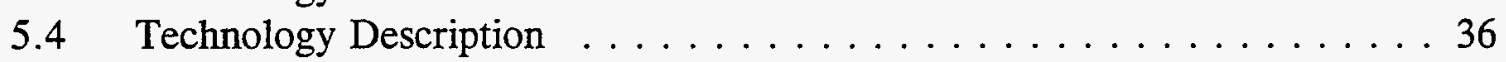

$5.5 \quad$ Scope . . . . . . . . . . . . . . . . . . . 41

5.6 Performance Objectives $\ldots \ldots \ldots \ldots \ldots \ldots \ldots \ldots \ldots \ldots \ldots$

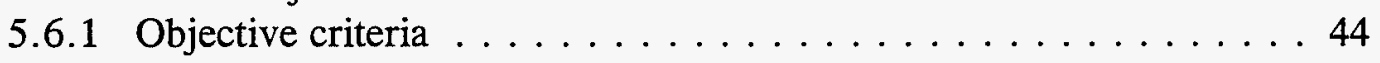

5.6 .2 Demonstration parameters $\ldots \ldots \ldots \ldots \ldots \ldots \ldots \ldots$

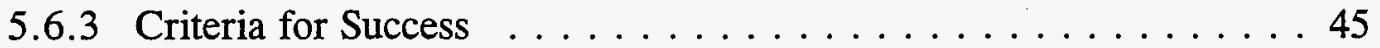

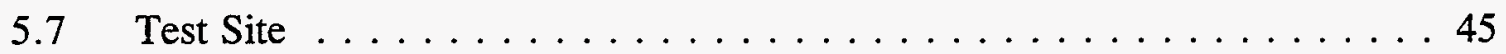

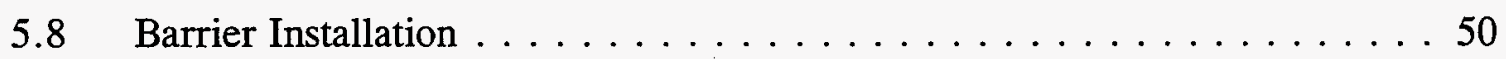

5.8.1 Environment, safety \& health requirements $\ldots \ldots \ldots \ldots \ldots 0$

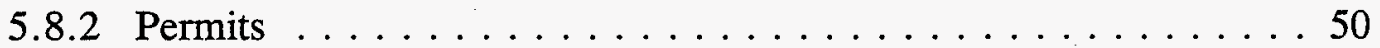

5.8 .3 Installation of the cement layer $\ldots \ldots \ldots \ldots \ldots \ldots \ldots$

5.8 .4 Installation of the polymer layer $\ldots \ldots \ldots \ldots \ldots \ldots \ldots$ 


\section{TABLE OF CONTENTS (cont.)}

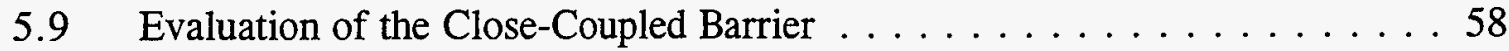

5.9 .1 Visual inspection of the barrier $\ldots \ldots \ldots \ldots \ldots \ldots \ldots \ldots$

5.9 .2 Field Permeability Testing . . . . . . . . . . . . 65

5.9 .3 Laboratory evaluation of core samples . . . . . . . . . . 65

5.9.3.1 Hydraulic conductivity measurements . . . . . . . . 66

5.9.3.2 Unconfined compressive strength testing . . . . . . . 70

5.9.3.3 Barrier homogeneity . . . . . . . . . . . . 70

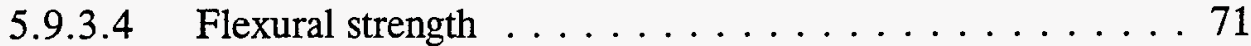

5.9.3.5 Immersion test of cores . . . . . . . . . . 72

5.9.3.6 Wet-dry cycling of cores . . . . . . . . . . 73

5.9.3.7 Conclusions from laboratory testing of cores . . . . . . 76

5.9.4 Evaluating the effect of barrier installation on the waste form . . . . 77

5.10 Meeting the Objectives of the Demonstration . . . . . . . . . 77

6.0 VERIFICATION TECHNOLOGIES TO ACCESS THE INTEGRITY OF THE CLOSE-COUPLED BARRIER $\ldots \ldots \ldots \ldots \ldots \ldots \ldots \ldots \ldots \ldots$

6.1 Proof-Of-Concept Demonstration of the Perfluorocarbon Tracer

Verification Technology $\ldots \ldots \ldots \ldots \ldots \ldots \ldots \ldots \ldots \ldots$

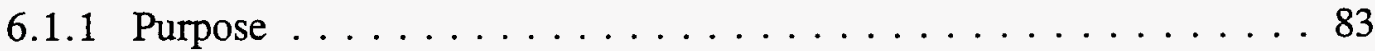

6.1 .2 Technology need $\ldots \ldots \ldots \ldots \ldots \ldots \ldots \ldots \ldots \ldots \ldots$

6.1 .3 Technology benefits $\ldots \ldots \ldots \ldots \ldots \ldots \ldots \ldots \ldots$

6.1 .4 Technology Description . . . . . . . . . . . . . . 84

6.1 .5 Scope . . . . . . . . . . . . . . . . 85

6.1 .6 Performance objective $\ldots \ldots \ldots \ldots \ldots \ldots \ldots \ldots$

6.1.6.1 Objective criteria . . . . . . . . . . . 86

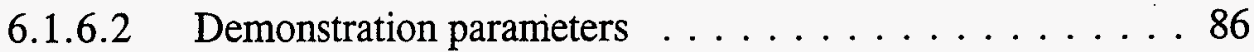

6.1 .6 .3 Criteria for success . . . . . . . . . . . . . . . 86

6.1 .7 Experimental systems $\ldots \ldots \ldots \ldots \ldots \ldots \ldots \ldots$

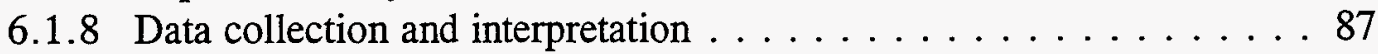

6.1.8.1 Conceptual model . . . . . . . . . . . . . . . 991

6.1.8.2 Computational model for the Hanford test site . . . . . . 92

6.1.8.3 Model results . . . . . . . . . . . . . 94

6.1.8.3.1 Model projections prior to data collection . . . . . 994

6.1.8.3.2 Effect of a breach on projected release from the barrier .............. . . 98

6.1.8.4 Comparison of experimental results with model predictions . . . . . . . . . . . . . . . 99

6.1.8.4.1 Modeling transport through the close-coupled

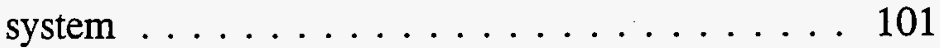

6.1 .9 Conclusions . . . . . . . . . . . . . . . . . . 107

6.2 Using Ground Penetrating Radar to Access the Subsurface Barrier . . . . . . 108

6.2 .1 Purpose . . . . . . . . . . . . . . . . . . 108

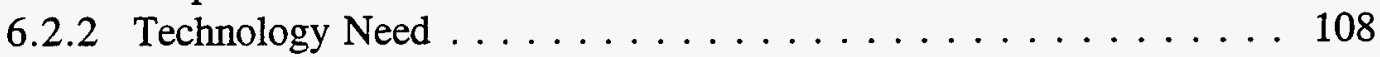




\section{TABLE OF CONTENTS (cont.)}

6.2.3 Technology Benefits . . . . . . . . . . . . . . . . . 108

6.2.4 Technology Description . . . . . . . . . . . . . . . . . . . 109

6.2 .5 Scope . . . . . . . . . . . . . . . . . . . . . . . . . . . . 109

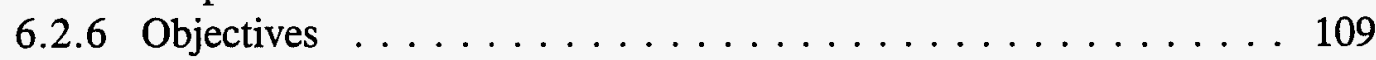

6.2.8 Results and Conclusions . . . . . . . . . . . . . . . . 109

7.0 IMPLEMENTATION OF CLOSE-COUPLED BARRIER TECHNOLOGY AT THE BROOKHAVEN NATIONAL LABORATORY CHEMICAL/

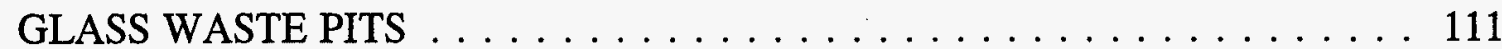

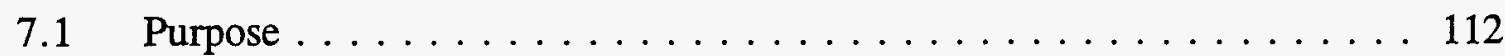

$7.2 \quad$ Need . . . . . . . . . . . . . . . . . . . 112

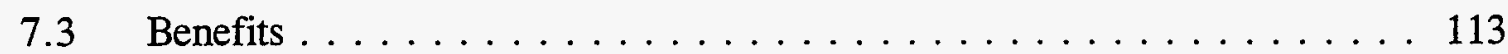

7.4 Technology Description $\ldots \ldots \ldots \ldots \ldots \ldots \ldots \ldots \ldots \ldots \ldots$

7.5 Scope . . . . . . . . . . . . . . . . . . . . . . . 119

7.6 Objectives . . . . . . . . . . . . . . . . . . . . . . . 119

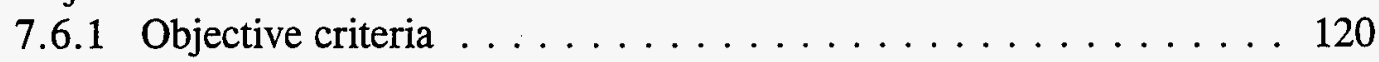

7.6.2 Demonstration parameters $\ldots \ldots \ldots \ldots \ldots \ldots \ldots \ldots$

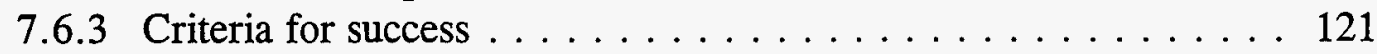

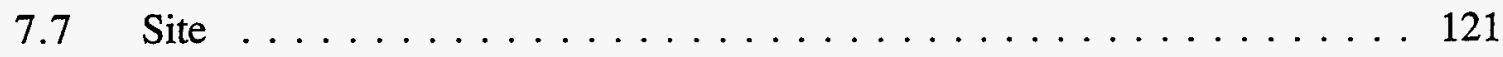

7.8 Barrier Installation and In-Situ Stabilization Demonstration . . . . . . . 126

7.8.1 Environmental, safety and health requirements . . . . . . . 126

7.8.1.1 National Environmental Policy Act . . . . . . . . . 126

7.8.1.2 Resource Conservation and Recovery Act . . . . . . 126

7.8.1.3 Clean Air Act . . . . . . . . . . . . . . . 127

7.8.1.4. Emergency Planning and Community Right-to-Know . . 127

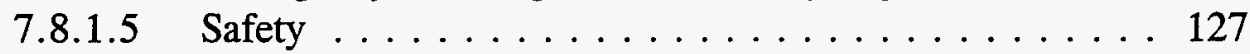

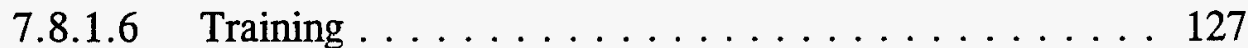

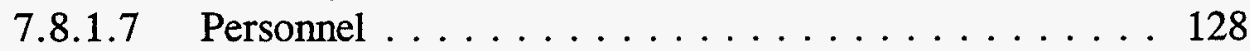

7.8 .2 Installation of the cement layer $\ldots \ldots \ldots \ldots \ldots \ldots \ldots \ldots$

7.8 .3 Installation of the polymer layer . . . . . . . . . . . . 129

7.8.3.1 AC-400 acrylic polymer grout . . . . . . . . . . . 129

7.9 Verification of the Barrier Continuity . . . . . . . . . . . . . 130

7.10 In-Situ Stabilization of the Pit Waste . . . . . . . . . . . 133

7.11 Excavation of the barrier and in-situ stabilized waste form . . . . . . . . 142

7.12 Laboratory Evaluation of the Barrier . . . . . . . . . . . 154

7.13 Meeting the Demonstration Objectives . . . . . . . . . . . . 159

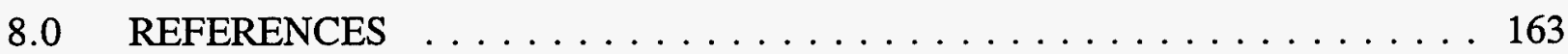

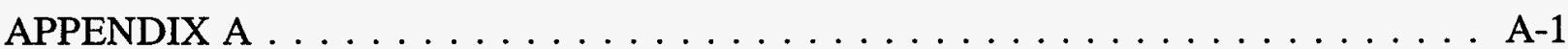




\section{LIST OF FIGURES}

Figure 1.1

Figure 1.2

Figure 4.1

Figure 4.2

Figure 4.3

Figure 4.4

Figure 4.5

Figure 4.6

Figure 4.7a

Figure $4.7 \mathrm{~b}$

Figure $4.7 \mathrm{c}$

Figure 4.8

Figure 4.9

Figure 4.10

Figure 4.11

Figure 4.12

Figure 4.13

Figure 4.14

Figure 5.1

Figure 5.2

Figure 5.3

Figure 5.4

Figure 5.5

Figure 5.6

Figure 5.7

Figure 5.8

Figure 5.9

Figure 5.10

Figure 5.11

Figure 5.12

Figure 5.13a

Figure 5.13b

Figure 5.14

Figure 5.15

Figure 5.16

Figure 5.17

Subsurface barriers prevent contaminant spread 2

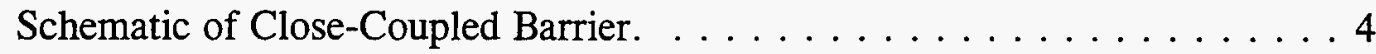

Casa Grande C-6S jet grouting unit $\ldots \ldots \ldots \ldots \ldots \ldots \ldots \ldots$

Temperature History of Acrylic Resins During Polymerization . . . . . . . 13

Time to on set of gel formation for acrylic resins (normalized for aging). . . 13

Schematic of Dual-Wall Drill Stem . . . . . . . . . . . . . . 18

Photograph of the dual-wall drill stem and tip . . . . . . . . . . . 19

Schematic of the two-part polymer grout delivery system . . . . . . 21

Photograph of the polymer grout delivery equipment (drill rig) . . . . . . 22

Photograph of the polymer grout delivery equipment (grout pumping system). 23

Transfer polymers from drums to holding tanks . . . . . . . . . 24

Photograph of the pneumatic transfer pump used to move grouts from drums to 1500 liter (400 gallon) supply tanks

Photograph of a 1500 liter (400 gallon) supply tank used for one

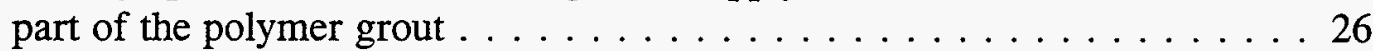

Photograph of the low-pressure Schwing pump used to deliver part B $\ldots 27$

Photograph of the high pressure pump used to deliver part A . . . . 28

Photograph of the flow meter used to measure grout flow rates . . . . . . 29

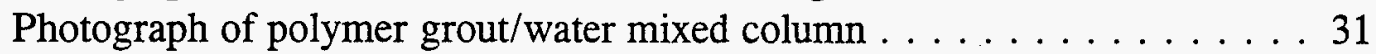

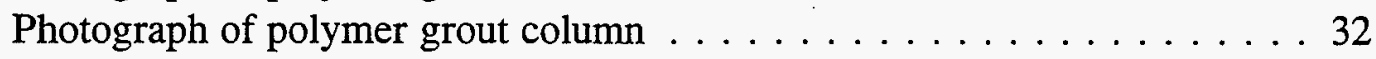

Schematic representation of jet grouting. . . . . . . . . . . 38

Photograph of excavated cement column formed by jet grouting . . . . . 39

Water being jetted at 70 bars (1000 psi) during flow calibration . . . . . 40

Plan view of the close-coupled barrier at the Hanford site . . . . . . . . 42

Cross-sectional view [A-A] of the Close-Coupled Barrier at Hanford. . . . 43

Tracer monitoring well locations in relation to the barrier . . . . . 48

Photograph of the Hanford demonstration site . . . . . . . . . . 49

Slurry pump used to transfer cement grout to the high pressure pump . . . . 52

Schematic of triangular pitch column layout . . . . . . . . . . 53

Photograph of excavated polymer test column installed using panel

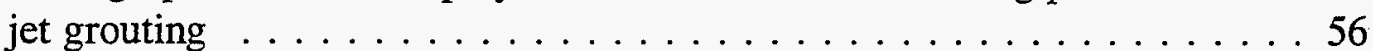

Layout of polymer panels for cone-shaped barrier . . . . . . . . . 57

Photograph of excavation of the exterior portion of the cement layer of

the Hanford barrier . . . . . . . . . . . . . . . . . . . . 60

Photograph of excavated barrier showing adjoining polymer panels . . . . 61

Photograph of excavated barrier showing adjoining polymer panels . . . . 62

Gap between polymer layer and cement layer . . . . . . . . . 63

Gap between two cement column due to misalignment of drilling . . . . 64

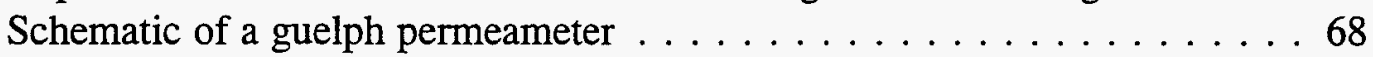

Flexible wall permeameter cell and control panel . . . . . . . . 69 


\section{LIST OF FIGURES (cont.)}

Figure 5.18 Flexible wall permeameter with polymer grout specimen sealed with a latex membrane . . . . . . . . . . . . . . . . . . . . 69

Figure 5.19 Cross-sections of polymer cores taken from the Hanford barrier . . . . . . 71

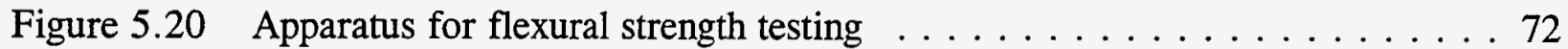

Figure 5.21 Weight history of Hanford barrier core samples during wet-dry cycling . . 74

Figure 5.22 Weight history of Hanford barrier core samples during dry cycling . . . . 75

Figure 6.1 Layout of barrier system used in modeling perfluorocarbon tracer transport . 88

Figure 6.2 Schematic representation of barrier configuration for tracer modeling . . . . 89

Figure 6.3 Ground view of the Hanford subsurface barrier system . . . . . . . . . 90

Figure 6.4 Finite element grid used to simulate transport through the subsurface barrier system . . . . . . . . . . . . . . . . . 93

Figure 6.5 Concentrations at 14.6 days for an intact barrier with a soil diffusion coefficient of $10^{-2} \mathrm{~cm}^{2} / \mathrm{s}$ and a barrier diffusion coefficient of $10^{-4} \mathrm{~cm}^{2} / \mathrm{s} \ldots 95$

Figure 6.6 Contour plot color key (normalized concentration) . . . . . . . . . . 96

Figure 6.7 Concentrations at 14.6 days for a barrier with a $5 \mathrm{~cm}$ breach and a soil diffusion coefficient of $10^{-2} \mathrm{~cm}^{2} / \mathrm{s}$ and a barrier diffusion

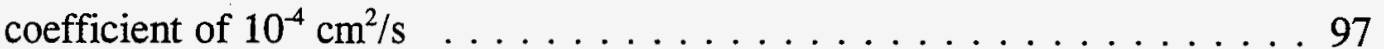

Figure 6.8 Time history of normalized PFT concentration in the seven exterior wells . 100

Figure 6.9 Comparison of the time history of the average monitoring well concentrations with model results . . . . . . . . . . . . . . . . 102

Figure 6.10 Sampling tubes in an exterior monitoring well. Each tube samples from a different depth . . . . . . . . . . . . . . . . . . . . . . . . 104

Figure 6.11 Each monitoring well was packed with sand to isolate sampling locations . 105

Figure 7.1 Schematic of V-trough close-coupled barrier . . . . . . . . . . . . . 114

Figure 7.2 Plan view of the V-trough barrier installed at Brookhaven National

Figure 7.3 Side view [A-A] of the V-trough barrier installed at Brookhaven National Laboratory . . . . . . . . . . . . . . . . . . . . . . 117

Figure 7.4 Side view [B-B] of the V-trough barrier installed at Brookhaven National Laboratory . . . . . . . . . . . . . . . . . . . . . . . . . 118

Figure 7.5 Location of Brookhaven National Laboratory on Long Island, New York . 122

Figure 7.6 Map of Brookhaven National Laboratory showing the operable units . . . 124

Figure 7.7 Map of Operable Unit I showing AOC 2C, the Glass Holes disposal area . 125

Figure 7.8 Layout of monitoring and injection wells at the G-11 waste pit barrier . . 131

Figure 7.9 Geoprobe unit used to install monitoring wells . . . . . . . . . . 132

Figure 7.10 Normalized ocPDCH concentrations at the four interior wells . . . . . 134

Figure 7.11 Normalized ocPDCH concentrations from the well designated as E-1 at the 6 meters (20 feet) location . . . . . . . . . . . . . . . . 135

Figure 7.12 Plan view of in-situ stabilization of waste pit $\ldots \ldots \ldots \ldots \ldots 136$

Figure 7.13 Cross-sectional [A-A] view of in-situ stabilization of waste pit $\ldots \ldots \ldots 137$ 


\section{LIST OF FIGURES (cont.)}

Figure 7.14 Cross-sectional [B-B] view of in-situ stabilization of waste pit $\ldots \ldots \ldots 138$

Figure 7.15 Plastic sheet piling was used to outline the pit stabilization zone . . . . 139

Figure 7.16a Photograph of spiral wound tubing for application of demolition grout . . 140

Figure 7.16b Photograph of spiral wound tubing for application of demolition grout . . 141

Figure 7.17 Waste pit after stabilization activities showing spiral-wound tubing

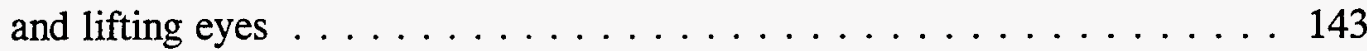

Figure 7.18 Cracking induced by demolition grout . . . . . . . . . . . . . . 144

Figure 7.19 Monolithic cells were formed that are $1.3 \mathrm{M}$ by $1.3 \mathrm{M}$ ( $4 \mathrm{ft}$ by $4 \mathrm{ft}) \ldots \ldots 145$

Figure 7.20 Gas cylinders disposed of in pit G-11 . . . . . . . . . . . 147

Figure 7.21 Metal 55 gallon drum disposed of in pit G-11 . . . . . . . . . . . 148

Figure 7.22 Section of in-situ stabilized waste form retrieved from pit G-11 . . . . 149

Figure 7.23 Section of in-situ stabilized waste form retrieved from pit G-11 . . . . . 150

Figure 7.24 Cross-section of waste form showing chemical bottle encased in grout . . . 151

Figure 7.25 Section of waste form from pit G-11 showing encapsulated glass bottles . . 152

Figure 7.26 Section of pit G-11 waste form showing solidified waste . . . . . . . 153

Figure 7.27 Section of the cement layer of the BNL close-coupled barrier showing adjacent columns $\ldots \ldots \ldots \ldots \ldots \ldots \ldots \ldots \ldots$

Figure 7.28 Side view of a jet-grouted column from the BNL close-coupled barrier . . 156

Figure 7.29 Top view of a section of a vertical wall from the BNL closecoupled barrier showing the overlap of columns . . . . . . . . 157

Figure 7.30 Cross-section of a jet-grouted column from the BNL close-coupled barrier 158 


\section{LIST OF ACRONYMS AND ABBREVIATIONS}

3M 3M Company, Inc.

AGEC Applied Geotechnical Engineering and Construction, Inc.

BNL Brookhaven National Laboratory

BPO benzoyl peroxide

CATS capillary adsorbent tracer sampler

CWL Chemical Waste Landfill (Sandia)

DOE United States Department of Energy

EPA United States Environmental Protection Agency

EWTC Environmental \& Waste Technology Center (Brookhaven)

GPR ground penetrating radar

GSSI Geophysical Survey Systems, Inc.

HGDTF Hanford Geotechnical Development and Test Facility

INEEL Idaho National Engineering and Environmental Laboratory

MSE MSE Technology Applications, Inc.

MWLID Mixed Waste Landfill Integrated Demonstration

OER

PFT

Office of Environmental Restoration

SNL perfluorocarbon tracer

TCE

TRU

TTP

Sandia National Laboratory

trichloroethylene

UST

transuranic

technical task plan

WHC

underground storage tank

Westinghouse Hanford Company 


\section{EXECUTIVE SUMMARY}

The purpose of this report is to provide a summary of the close-coupied subsurface barrier technology development from pilot- to full-scale demonstrations. The report includes some of the performance and quality achievements attained. The primary objective of this project was to develop and demonstrate the installation, and to measure the performance, of a close-coupled barrier for the containment of subsurface waste or contaminant migration. A close-coupled barrier is produced by first installing a conventional, low-cost, cement-grout containment barrier, followed by a thin lining of a polymer grout. The resultant barrier is a cement-polymer composite that has economic benefits derived from the cement, and performance benefits from the durable and resistant polymer layer.

Sites within the U.S. Department of Energy (DOE) complex have experienced numerous loss of confinement failures during the past five decades, from underground storage tanks (USTs), piping systems, vaults, landfills, and other structures containing hazardous and mixed wastes. One of the options for control of contaminant migration from such buried waste sites is the construction of a subsurface barrier that consists of a wall of low permeability material. Subsurface barriers increase the performance of waste disposal sites by removing pathways for contaminant transport due to groundwater movement, meteorological water infiltration, vapor- and gas-phase transport, and transpiration. In addition, subsurface barriers can be constructed to envelop a site or plume completely, there by containing the contaminants and any potential leakage. Impermeable barriers may be used to contain contaminant plumes during remediation, to "direct" contaminant movement to collection sumps/lysimeters in cases of unexpected remediation failures or transport mechanisms, to contain leakage from underground storage tanks, or to restrict in-situ soil cleanup operation and chemicals. They may be used alone or in combination with techniques such as groundwater pumping, subsurface drains, and in-situ biological or chemical treatment methods. Such in-situ treatment could result in large cost savings and reduced worker exposure as compared to conventional restoration technologies (e.g., excavation, retreatment and re-disposal of the waste), in addition to preventing spread of contamination (and resultant clean-up costs).

The Environmental Protection Agency (EPA) has considered subsurface barriers to be among the technologies potentially applicable to remediation of waste sites. For example, such subsurface barriers may consist of low permeability cut-off walls or diversions, which are installed below ground to contain, capture, or redirect groundwater flow in the vicinity of a site. The most commonly used subsurface barriers are slurry walls, particularly soil-bentonite slurry walls, but cement-bentonite or concrete slurry walls, grouted barriers, and sheet metal piling cut-offs have been used also for the same purpose, and grouted horizontal barriers have been used to seal the bottoms of contaminated sites. Slurry walls are applicable at Superfund sites, where residual contamination needs to be isolated at its source. Traditional soil-bentonite or cement-bentonite slurry walls can be installed quickly. The construction requirements and practices associated with 
the installation of slurry walls are well understood, since the use of these barriers in the construction industry for de-watering building foundations and excavations is well established. Therefore, slurry walls are considered the baseline barrier technology. Their construction is considered a well-established technology for effectively isolating wastes and containing the migration of hazardous constituents.

Portland cement grout curtains have been used for barriers around waste sites. However, large castings of hydraulic cements invariably result in cracking due to shrinkage, thermal stresses induced by the hydration reactions, and wet-dry cycling prevalent at arid sites. It would be almost impossible using a cementitious grout to achieve the goal of zero tolerance in leak rate for a barrier. Efforts have been promoted to improve containment technologies and to develop better barrier materials, due to the problems associated with slurry wall and cementitous grouts.

Brookhaven National Laboratory (BNL) had been developing improved polymer-grout barrier materials for applications where impermeability and long-term durability are required. These materials have proven commercial applicability such as chemical vats, sewage and brine handling systems, and electrolytic baths. Polymer grouts are candidates for high quality barrier materials due to their impermeability to gases and liquids, combined with their resistance to radiation, acidic, and alkaline environments.

Pilot-scale field tests were conducted including a single column injection at the Sandia chemical waste landfill and a single-column test at INEL. The Sandia test was able to show the ability to use jet grouting technology with thermosetting resins. Dual fluid injection was proven to be the preferred method of injection when using thermosetting polymers. Split stream injection using dual-wall (dual-annulus) drill pipe was the best way to proceed, according to this field test. At INEL, excavation of two test columns was performed. Examination of the first grouted area failed to show development of a solid grouted column. It was clear that the water had adversely impacted the formation of the first column and that the demonstration parameters were in the correct range for forming columns in compacted soil. The INEL in-situ stabilization demonstration proceeded as planned. The second grout column was examined. The column consisted of a solid mixture of the soil and polymer as expected. The second test column was cross-sectioned perpendicular to the drill axis. Several pieces were sliced and all were uniform, void-free pieces. All the objectives of this pilot-scale demonstration were met.

A full-scale demonstration of the close-coupled barrier technology was conducted at the DOE Hanford Site. The close-coupled barrier was evaluated in detail. After completion of the non-intrusive verification studies, the barrier was excavated to determine the success of the verification technologies. Barrier performance determinations included: visual inspection, fallinghead test (water flood test) on the barrier to estimate the in-situ field hydraulic conductivity, and core sampling. Results of this intrusive examination are explained thoroughly. An extensive laboratory evaluation of core samples was performed. After excavation, the final barrier was sampled by coring specimens from various locations throughout the barrier. Cores were taken using standard concrete coring methods. The performance testing that was executed on the cores 
is described at length. The testing focuses mainly on the primary polymer layer, since the secondary cement layer is composed of a standard construction grade grout. Characterization of the cement was done as a quality check only. The feasibility of the close-coupled barrier concept was proven in the full-scale "cold" demonstration at Hanford, Washington, and then moved to the final stage with a full-scale demonstration at an actual remediation site at Brookhaven National Laboratory.

Implementation of close-coupled subsurface barrier technology at the Brookhaven National Laboratory chemical/glass waste pits was successful. All of the project installation objectives were met for the BNL pit G-11 close-coupled barrier. A close-coupled barrier was installed as planned, with no technical complications. The barrier achieved all of the performance requirements. The polymer materials were installed using the dual-fluid injection procedures developed at the INEL and Hanford demonstrations and performed flawlessly. The AC-400 acrylate grout was placed and polymerized as intended. The barrier was installed without disturbing the waste form. The perfluorocarbon tracer (PFT) verification technology was employed successfully to ascertain the integrity of the barrier, prior to stabilizing the waste pit. The PFT verification indicated that the barrier was intact and breach free. Therefore, the stabilization task could be continued. The PFT technology still requires further refinement to determine resolution limitations and to accommodate other complex barrier configurations, but the proof-of-concept was demonstrated. Preliminary testing of core samples are presented. More extensive testing to determine if the performance objectives for the barrier materials were met will be performed during fiscal year 1998. The results of these future tests will be published in a separate report.

Close-coupled subsurface barrier technology has been proven to be both an achievable and a cost-effective remediation technology. The cost of installing a composite barrier can be offset by the cost savings of preventing further contamination of the subsurface, either by inaction or cleanup activities. The economics of close-coupled barriers are discussed briefly and a conclusion is reached that the cost of demonstrated technology compares favorably to many remediation alternatives.

Dual-fluid jet-grouting has been shown to be both a reliable and a commercially feasible technology. A standard jet grouting rig set up for single fluid injections has been modified and is capable of injecting two component, thermosetting polymers, without the problem of early gelation which could clog the fluid pathways. Also, this injection methodology has proven useful for in-situ stabilization of buried waste. In addition, dual-fluid injection of thermosetting polymers may be used for many other remediation needs, such as temporary leak control from underground storage tanks or sewer/discharge lines.

Both the close-coupled barrier concept and the use of dual-fluid injection of thermosetting polymers are considered ready for commercial application. A no-cost cooperative agreement between AGEC, Incorporated, and Sandia National Laboratories was reached in order to further the commercial applicability of the demonstrated close-coupled subsurface barrier technology. 


\section{ACKNOWLEDGMENTS}

The authors would like to thank several people and companies without whom this project would not have proceeded as smoothly. Grover "Skip" Chamberlain and Scott McMullin from U.S. Department of Energy (DOE) for guidance, support and assistance in bringing parties together during the full-scale demonstrations and "hot" implementation. Teresa Baker and Jason Remien from BNL's Office of Environmental Restoration for logistical support and installation of monitoring wells at the BNL demonstration. 3M Company for support in terms of laboratory testing, personnel support at the field trials and developing the specialized polymer grouts. To the BNL Office of Environmental Restoration for complete support and assistance whenever asked. Geochemical Corporation for coming to BNL and performing quality checks on the AC400 acrylate grout, thus assisting in turning a "waste" into a commodity. To all the contributors, thank-you for the cooperation, unity and team-oriented goals that were universal to all. Your attitudes and efforts were refreshing and were the major reason for the complete success of this technology development/demonstration.

This work was funded by the U.S. Department of Energy Office of Science and Technology. 


\subsection{INTRODUCTION}

Over the past five decades, the US Department of Energy (DOE) Complex sites have experienced numerous loss of confinement failures from underground storage tanks (USTs), piping systems, vaults, landfills, and other structures containing hazardous and mixed wastes. One of the options for control of contaminant migration from such buried waste sites is the construction of a subsurface barrier that consists of a wall of low permeability material. Subsurface barriers increase the performance of waste disposal sites (Figure 1.1) by removing pathways for contaminant transport due to groundwater movement, meteorological water infiltration, vapor- and gasphase transport, transpiration, etc. Also, subsurface barriers can be constructed to envelop a site or plume completely, thereby containing the contaminants and any potential leakage. Impermeable barriers may be used to contain contaminant plumes during remediation, to "direct" contaminant movement to collection sumps/lysimeters in cases of unexpected remediation failures or transport mechanisms, to contain leakage from underground storage tanks, or to restrict in-situ soil cleanup operation and chemicals. They may be used alone or in combination with techniques such as groundwater pumping, subsurface drains, and in-situ biological or chemical treatment methods. In addition to preventing spread of contamination (and resultant clean-up costs) such insitu treatment could result in large cost savings and reduced worker exposure when compared to conventional restoration technologies (e.g., excavation, re-treatment and re-disposal of the waste).

The Environmental Protection Agency (EPA) has considered subsurface barriers to be among the technologies potentially applicable to remediation of waste sites. For example, in an EPA handbook intended for use as a basic reference tool on remedial action, EPA devotes a whole section to subsurface barriers consisting of low permeability cut-off walls or diversions which are installed below ground to contain, capture, or redirect groundwater flow in the vicinity of a site. According to this handbook, the most commonly used subsurface barriers are slurry walls, particularly soil-bentonite slurry walls, but cement-bentonite or concrete slurry walls, grouted barriers, and sheet metal piling cut-offs have also been used for the same purpose, and grouted horizontal barriers have been used to seal the bottoms of contaminated sites.

An EPA Engineering Bulletin ${ }^{1}$ describes slurry wall technology. According to this bulletin, slurry walls are applicable at Superfund sites where residual contamination needs to be isolated at its source. Traditional soil-bentonite or cement-bentonite slurry walls can be installed quickly, and, since the use of these barriers in the construction industry for de-watering building foundations and excavations is well established, the construction requirements and practices associated with their installation are well understood. (See, for example, a handbook published by the EPA in $1984 .^{2}$ ) For this reason, slurry walls are considered the baseline barrier technology. As an example of EPA's acceptance of the slurry wall technology, the bulletin notes that in FY 1989, there were 26 records of decision (RODs) specifying the use of slurry walls as part of the remedial action. Their construction is considered a well-established technology for effectively isolating wastes and containing the migration of hazardous constituents. They may be implemented rather quickly in conjunction with other remedial actions, but long-term monitoring is needed to evaluate their effectiveness. ${ }^{1}$ One caution which the EPA literature on slurry walls 


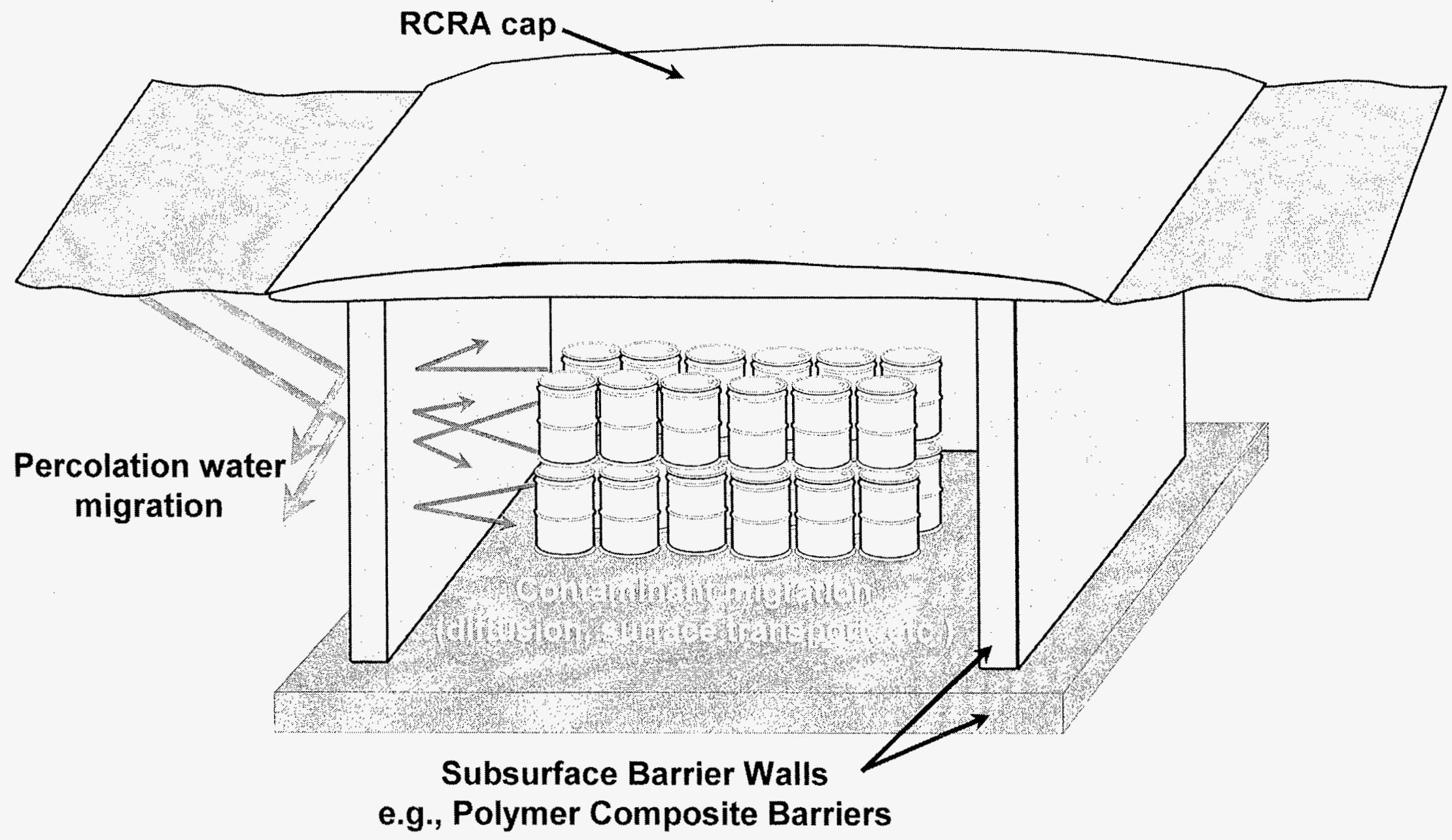

Figure 1.1 Subsurface barriers prevent contamination spread. 
mentions, is the detrimental effect which certain chemicals can have on slurry walls containing bentonite mixtures. ${ }^{1,2,3}$ Certain chemicals can increase the permeability of bentonite mixtures or even result in dissolution of the material. Some organic fluids result in desiccation and cracking of the bentonite material. In any case, the EPA literature emphasizes the necessity of compatibility testing between the slurry wall material and the chemicals it is likely to come in contact with.

Portland cement grout curtains have been used for barriers around waste sites. ${ }^{3}$ However, large castings of hydraulic cements invariably result in cracking due to shrinkage, thermal stresses induced by the hydration reactions, and wet-dry cycling prevalent at arid sites. For a barrier where zero tolerance in leak rate is required it would be nearly impossible to achieve this goal using a cementitious grout. Due to the problems associated with slurry wall and cementitous grouts, the DOE EM-50 has promoted efforts to improve containment technologies and to develop better barrier materials.

Brookhaven National Laboratory (BNL) had been developing improved polymer-grout barrier materials for applications where impermeability and long-term durability are required ${ }^{4,5}$. These materials have proven commercial applicability such as chemical vats, sewage and brine handling systems and electrolytic baths. Polymer grouts are candidates for high quality barrier materials due to their impermeability to gases and liquids, combined with their resistance to radiation, acidic, and alkaline environments. ${ }^{6}$ However, improved chemical and/or physical durability and performance increases the cost of the barrier grout.

Concurrently, Sandia National Laboratory (SNL), through the Mixed Waste Landfill Integrated Demonstration (MWLID), was investigating placement methods and cementitious grouts for subsurface barriers. During the summer of FY94 the MWLID placed several pilot scale jet-grouted cement configurations (v-trough, cone, and $7 \times 7$ matrix) at a site adjacent to the Chemical Waste Landfill at Sandia. During this demonstration, BNL was invited to demonstrate a polymer grout using the same placement equipment. It was at this time that the concept of a close-coupled barrier was developed. A barrier would be produced by first installing a conventional cement grout barrier followed by a thin lining of a polymer grout. The resultant barrier is a cement-polymer composite that has economic benefits derived from the cement and performance benefits from the durable and resistant polymer layer (see figure 1.2). This report will describe the polymer system, the initial pilot-scale injections, the full-scale "cold" installation at Hanford and the full-scale "hot" demonstration at BNL and a unique verification technology using perfluorocarbon tracers that was developed to detect breaches in a subsurface barrier. 


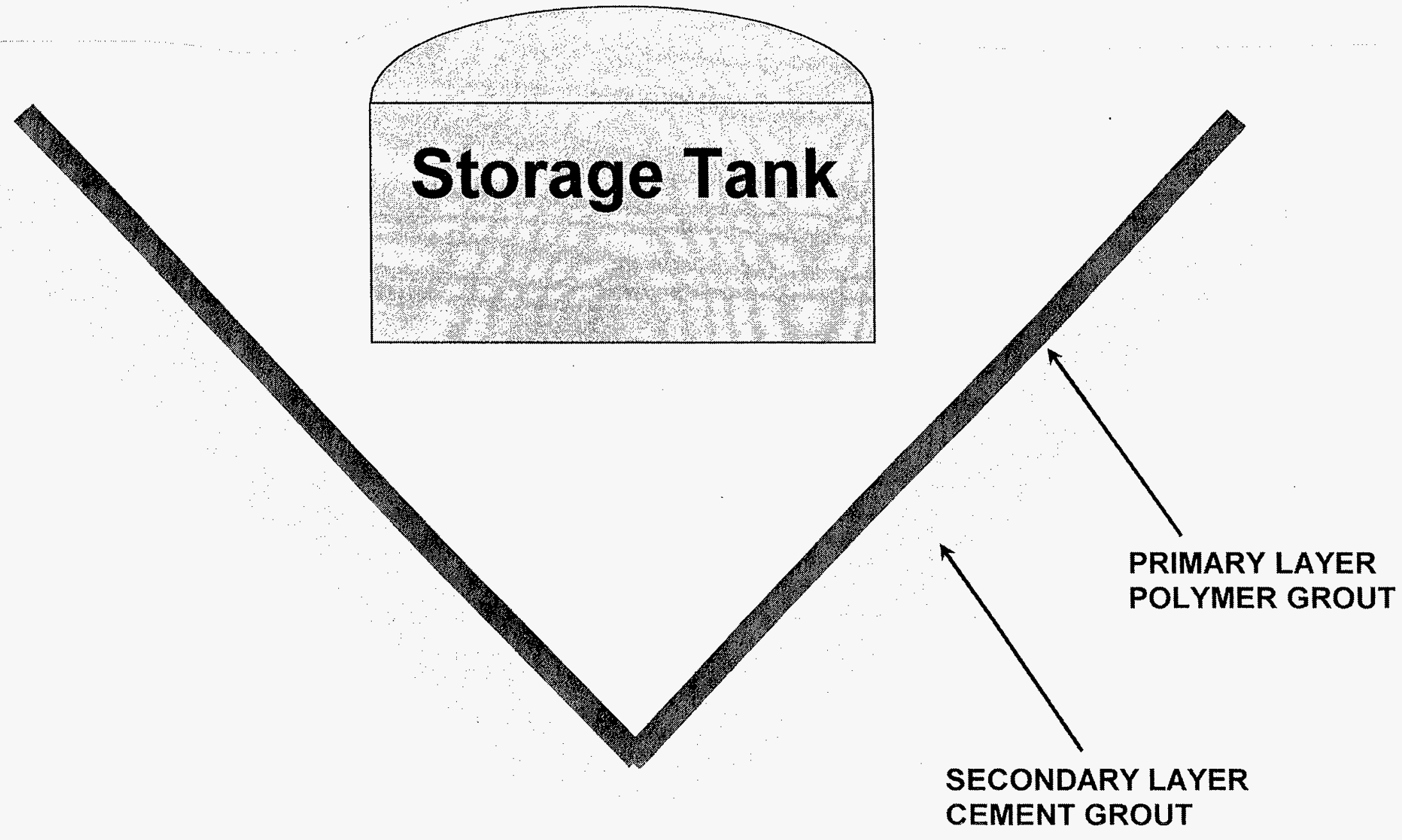

Figure 1.2 Schematic of Close-Coupled Barrier 


\subsection{POLYMER BARRIER MATERIALS}

The Environmental and Waste Technology Center at BNL has been developing and characterizing polymers for waste management uses for several decades. BNL has developed and characterized polymers for encapsulation of hazardous, mixed, and radioactive waste, and for container materials. Through the In-Situ Remediation Integrated Program (ISRIP), BNL investigated the regulatory issues, assumptions and drivers associated with the use of barriers and advanced polymer systems around buried waste sites. ${ }^{4}$ During FY94 BNL developed formulations and characterized performance and durability of several polymer systems for use in subsurface barriers. ${ }^{6,2}$ A series of binders were examined based upon experience with polymer/waste interactions and compatibilities. These binders covered the broad range of conditions expected throughout the DOE complex. Environmentally, conditions vary from the arid sites at Hanford and Sandia, to the more humid sites at Savannah River and Fernald. The geotechnical variability ranges from coarse sand with hydraulic conductivities of $10^{-3} \mathrm{~cm} / \mathrm{sec}$ and greater, to sandy clays with hydraulic conductivities of $10^{-7} \mathrm{~cm} / \mathrm{sec}$ or less. Wastes types are as varied as the sites. There are hazardous materials such as acids, solvents and chromium sludges, mixed waste such as the nitrate brines at Hanford, Rocky Flats and Savannah River, and radioactive contaminants including strontium, cobalt, cesium, and tritium. It is difficult, if not impossible, for any one barrier material to be compatible with all of these conditions. The BNL report attempted to provide DOE Environmental Management personnel with the flexibility to chose a barrier material that best suits their site. The binders that have been characterized include: an acrylic, a vinylester styrene, bitumen, a polyester styrene, furfuryl alcohol, and sulfur polymer cement. These materials cover broad ranges of chemical and physical durability, performance, viscosity, and cost.

Acceptability of these materials by the EPA for use at hazardous waste sites was confirmed prior to laboratory characterization of the polymer systems. ${ }^{4}$ The chemical compatibility of the material with the wastes, leachates, and geology with which it is likely to come in contact is of particular importance for barriers constructed from fluids which are supposed to set in-situ. EPA emphasizes this compatibility in its guidance documents, noting that thorough characterization of the waste, leachate, barrier material chemistry, site geochemistry, and compatibility testing of the barrier material with the likely disposal site chemical environment are all required. Furthermore, EPA requires that the potential release of toxic barrier material constituents be addressed as part of the characterization and testing. This requirement for characterization and testing applies to both traditional, and non-traditional, materials.

As a result of a preliminary series of telephone calls to the EPA regarding their acceptance of subsurface barriers constructed from polymer materials, the EPA's Technology Innovation Office expressed no regulatory concerns with the use of polymer materials for subsurface barriers, 
as long as the final product is inert; the EPA would have no further regulatory interest in what is essentially a construction operation. ${ }^{*}$

Generally, improved chemical and/or physical durability and performance increases the cost of the barrier grout. Choosing a grout must be done on a site and job specific basis, while balancing cost and performance. Most likely, the driving force behind grout choice will be determined by environmental and geotechnical parameters at sites like the Sandia Chemical Waste Landfill where contaminants are not highly mobile and/or reactive. A less expensive barrier material might be appropriate and, yet, still provide sufficient environmental protection. Other DOE facilities have harsher contaminant environments. Hanford tank farms have 149 Underground Storage Tanks (USTs) containing nitrate brines, of which 11 are considered high heat [12 kilowatts $(40,000 \mathrm{Btu} / \mathrm{hr})]$ tanks. Heating is due to radionuclide decay. The average temperature of the tanks is $70^{\circ} \mathrm{C}$. Gamma radiation is up to $240 \mathrm{~Gy} /$ day $(1000 \mathrm{rad} / \mathrm{hr}$ ), which results in 25 year (interim containment lifetime) doses of $>10^{6} \mathrm{~Gy}\left(10^{8} \mathrm{rad}\right)$. The tank waste is a corrosive $(\mathrm{pH} \geq 12.5)$ nitrate brine. Cost may be overshadowed by performance requirements, placement technology, and/or stakeholder concerns for such extreme conditions.

*Telephone conversation between B. Siskind, Brookhaven National Laboratory, and R. Steimle, Federal Technology Users' Group, Technology Innovation Office, EPA, on February 10, 1993. 


\subsection{CLOSE-COUPLED BARRIER CONCEPTUAL DESIGN}

The concept of close-coupled barrier technology is the combination of two technologies developed at Brookhaven National Laboratory (BNL) and Sandia National Laboratories (SNL). Under TTP CH331001, "Barriers in the Vadose Zone", BNL was developing polymer grouts for subsurface barriers. At the same time SNL was investigating placement methods and cementitious grouts for subsurface barriers (TTP AL27SS21). At a peer review (June 29, 1994) of the BNL project discussions with Hanford personnel centered on the use of close-coupled barriers around underground storage tanks to minimize contaminated soil in the event of a tank leak. In order for this approach to be feasible, a placement method must be developed that could deliver a polymer material to the subsurface without causing additional damage to the tank. Their objective was to demonstrate at a field-scale level that a close-coupled barrier can be installed that will mitigate the migration of mobile waste contaminants from a waste site such as a UST without causing damage to the tank or other waste form.

SNL, through the Landfill Stabilization Focus Area (LSFA), had been investigating placement methods and cementitious grouts for subsurface barriers. During the summer of FY94 SNL placed several pilot-scale, jet-grouted cement columns at a site adjacent to the Chemical Waste Landfill at Sandia. At this time, BNL was invited to demonstrate a polymer grout using the same placement equipment. BNL would provide the polymer grout and technical assistance while SNL provided the grout installation equipment, site and logistical assistance. While the installation of the polymer grout was unsuccessful due to incompatibilities between the grouting equipment and the gel-time of the polymer system, the final polymer-soil product was impressive. [This field test is discussed in full later]. It was becoming clear that polymers offered great advantages but still required refinements to the installation technique and that the economics had to be improved. The usefulness of combining the BNL and SNL technologies became readily apparent. For a barrier where zero tolerance in leak rate is required it would be nearly impossible to achieve this goal using a cementitious grout. Large castings of hydraulic cements result invariably in cracking due to shrinkage, thermal stresses induced by the hydration reactions, and wet-dry cycling prevalent at arid sites. The improved, low permeability, high integrity polymer materials under investigation by BNL could achieve the permeability and durability goals not attainable by cement, but would be costly if used exclusively. A joint venture was proposed by Brian Dwyer of SNL, John Heiser of BNL, and Steve Phillips (grouting contractor) currently with Applied Geotechnical Engineering and Construction, Incorporated (AGEC). SNL could design an economical cement grout curtain that would be used as a backdrop for the polymer curtain. The grouting contractor was convinced dual-fluid grouting would solve the installation problems by removing gel-time considerations and that it was possible to apply a thin layer of polymer grout to the cement barrier in a close-coupled fashion. A cementitious "bath tub" would be formed and the inside lined or flooded with a polymer binder. The resultant containment is a multibarrier of a cementitious grout followed by a polymer grout. The final composite barrier would have cost benefits from using mostly portland cement grout while retaining the performance benefits of the polymers from the inner lining. 


\subsection{PILOT-SCALE FIELD TESTS}

In FY93, BNL began an EM-50 funded project that investigated advanced polymer materials for subsurface barriers. The project has investigated the regulatory issues, assumptions and drivers associated with the use of barriers and advanced polymer systems around buried waste sites. This task was accomplished from November 1992 to February 1993 and resulted in the issuance of the report "Regulatory Issues and Assumptions Associated with Barriers in the Vadose Zone Surrounding Buried Waste"4. Laboratory evaluations began with sample fabrication and preliminary testing during FY93. Binders included a high molecular weight acrylic, polyester styrene, a furfuryl alcohol based furan polymer, vinylester styrene, sulfur polymer cement, and bitumen. Final laboratory testing was completed during March 1994. Testing included compressive strength, hydraulic conductivity, splitting tensile strength, flexural strength, 120 day solvent (TCE) resistance, wet-dry cycling, 120 day acid resistance, rapid chloride diffusivity, 120 day base resistance, and 90 day water immersion. The polymer materials proved to be durable and have performance values capable of meeting the needs for subsurface barriers throughout the DOE complex. A database on materials properties of advanced polymer construction materials for use in subsurface hydraulic/diffusion barriers was published with the long term goal of providing the DOE waste management community improved barrier alternatives which will better isolate buried waste from the environment. ${ }^{6,2}$

The greatest interest in using polymer grouts (as defined by a peer review and stakeholder questioning) was to combine them with some form of jet grouting. Most parties agreed this would provide the most useful and versatile installation technique. The next logical step was a proof-ofconcept of using polymers with traditional jet grouting, particularly the thermosetting resins. This was to be provided in the most basic sense by the installation a single borehole jet-grouted column. This section describes two single bore hole tests conducted at Sandia and INEEL in FY94 and FY95.

\subsection{Single Column Injection at the Sandia Chemical Waste Landfill}

During the week of July 18,1994 , a field test of polymer grouting with thermosetting resins was conducted at the Chemical Waste Landfill (CWL) at Sandia National Laboratory. The purpose of this test was to provide a proof-of-concept demonstration of the application of polymer grouts, particularly thermosetting resins via jet grouting. The scope of this test was to install a single column using conventional jet grouting equipment. The installation would produce an acrylic soil mortar column nominally 1 meter in diameter and 3 to 4 meters tall. Objectives for this test were:

1. To demonstrate the feasibility of using a thermosetting resin with jet grouting technology;

2. Determine the homogeneity of the column through density measurements and cross sectioning of cored samples; 
3. Compare the hydraulic conductivity of core samples taken from the column to laboratory samples produced using soils from the same site; and,

4. Determine the penetration of low viscosity, zero solids grouts into the soil and compare this to cement-based grouts placed under similar jetting parameters

Grouting was performed using conventional jetting techniques,. The test used an acrylic thermosetting resin manufactured by $3 \mathrm{M}$ Company and reformulated specifically for this demonstration. The product, designated 3M4R 5742-DOE, is a high molecular weight, low-odor, low-modulus methacrylate. This resin while more expensive than other polymers studied by BNL, was chosen based on the grouting contractors familiarity with the product. The system is typical of thermosetting polymers and successful installation would provide a proof-of-concept for all of the thermosetting resins characterized at BNL. To aid in acceptance of the methacrylate by site and regulatory personnel BNL forwarded a copy of report "Regulatory Issues and Assumptions Associated with Barriers in the Vadose Zone Surrounding Buried Waste"4. In addition to this report a letter report was prepared detailing laboratory compatibility testing of the acrylic polymer with Sandia soils that was performed by BNL. Samples were prepared using clean soil from near the CWL and the $3 \mathrm{M}$ resins in various ratios. Gel times were measured to see if any retardation or acceleration of the reaction occurred, indicating chemical interaction of the soil with the polymerization. Short term immersion tests were also performed to see if any incompatibilities with the polymer and the alkali soil were evident. No incompatibilities were discovered and the gel and set times of the resins with Sandia soil were identical to mortar samples made with a nonreactive quartz sand. Final gel time of the resin was set at thirty minutes, based on discussions with Mr. Phillips and consideration of pumping and jetting requirements and hydraulic conductivity of the soil (we did not want the grout seeping away from the grouted zone prior to gelation). The drilling rig used was a Casa Grande C6 unit. This is a track/trailer mounted jet grouting rig and is depicted in Figure 4.1. Initial drilling of the hole went smoothly using 280 liters (75 gallons) of resin. Mid way through the grouting process one 190 liters (50 gallons) batch of the resin began to cure prematurely. The resin began gelling only five minutes after initiator additions. This caused the grouting to be aborted and resulted in partial polymerization of the resins in the jetting pumps. The equipment had to be taken apart and mechanically cleaned, causing about five days downtime.

When BNL ordered the resins from 3M company the gel time was specified as thirty minutes in bulk, with the bulk volume being 210 liters (55 gallons) drum quantities. 3M supplied 4L (1gal) samples to BNL for testing. The gel times were thirty minutes for $0.5 \mathrm{Kg}$ aliquots. BNL was told the gel time in 190L (50gal) quantities should be 25 to 30 minutes. After the rapid gel occurred at Sandia, BNL contacted $3 \mathrm{M}$ to determine the cause of the unexpected gel time. First thoughts were focused at inhibitor concentrations in the resin. If the inhibitor level was different in one drum this might explain the differing gel times. $3 \mathrm{M}$ had processed all $950 \mathrm{~L}$ (250gal) as a single lot so there should have been no drum-to-drum differences. This caused BNL to focus on heat generation and associated scale-up problems. $3 \mathrm{M}$ had not done scale gel time studies on the exact resin formulation used by BNL but relied on data from a similar formulation 


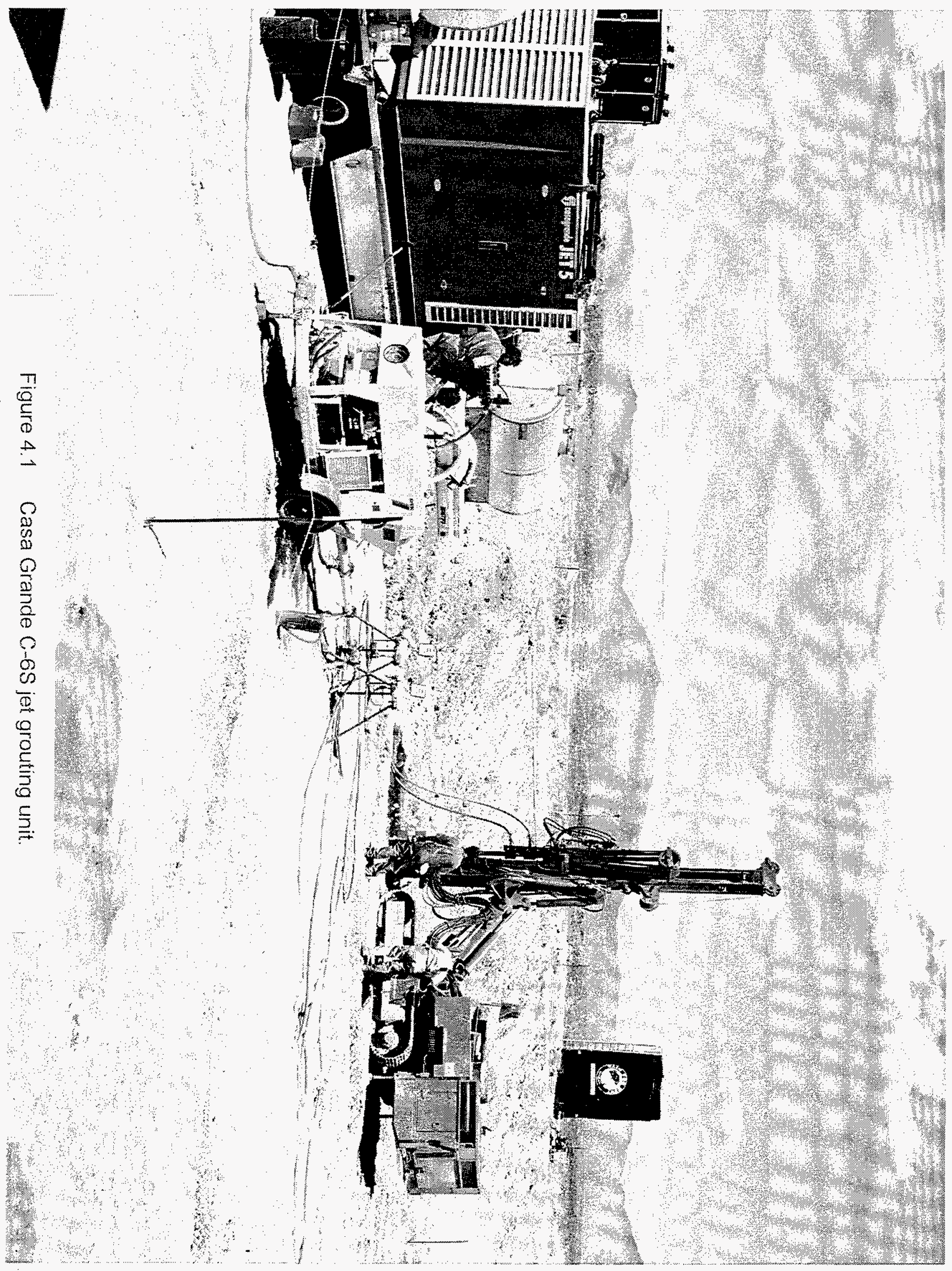


having a 150 minute gel time and on past experience. A $0.2 \mathrm{Kg}$ batch gelled in 150 minutes while a $3 \mathrm{Kg}$ lot gelled in only 90 minutes. This was within the control limits set by $3 \mathrm{M}$, which specialized in thin film applications. BNL was more familiar with bulk applications and felt this amount of change clearly pointed to an adiabatic scale-up problem. Assuming that the $3 \mathrm{Kg}$ lot was at or near adiabatic conditions during curing and assuming the $3 / 5$ (90 minutes $\div 150$ minutes) gel time scale up applies to the BNL resins, yields a maximum gel time of only 18 minutes at $24^{\circ} \mathrm{C}\left(75^{\circ} \mathrm{F}\right)$. Given this information and the slightly higher field temperature $\left(32^{\circ} \mathrm{C} / 90^{\circ} \mathrm{F}\right)$ a five minute gel time for the $3 \mathrm{M}-\mathrm{DOE}$ resins in $190 \mathrm{~L}$ (50gal) quantities is reasonable.

The remaining resins from the Sandia field test were shipped back to BNL to determine the cause of the rapid gelling. Adiabatic effects on peak exotherm and gel time were investigated. The absolute gel times had increased (for $0.5 \mathrm{Kg}$ samples) from 30 minutes to approximately 2 hours. Some of the resins were shipped back to $3 \mathrm{M}$ where it was determined the likely cause of this change was due to some degradation of the co-polymers. This had little effect on the heat measurements other than requiring the results to be normalized to the Sandia gel times. Resin samples of $0.1,0.5,3.5,25$, and $100 \mathrm{Kg}$ were transferred into cylindrical containers such that the ratio of width to height was $\sim 1$. The promoter was mixed into the resins followed by the initiator and a thermocouple was placed into the mix at the center. No mixing took place after the thermocouple was in place. Computer data acquisition software recorded the time and temperature every 0.5 minutes for at least 360 minutes. The results are given in Figure 4.2 . The peak exotherms were $91,128,173,180$ and $183^{\circ} \mathrm{C}$ for the $0.1,0.5,3.5,25$, and $100 \mathrm{Kg}$ lots respectively. The gel times were taken when the resins reached $50^{\circ} \mathrm{C}$ (viscosity $\sim 200 \mathrm{cps}$ ) and were $163,129,89,73$ and 69 minutes for the $0.1,0.5,3.5,25$, and $100 \mathrm{Kg}$ lots respectively. The gel time was of most interest and is depicted in Figure 4.3 normalized to the Sandia field test gel times. The test samples at Sandia were $0.5 \mathrm{Kg}$ and the average gel time for three drums was 26 minutes, a factor of 5 times faster than the laboratory gel times for similar sized lots. Using the simple normalization of dividing the laboratory gel times by 5 to obtain the expected field gel times yields a useful life of 12 minutes in $210 \mathrm{~L}$ (55gal) drum quantities at $24^{\circ} \mathrm{C}\left(75^{\circ} \mathrm{F}\right)$. The drum that "quick set" gelled in approximately 5-7 minutes. This is close to the normalized gel time for a $210 \mathrm{~L}$ (55gal) drum. The slight discrepancy is most likely due to the 6 months "aging" of the resins or the temperature differences between the laboratory and the field.

The cause of the rapid gelling was a simple adiabatic heat process. It is well known that the volume of resin can greatly affect the gel time of thermosetting resins. The polymerization process is begun by reacting the initiator and promoter in the resin mix. The rate of reaction between the two is very dependent on temperature. The polymerization process is exothermic and the heat released can increase the rate of reaction of the initiator and promoter, the reaction is said to be autoaccelerating. Small quantities of resin can dissipate heat fast enough so that rapid curing does not occur. As the volume is increased, exothermic heat generated can not dissipate as rapidly due to the insulating properties of the resin itself and thus causes auto acceleration of the polymerization reaction. If the heat released from the polymerization is small or the heat can be 


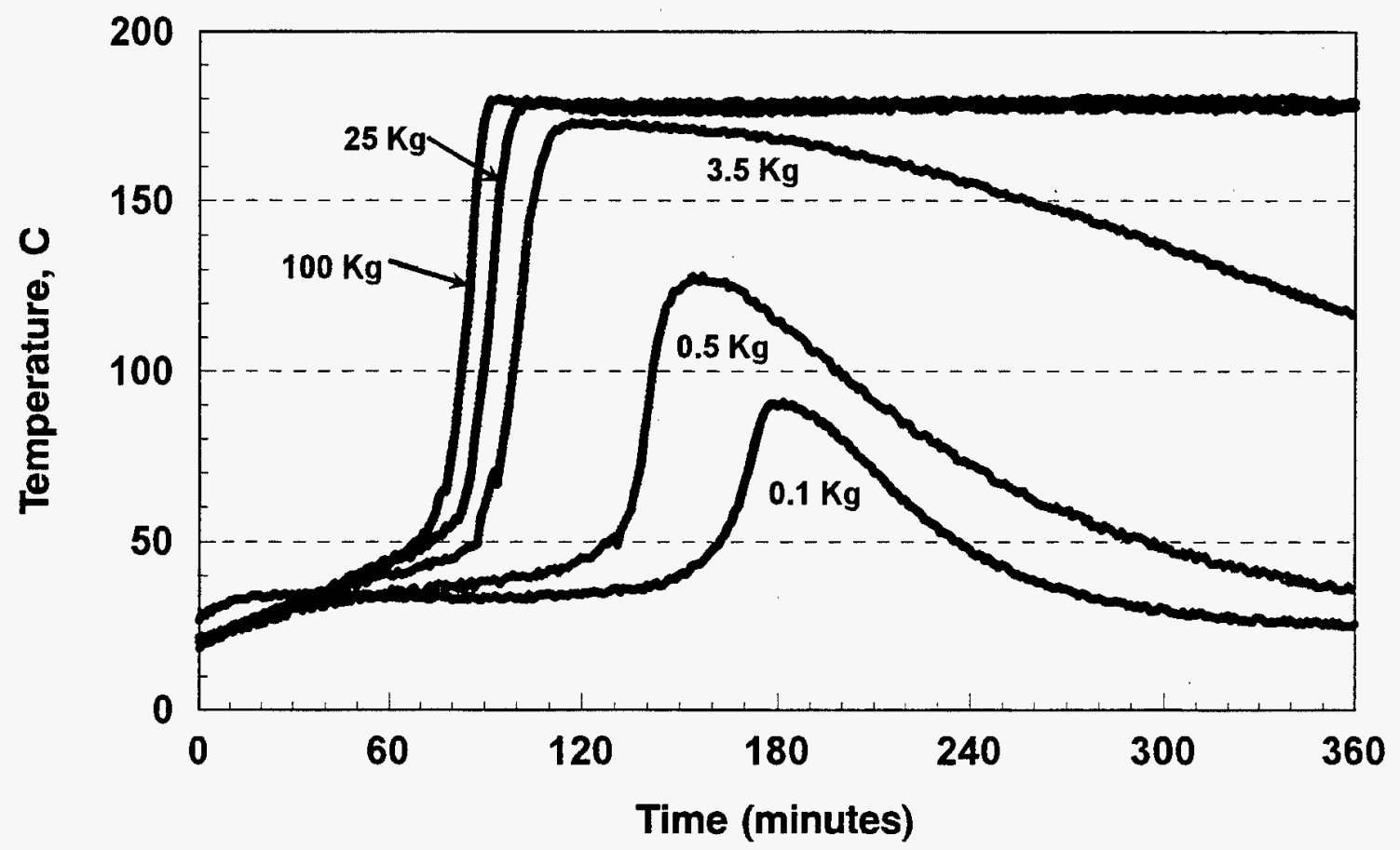

Figure 4.2 Temperature History of Acrylic Resins During Polymerization.

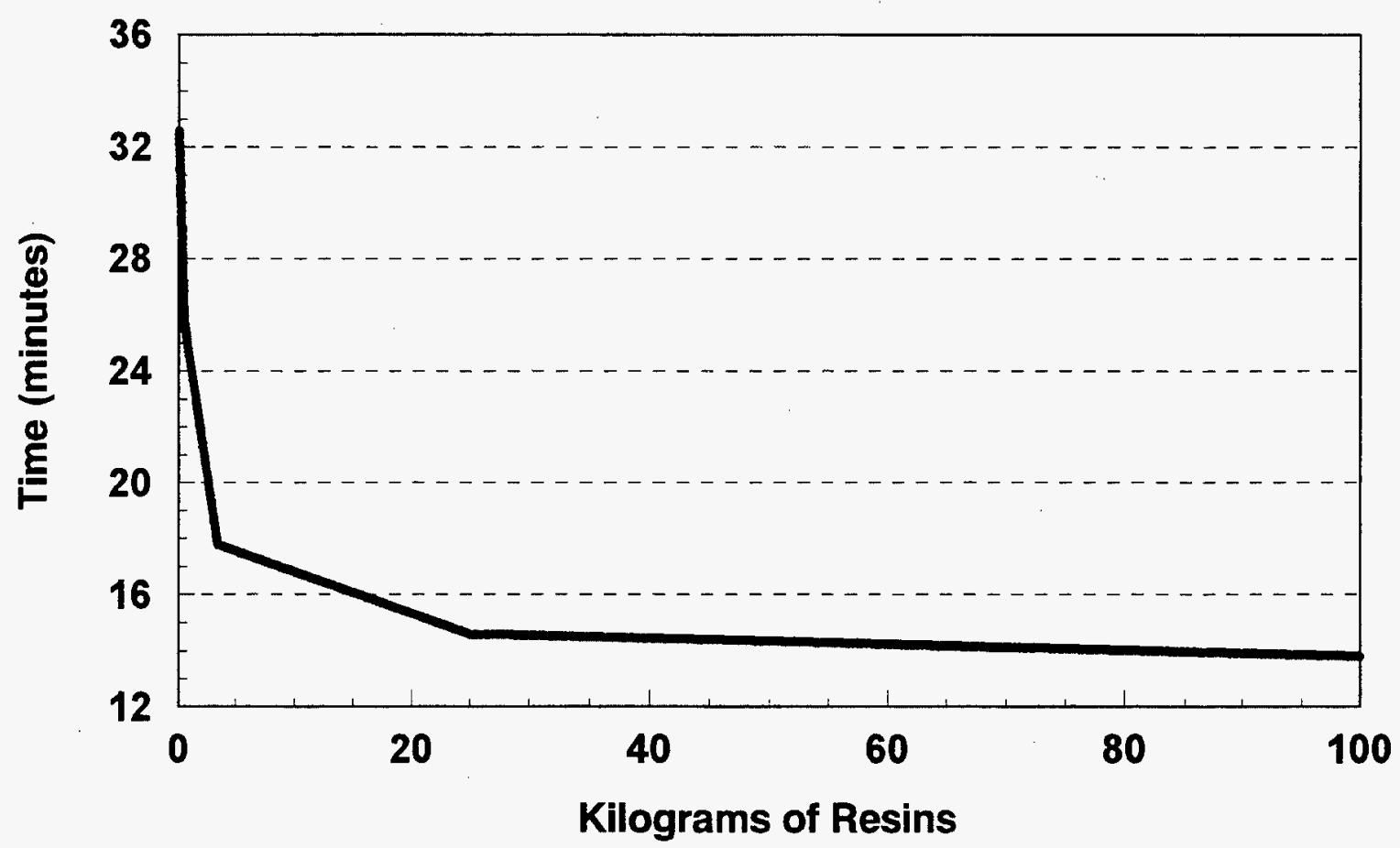

Figure 4.3 Time to on set of gel formation for acrylic resins (normalized for aging). 
dissipated fast enough the change in gel time with increasing volume will be small. Proper scaleup measurements to determine the bulk gel time in an adiabatic system would prevent such unexpected gel times ("quick sets") from occurring.

\subsubsection{Lessons learned}

The Sandia test was still able to show the ability to use jet grouting technology with thermosetting resins. We were able to drill and begin jetting. The high pressure system did not adversely effect the gel times. The problem of rapid gelling was independent of the jetting procedure. Spoils from the drilling took thirty minutes to gel. The first objective of determining the feasibility of using polymer grouts with jet-grouting was accomplished but the later three performance related objectives could not be completed for lack of product due to the premature stoppage in grouting. As will be seen later, these objectives will be met in other demonstrations.

We have also learned/reconfirmed several valuable lessons;

1. Gel times and peak exotherms must be obtained under adiabatic conditions.

Proper determination of the effects of adiabatic conditions on the resins must be performed or the circumstances leading to adiabatic conditions must be eliminated to avoid "quick sets" if injecting with single stream equipment. During the field test the first $280 \mathrm{~L}$ ( $75 \mathrm{gal}$ ) batch of resins took thirty minutes to gel while the second 190L (50gal) batch took only 5 minutes. The reason for this lies in different mixing methods that were used for the two batches. The resins had to be transferred from 210L (55gal) drums into mixing drums for addition of the promoter and then the initiator. After the initiator was added the resins would be pumped into the holding tank of the jetting pump. The first $280 \mathrm{~L}$ (75gal) was mixed directly in the holding tank using the recirculation from the shear pump to mix the resins. The shear pump recirculated continuously and was never interrupted. The second $190 \mathrm{~L}$ (50gal) batch was mixed with a drum mixer in a separate plastic drum. After mixing for several minutes the resins were transferred to the holding tank using a small pump at the rate of 55 to $75 \mathrm{~L}$ (15 to 20gal) per minute. During the transfer, the resins contained in the plastic drum were not mixed. The constant recirculation of the holding tank dissipated the heat for the first 280L (75gal) and removed the adiabatic conditions. The second drum was adiabatic during transfer and autoaccelerated. The use of continuous stirring reduces the probability of rapid curing but may not eliminate it. Adiabatic conditions may occur in the jetting pump or drill tubing (although the resonance time in this part of the equipment is short). Proper formulation of the bulk gel time is a must when using a single pump grouting system.

2. Dual fluid injection is the preferred method of injection when using thermosetting polymers.

The drilling rig used at Sandia was equipped with a single pump, single annulus drill pipe and did not support split stream application of the resin. For the Sandia field test safety of the 
equipment was dependent on the proper gel time. Gel formation had to occur at some time that is significantly greater than the resonance time of the resin in the grouting equipment. Then gel formation occurs downhole and not in the equipment. The drilling equipment uses a 190L (50gal) batch of resins in 3 to 5 minutes. The expected gel time of thirty minutes should have been sufficient time for jetting and still allow for flushing of pumps and lines in the case of equipment breakdown. The safest way to avoid rapid gel time problems is to use a dual pump system with dual wall drill pipe that allows split stream injections. To protect equipment from flash gels you can put the promoter into one half of the resin and the initiator into the other half. The polymerization only occurs when the two parts are mixed. Dual wall drill pipe can be used so that the two separate grouting media can be simultaneously injected and therefore, the two fluids mix together in the soil after leaving the drill stem. Mixing is accomplished by the soil mastication/mixing that normally occurs from high pressure jetting. With such a dual fluid system the split resin mixes are combined downhole and polymerization cannot occur in the equipment. Based on this field test all parties involved agreed that the best way to proceed was with split stream injection using dual-wall (dual-annulus) drill pipe.

\subsection{Proving the Dual-Fluid Injection Technique for Polymer Grouts}

In early FY95, BNL and SNL were attempting to put together a full-scale demonstration of the close-coupled barrier design. Several steps were required before this could take place. First, based on the initial single column test, a second pilot test was required that would install a polymer grout using dual-fluid injection technology. Secondly, site selection and design of the full-scale barrier had to be completed. Last, and perhaps the limiting step, funding had to be obtained. SNL and BNL would be able to, with existing EM-50 funding, complete the design, installation and testing of the barrier, but there was still a need to purchase materials and make the required modifications to the grout injection unit to provide for dual fluid injection. The engineering of the rig modifications was completed by Applied Geotechnical Engineering and Construction, Inc. (AGEC), the grouting contractor. [AGEC also arranged for the barrier demonstration site at the HGDTF and provided some instrumentation, see later Section 5 on fullscale demonstration]. During the site selection process, BNL approached INEEL to determine if any partnering could be accomplished in the area of subsurface barriers. From this initial contact it was learned that another INEEL project had a mutual interest in polymer grout injection technologies. This interest came from the In Situ Stabilization of TRU/Mixed Waste project. They also had a need to inject polymer grouts, but for a different function. INEEL was interested in stabilizing buried waste in-situ using jet-grouting and wanted to evaluate a host of binders (grouts). The group lacked the expertise in the polymer systems and what background information (i.e., compatibility testing) was required. BNL was able to offer the expertise in polymers and preliminary testing and at the same time arranged to bring in the 3M Company, Inc. (3M) to assist in the development of the specialty grout required for the INEEL project. INEEL was able to offer up the required modifications (capital equipment costs) for the grout injection unit. The final partner was MSE-TA, Inc. (MSE) which was brought in by EM-50 to provide the funding and purchasing (including contract specifications) of the polymer grout(s) required for both the barrier and the in-situ stabilization demonstrations. In addition, MSE funded BNL to demonstrate on a 
proof-of-concept level a novel barrier verification technique (see Section 6). The partnering consisted of BNL, SNL, INEEL, 3M, MSE, and AGEC, Inc. This section will discuss the modifications to the jetting unit and the single-column pilot-test injection performed at INEEL.

\subsubsection{Objectives}

For the single borehole test performed at INEEL during FY95 the objectives were:

1. To demonstrate the feasibility of using a two-part, thermosetting polymer grout with dualfluid jet grouting technology.

2. Determine the homogeneity of the column through cross-sectioning.

3. Determine the penetration of low viscosity, zero solids grouts into the soil and compare this to cement-based grouts placed under similar jetting parameters.

\subsubsection{The polymer grout system}

With the partnership came specific requirements for the polymer grouts for each demonstration. The close-coupled barrier was committed to using an acrylic polymer but the cost was slightly prohibitive. Our commitment to the $3 \mathrm{M}$ acrylic resins were due to the resins being non-flammable (as opposed to many of the styrene containing resins), was very low viscosity (3$10 \mathrm{cps}$ ) and had been well characterized by BNL. We approached George Frost of $3 \mathrm{M}$ and asked why the resins were so expensive (since other acrylates existed that were cheaper) and if the cost could be reduced. $3 \mathrm{M}$ answered that the original resin blend was developed for surface concrete restoration and had several very expensive co-polymers that greatly decreased the cure time of the polymer in thin film applications. Given that we would not be using thin film applications, we agreed this was not a property we needed and that reasonable adhesiveness to the cement layer was acceptable. $3 \mathrm{M}$ provided laboratory formulation and testing to meet the specific needs of the grouting demonstration. [They also provided expertise in the field during the single column test at INEEL and the construction phase of the Hanford demonstration]. By removing the unwarranted resins $3 \mathrm{M}$ was able to reduce the cost of the resin blend from $\sim \$ 15.8 / \mathrm{L}$ ( $\$ 60 / \mathrm{gal}$ ) to $\sim \$ 5.3 / \mathrm{L}(\sim \$ 20 / \mathrm{gal})$ without altering the basic physical and chemical characteristics of the polymer (in terms important to subsurface barriers) to any great extent. The new resin blend was designated 3M4R 5750.

INEEL had similar durability/resistivity requirements and installation requirements, but they also had a unique need. They wanted two polymer grouts; one that was for permanent treatment of the buried waste, and one for hot spot removal. As formulated, the $3 \mathrm{M}$ product met the needs for the first case but was considered too strong and too brittle for hot spot retrieval. In hot spot retrieval there is a need to be able to break apart the monolith formed by grouting into manageable pieces. This is normally done with a backhoe and if the material is very brittle a large quantity of dust can be generated in the breaking process. This in turn results in unwanted 
airborne contamination. INEEL needed a polymer that would have little dust formation when broken. INEEL requested a "gum rubber eraser-like" consistency for the retrievable grout. We did not want to have to purchase small lots (genrally expensive per gallon) of resin blends. It would be far more economical to make one large bulk purchase. Knowing that the final properties of the polymer are dependent on the co-monomers in the resins and that small formulational changes can greatly effect the final polymers, BNL again went to $3 \mathrm{M}$ for modifications to the resin blend. 3M was able to change the consistency of the final polymer to meet the INEEL requirement by adding slightly more cross-linking agent. This allowed $3 \mathrm{M}$ to produce one large lot and simply modify a small percentage of the resins by adding the cross-linking agent. $3 \mathrm{M}$ delivered two resin blends to the INEEL site, designated 3M4R 5750 (hard) and 3M4R 5751(soft) for the in-situ stabilization demonstration and one (5750) to the Hanford site for the full-scale demonstration.

The final $3 \mathrm{M}$ product(s) is used as a two-part system and consists of a low-viscosity, proprietary blend of acrylic co-monomers including 5\% trimethylolpropane-trimethacrylate (TMPTA) and isooctylacrylate. The resin is polymerized using an initiator, $50 \%$ benzoyl peroxide (BPO), in combination with a promoter, $\mathrm{N}$-ethyl, $\mathrm{N}$-hydroxyethyl, $\mathrm{m}$-toluidine. Baseline gel time was set at $\sim 90$ minutes for this study and was specified to be measured on $3000 \mathrm{~g}$ lots or larger to make certain the conditions were adiabatic. The resins were delivered as two components, A and B. Part A was the resin blend containing $0.16 \mathrm{wt} \%$ of the toluidine promoter. Part B was shipped as the pure resin blend and $4.0 \mathrm{wt} \%$ BPO [BBF50 from AKZO Chemie America] was added just prior to use. When parts $A$ and $B$ are mixed (in a 1:1 ratio) the promoter and initiator are united to start the polymerization reaction. The resultant mix contains $0.08 \mathrm{wt} \%$ promoter and $2.0 \mathrm{wt} \%$ initiator having a gel time of approximately 90 minutes @ $24^{\circ} \mathrm{C}\left(75^{\circ} \mathrm{F}\right)$.

\subsubsection{Modifications to the Casa Grande C-6S Jet Grouting Unit}

Prior to demonstration, modifications to the jet grouting unit to allow delivery of two fluids simultaneously were made. The objective was to keep parts $\mathrm{A}$ and $\mathrm{B}$ of the $3 \mathrm{M}$ polymer system separated in the drill stem. By delivering the two parts separately the polymerization reaction begins only after the resins leave the drill stem and are mixed in the soil. Mixing is accomplished as part of the soil mastication/mixing that occurs from high-pressure jetting. The grouting contractor designed the modifications and specified parts requirement. INEEL purchased the equipment and the contractor completed the modifications and shakedown at the INEEL demonstration site. The modifications included use of dual-wall drill stem, flow metering devices and a low-pressure pump. The dual-wall drill stem consisted of a dual concentric annulus delivery system (see schematic in Figure 4.4 and photograph in Figure 4.5). Part A was injected through the center of the nozzle at 400 bars ( $6000 \mathrm{psi}$ ) and part B was injected through the outer annulus at 70 bars (1000 psi). The differences in pressures is proportional to the surface area differences (hence volume delivery) between the two annulus and allows a 1:1 ratio of parts $\mathrm{A}$ and $\mathrm{B}$. 


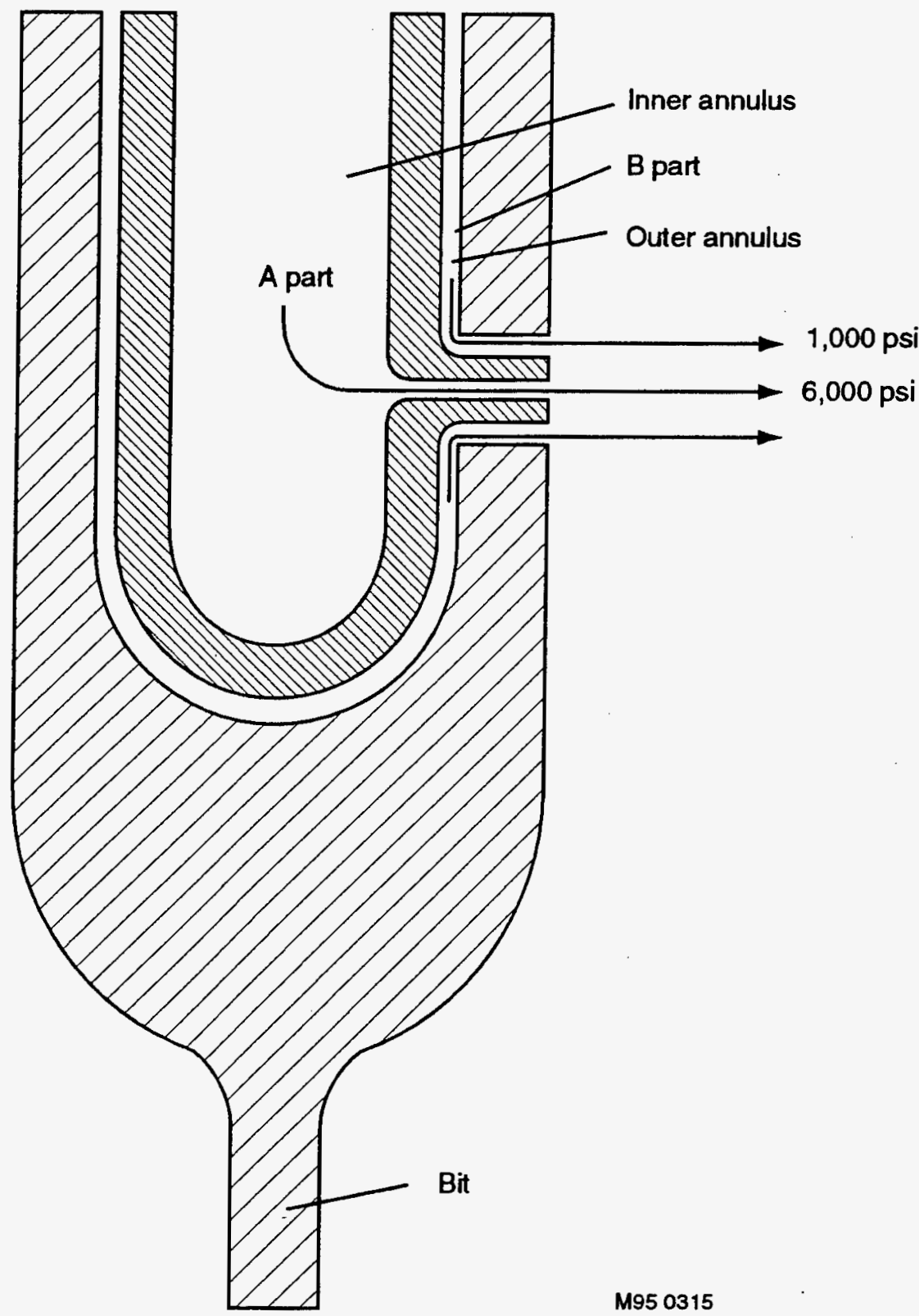

Figure 4.4 Schematic of Dual-Wall Drill Stem. 

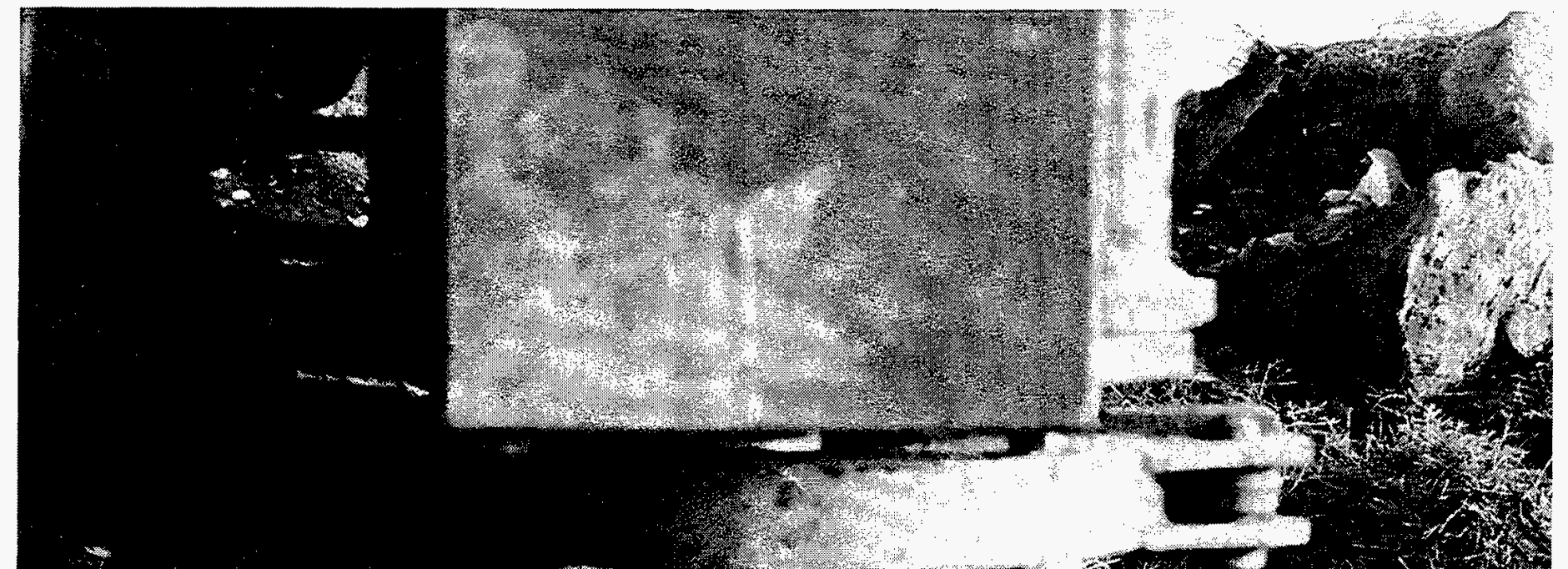

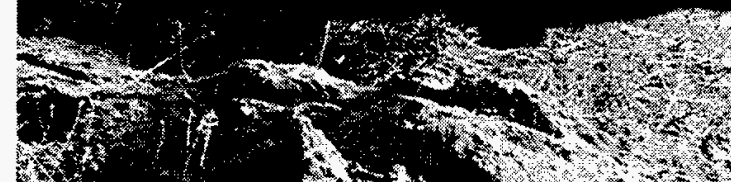

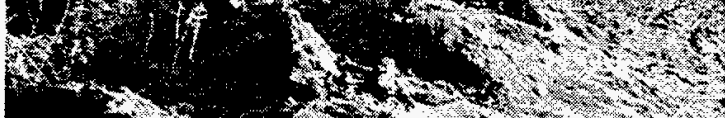

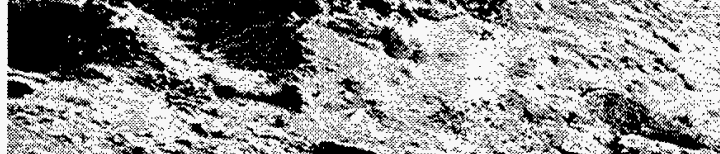

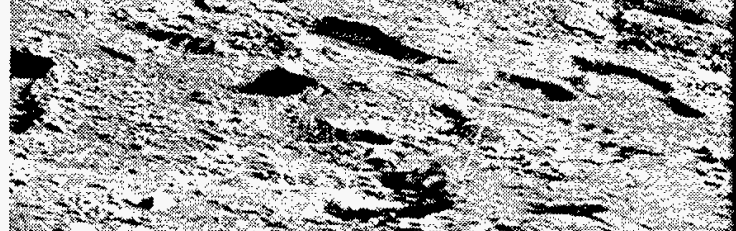

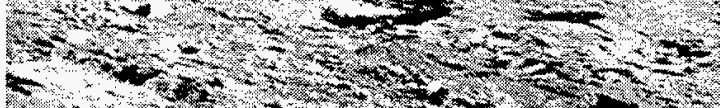

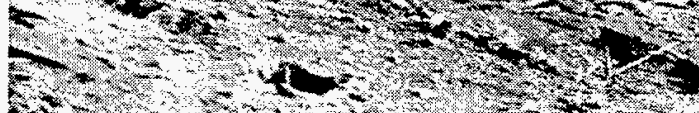

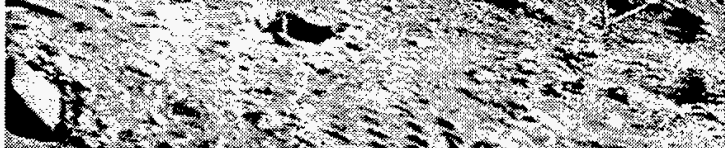

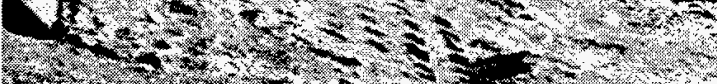

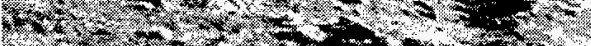

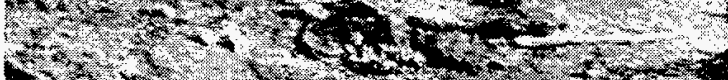

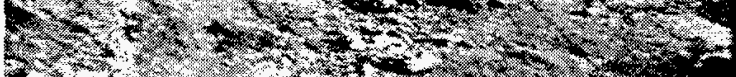

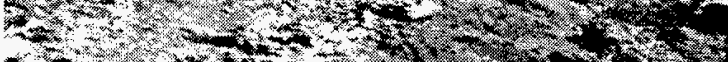

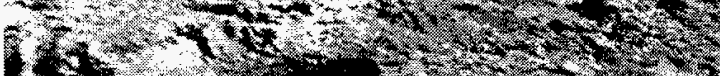

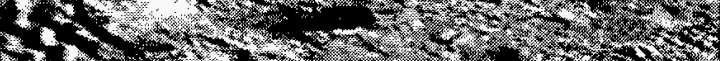

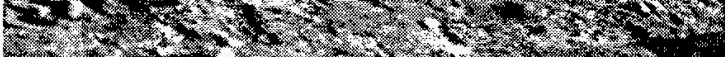

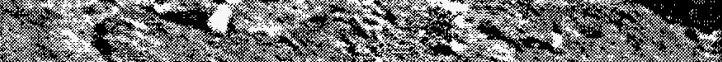

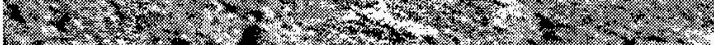
26t

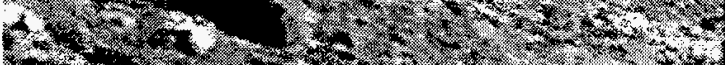

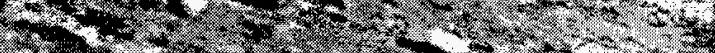

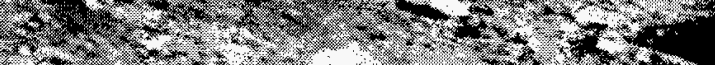

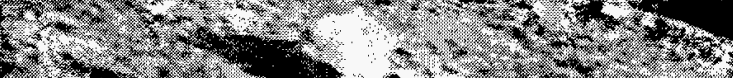

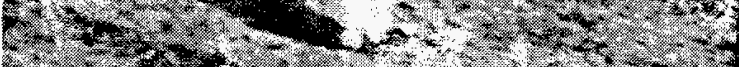

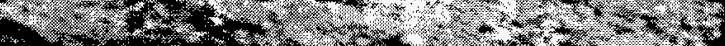

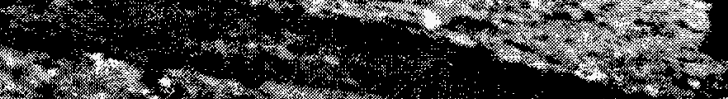

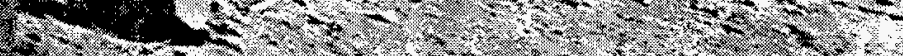

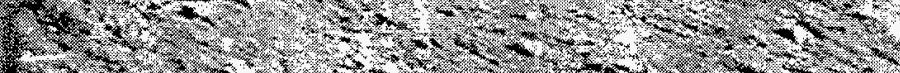

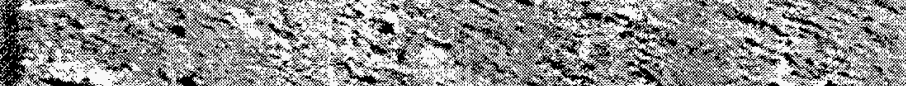

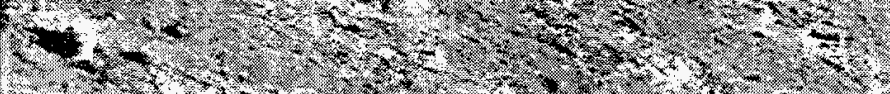

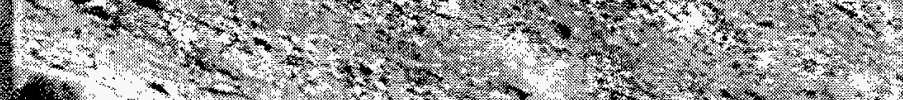

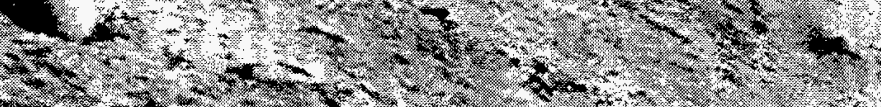

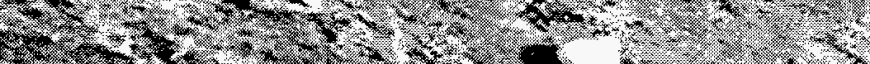

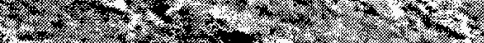

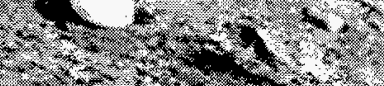

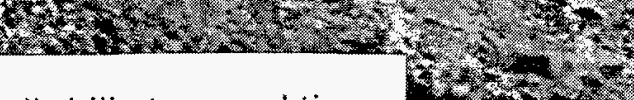

Figure 4.5 Photograph of the dual-wall drill stem and tip. $+2 x^{2}+2$ 
The final grout delivery system (schematic in Figure 4.6 photographs in Figures $4.7 \mathrm{a}$ and $4.7 \mathrm{~b}$ ) consisted of separate transfer pumps for parts A and B (Figure 4.8) to deliver the resins from drums to separate supply tanks (Figure 4.9), a low-pressure pump to inject part B (Figure 4.10), a high-pressure pump to inject part A (Figure 4.11), separate flow meters (Figure 4.12) to monitor the flow rates of parts A and B, delivery lines and the dual-wall drill pipe (Figure 4.5). The system operated off a trailer mounted diesel unit and did not require any facilities other than a water tank for clean up.

\subsubsection{Grouting the column}

The INEEL Buried Waste Site is a semi-arid region containing a very fine alluvial sand that has a high carbonate content. As mentioned earlier laboratory tests were performed that proved the compatibility of the $3 \mathrm{M}$ system with this soil. The test injection area was located close to the simulated buried waste pits to be used in the INEEL In Situ Stabilization of TRU/Mixed Waste project. The single-column tests provided the pilot-scale proof-of-concept required for the close-coupled barrier technology to move forward and also was required pre-testing for the in-situ stabilization of the buried waste pits. INEEL needed to determine penetration depths, grout requirements and spoils expectations prior to grouting the pits. [Results of the INEEL in-situ stabilization demonstration can be found in the INEEL report "Innovative Subsurface Stabilization of Transuranic Pits and Trenches"7].

Two single column injections were performed to set the jet-grouting parameters and to test the dual wall drill stem. The first injection involved drilling 2.75 meters ( 9 feet) into the INEEL soil and jet grouting the bottom $4 \mathrm{ft}$ using 4 revolution/step, $3 \mathrm{~cm} / \mathrm{step}, 3 \mathrm{~s} / \mathrm{step}$ as jet-grouting parameters with the Schwing pump set at nominally 70 bars $(1,000 \mathrm{psi})$ and the JET5 pump set at 400 bars $(6,000 \mathrm{psi})$. For the second column injection parameters were 2 revolutions/step, 3 $\mathrm{cm} / \mathrm{step}$, and $2 \mathrm{~s} / \mathrm{step}$. A $1 \mathrm{~cm}(3 / 8 \mathrm{in})$ copper tube with the bottom end sealed was placed in the first hole covering the full drill length. A thermocouple was placed down the copper tube to monitor the temperature profile with a portable digital meter. The temperature profile of the first trial hole is listed in Table 1. The elevated temperatures did not agree with those observed during mixing of laboratory samples where the heat of reaction caused temperatures of $116^{\circ} \mathrm{C}\left(240^{\circ} \mathrm{F}\right)$. Only the surface temperatures (in the spoils collection pit around the top of the hole) approached this cure temperature. The second field trial hole was jet grouted, but the B part Schwing pump failed to pump a full charge of B part into the hole. A total of 30L (8gal) of B part was pumped and $87 \mathrm{~L}$ (23gal) of A part was pumped. The $3 \mathrm{M}$ representative claimed that this mix would cure, but slower than the 70 to 80 minutes required for equal parts of $\mathrm{A}$ and $\mathrm{B}$. 


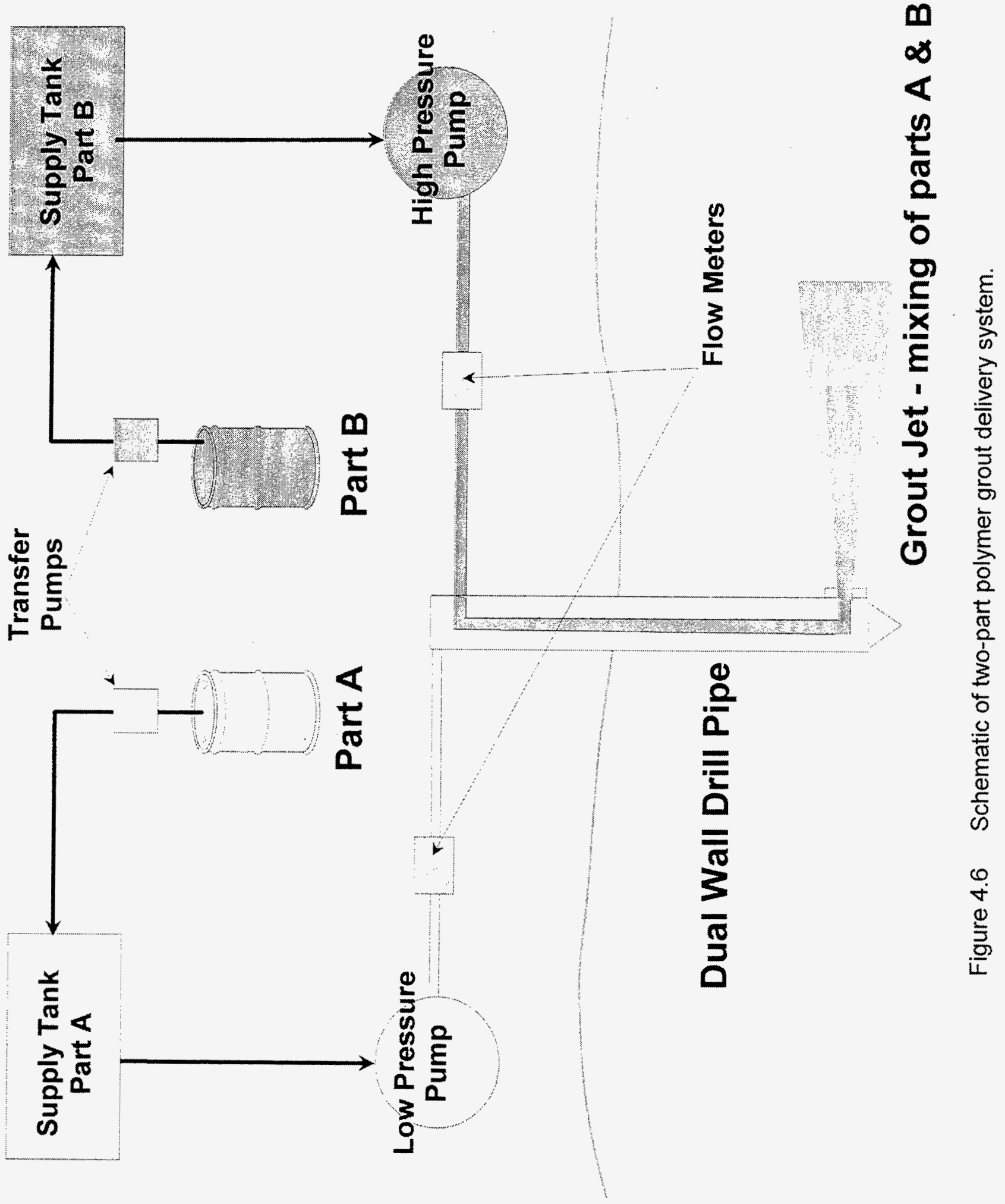




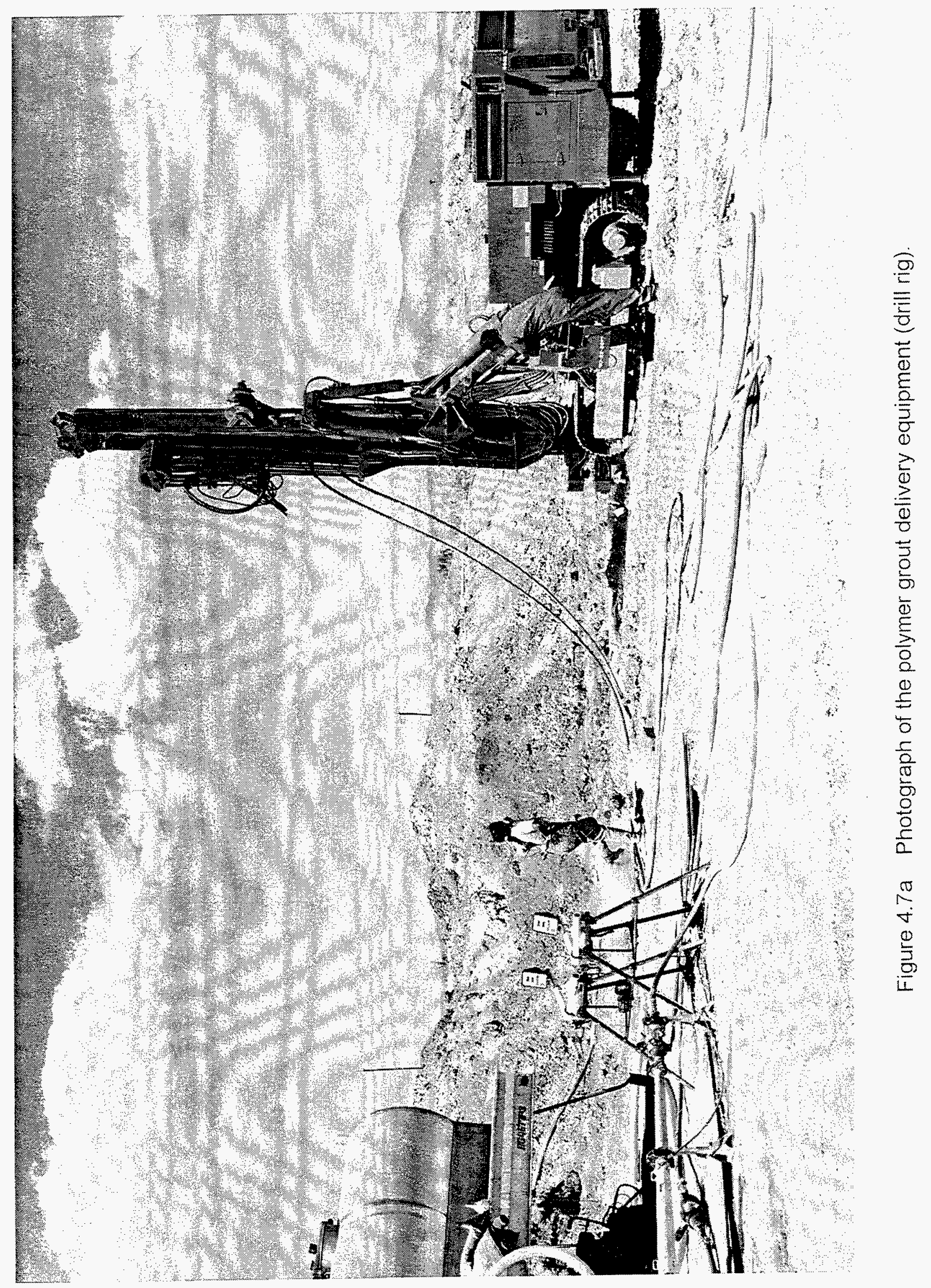




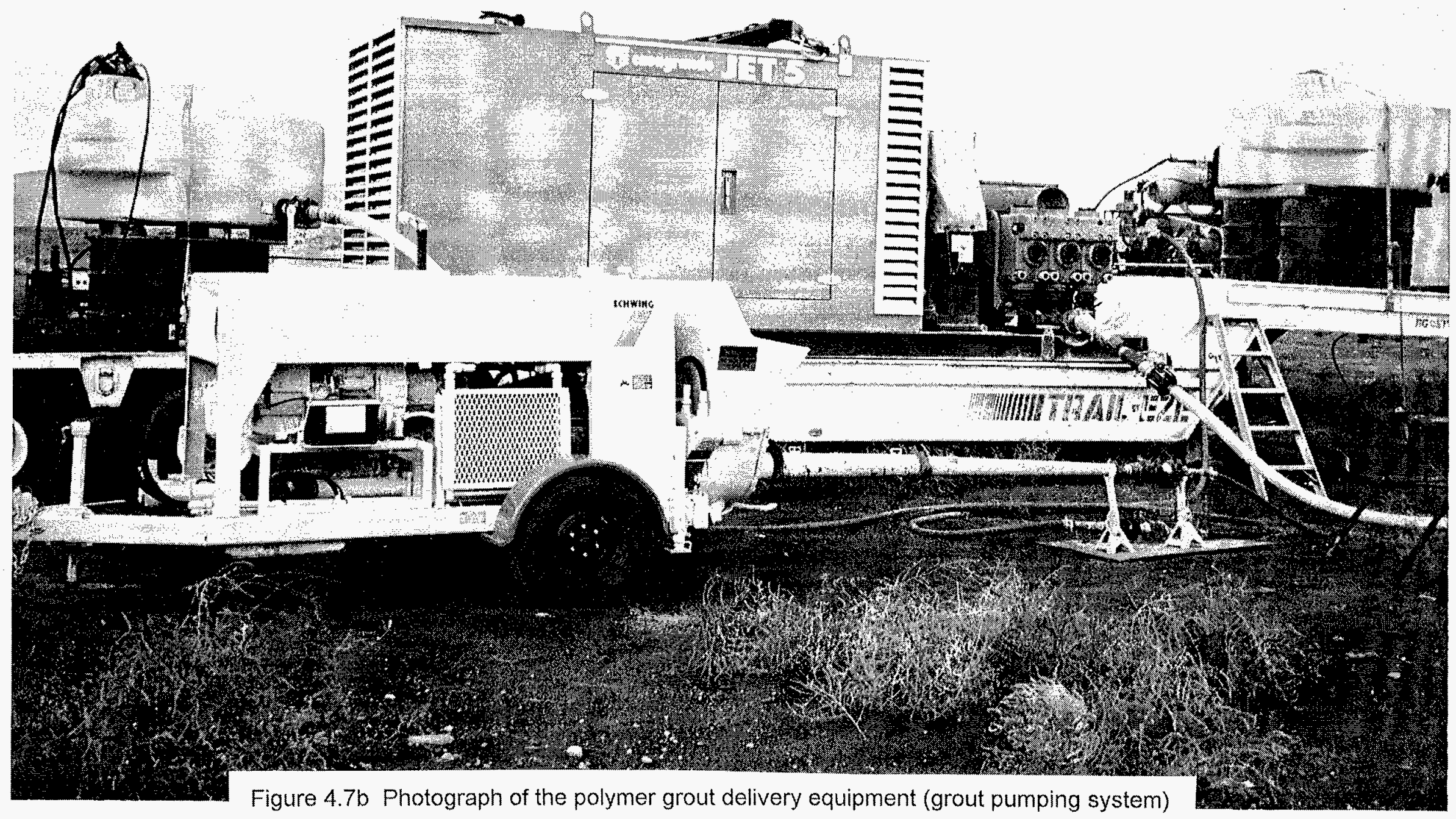




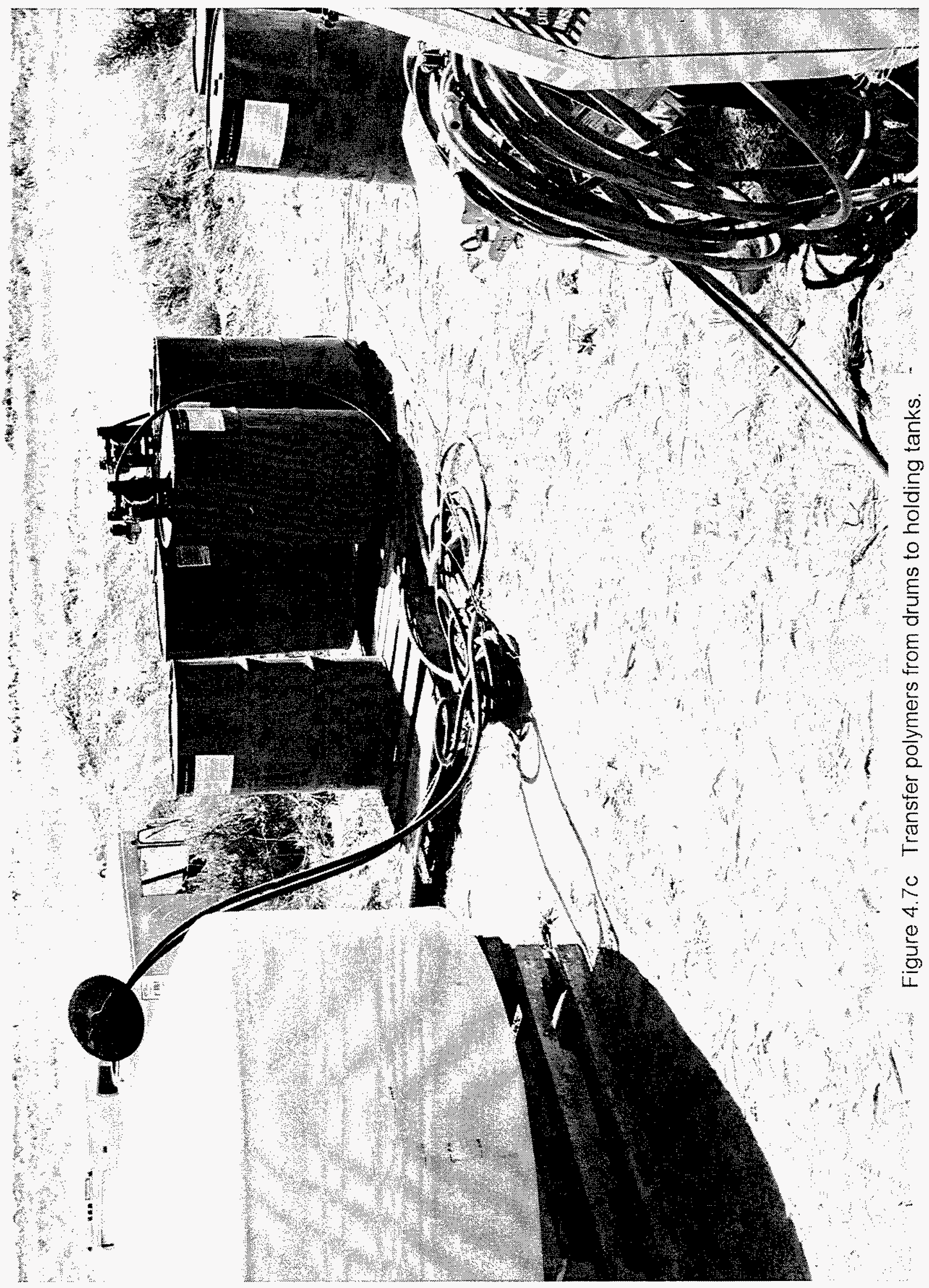




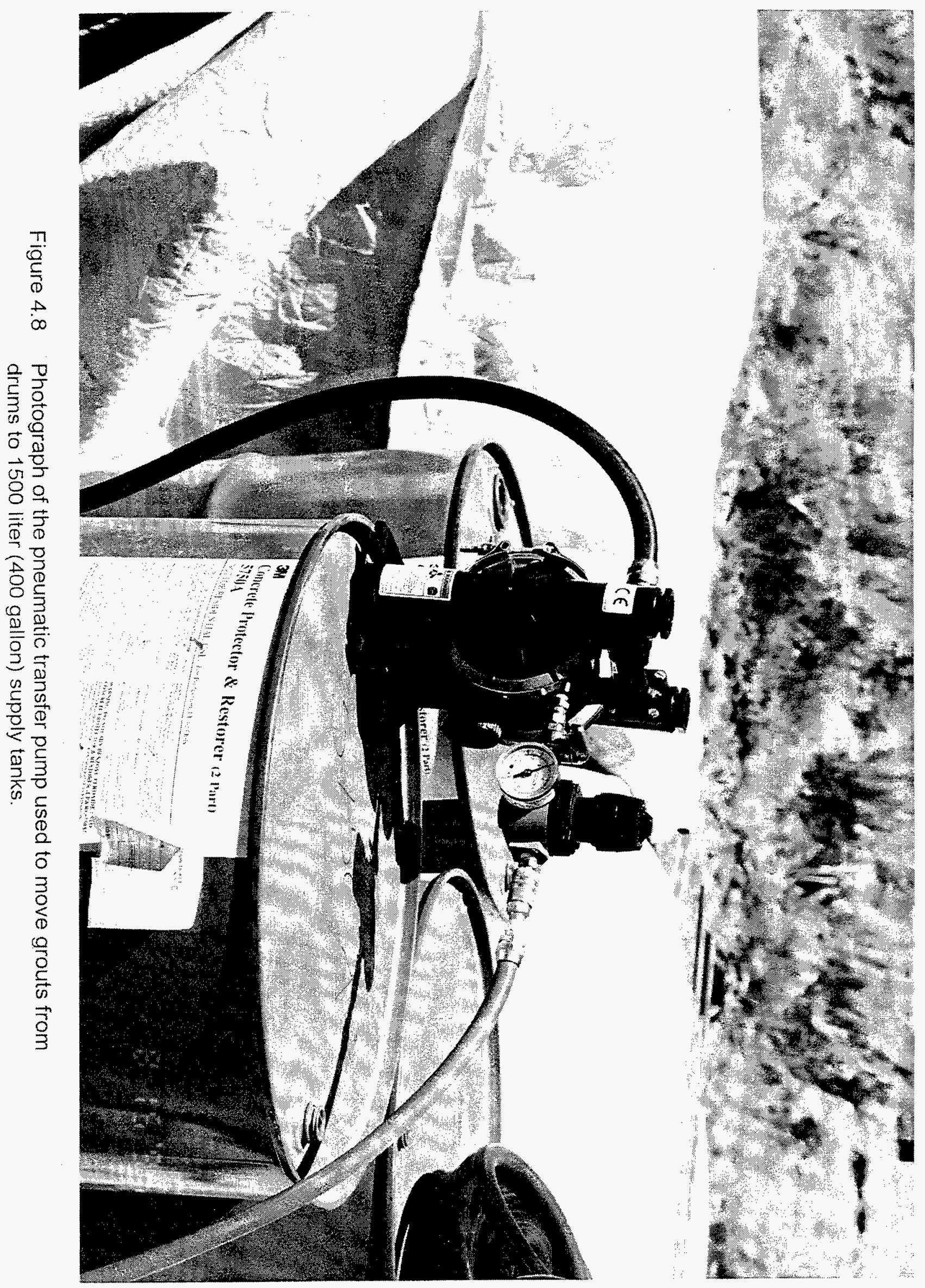




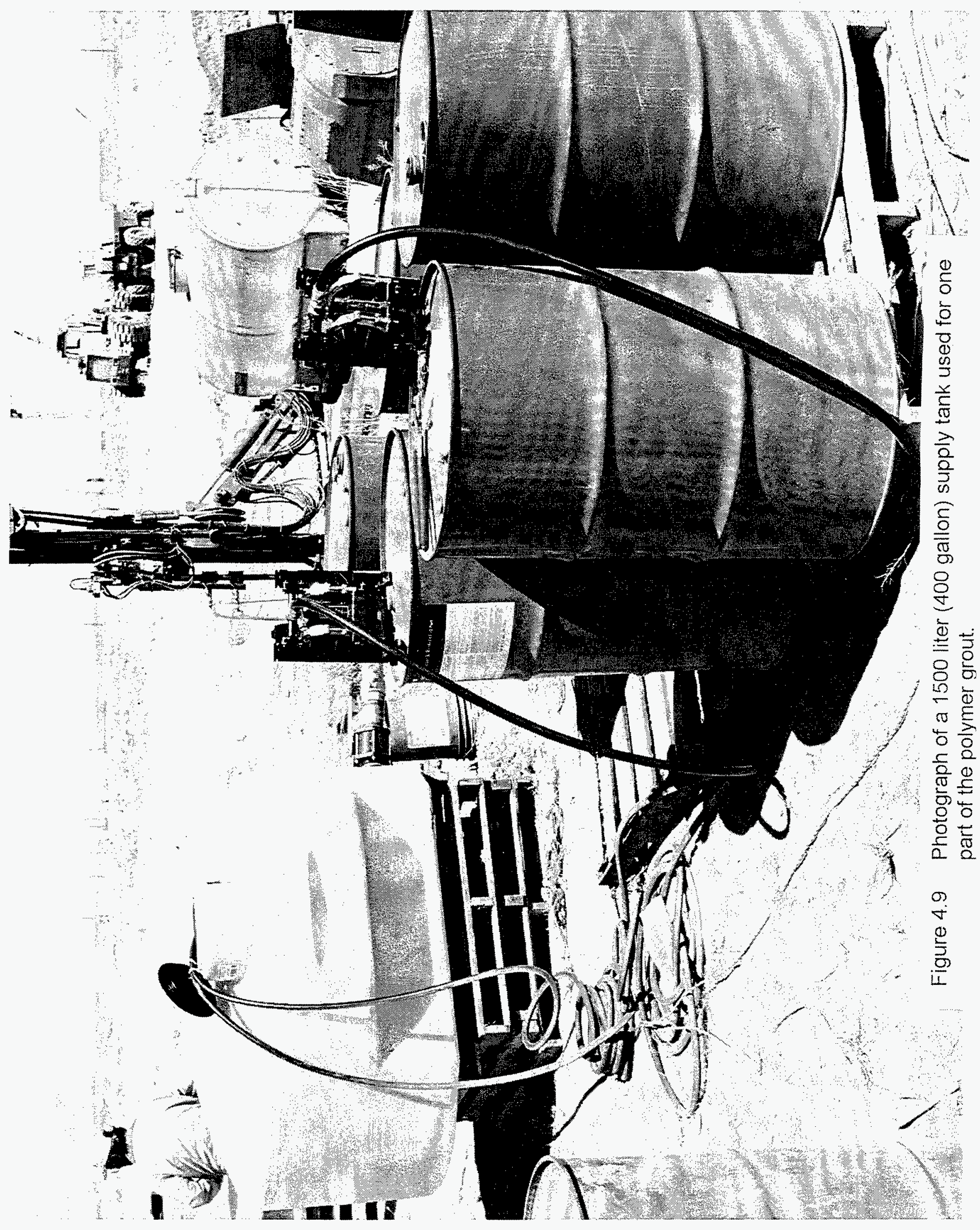




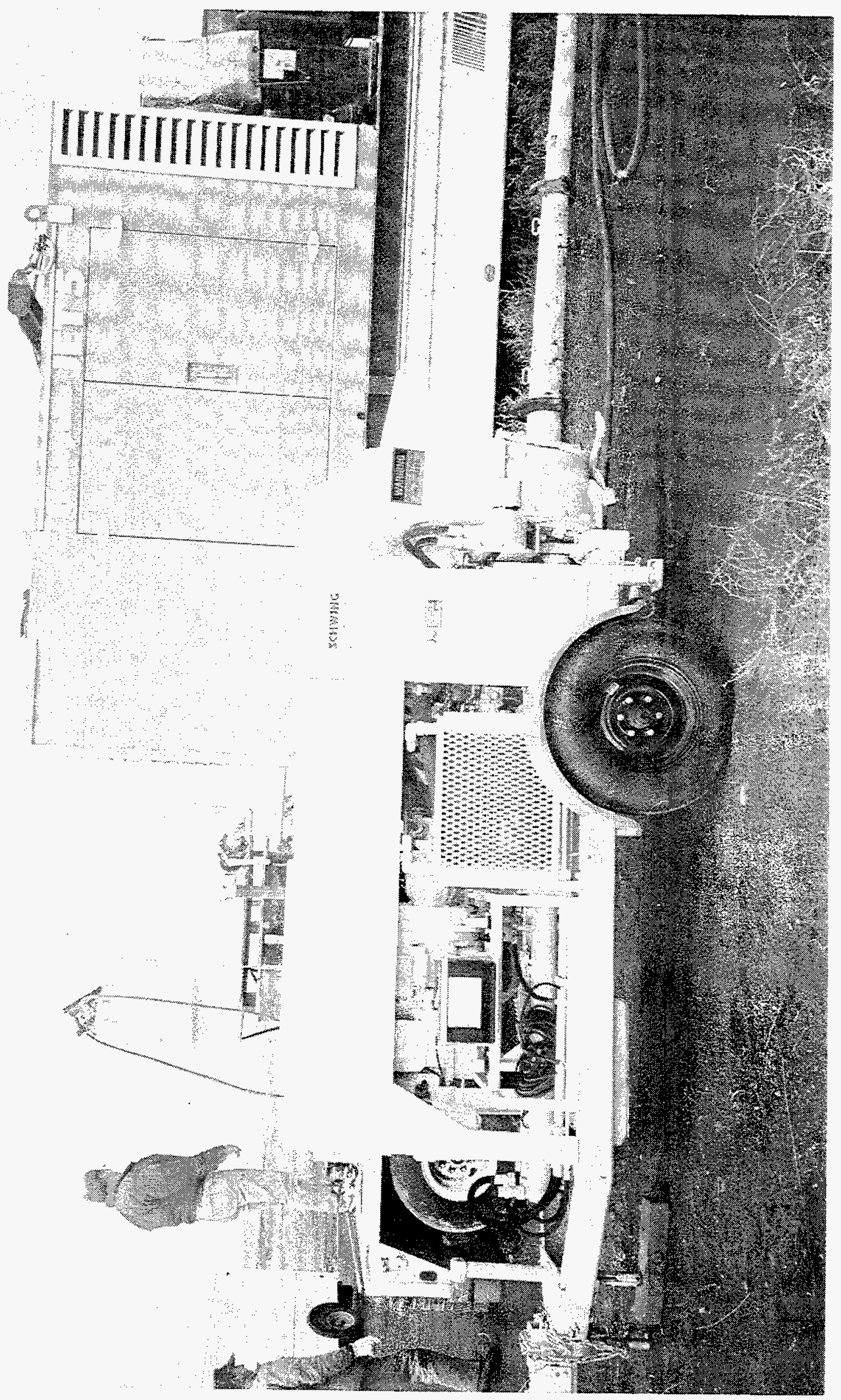

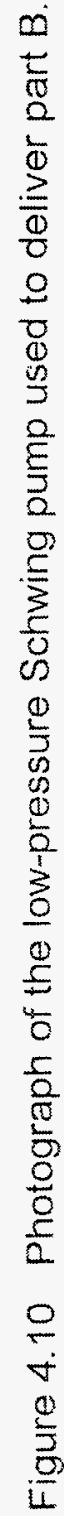




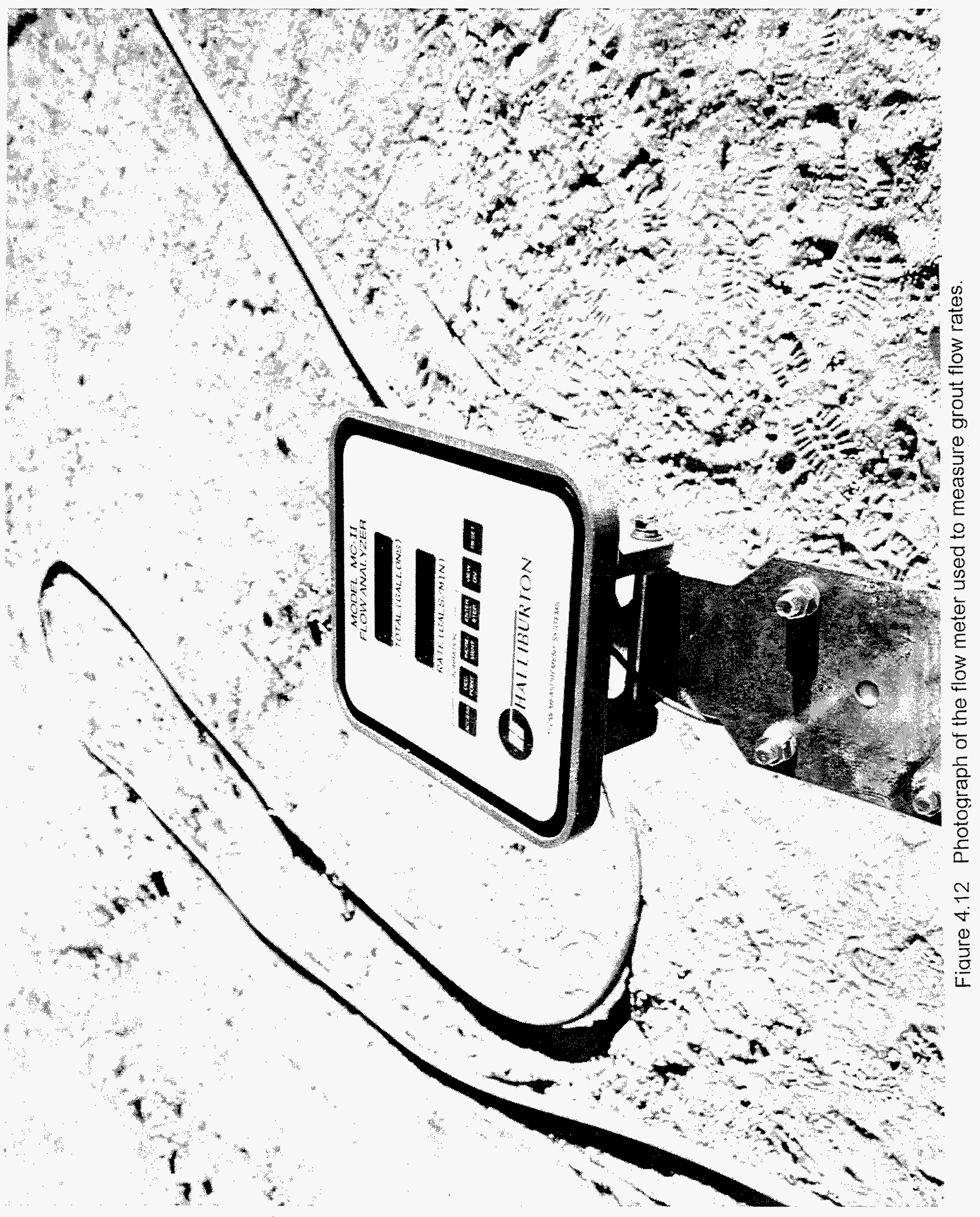




\subsubsection{Results of the single-column test at INEEL}

At this point excavation of the two columns was performed. Examination of the first grouted area failed to show development of a solid grouted column. In fact, the only evidence of a column was at the lower portion of the grouted region where there was a $50 \mathrm{~cm}$ (20in) long right circular cylinder of hard polymer-soil was found. The region (see Figure 4.13 ) was a $46 \mathrm{~cm}$ (18in) in diameter ring of polymer soil grout that was $5 \mathrm{~cm}$ (2in) thick, filled with a highly viscous clay-water mixture (determined by the lack of the polymer odor for the interior material). The technical possibilities included the potential for the low-viscosity polymer material to have leaked out of the pit prior to grouting. However, this would not explain the large amount of water in the central region of the ring and given the hydraulic conductivity of the soil didn't seem reasonable. The grouting contractor, Westinghouse Hanford Company, personnel claimed that when setting the flow rates to achieve equal parts $\mathrm{A}$ and $\mathrm{B}$ the calibration of the flow meters was performed with water. About $75 \mathrm{~L}$ (20gal) of water remained in the high-pressure injection lines, and injection hole number 1 became saturated with water during the initial jet-grouting process. This explained the high water content in the interior of the first grouted column. The high water content of the grouted zone also explained the low temperature readings measured downhole. The polymer zone occurred at the very outer circumference of the column due to centrifugal forces flinging the less dense material outward. The polymer zone may have reached $116^{\circ} \mathrm{C}\left(240^{\circ} \mathrm{F}\right)$ but this temperature would not be seen through the water zone. At best $100^{\circ} \mathrm{C}\left(212^{\circ} \mathrm{F}\right)$ [boiling of water] would have been reached. It is also possible that the thin layer of polymer with such good heat sinks surrounding it would not reach the peak exothermic temperature expected.

With this speculation in mind, the second grout column comprising $30 \mathrm{~L}$ (8gal) of part A and $87 \mathrm{~L}$ (23gal) of part B was examined. The column was approximately $1 \mathrm{M}(3 \mathrm{ft})$ long and $41 \mathrm{~cm}$ (16 in) in diameter and consisted of a solid mixture of the soil and polymer as expected (shown in Figure 4.14). The dual-wall drill pipe was successful in injecting a uniform well mixed (as evidenced by final curing of the polymer which requires mixing $A$ and $B$ ). The column was in fact more uniform in diameter than cement grouted columns emplaced nearby in an earlier demonstration. At this point, it was clear that the water had adversely impacted the formation of the first column and that the demonstration parameters were in the correct range for forming columns in compacted soil and the INEEL in-situ stabilization demonstration proceeded as planned.

Afterwards the second test column was cross-sectioned perpendicular to the drill axis. Several pieces were sliced and all were uniform, void-free pieces. We were able to meet all the objectives of this pilot-scale demonstration. The dual-wall drill system worked as planned and continued to work flawlessly for the duration of INEEL in situ stabilization of buried waste demonstration. Excavation of the test column showed the grouting to be $\sim 46 \mathrm{~cm}$ (18in) in diameter and very uniform in diameter. Two differences were noted for the dual-fluid polymer grout injection using dual injection nozzles versus single-fluid cement grout using a single nozzle injection. First was uniformity of the column. The polymer column didn't vary much while cement columns from a previous test varied considerably. It is believed that the single nozzle 


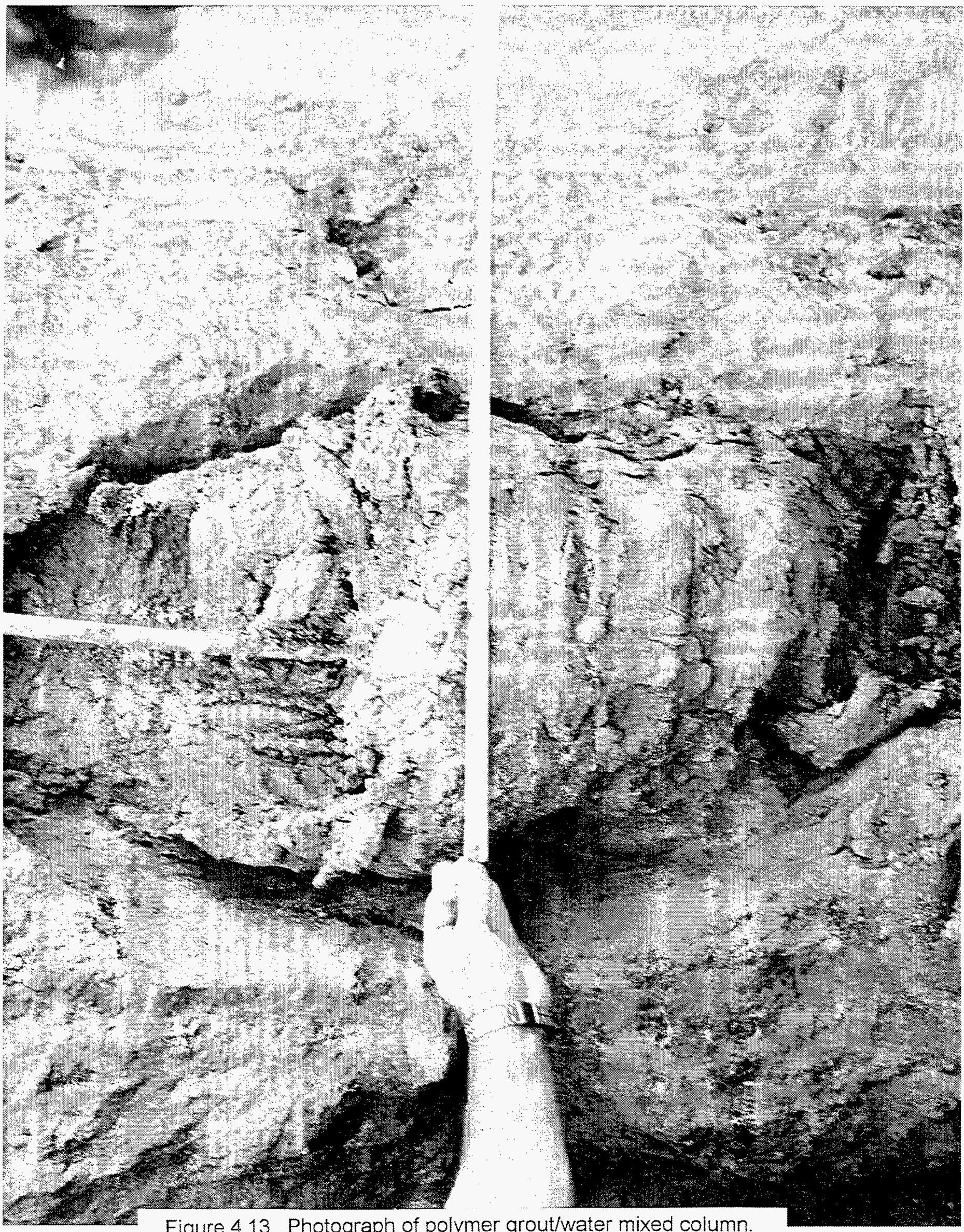

Figure 4.13 Photograph of polymer grout/water mixed column. 


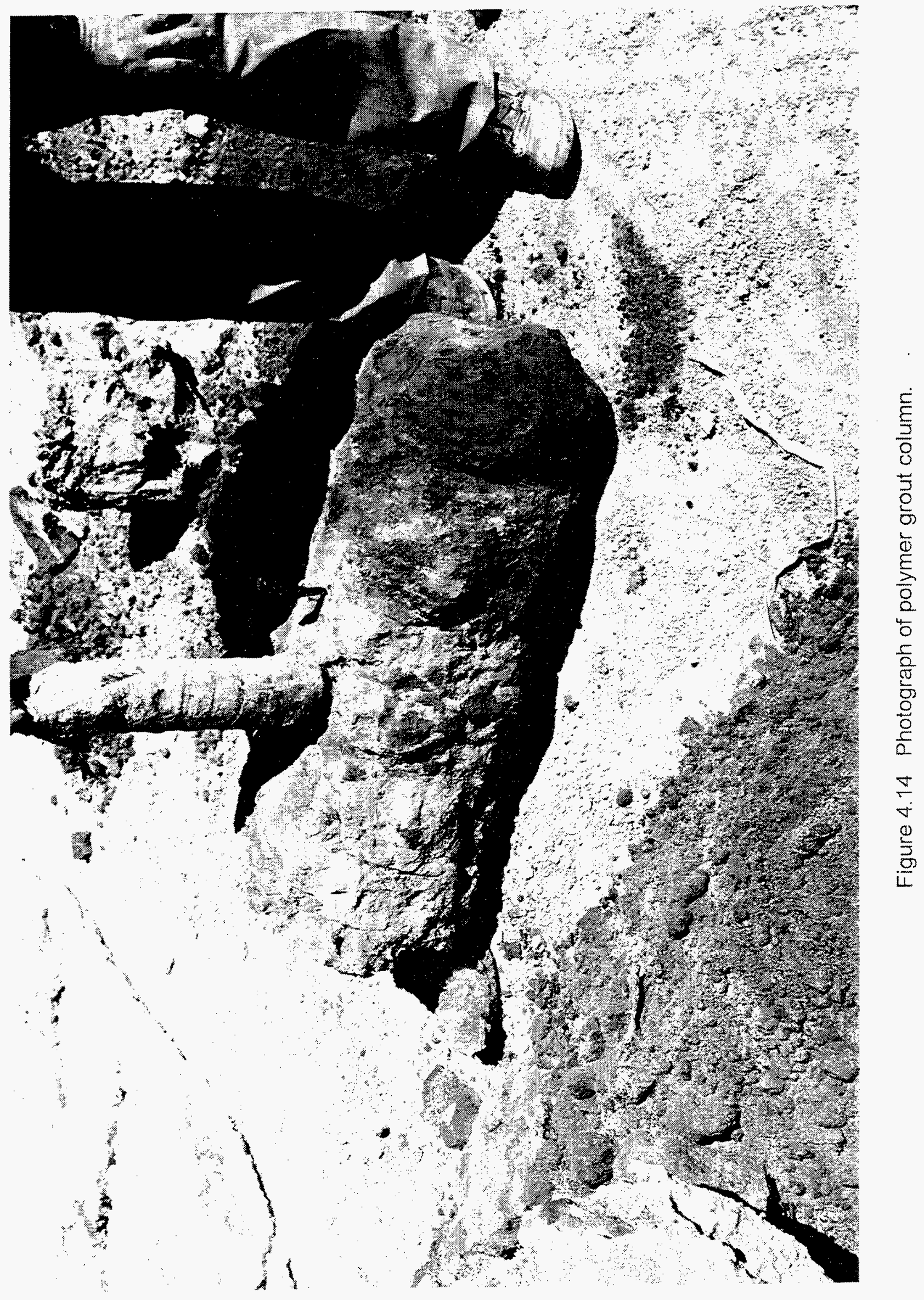


combined with the particulates in the cement grouts resulted in occasional partial blockage of the nozzle. This would result in decreased column widths during the time of the restricted flow. In the dual fluid injection the presence of two nozzles decreases the chance of extremely reduced grout flows.

The second difference noted was the column width. Cement columns jetted with 400 bars (6000 psi) from a single nozzle were $\sim 61 \mathrm{~cm}$ (24in) in diameter versus the $46 \mathrm{~cm}$ (18in) seen using polymers and dual nozzles. The grouting contractor speculated that since the dual nozzle design used was originally engineered for one nozzle to deliver air the system was not optimized for penetration depth. It may be possible to increase the column diameter in INEEL soils by using different nozzle sizes.

Cross-sectioning of the test column proved the grouting to be homogenous and void-free. From the test column injections, destructive examination and the success of the INEEL stabilization demonstration the Hanford full-scale demonstration was now ready to proceed. 


\subsection{FULL-SCALE DEMONSTRATION OF THE CLOSE-COUPLED BARRIER TECHNOLOGY AT THE DOE HANFORD SITE}

This section of this report details the full-scale demonstration of close-coupled subsurface barrier technology performed at a clean site in Hanford, WA. Only the barrier installation and performance will be covered here, discussion of verification technologies will be limited to how the results of those technologies validated the objectives of the barrier demonstration. Specifics on the two related verification technologies linked to this project are detailed in section 6.0. The original work plan can be found in a report by Heiser and Dwyer. ${ }^{8}$

\section{$5.1 \quad$ Purpose}

The primary objective of this project was to develop and demonstrate emplacement of a close-coupled barrier technology capable of containing waste forms within their existing subsurface transport, disposal, or storage structures. It is essential that materials (grouts) and emplacement techniques be compatible; therefore, they were developed and demonstrated simultaneously. This is not a trivial issue. Barrier materials must simultaneously be emplaceable, i.e., compatible with emplacement equipment and site geology, withstand a wide variety of chemical, thermal, physical and radiological conditions, and meet acceptable longevity requirements.

The secondary objective of this project was to provide a demonstration barrier for integrity verification technologies. The barrier will serve as a test site for both perfluorocarbon tracer (PFT) technologies and ground penetrating radar (GPR).

\section{$5.2 \quad$ Technology Need}

Contaminated soils and buried waste, treated and untreated, pose a threat through contaminant transport to groundwater or back to the surface. Nearly every hazardous waste site contains buried waste constituents that, if left untreated, may eventually become mobile in the environment. In many instances this may result in unacceptable human health and environment exposures. Caps are used to prevent or minimize the percolation of atmospheric water into and through the vadose zone. These caps do not prevent migration of contaminants from the waste area. Volatile species can diffuse horizontally and it has been shown that soils beneath clay caps can have significant moisture content. The moisture increases soil diffusivity and may increase the migration of contaminants toward the boundary of the cap were percolating atmospheric water can transport the contaminants to the groundwater. Subsurface containment barriers will improve remediation performance by removing pathways for contaminant transport due to water infiltration, vapor- and gas-phase transport, transpiration, etc.

A subterranean barrier will increase the performance of the waste storage site and reduce the possibility of contaminant migration into local geologic media or groundwater. Failure to treat contamination in situ will also result in exorbitant restoration costs at a later date. In addition, 
the legal ramifications for not treating many of these waste sites could be detrimental to the responsible parties.

This demonstration was jointly funded by the Landfill Focus Area (LFA) and the Plumes Focus Area (PFA). For the LFA close coupled barriers have many applications. They can be used to contain buried waste and will provide a lower permeability, more durable and chemically resistant barrier than a cement grout alone would. The polymers are not expected to crack as easily as cement (wet-dry cycling) or slurry walls (solvent or organics). Close-coupled barriers are also useful in hot spot retrieval for containing aggressive contaminants while excavation and removal take place and can serve as shoring reducing the amount of contaminated soil. Utilization by PFA related projects include sealing off a source term (e.g., sealing a leaking UST or containing a subsurface spill of solvent) and preventing continued growth of a plume.

Letters of interest in subsurface barrier technologies, and in particular interest in the goals of this barrier demonstration where obtained from INEEL, BNL and Sandia. These letters are reproduced in appendix $A$.

\subsection{Technology Benefits}

The polymer/cement based close-coupled barrier demonstrated by this task is applicable to final, interim, and emergency loss of confinement conditions. The technology is applicable to any buried or surface waste form that has the potential to release mobile contaminants. Unlike many other subsurface barrier technologies, close-coupled barriers are applicable to a wide range of waste materials and geohydrologic conditions. This is extremely advantageous because nearly every waste site has site specific conditions that require the flexibility offered by this technology, more specifically this technology offers an ability to place barrier materials that are compatible with virtually any waste form in almost any geologic setting.

End users for this technology include any DOE, state or commercial facility that has buried waste that may release contaminants to the environment at unacceptable levels. Specific end users have been identified and include Idaho National Engineering Laboratory (INEEL), Brookhaven National Laboratory (BNL) and the Hanford reservation. INEEL and BNL are interested in the full subsurface polymer/cement based close-coupled barrier technology. Letters of support of the demonstration were obtained from Lockheed Idaho for INEEL and the DOE area office for BNL. Hanford has expressed interest in the use of polymers to form a close-coupled barrier. ${ }^{9}$ A method of sealing leaking USTs at Hanford could be developed based on this technology.

\subsection{Technology Description}

A close-coupled barrier is produced by first installing a conventional, low-cost, cementgrout containment barrier followed by a thin lining of a polymer grout. The two grouts are placed in a close-coupled fashion such that the polymer barrier is bonded to the cementitous barrier. The resultant barrier is a cement-polymer composite that has economic benefits derived from the 
cement and performance benefits from the durable and resistant polymer layer (see Figure 1.2). The secondary (cementitous) barrier is placed first by column jet grouting and is $\sim 1 \mathrm{M}$ thick. This layer serves foremost as a backdrop for the polymer layer and secondly as a redundant, albeit less durable, barrier. The secondary layer allows a thin layer of a polymer grout to be applied to the inside of the cementitous barrier, reducing cost tremendously over column (re: thick) grouting with polymers. Cementitous grouts are inexpensive (comparable to a slurry wall) and when cured give enough durability that the jetting action, when installing the polymer layer, will not "chew up" the secondary layer. The polymer layer is thin ( 0.3 meters) and serves as the primary barrier to contaminant mobility. The primary barrier is placed by panel jet-grouting using a two-part polymer grout system, in this case the 3M4R 5750 resins described earlier.

This demonstration produced a technology that can be used for remediation of subsurface waste sites with:

1. current loss of containment,

2. high probability of near-term loss of containment, and

3. loss of containment caused by retrieval or in situ remedial actions.

Thousands of buried waste structures throughout the DOE Complex can be treated and/or brought into compliance with state and federal regulations by construction of subsurface containment barriers. This project demonstrated a Systems Approach to construction of a closecoupled subsurface barrier. This included the integration of barrier materials, emplacement equipment, verification techniques, and post monitoring instrumentation to produce a closecoupled engineered barrier. Results are applicable to construction of subsurface barriers throughout the DOE Complex and will have direct applicability to other government and private sector waste confinement actions. The technology is applicable to construction of final, interim, and emergency barriers for a wide variety of waste/storage disposal sites.

Installation of the close-coupled barrier required using two variations of jet grouting; conventional jet grouting where a column is produced and panel jet grouting were a thin panel of grout is formed. Conventional jet grout curtains are constructed by injecting the grout through a pipe into subsurface. The pipe has a drill tip on it which is used to drill the initial borehole. The pipe is then rotated while injecting the grout and slowly withdrawn from the ground. The high velocity jet masticates and mixes the soil and grout which results in a column $\sim 1$ meter in diameter that resembles a pancake stack (Figure 5.1). Figure 5.2 is a photograph of an excavated cement column. After the grout pumped into the primary holes has gelled, secondary boreholes are drilled ( in a honeycomb fashion) and grout is injected to fill gaps in the primary grout injection. This results in a barrier $\sim 1$ to $1 \frac{1 / 2}{2}$ meters thick. The technique requires a pumpable grout that can be injected at pressures greater than 300 bars (5000 psi) through a small orifice, typically $2 \mathrm{~mm}$. Figure 5.3 illustrates the force and shape of a high pressure jet, water is being jetted at 70 bars (1000 psi) during a routine flow calibration. The small orifice limits any aggregate additions to fine particle sizes. Most often, the jet grouting uses a low viscosity grout ( $5 \mathrm{cps}$ ), and incorporates only the existing soils for aggregate. Jet grout curtains can be vertical using conventional drilling, or may be angled, or horizontal, using directional drilling. 


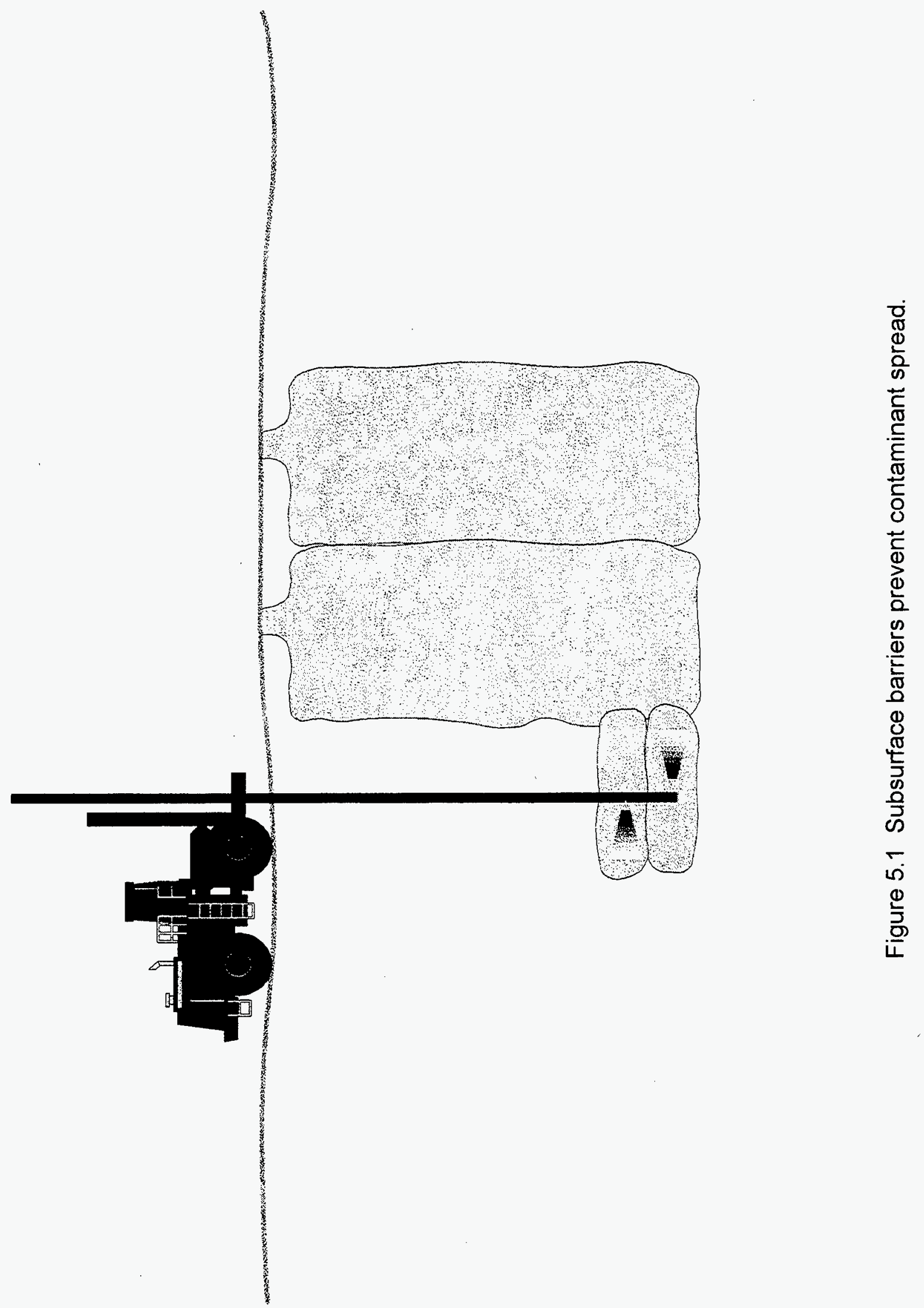



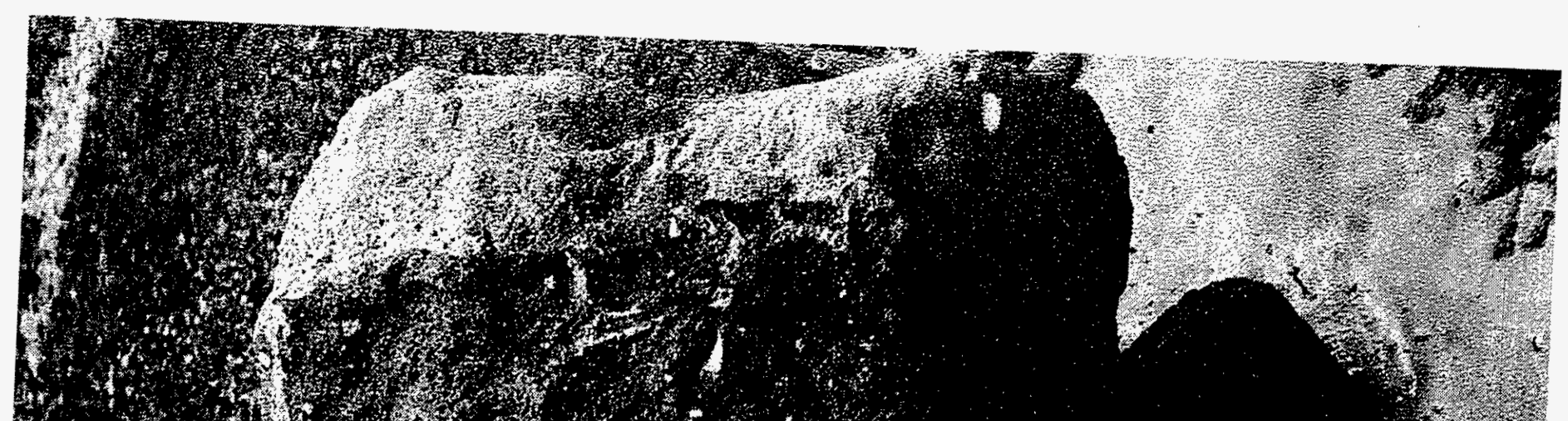

, n,

(6)

H. W

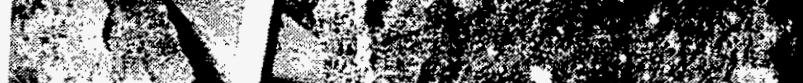

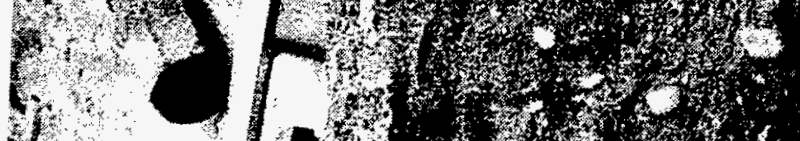

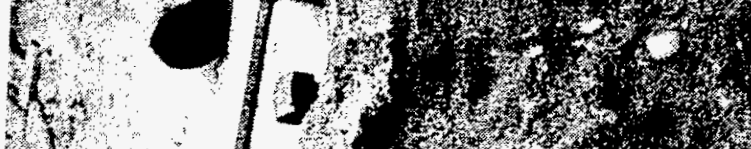
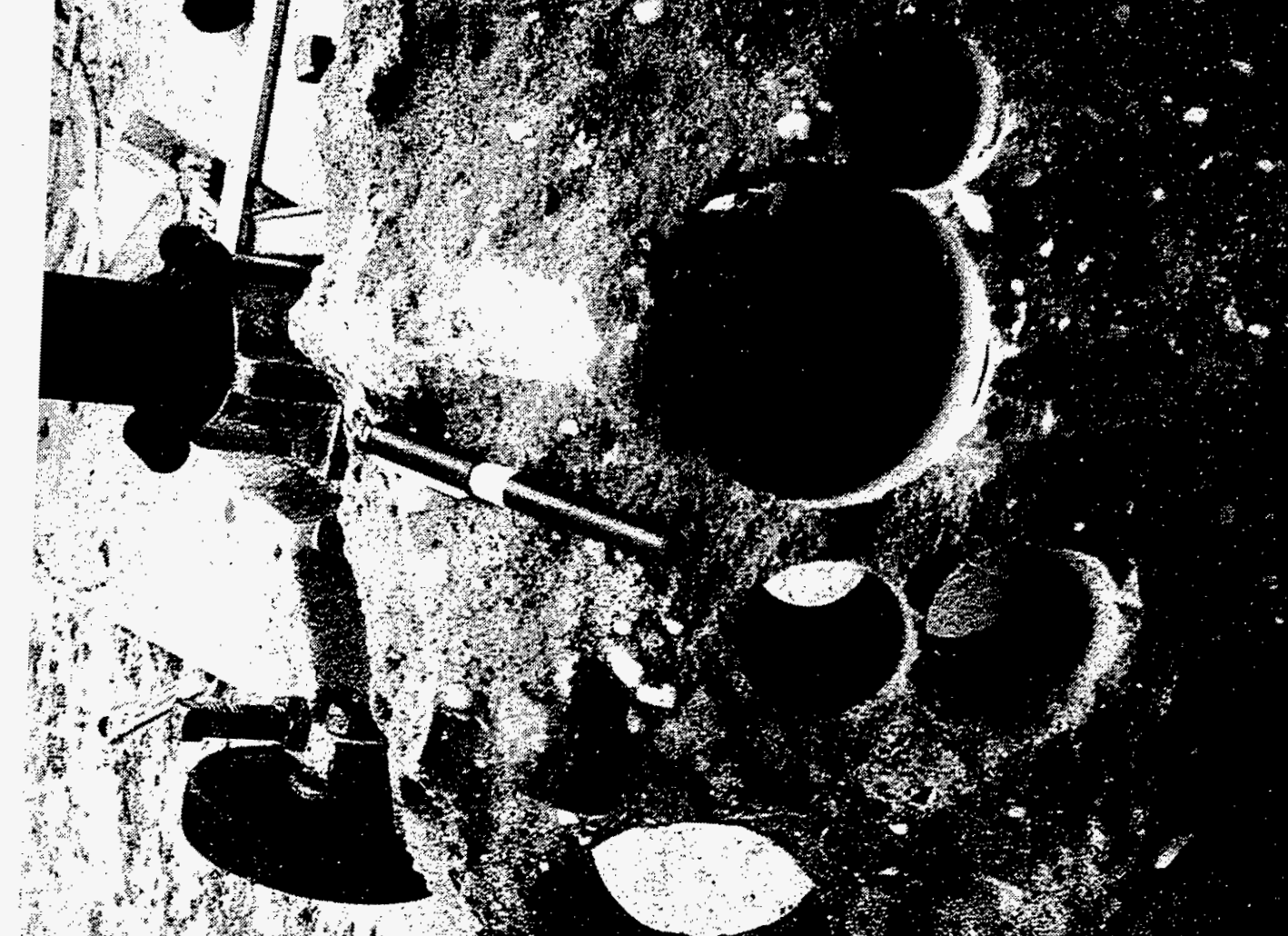

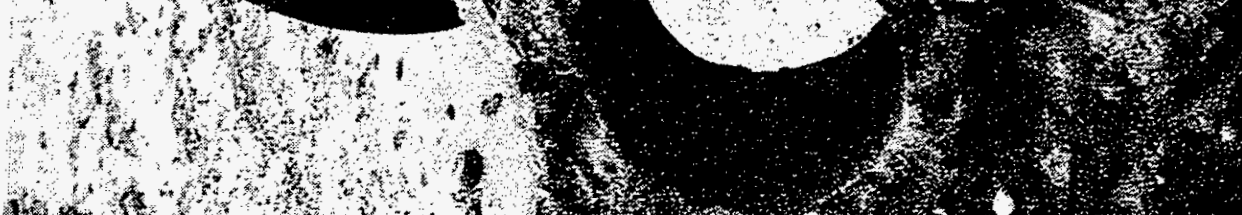
16.

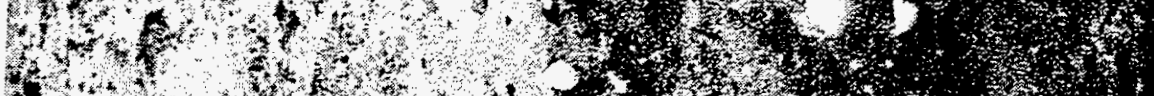

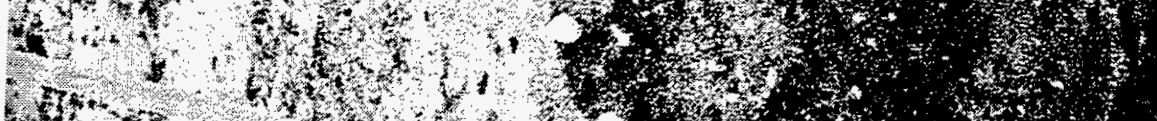

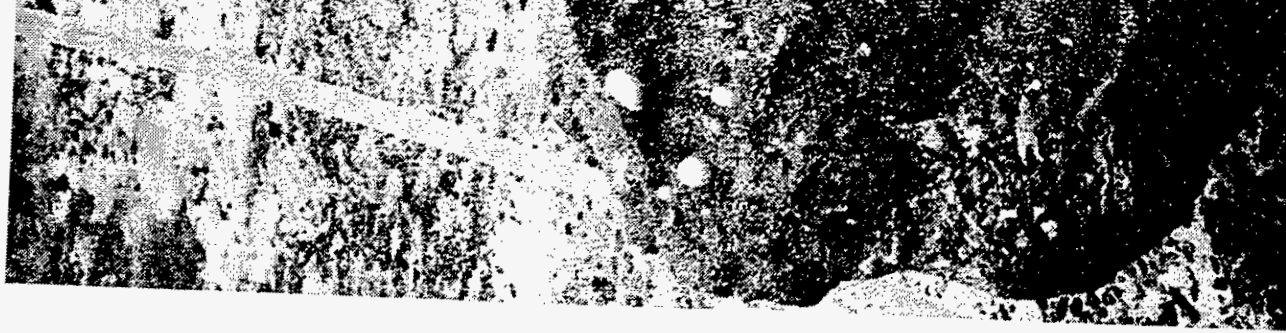

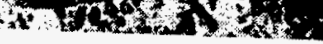




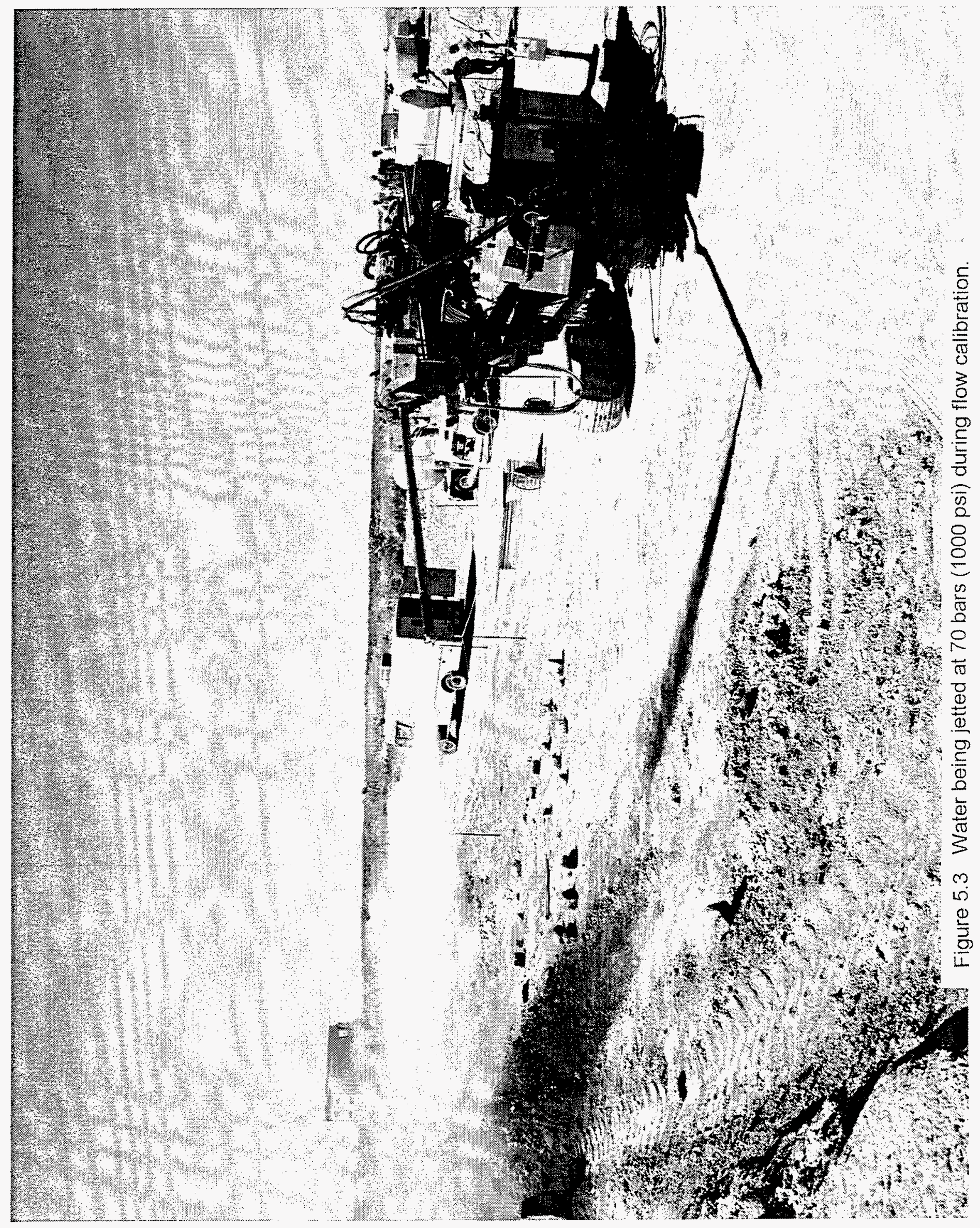


The primary polymer layer was installed using panel jet grouting. Panel jet grouting is a simple refinement to conventional jet grouting. The tool is turned back and forth only a few degrees, rather than rotating the jetting tool $360^{\circ}$ and forming a cylindrical column. This forms

a thin bow tie shaped panel, typically 30-40 centimeters wide. Panels are laid side by side with a slight overlap in order to form a continuous barrier. This results in a significant reduction in the volume of grout required as opposed to the volume of grout required for column jet grouting.

\subsection{Scope}

The scope of the project was to emplace a low permeability containment barrier beneath a simulated waste site without disturbing the waste form. The containment is a multibarrier of a cementitous grout followed by a polymer grout. The two grouts were placed in a close-coupled fashion such that the polymer barrier is bonded to the cementitous barrier (Figures 5.4 and 5.5). The barrier was installed by jet grouting a conventional column formed barrier using a cementitous grout followed by application of a close-coupled polymer layer on the inside surface of the cement barrier. The polymer barrier was installed as a thin ( $~ 0.3$ meters) liner and serves as the primary barrier to contaminant mobility. The cementitous barrier is thick ( $\sim 1$ meter) and serves as a secondary barrier to contaminant mobility.

During primary and secondary barrier emplacement, the waste form (tank) was to be monitored for structural performance during and after emplacement. Tank wall and floor stress/strain relationships were to be determined using extensiometers, strain gauges, inclinometers, accelerometers, earth pressure cells, and precision leveling.

The barrier was checked for breaches after the installation of the cement layer and again after the polymer layer installation. At the culmination of performance verification activities, intrusive verification was conducted. Intrusive verification included removing the tank, wells and earth from the inside of the barrier. After the site was excavated, samples were cored from the primary and secondary barriers for laboratory testing. The barrier walls were visually inspected to determine the completeness and homogeneity of the emplacement. All observations were recorded in a field log book. Laboratory testing of core samples included: unconfined compressive strength, flexural strength, hydraulic conductivity, density measurements and wet-dry cycling.

Following the PFT and GPR verification demonstrations the barrier was flooded with water to provide an hydraulic gradient across the barrier. The fluid flux across the barrier was measured to provide at least a primitive check of the performancelintegrity of the barrier if it is stressed.

\subsection{Performance Objectives}

1. The performance of the jetting equipment using polymer grouts will be compared to the performance values expected for conventional grouts. 


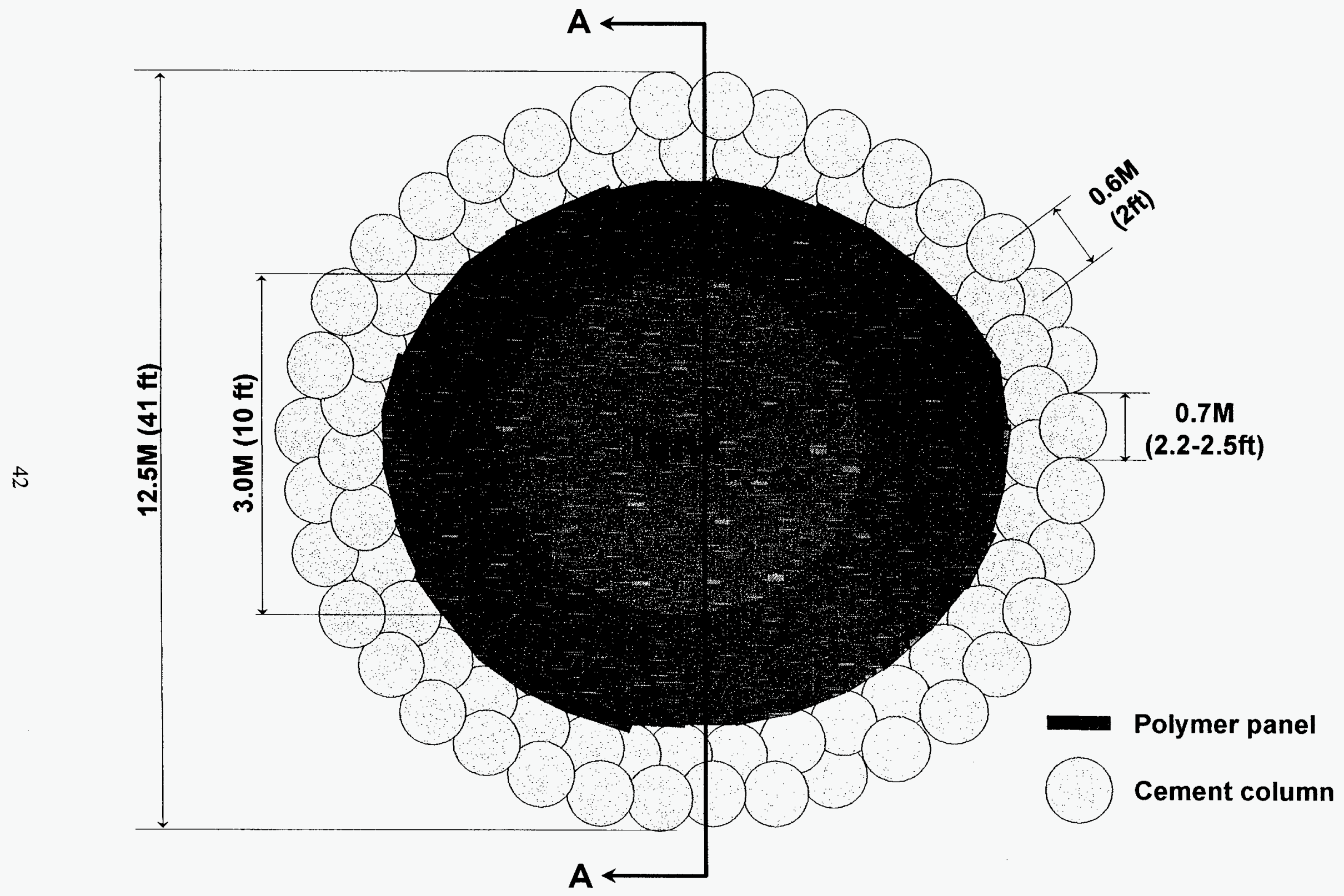

Figure 5.4 Plan view of the Close-Coupled Barrier at Hanford. 


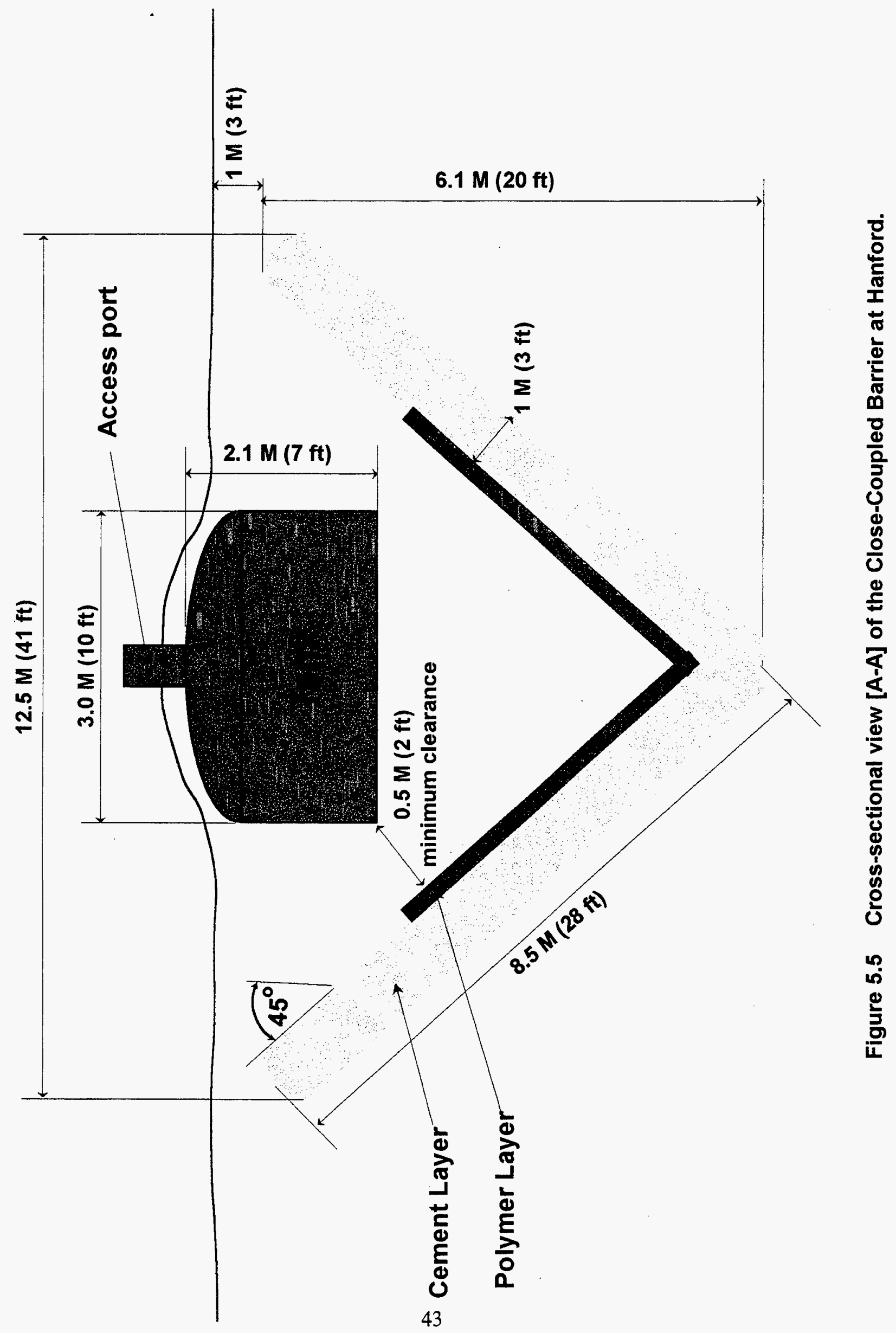


2. Cores will be taken from various locations throughout the barrier. The density of these core samples will be measured and the variation determined. The variation will be compared to the expected density variation of ungrouted soil from the same or a similar location. Some of the core samples will be cross-sectioned and visually inspected for the degree of grout penetration. The grout chosen has a contrasting color to the native soils and should be easily seen.

3. The hydraulic conductivity of appropriately sized core samples will be measured in a flexible wall permeameter according to ASTM D-5084.

4. The penetration depth (diameter of columns) will be measured at several locations and compared to results obtained using cementitious grouts at similar jetting parameters.

This project was to demonstrate a close coupled, engineered subsurface barrier system for the containment of buried waste. The objective criteria for the demonstration were derived from the objectives statements of the demonstrations and from questions from potential end users.

\subsubsection{Objective criteria}

The objective of this project is to demonstrate a Systems Approach that integrates directional drilling, grout emplacement (e.g., two pump system for multi-part resins), multiple barrier material usage, and verification/monitoring technologies.

Questions by end users covered such topics as compatibility between grout materials and emplacement methods; effect of grouting process on the waste form(s); barrier performance issues such as life expectancy, probable failure mechanisms, final properties, and reactions between barrier materials and targeted wastes; how barrier integrity will be verified; and cost versus performance values.

To achieve the above objective and provide answers to the questions posed by end users, the following criteria must be successfully demonstrated:

1. Barrier materials are compatible with the placement equipment,

2. Install the barrier without disturbing the waste form,

3. Reduce the formation permeability by a minimum of two orders of magnitude,

4. A barrier verification system can be installed at the site to evaluate barrier integrity in a reasonable time frame, and

5. That the cost of installing a close-coupled barrier is offset by the cost savings of preventing further contamination of the subsurface either by inaction or cleanup activities. 


\subsubsection{Demonstration parameters}

The parameters that will be observed or measured to verify successful completion of the criteria for the close-coupled polymer/cement grout barrier as defined in Section 5.6.1 above are as follows:

1. Compatibility of the grout materials with the emplacement equipment will be observed, this will include observations of the location(s) where the polymer grout cures to determine if the grout can be placed using the dual wall drill pipe,

2. The stresses on the simulated waste form will be measured to determine if the grout placement will cause damage to the waste form,

3. Measurements of the barrier permeability will be made,

4. The ability to emplace a barrier integrity verification system at the site will be observed and evaluated, and

5. The cost of installing the close-coupled barrier will be documented and compared to the estimated costs of removing and treating soil and/or groundwater.

\subsubsection{Criteria for Success}

Successful demonstration of technology for close-coupled subsurface barriers shall be verified by operational testing, post operational monitoring, and destructive examination of the tank and geologic system.

Specific criterion for measuring success include:

1. formation hydraulic conductivity reduction of greater than two orders of magnitude,

2. emplacement of primary and secondary barriers without compromising the integrity of the waste form (tank), and

3. smooth integration of emplacement, barrier materials, verification, and post monitoring technologies, providing a comprehensive subsurface barrier program.

\section{$5.7 \quad$ Test Site}

The site selected for the field-scale demonstration is the Hanford Geotechnical Development and Test Facility (HGDTF) in the 400 Area ("Little Egypt") at the Hanford Site near Richland, Washington. This site was selected for several reasons: in geotechnical terms it is typical of many DOE facilities, the HGDTF is fully characterized and permitted for such a 
demonstration, the grouting contractor is located nearby (eliminating mobilization costs), and has low cost access (via the grouting contractor)' to instrumentation and equipment (e.g., accelerometers, steel tank, etc). The site is a "cold" site, that is there is no contamination at the site and the installation was designed for a demonstration rather than full-scale implementation.

Other sites that were considered include BNL, INEEL and Sandia. Sandia was originally considered because it was the site of pilot-scale demonstrations of the jet grouting equipment and a small polymer injection in FY94. The site was eliminated because the geotechnical conditions there were less typical of the identified end users. BNL and INEEL were eliminated on the basis of logistics and scheduling; and it was advantageous to have the grouting contractor nearby in case modification to the barrier or repairs after verification were required. Mobilization costs and large lead times would be required every time any modifications andlor repairs to the barrier or equipment were required.

The HGDTF was completed in FY82. It was originally designed to test and demonstrate burial ground subsidence control methods. The site is NEPA approved and well characterized and is described in a report by Phillips and Fischer ${ }^{10}$. The HGDTF soil is coarse sand to gravel, hydraulic conductivity of the soil in the test area ranges from $10^{-3}$ to $10^{-1} \mathrm{~cm} / \mathrm{sec}$. This compares to BNL which is a coarse sand, mostly free of clay lenses or cobble and INEEL which is an alluvial/eolian deposit consisting of fine clay sized silts to coarse gravel of carbonaceous origin overlying basalt.

Jet grouting has been accomplished in all soil types. Soil type affects the effective diameter (jetting distance) of the column, for example in a clay soil the jetting distance will be reduced due to the energy absorbing characteristics of clay. This effect will require slightly reduced spacing of the installation bore holes (columns) or increased jetting pressures. The biggest impediment soil type could impose to jetting would be large cobble that could block the jetting pathway, which could result in a gap in the barrier. It is anticipated that with a closecoupled approach the cobble will become part of one or both of the barrier layers (since the jetting would occur parallel and perpendicular to the cobble; column jetting followed by panel jetting). Therefore the success of the demonstration is virtually independent of the test-site soil type.

Soil particle-size distribution will have an effect on grout strength and volume requirements. If the soil were well graded the increased packing would decrease the void volume thereby increasing compressive strength and decreasing the volume of grout required to fill the voids. The DOE complex is predominantly unimodal soils (Sandia, INEEL, Hanford, BNL) and as such this effect should not be appreciable. More importantly the strength of the grout is not as relevant to the barrier success as is the durability and performance of the grout. Often change in strength is measured in durability determinations. It is not the absolute strength that is important but rather the percent of original strength retained. Soil size should not effect the shortor long-term durability. Such stability will be controlled by the binder type, environmental conditions, waste types and to some extent soil type. The soil-size distribution will effect the performance of the barrier in such areas as hydraulic conductivity. Well graded soils will have 
less void space, hence smaller, far more tortuous transport paths and lower conductivity to liquids. As already mentioned the DOE complex is mostly unimodal so this effect is minimal. The size of the soil particles will also effect the hydraulic conductivity, larger particles mean bigger (albeit less) pores, less tortuosity and greater flow capacity. There will be differences in performance of a grout depending on the site chosen which will correlate to the soil particle size. For the DOE complex these differences are expected to minimal and should not effect the lifetime of the barrier to any appreciable extent.

The HGDTF soil is alkaline in nature, due to carbonate minerals. This can affect the durability and performance of a grout. The grout must be able to withstand the alkaline conditions. The grout polymerization may be effected and/or the final durability compromised. The compatibilities of all the polymer grouts with alkali were considered by BNL in the laboratory stage of development and no problems are foreseen. In terms of being representative of the DOE complex the alkalinity of the HGDTF soil is similar to INEEL and Sandia and since BNL is neutral (silica sand) the HGDTF represents a worst case scenario.

The PFT technology is slightly affected by soil permeability. The travel times of the tracers will obviously be dependent upon the transport properties of the soil. This is a minor challenge and is easily handled by using site specific parameters in the modeling codes. The soil is not expected to affect the tracers in any other manor (e.g., chemical interactions).

Soil type will affect the GPR but the effects are known. If the soil contains $>10 \%$ fines (clays) the GPR penetration distance is greatly limited. The test site is primarily coarse sand with minimal fines; therefore, no fine material interference problems are anticipated.

Prior to the demonstration the site was prepared by the subcontractor. This included the burial and backfill of a 20,000 liter ( 5000 gallon) steel tank with an access port and the installation of monitoring equipment within the tank. Prior to the barrier installation the subcontractor also installed monitoring wells. The wells were positioned such that seven wells (an eighth was broken off by construction equipment prior to the grouting) lie outside the final barrier and eight inside the cone. The wells were spaced every 45 degrees (see Figure 5.6). These wells were for verification of the barrier integrity using perfluorocarbon tracers and for moisture determinations during water infiltration testing. The site after completion is shown in Figure 5.7. The central feature is the access port to the strrage tank and allows for personnel entry. 


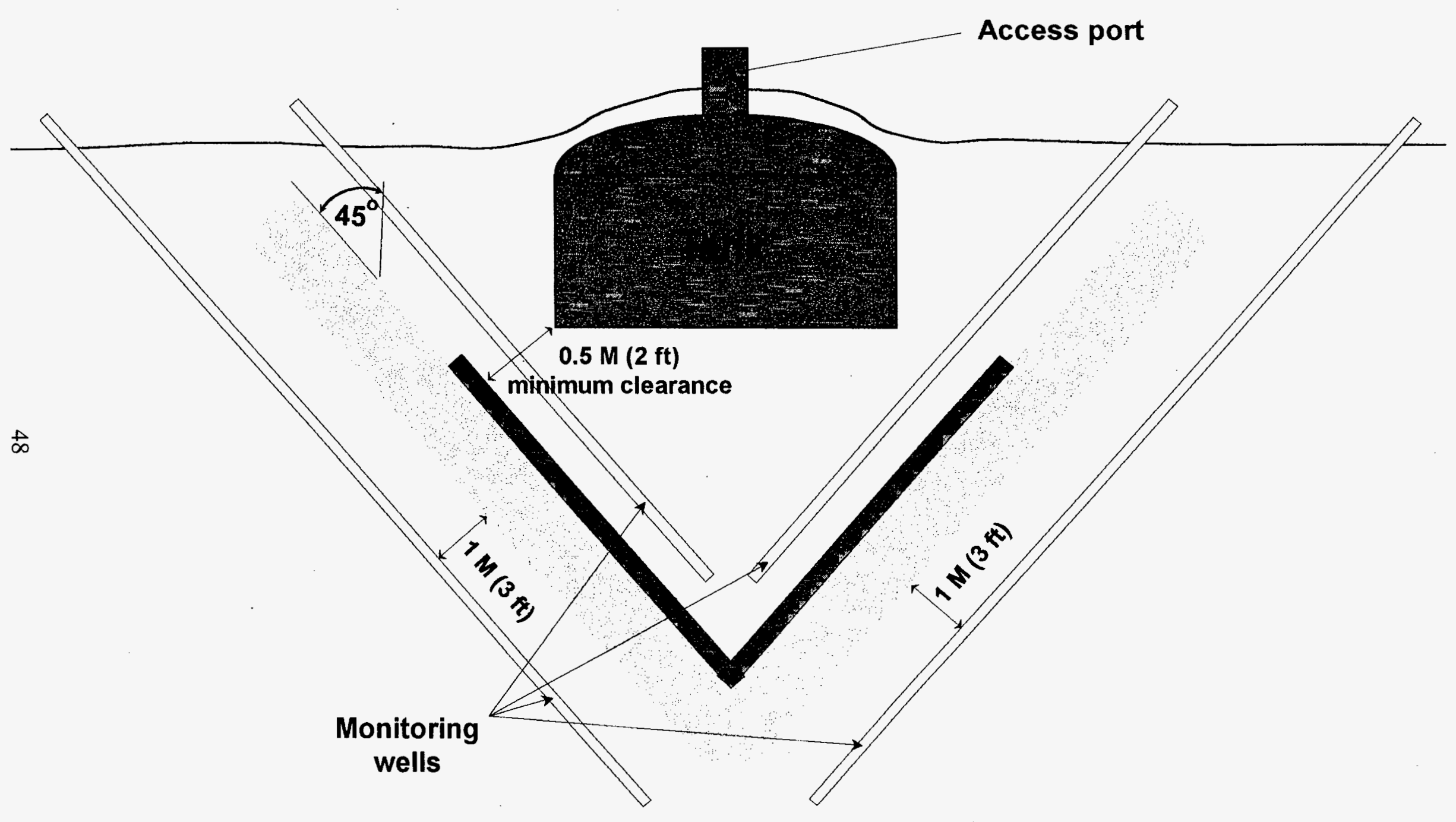

Figure 5.6 Tracer monitoring well locations in relation to the barrier. 


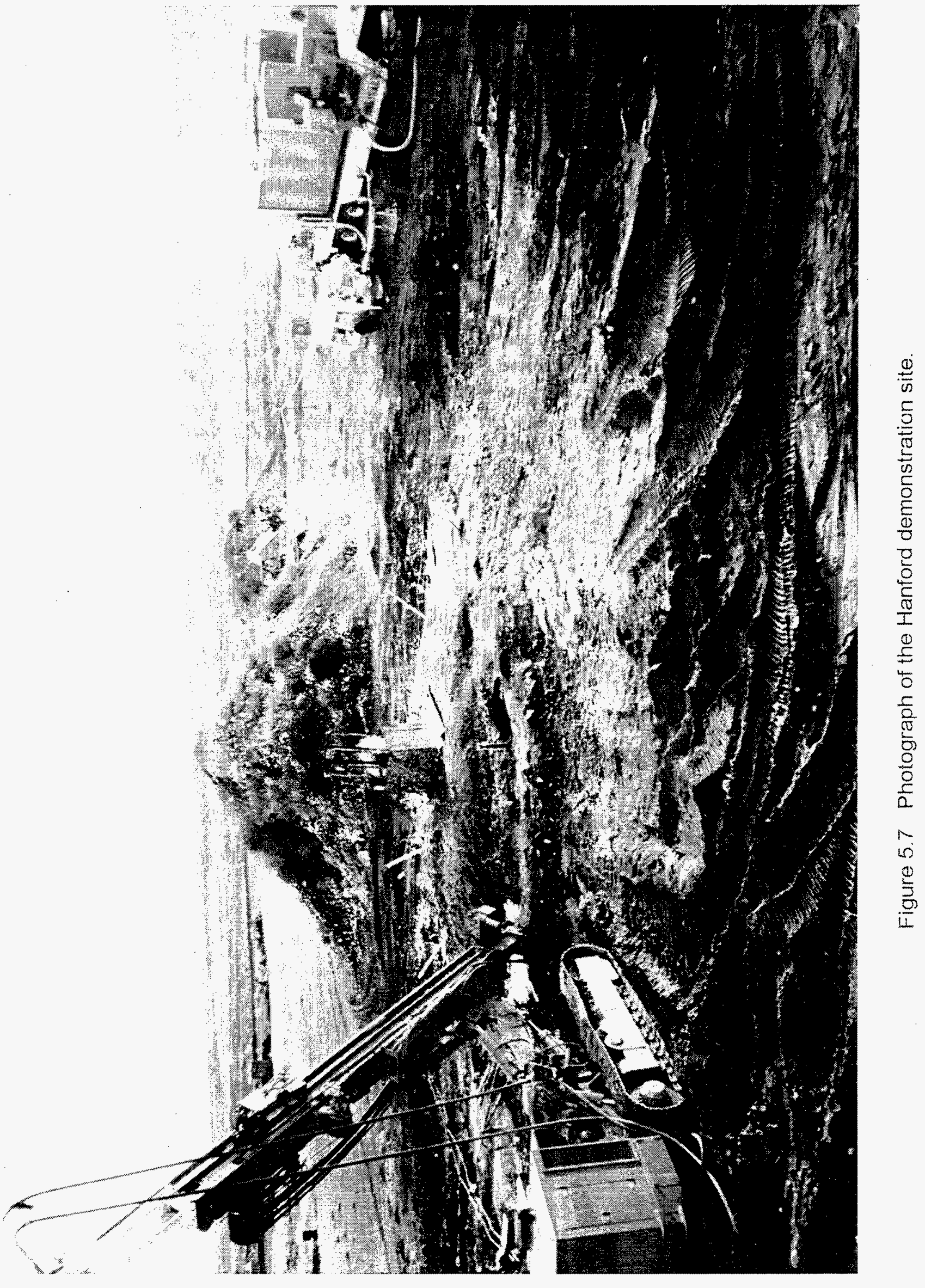




\subsection{Barrier Installation}

This section describes the construction phase of the Hanford Demonstration.

\subsubsection{Environment, safety \& health requirements}

The environmental issues associated with subsurface barriers and in particular the use of polymers were addressed in an initial report from BNL "Regulatory Issues and Assumptions Associated with Barriers in the Vadose Zone Surrounding Buried Waste"4. The perfluorocarbon tracers are environmentally benign and have been used in oceanographic and atmospheric studies with regulatory approval. There were no environmental problems associated with this demonstration.

\subsubsection{Permits}

NEPA Permit: The HGDTF is a NEPA approved site with Environmental Assessment and Categorical Exclusion permit documentation. This includes explicit approval to excavate and backfill geologic media, in situ inject treatment materials (benign), emplace barriers and instrumentation, monitor barrier and component performance, operate systems and heavy equipment, and conduct associated geotechnical actions in support of research, development, demonstration, testing, and evaluation.

Welding, cutting, grinding and associated construction activity permits - completed by contractor.

Confined Space permit - completed by contractor.

Notice of intent (NOI) to discharge water permit - completed by contractor.

All site specific $\mathrm{E}, \mathrm{S} \& \mathrm{H}$ requirements were strictly adhered to.

\subsubsection{Installation of the cement layer}

For this demonstration the grout injection and pumping systems detailed earlier were used. Grouting was performed in the latter part of July 1995, by a group from WHC headed by Steve Phillips. [This group later privatized and formed AGEC, Inc] Prior to emplacing the cement layer six test columns were injected into a region nearby and of similar backfill as the storage tank/demo area. The grouting parameters were varied slightly (pressure and step time) to optimize the column width and minimize spoils. The six columns were excavated and the injection representing the optimal grouting parameters resulted in a column that was $76 \mathrm{~cm}$ (30in) in diameter and relatively uniform in thickness throughout its length. The parameters chosen to install the cement were: a $2.2 \mathrm{~mm}$ nozzle, injection pressure of 400 bars $(6000 \mathrm{psi}), 2$ revolutions $/ \mathrm{step}, 5 \mathrm{~cm} / \mathrm{step}$, and $4.25 \mathrm{sec} / \mathrm{step}$. 
Drilling for the barrier was completed at a $45^{\circ}$ angle to the horizon. Columns were placed in a circular pattern forming a cone-shaped barrier (see Figure 5.4). One row of cement columns was grouted followed by a second row of columns behind and touching the first row in a honey comb fashion (see Figure 5.5). Columns were 66 to $76 \mathrm{~cm}$ (26 to 30in) in diameter and spaced $0.6 \mathrm{M}(24 \mathrm{in})$ on centers to allow for sufficient overlap of adjoining columns and assuring a gap free barrier. The cement grout was a standard Portland type I $\operatorname{mix}(\mathrm{w} / \mathrm{c}=1$ by weight) specified by the grouting contractor, supplied by a local vendor and trucked to the site in a cement mixer. The cement was delivered to a $210 \mathrm{~L}$ (55gal) surge tank fitted with a screen to remove coarse particulates that may have been in the ready-mix truck. From the surge tank a slurry pump (Figure 5.8) was used to pump the grout to the high pressure pump, which delivered the grout to the drill stem at 400 bars $(6000 \mathrm{psi})$. The drilling unit was positioned at the first hole, the drilling angle set at $45^{\circ}$ and the drill stem driven into the ground to the desired depth. The cement stream was activated and grouting proceeded as follows. While delivering the grout the drill stem is slowly revolved and withdrawn from the ground. The withdrawal was performed in discrete 5 $\mathrm{cm}$ steps at a rate of 4.25 seconds per step. Rotation occurred at two revolutions per step. These grouting parameters were optimized for the Hanford site in earlier test injections, resulted in columns roughly $76 \mathrm{~cm}$ ( $30 \mathrm{in}$ ) in diameter. The step rate was adjusted in the field from 4.25 $\mathrm{sec} / \mathrm{step}$ to $3.0 \mathrm{sec} / \mathrm{step}$ to minimize spoils return. This sequence was repeated for each of the odd number holes in the first line of columns and then repeated on the even number holes. Skipping hole was performed to eliminate cross-communication between columns. If the second column injection were to be performed immediately adjacent to the first, because of the overlap in column the jet would break through to the first grouted area. Any grout injected would/could short circuit into the first hole and be pumped to the surface as spoils rather than completing the second column. Allowing the first column to set slightly eliminates such cross-communication. Once the first ring of columns was completed a second ring was grouted inside the first [61 $\mathrm{cm}$ (24in) center to center separation] and the columns were spaced to lie midway between the first set of columns (see Figure 5.9). This is known as a triangular pitch and results in each hole being an equal distance from all adjacent holes. Each ring required 60 holes spaced every $6^{\circ}$. The outer columns were $~-9 \mathrm{M}$ (28-30ft) long. The final cement barrier is $12.5 \mathrm{M}(41 \mathrm{ft})$ in diameter at the top (nearest the surface, see Figure 5.3), extends approximately 6-6.5M (20-21ft) below grade and is $\sim 1 \mathrm{M}(3 \mathrm{ft})$ thick.

The cement layer was allowed to cure for thirty days before any verification technologies were attempted. After this curing time the integrity of the layer was checked using perfluorocarbon tracers and GPR. The results of the tracer testing indicated that the barrier was intact and breach free and that we could continue with installation of the polymer layer. The GPR data was not analyzed prior to installation of the polymer layer and was not used as a quality check but simply served as a demonstration of GPR verification. The GPR was greatly hindered by the steel storage tank and as such the results were not useful for QA/QC. Details of the PFT and GPR tests can be found in section 6 . 


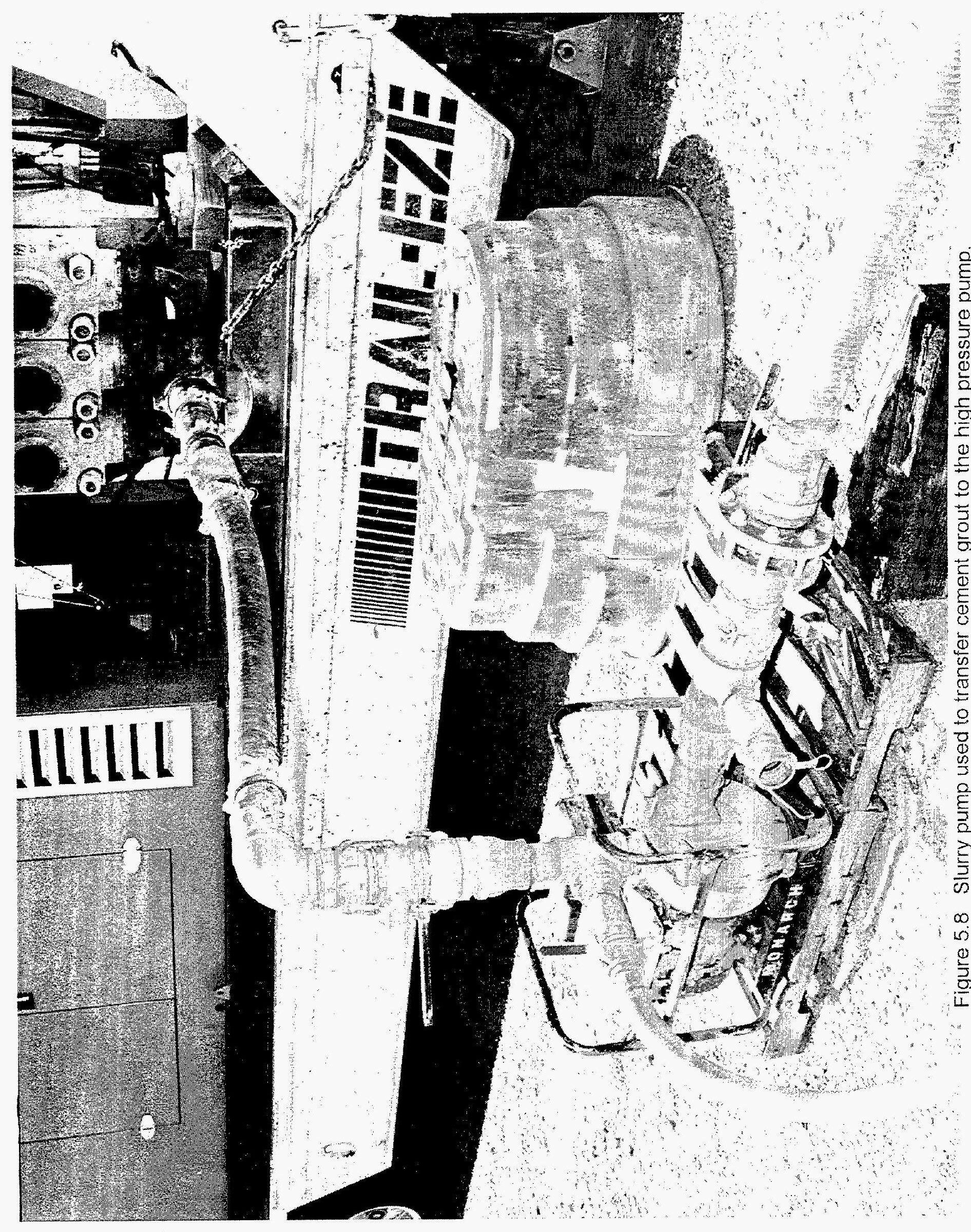




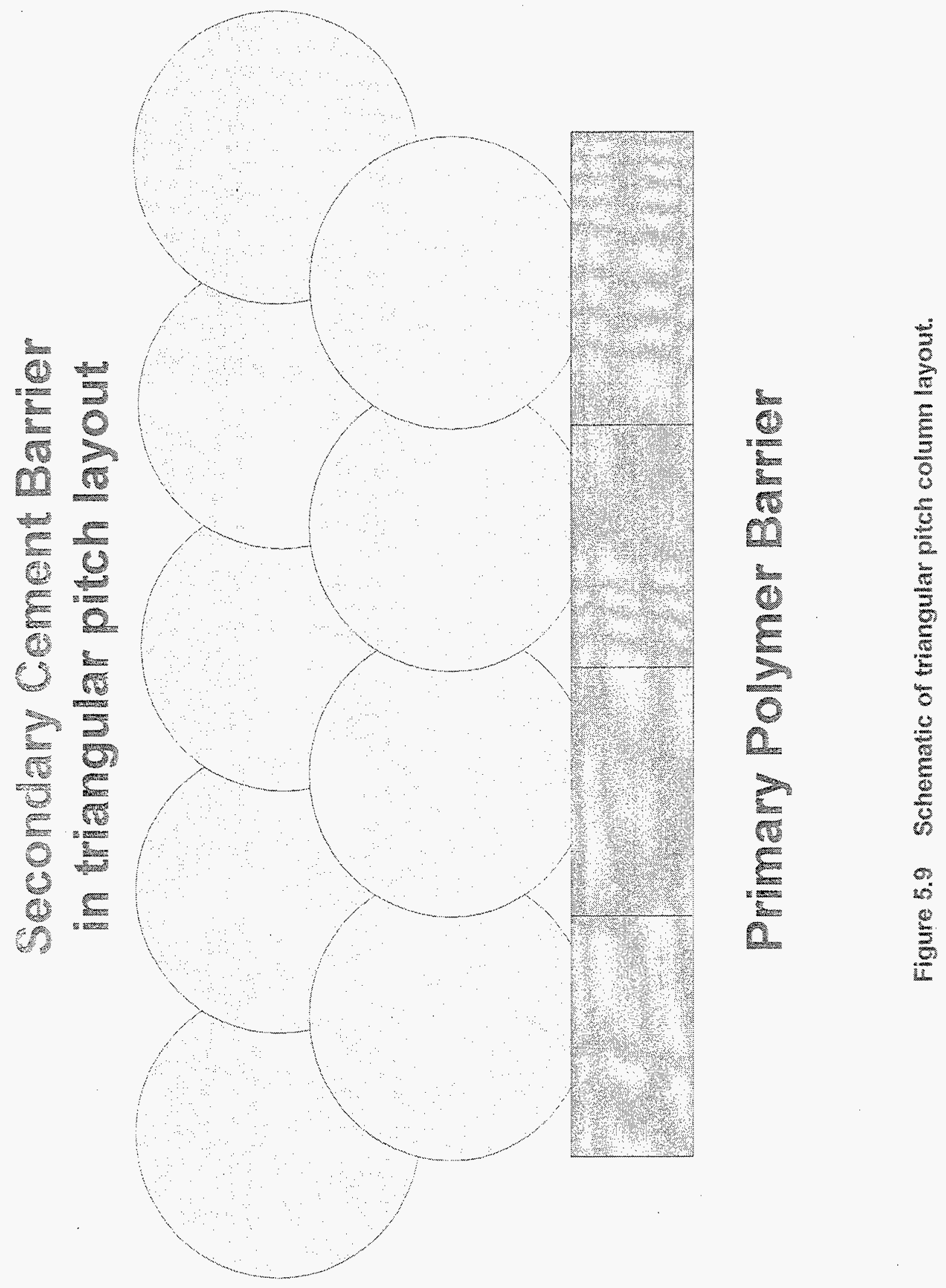




\subsubsection{Installation of the polymer layer}

A large time lapse occurred between installation of the secondary (cement layer) barrier and the primary (polymer layer) containment barrier. The cement was emplaced in July 1995 while the polymer was emplaced in December 1995. Several reasons for this exist. First, we wanted to perform verification studies on the cement barrier prior to completing the close-coupled barrier. This would allow us to test a barrier several orders of magnitude more permeable than the final composite barrier. If no breaches occurred in the cement layer (which was the goal of the barrier demonstration) then at least with the cement we might be able to estimate the diffusivity of the barrier. Secondly, the grouting contractor had to make and test the modifications to the drill rig to allow dual-fluid injection of the polymer. These modifications and the subsequent shakedown and system optimization were made at the INEEL demonstration of in situ stabilization of buried TRU waste. The contractor then had to complete the INEEL project before returning to Hanford to install the polymer layer. This delay had been previously agreed upon by all parties and did not alter the outcome of the close-coupled barrier demonstration.

The polymer layer of the close-coupled barrier at the Hanford site was installed during the week of December 11, 1995. John Heiser (BNL), Brian Dwyer (SNL), Dave Reichhardt (MSE, Inc.) and George Frost (3M Company) assisted the grouting contractor. Installation was performed using the dual-fluid injection method described for the INEEL single-column test. The first day was shortened due to weather, we were only able to mix the initiator and promoter additions into the resins. The next day was used to install several test panels near the barrier to optimize the grouting parameters and to ascertain that the set times would be acceptable for the soil conditions. As mentioned earlier, the gel time was specified as 90 minutes @ $24^{\circ} \mathrm{C}\left(75^{\circ} \mathrm{F}\right)$ when the resins were purchased. This was fine at the INEEL site where the hydraulic conductivity of the soil was $10^{-5} \mathrm{~cm} / \mathrm{s}\left(10^{-3} \mathrm{M} / \mathrm{s}\right)$ or less. At the HGDTF the soil type was a coarse near gravel sand and the hydraulic conductivity was in the range $10^{-1}$ to $10^{-3} \mathrm{~cm} / \mathrm{s}\left(10^{1}\right.$ to $\left.10^{-1} \mathrm{M} / \mathrm{s}\right)$. There was some concern that once injected the low-viscosity resins would percolate away from the injection zone before they could set and form a barrier. Six test panels were installed using 110 to $150 \mathrm{~L}$ ( 30 to $40 \mathrm{gal}$ ) of grout for each test. Four panels were installed with the gel time of the resins set to 120 minutes. These four injections were used to optimize the drilling parameters. Two were injected at 400 bar (6000 psi) and two at 100 bar (1500 psi). The pressures given refer to the high pressure nozzle, the low pressure side was kept at 70 bar (1000 psi) or adjusted downward to accommodate the 1:1 mix ratio for parts $\mathrm{A}$ and $\mathrm{B}$. For each pressure setting two different withdrawal rates were used to determine spoils production. Withdrawal rate was kept constant rather than performed in discrete steps and no rotation was used (this is what results in a panel rather than a cylinder). The last two panels had gel times of 60 minutes. This was done to minimize the time the grout had to "run-out".

The following day the test slabs were excavated for inspection. The panels with 120 minute gel times were dispersed to the point that there was little soil cohesion. The two panels with 60 minute gel times were solid hard panels. The 400 bar panel had a higher grout to soil ratio and showed some signs of slumping and minimal run-out. The 100 bar panel was a bow-tie 
shaped panel approximately 10-12" thick and 30" in length. Figure 5.10 shows a photograph of the excavated test column. Note the classic bow tie shape in the center, this is the shape of the jet coming out of the nozzle and represents an area with a slightly greater grout to soil ratio. From these tests the decision was made to use a 60 minute gel time and 100 bar grouting pressure. The gel time was decreased by adding additional promoter to part $\mathrm{A}$ and initiator to part $\mathrm{B}$. [We had anticipated the need for modifications to the gel time and had extra initiator and promoter on hand]. The test also showed that because of the unusually high porosity of this test site (40-45\%) we were using more grout per hole than originally anticipated. This resulted in a decision to slightly alter the installation plan. To conserve the resins, the polymer layer would be grouted from the bottom of the cone to - three feet from the top of the cone. The composite barrier would still be large enough to contain the tank contents and we would be able to stay within the grout quantities remaining on hand [9800L (2600gal)].

The cone shape of the barrier resulted in large overlap of columns at the base of the cone. This overlap and resultant excessive grout can cause the bottom of the cone to be filled and the inside of the cone will have a reduced volume and resembled an inverted trapezoid. For an inexpensive grout like cement it is reasonable to waste large quantities of grout to save installation time and if the cone is large enough the lost containment volume is insignificant. For polymer grouts the material cost outweighs time savings and being that the polymer is installed inside the cone any excess grout volume reduces the containment volume. To avoid excessive grout delivery and to conserve an already tight supply of polymers two suggestions were made. Making tapered panels by decreasing the step duration at the bottom of the panel and slowly increasing the time as the jet approached the top of the barrier was suggested by the grouting contractor. This should produce narrow widths at the bottom and wider as the resonant time increases. This idea was discarded because of the assumed difficulty in controlling the taper of the panels and the exact shape would not be known until after the demonstration was complete.

BNL suggested using standard width panels and grouting parameters and use the overlap of panels to an advantage. The first four panels would be placed at $90^{\circ}$ intervals. These panels would overlap near the bottom of the cone for $1 \mathrm{M}$, giving complete coverage to the bottom section of the cone. The next four panels would also be placed at $90^{\circ}$ interval but at the bisector of the previous panels (starting at a $45^{\circ}$ offset from the first panels). This set of panels would begin 1M from the bottom, where the first set of panels joined. This second set of panels would fill-in the gaps between the first set of panel (see schematic in Figure 5.11). Each successive layer of panels would further "fill" the gaps until there was a continuous barrier. This would allow successively shorter and shorter (1M per row) panels to be placed until all of the exposed surface was covered. This method was developed to maximize coverage and minimize grout usage and was calculated that the volume reduction would provide the coverage required with the resins remaining. BNL proposed starting with 4 panels, followed by four intersecting panel, then 8 intersecting, and finally 16 short panels to fill the final gaps. WHC approved the idea but requested that we start with eight panels (every $45^{\circ}$ ), then eight intersecting and 16 final panels. The WHC scheme minimized time while the BNL scheme minimized grout usage. The grout saving would amount to four times $1 \mathrm{M}$ of panel or the equivalent of one $4 \mathrm{M}$ panel. Eventually, the grouting contractor drill scheme was adopted. 


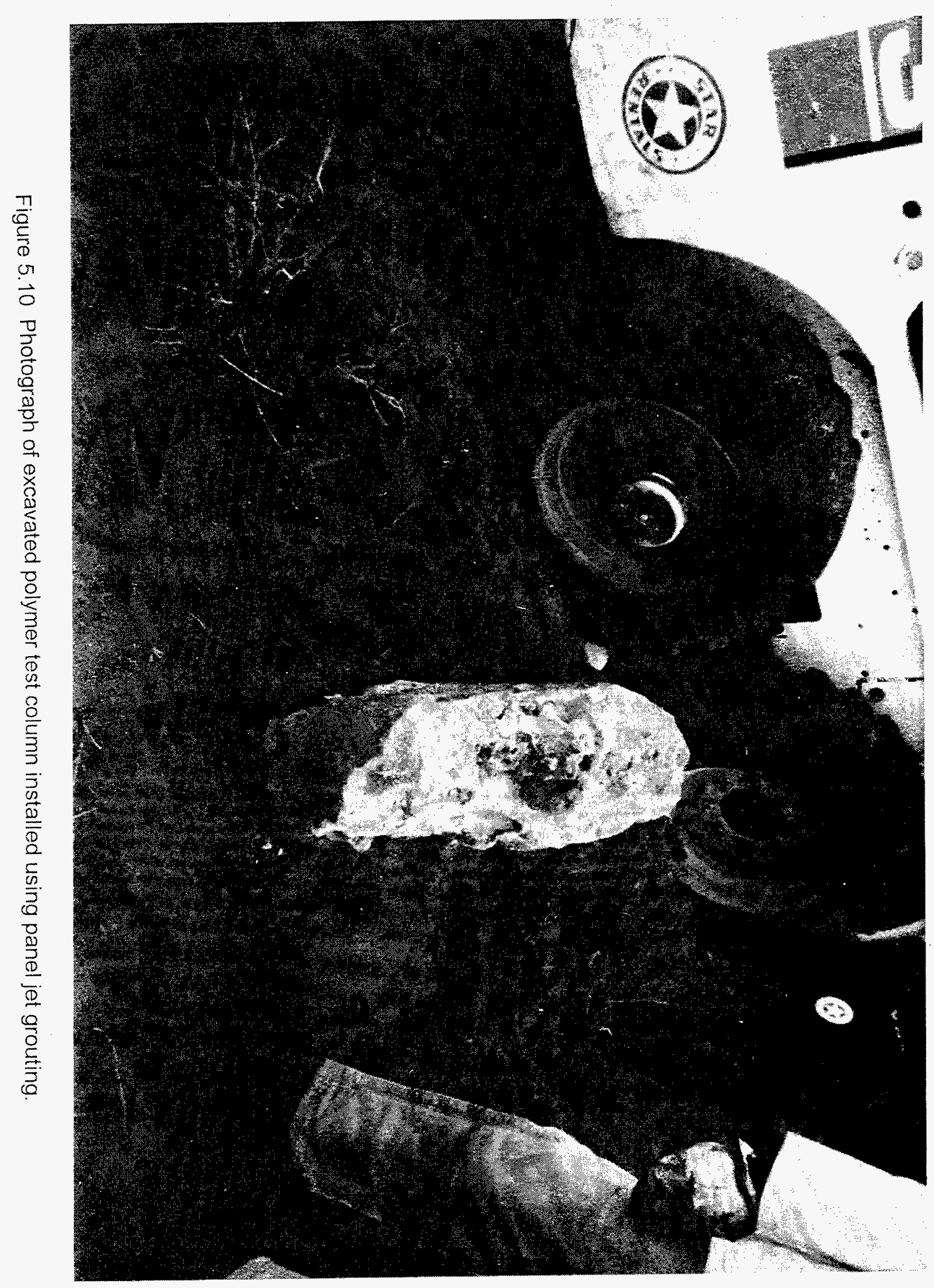




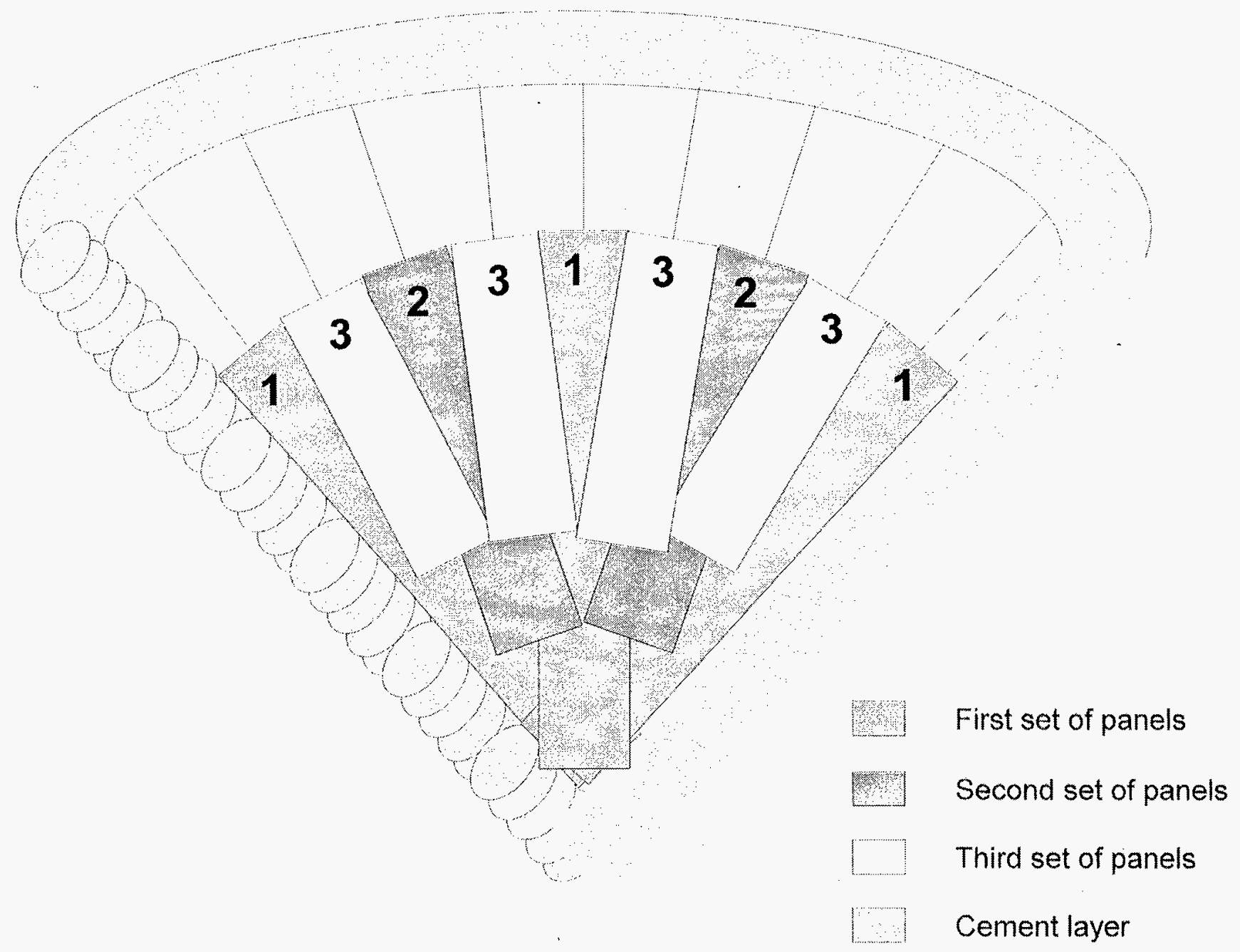

Figure 5.11 Layout of polymer panels for cone-shaped barrier. 
The polymer injection used the same grout delivery system that was employed at the INEEL demonstration, described earlier (see section 4.2.3 and Figure 4.6). The first eight panels were installed every 45 degrees around the barrier. These panels were approximately 30 inches wide and 5 meters (15-16 feet) long. The panels ended up shorter than expected due to the inside volume of the cone being reduced by the excess cement grouted used in the overlapping column scheme for the secondary barrier installation. Once these gelled a second set of eight panels was installed at the bisects of each of the angles formed by the first set. This second set did not have to be drilled as deeply since the first set of panels would converge at the bottom of the cone. The bottom two meters of the cone was fully covered and additional injection of grout at the bottom of the cone would be rejected. The second set of panels were approximately 9 feet long. After the second set had gelled a final set of panels ( $\sim 2 \mathrm{M}$ long) were installed to fill the gaps between the first and second panels. Due to the limited amount of polymer available, grouting of the final set of 16 panels was not completed. Two $2 \mathrm{M}$ long panels were left ungrouted but the depth and volume of the finished portion was sufficient to contain the tank volume. The final polymer barrier was approximately; $10 \mathrm{M}(34 \mathrm{ft})$ in diameter, $0.3 \mathrm{M}(1 \mathrm{ft})$ thick and covered the inside portion of the cement cone to a point about one meter from the top of the cement barrier. Drilling went smoothly and almost no spoils were produced. Again the dual-wall drill pipe worked flawlessly and gave further confidence in the system.

\subsection{Evaluation of the Close-Coupled Barrier}

After completion of the non-intrusive verification studies (see section 6), the barrier was excavated to determine the success of the verification technologies. Barrier performance determinations included: visual inspection; falling-head test (water flood test) on the barrier to estimate the in-situ field hydraulic conductivity; and core sampling. This section details the results of this intrusive examination.

\subsubsection{Visual inspection of the barrier}

The barrier was excavated and visually examined by the grouting contractor. Video documentation was performed as well as core sampling of the polymer and cement layers. The tank, instrumentation and monitoring wells on the internal portion of the barrier were removed as well as the earth contained within this area. This allowed visual inspection of the entire polymer layer and the upper exposed portion of the cement layer. A small portion of the exterior wall of the barrier was also unearthed to examine the outer section of the cement layer. 
The cement section somewhat resembled a fluted coffee filter (see Figure 5.12) due to the triangular pitch layout of the columns. The entire exposed portion of the cement layer was continuous and breach free. Column widths ranged from 66 to $76 \mathrm{~cm}$ ( 26 to $30 \mathrm{in}$ ) and were uniform in diameter along the length of the columns. The polymer layer consisted of overlapping panels (Figures 5.13a and $\mathrm{b}$ ) and also was continuous and breach free with the exception of the two small wedges that could not be grouted due to materials shortage. Near the top of the cement layer the polymer panels diverged and had V-shaped gaps between them. This followed the planned layout and was expected. Only the bottom $2 / 3$ or the cone was expected to be covered by a continuous layer of polymer. The polymer panels converged at a point approximately one meter above the bottom of the storage tank. From that point on the polymer layer was complete and breach free. Since the cement columns are circular and the polymer panels are planar, there is a small pocket of ungrouted soil at each column to column interface. The polymer panels are tangential to the columns, connecting across columns somewhat like a plank across two rocks. Most of the panel is mated to or in close coupling with the column but where the column dips away from the interior and meets the adjoining column there is a 10 to $13 \mathrm{~cm}$ (4 to $5 \mathrm{in}$ ) gap between panel and column. This can be seen in Figure 5.14. This "trapped" soil mass and small void is meaningless, the polymer panels form a continuous, breach-free sheet and the backing cement still provides a redundant barrier. In summary the inner section of the barrier was continuous and grout placement occurred as planned.

The upper exterior section of the cement layer was also continuous but, there was less than expected overlap in a few of the columns of the upper most portion of the outer ring of this layer. As the columns in the outer ring approached the surface, the divergence was such that several columns were separated from one another (see Figure 5.15 ) by 2 to $3 \mathrm{~cm}$. This occurred only at the top meter or so and has to do with some columns being slightly smaller than expected, $66 \mathrm{~cm}$ (26in) versus $76 \mathrm{~cm}$ (30in) and slight drill hole alignment deviations. This did not result in an opening in the barrier because of the triangular pitch layout. The inner ring of columns was placed to fill any gaps that occurred in the first ring. This justifies (and perhaps mandates) the use of a triangular pitch or similar overlapping layout of the second row of columns.

The conical configuration of the barrier proved to have one flaw: it presented too much overlap and excess grout at the bottom of the barrier. The convergence of the columns at the bottom of the barrier meant that the apex area would be grouted at the beginning of every column. The inner volume of the cone was reduced quite a bit by the excess grout and it is suspected that there is also excessive grout at the exterior of the apex below bottom of the barrier.

Visual inspection proved the barrier placement was completed as planned. The composite barrier provided integral containment for the storage tank and showed no signs of breached areas or leak pathways. Interior inspection showed the primary polymer layer to be continuous and breach free and the upper portion of the cement layer to be the same. Exterior inspection revealed several small gaps in one ring of columns but, still proved the upper portion cement layer to be continuous and breach free. The lower section of the cement cone could not be inspected since it was covered by the polymer on the interior and below the excavation point on the exterior. It is assumed that since the upper section is intact and the columns continue to converge approaching the apex, that the lower portion is intact and of greater grout density than the upper section. 


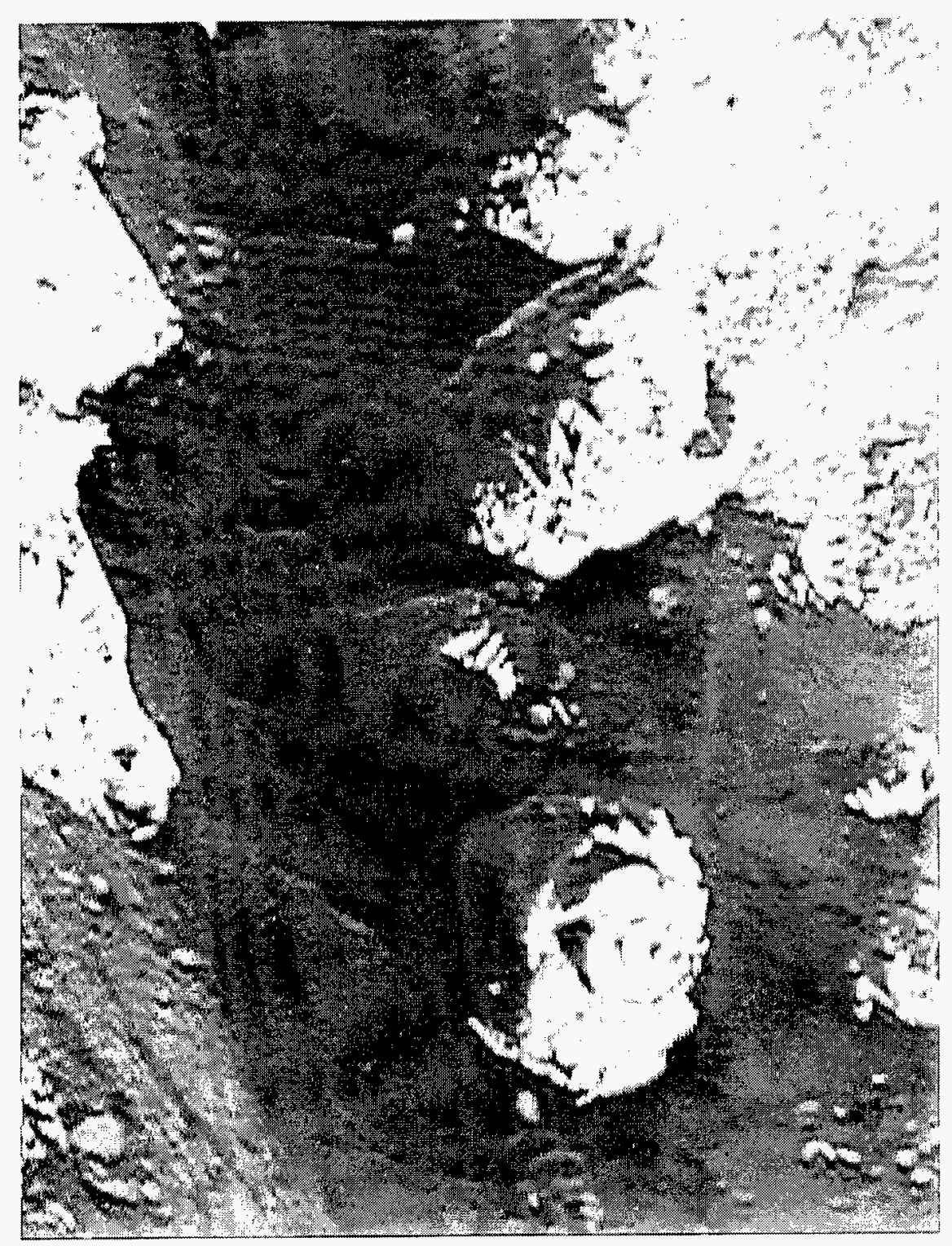

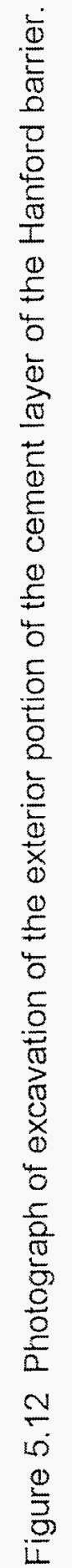




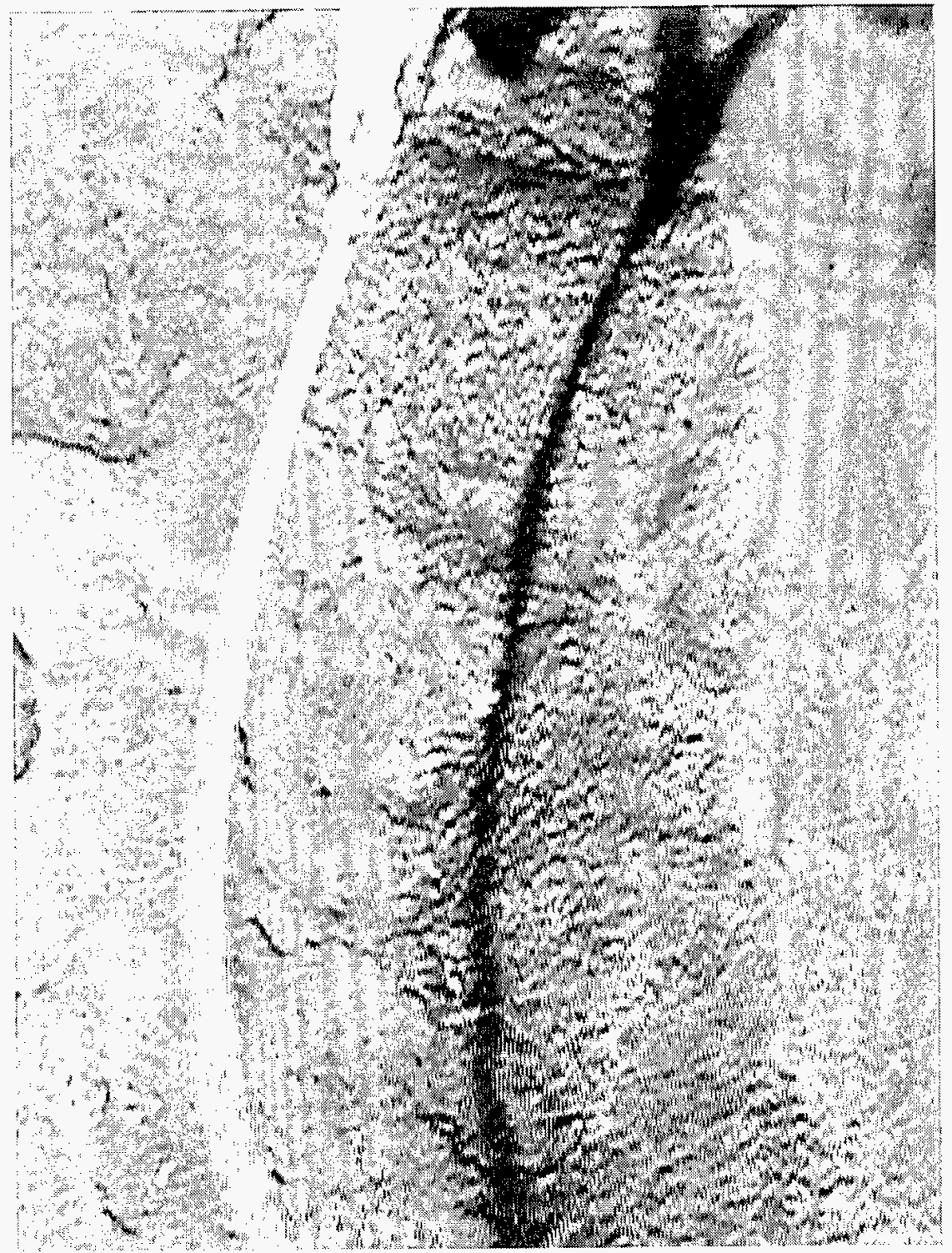

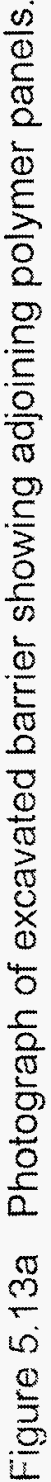




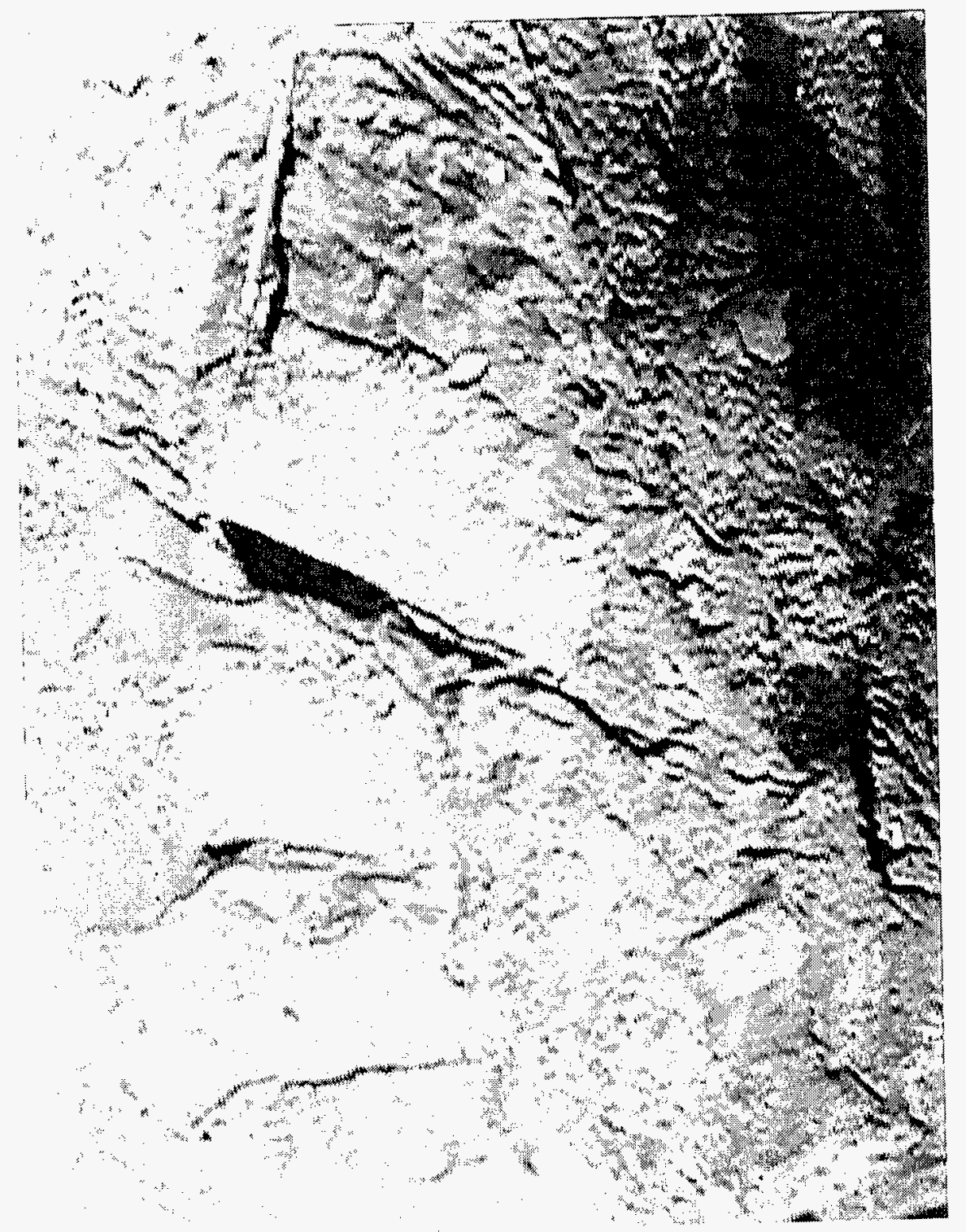

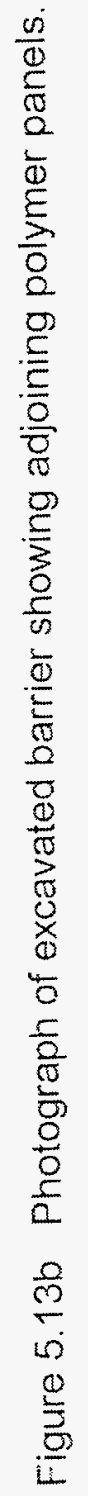




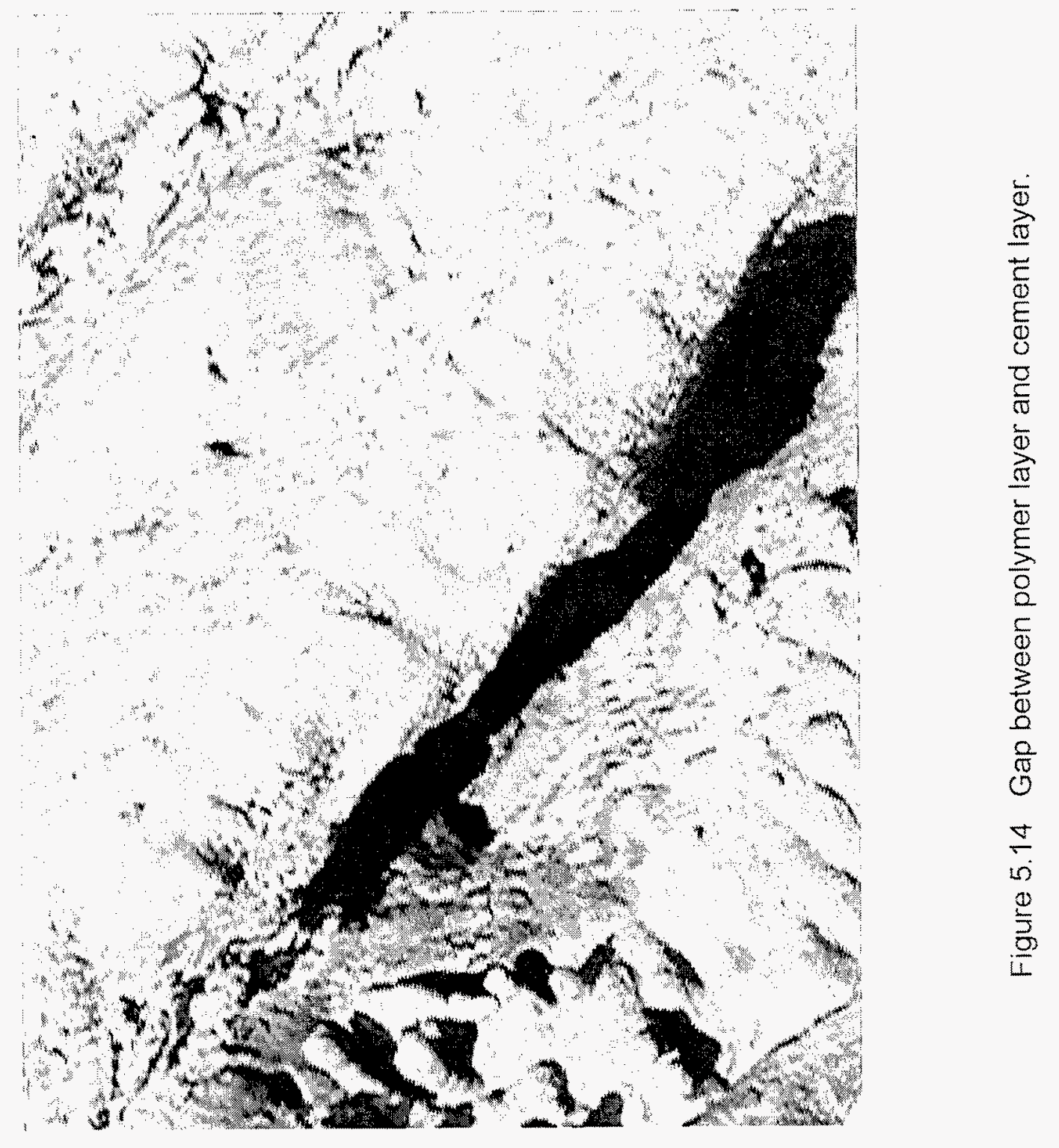




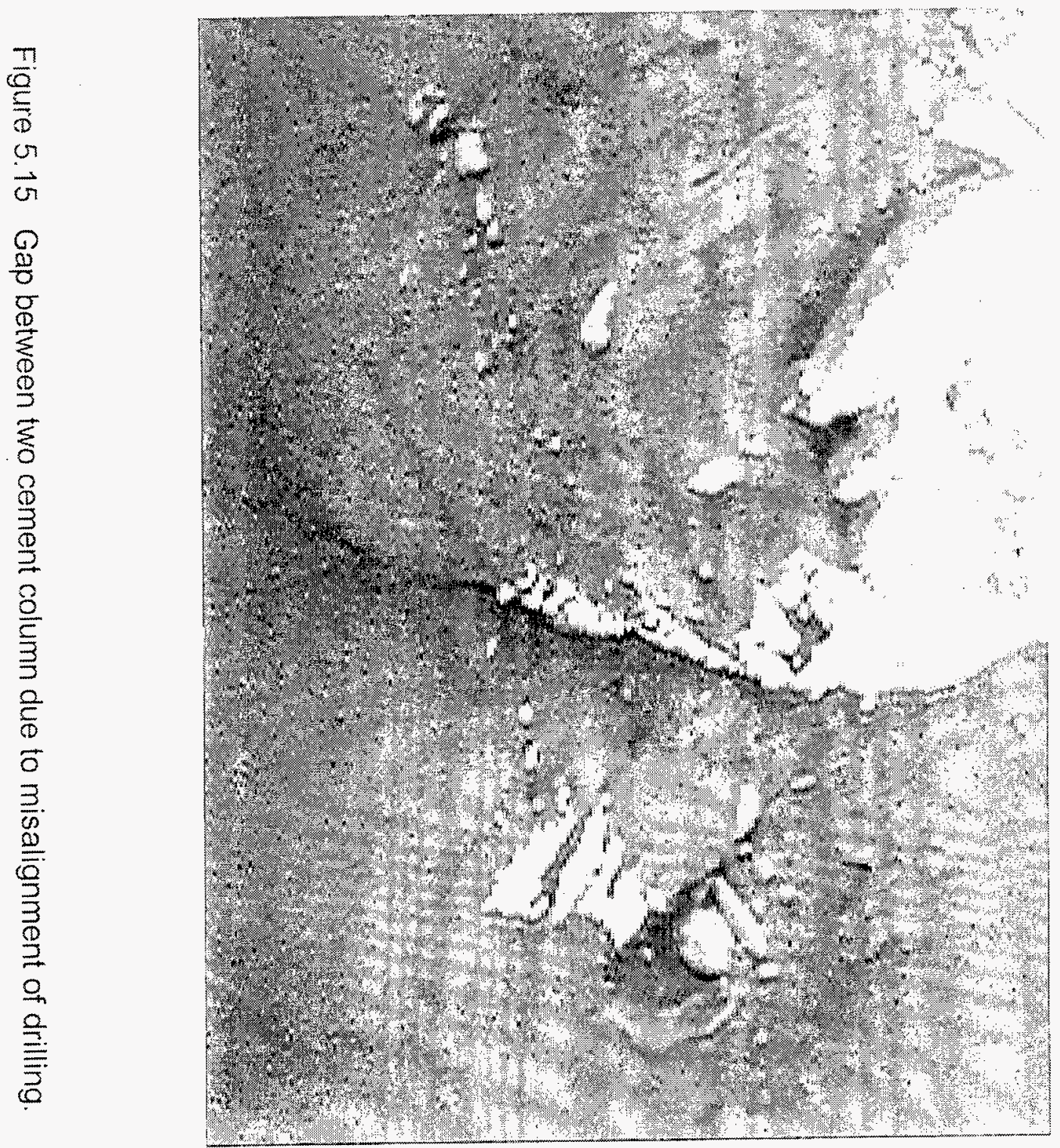




\subsubsection{Field Permeability Testing}

After removal of the tank (simulated waste form) and careful excavation of the soil internal to the barrier, constant head permeability testing was performed using water. This test measures the permeability or how pervious the barrier is to a liquid. More specifically, permeability (k) of a soil is a measure of continuous voids, i.e., pathways for water transport. A commercial guelph permeameter was used measure the hydraulic conductivity. A Guelph permeameter is a borehole installed device that requires a constant water level be maintained within the borehole (see Figure 5.16).

The standard method for calculating Hydraulic Conductivity requires two measurements of varied well head heights. This adds to the accuracy of results. The generalized equation for hydraulic conductivity is:

$$
K_{\mathrm{fs}}=G_{2} R_{2}-G_{1} R_{1}
$$

where $\mathrm{G}$ is a factor describing the three dimensional shape of the "bulb," and $\mathrm{R}$ is the constant rate of fall of water.

AGEC, Inc. conducted the in-field permeability tests using a Guelph permeameter. Mean field saturated hydraulic conductivity for the portland cement/sand was determined to be $1.7 \times 10^{-8}$ $\mathrm{cm} / \mathrm{s}\left[1.7 \times 10^{-10} \mathrm{M} / \mathrm{s}\right]$; and for the polymer/sand $3.0 \times 10^{-9} \mathrm{~cm} / \mathrm{s}\left[3.0 \times 10^{-11} \mathrm{M} / \mathrm{s}\right]$. These values are outside the range normally considered valid for guelph permeameters and should not be taken with much weight beyond showing that the hydraulic conductivity was less than $10^{-6} \mathrm{~cm} / \mathrm{s}\left[10^{-8}\right.$ $\mathrm{M} / \mathrm{s}$ ]. The manufacturer's specification range for the guelph permeameter does not extend below $1.0 \times 10^{-6} \mathrm{~cm} / \mathrm{s}\left[1.0 \times 10^{-8} \mathrm{M} / \mathrm{s}\right]$.

\subsubsection{Laboratory evaluation of core samples}

The final barrier was sampled (after excavation) by coring specimens from various locations throughout the barrier. Cores were taken using standard concrete coring methods. This section describes the performance testing that was performed on the cores. The testing focuses mainly on the primary polymer layer as the secondary cement layer is composed of a standard construction grade grout. Characterization of the cement was done as a quality check only.

Initial consultation with personnel from the Office of Environmental Restoration at BNL, Brian Dwyer of Sandia National Laboratory and experimenters at the INEEL In-Situ Stabilization of Buried Waste Project was used to assist in producing a list of tests to be performed. These parties represent the developers and some of the potential end users of the technology. The key parameter identified by all concerned was hydraulic conductivity, which is a measurement of how quickly water can penetrate the barrier. The second concern of potential users was durability of the barrier. In the initial workplan it was suggested that barrier core samples be evaluated for 
resistance to water immersion and wet-dry cycling to simulate anticipated in-situ environmental conditions. Additional laboratory performance testing was to include investigating the homogeneity of the barrier grouts throughout the barrier and rapid chloride penetration (diffusivity). After the barrier was installed and initial density and strength measurements were obtained it became readily apparent that the field samples were as good as the laboratory samples. Rather than repeat both the hydraulic conductivity and rapid chloride penetration BNL was asked by Sandia to substitute tests. 'Flexural strength measurements were performed in place of the rapid chloride penetration tests. Such measurements offered new data on the barrier material rather than redundant measurements.

\subsubsection{Hydraulic conductivity measurements}

The hydraulic conductivity of core specimens was measured using a flexible wall permeameter (see Figures 5.17 and 5.18) following ASTM D-5084 ${ }^{11}$. The permeant was de-aired tap water with an electrical conductivity of $\sim 120 \mu$ mhos. Test samples were prepared from four cylindrical upper-surface (near the top of the barrier) cores $(\sim 4.5 \mathrm{~cm}$ diameter) taken from four different compass positions (NE, NW, SW, \& SE) sections of these cores were cut to $-2.9 \mathrm{~cm}$ lengths. Core samples were taken from the polymer and cement layers. Samples were preconditioned by placing them in a vacuum desiccator and evacuating ( $<1 \mathrm{~mm} \mathrm{Hg}$ ) for 3 hours. Deaired water was then introduced into the desiccator at the end of the three hours, without losing the vacuum. The vacuum was disconnected and air allowed to enter the desiccator. The samples were conditioned in the de-aired water for up to 1 month in order to facilitate saturation. The water in the desiccator was de-aired periodically by re-applying a vacuum to the desiccator for $1-2$ hours.

After pre-conditioning the test specimens were placed in the permeameter cell and sealed using a latex membrane and a $35 \mathrm{kPa}$ differential cell pressure. Back pressuring was used to accomplish full saturation of the samples. Full saturation was determined by measuring the pore pressure parameter B according to ASTM D-4767-(88). ${ }^{12}$ The samples were considered fully saturated when the $B$ value reached 0.95-0.96. For brittle incompressible materials like polymer concrete the $B$ value may not reach the specified 0.95 . In this case the $B$ value was measured at two different pressure differentials to see that it does not change. If after one week the $B$ value changes the backpressure was increased in $35 \mathrm{kPa}$ steps. Once the B value stabilized the hydraulic conductivity measurements began. The cell pressures were set to $310 \mathrm{kPa}$ (45 psi), the lower cap pressure to $275 \mathrm{kPa}$ (40 psi), and the upper cap pressure to $70 \mathrm{kPa}(10 \mathrm{psi})$. This results in a pressure differential across the specimen of $210 \mathrm{kPa}$ (30 psi). The water flow in and out of the sample was recorded versus time for a period of approximately one month. The hydraulic conductivity was calculated according to: 


$$
k=Q L / A t h
$$

where:

$\boldsymbol{k}=$ hydraulic conductivity, $\mathrm{cm} / \mathrm{sec}$

$Q=$ water quantity through the sample, taken as the average of inflow and out flow, $\mathrm{cm}^{3}$

$L=$ length of the specimen, cm

$\boldsymbol{A}=$ cross sectional area of the sample, $\mathrm{cm}^{2}$

$t=$ time interval, s over which $\mathrm{Q}$ was measured

$\boldsymbol{h}=$ pressure differential across the sample, $\mathrm{cm}$ of water

The hydraulic conductivities were $6.3 \times 10^{-10} \mathrm{~cm} / \mathrm{s}\left[6.3 \times 10^{-12} \mathrm{M} / \mathrm{s}\right]$ for the NE specimen, $6.7 \times 10^{-9} \mathrm{~cm} / \mathrm{s}$ for the NW specimen, $4.6 \times 10^{-10} \mathrm{~cm} / \mathrm{s}\left[4.6 \times 10^{-12} \mathrm{M} / \mathrm{s}\right]$ for the $S W$ sample and $1.9 \times 10^{-9} \mathrm{~cm} / \mathrm{s}\left[1.9 \times 10^{-12} \mathrm{M} / \mathrm{s}\right]$ for the SE sample. The average value is $2.4 \times 10^{-9} \mathrm{~cm} / \mathrm{s}[2.4$ $\left.\times 10^{-11} \mathrm{M} / \mathrm{s}\right]$, which compares well with the field value of $3.0 \times 10^{-9} \mathrm{~cm} / \mathrm{s}\left[3.0 \times 10^{-11} \mathrm{M} / \mathrm{s}\right]$ and the average value of $4 \times 10^{-9} \mathrm{~cm} / \mathrm{s}\left[4 \times 10^{-11} \mathrm{M} / \mathrm{s}\right]$ measured for laboratory prepared samples from studies completed in FY 94. ${ }^{6,2}$ Samples (duplicates) taken from the cement (secondary) layer measured $3.7 \times 10^{-8} \mathrm{~cm} / \mathrm{s}\left[3.7 \times 10^{-10} \mathrm{M} / \mathrm{s}\right]$ which also compares well with the field measurements of $1.7 \times 10^{-8} \mathrm{~cm} / \mathrm{s}\left[1.7 \times 10^{-10} \mathrm{M} / \mathrm{s}\right]$. 


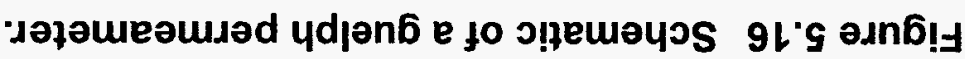

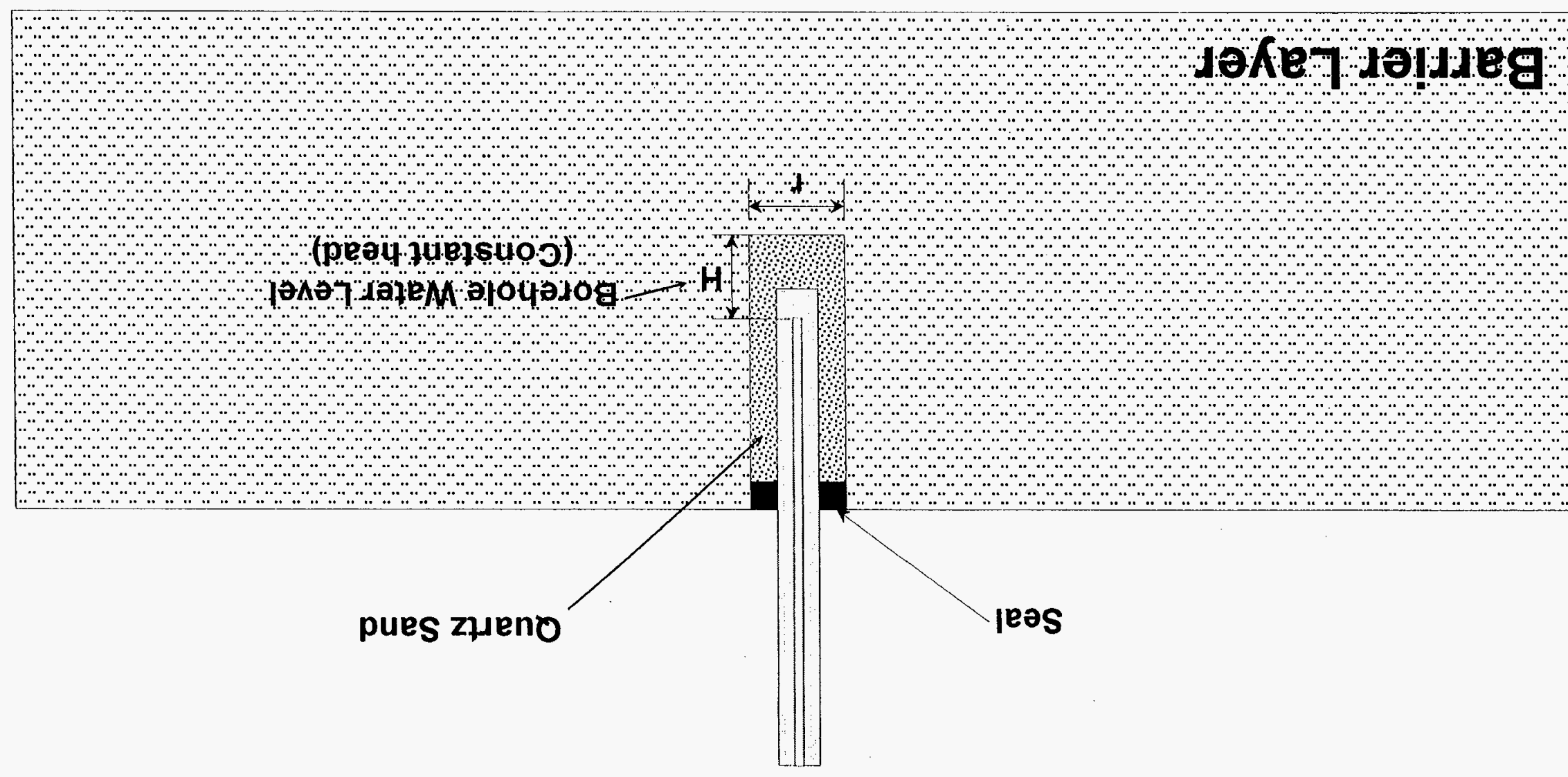




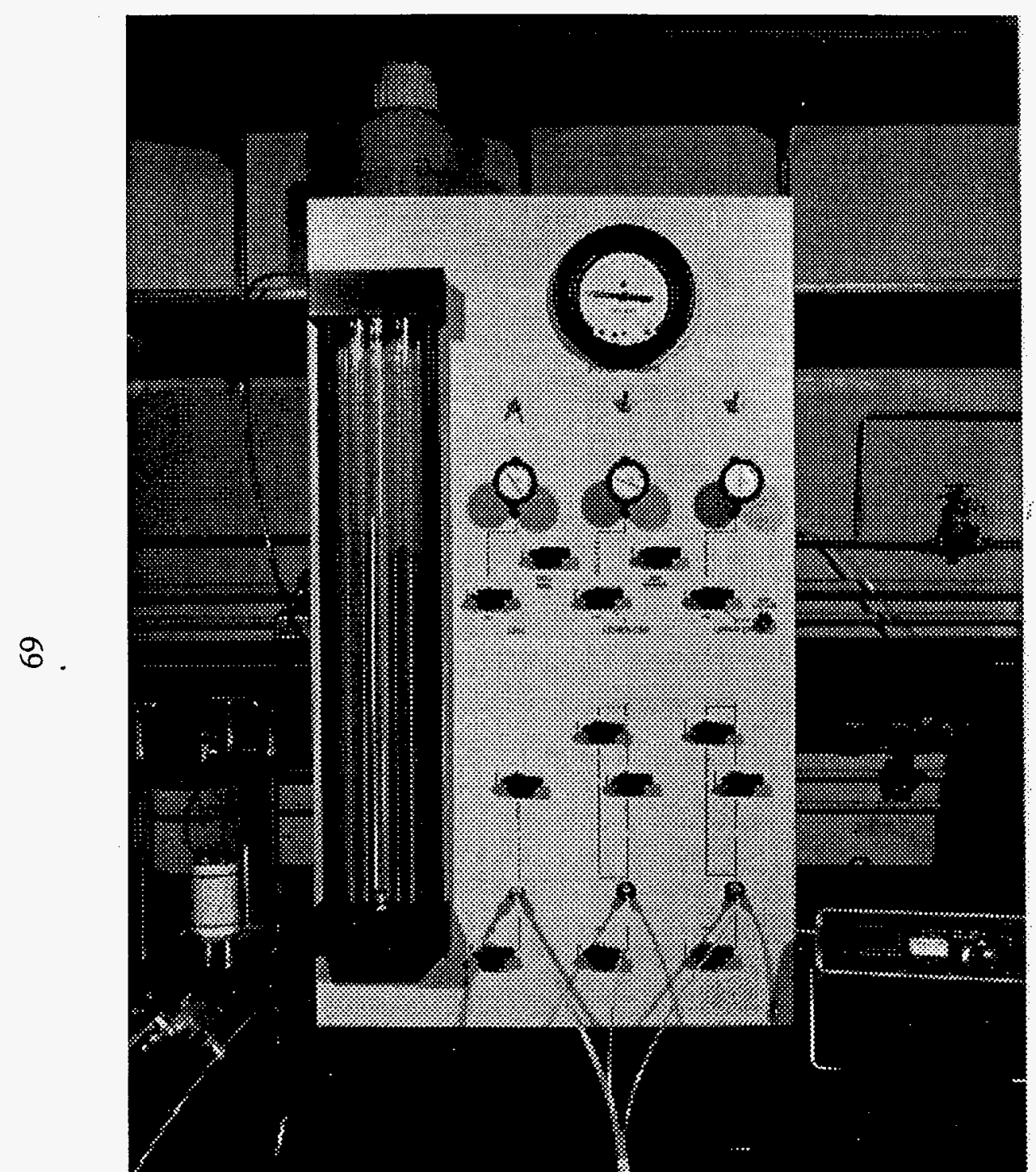

Figure 5.17. Flexible wall permeameter cell and control panel.

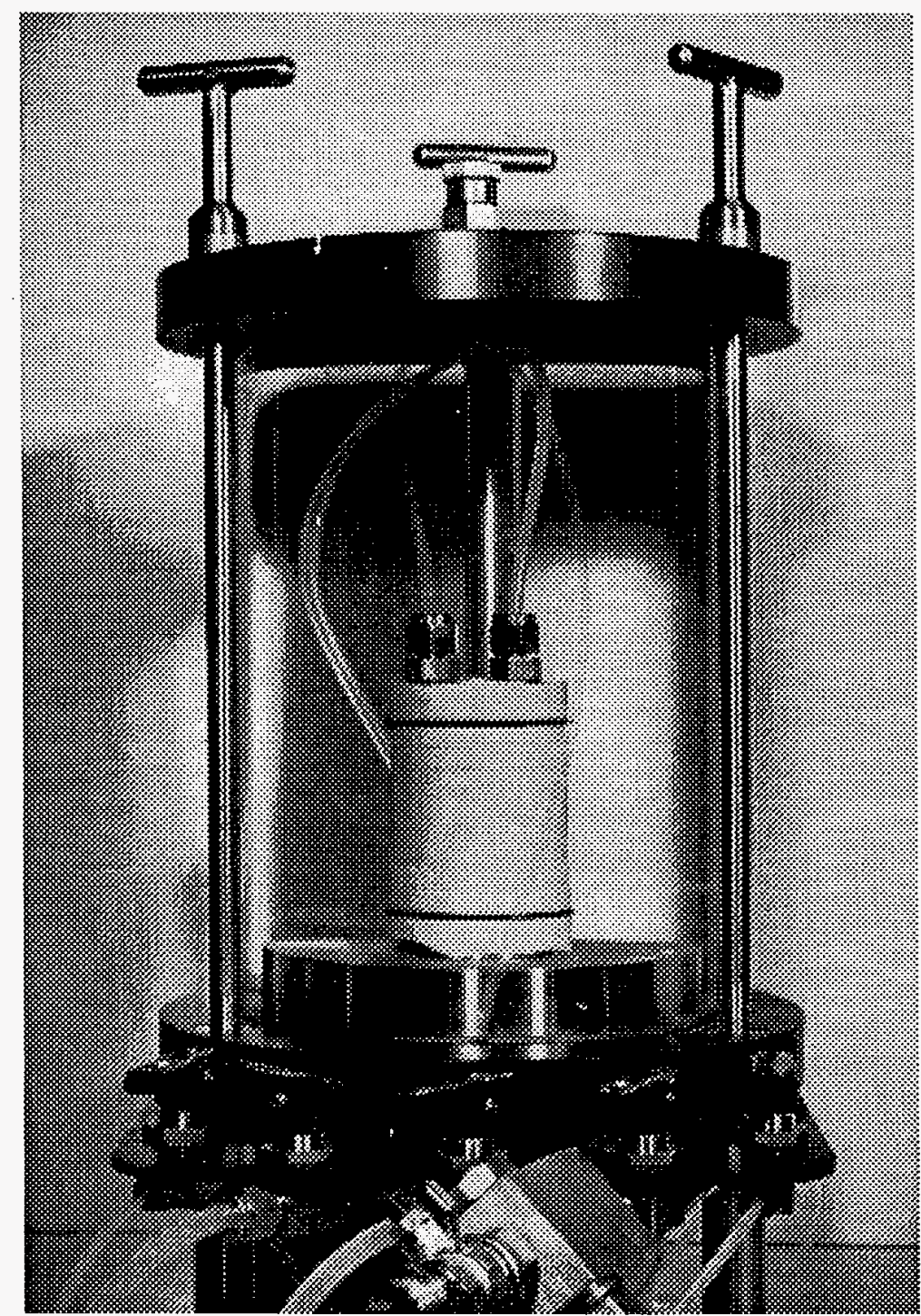

Figure 5.18. Flexible wall permeameter with polymer grout specimen sealed with a latex membrane. 


\subsubsection{Unconfined compressive strength testing}

Core samples retrieved from the Hanford barrier demonstration were compression tested in accordance with ASTM C-39 ${ }^{13}$. Six polymer samples representative of various core depths and locations were tested. Each measured nominally $4.39 \mathrm{~cm}$ in diameter; all were cut square to a length of $8.76 \mathrm{~cm}$. Sample densities ranged from 1.95 to $2.04 \mathrm{~g} / \mathrm{cm}^{3}$, with a mean value of $2.01 \pm 0.03 \mathrm{~g} / \mathrm{cm}^{3}$. Average compressive strength was $9.2 \pm 2.1 \mathrm{MPa}$. Compressive strength of four samples was high $(10.7 \pm 0.7 \mathrm{MPa})$ relative to two others $(6.3 \pm 0.3 \mathrm{MPa})$ and the scatter associated with each grouping is reasonable. This aberration did not correlate with sample depth or location or sample density, but did appear to be due to stratification of the aggregate phase (soil) as evidenced by light and dark regions in these weaker samples. In both cases, cracking occurred preferentially in the lighter phases of these samples as opposed to the four other samples which showed deformation along the entire length of the samples. The mean compressive values for similar laboratory prepared specimens (polymer mortar) measured $12.8 \pm 1.5 \mathrm{MPa}$, while the four acrylic/soil cores not affected by an apparent aggregate (soil) phase change from the Hanford demo site resulted in a mean compressive strength of $10.7 \pm 0.7 \mathrm{MPa}$. The mortar samples should be expected to be $\sim 10 \%$ higher in strength than the soil samples due to better packing of the blended sand versus the Hanford soil. These results show a good correlation between laboratory prepared and in-situ prepared/retrieved specimens, thus validating the laboratory product testing prior to any costly in-situ demonstration or full-scale grout material application.

In addition to the polymer cores, three cement cores were tested for compressive strength. Specimens nominally measured $4.39 \mathrm{~cm}$ in diameter and were $8.76 \mathrm{~cm}$ in length. Average sample density was $2.01 \pm 0.05 \mathrm{~g} / \mathrm{cm}^{3}$. Compressive strength was $20.1 \pm 4.3 \mathrm{Mpa}$.

\subsubsection{Barrier homogeneity}

Homogeneity can be inferred by comparing the densities and compressive strength of the various core samples from the different quadrants. For the polymer grout, the densities of test samples were measured for several core samples as well as the flexural samples. Core sample densities ranged from 1.95 to $2.04 \mathrm{~g} / \mathrm{cm}^{3}$, with a mean value of $2.01 \pm 0.03 \mathrm{~g} / \mathrm{cm}^{3}$. Flexural sample densities ranged from 1.89 to $1.97 \mathrm{~g} / \mathrm{cm}^{3}$, with a mean value of $1.93 \pm 0.02 \mathrm{~g} / \mathrm{cm}^{3}$. This compares very favorably to laboratory measured values of $1.95 \mathrm{~g} / \mathrm{cm}^{3}$. Note, also that the core specimens tested include specimens taken from three different depths (top, middle and bottom), as well as, different compass locations (e.g., NE, SW, SE, and NW). Such close agreement between field emplaced samples and laboratory prepared samples (where an homogenous sample is easy to prepare) is indicative of a well regulated, reproducible barrier system, free from interferences that commonly plague materials like hydraulic cements.

To deduce grout homogeneity we must look at the compressive strength values, the density measurements and the scatter in both of these. The density results, which are in good agreement with laboratory values have very low scatter. From this it can be assumed that the grout was placed reasonably uniform. Most of the compressive strength values are in agreement with 
laboratory values with the exception of the two samples that showed some soil stratification. While the strength of these samples was still sufficient it was lower than the majority. These samples also failed along the stratified layer. The fact that samples with no stratification were similar in strengths, had low scatter and were in good agreement with lab values implies that the grout curing was uniform and not affected by field conditions. The results do imply that inhomogeneities in the soil matrix can and will affect some physical properties and that jet grouting, while vigorous, will not completely homogenize the local area of influence.

Samples were also cross-sectioned to determine visually the homogeneity, in terms of voids or stratification. Figure 5.19 shows two core samples that were cut in half along the vertical axis. These samples show a well mixed grout with no small voids apparent.

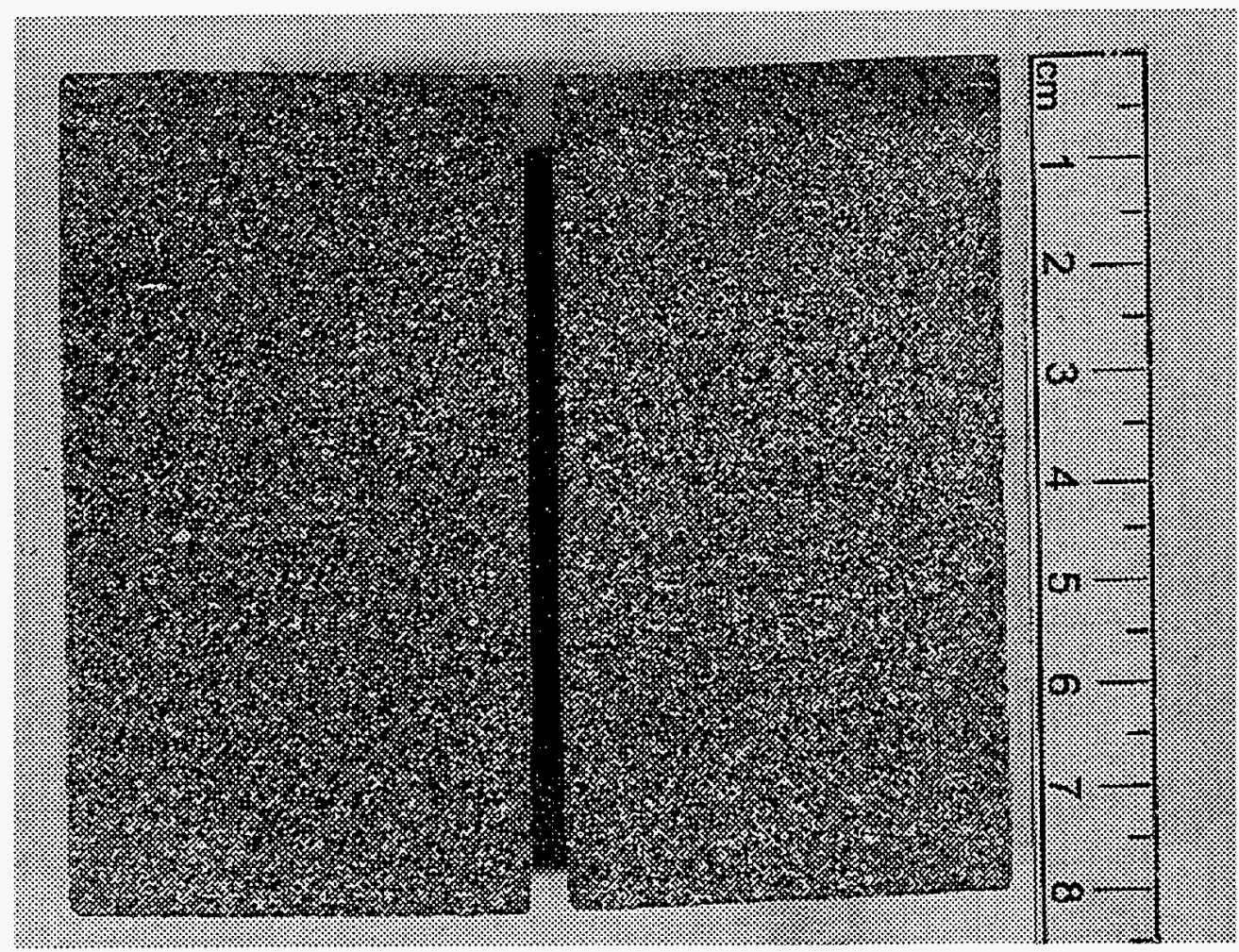

Figure 5.19 Cross-sections of polymer cores taken from the Hanford barrier.

For the cement grout, densities and strengths were taken from core samples only. Densities averaged $2.01 \pm 0.05 \mathrm{~g} / \mathrm{cm}^{3}$. Visually, the samples appeared uniform and void free.

\subsubsection{Flexural strength}

One large piece $(64.4 \mathrm{Kg}$ [142 lbs]) of polymerized acrylate grout/soil which had been jetgrouted as part of the Barrier Demonstration Project in Hanford was retrieved and shipped to BNL. From this large monolithic piece of acrylate grout/soil seven $-7.6 \times 7.6 \times 28.6 \mathrm{~cm} \mathrm{(3"} \mathrm{x}$ 
$3 " \mathrm{x} 11.25^{\prime \prime}$ ) prisms were cut for flexural strength testing. Sample densities ranged from 1.89 to $1.97 \mathrm{~g} / \mathrm{cm}^{3}$, with a mean value of $1.93 \pm 0.02 \mathrm{~g} / \mathrm{cm}^{3}$. A $30 \mathrm{~cm}(12 ")$ wet-band saw and diamond impregnated blade was used to perform the initial cuts and the remaining cuts, when necessary were made using a cut-off wheel/diamond impregnated blade. Cut surfaces were very uniform and only a few $1 / 4$ " voids were found in all seven samples and all of the waste cuttings. This shows a well mixed homogeneous barrier material. Flexure (4 point bend) [see Figure 5.20] testing was completed on five of the specimens in accordance with ASTM D- $1635^{14}$. Modulus of rupture (MOR) values ranged from 4.3 to $3.0 \mathrm{MPa}$ ( 620 to $430 \mathrm{psi}$ ), with a mean value of $3.6 \pm 0.4 \mathrm{MPa}(530 \pm 60 \mathrm{psi})$. There was no correlation of MOR with sample density.

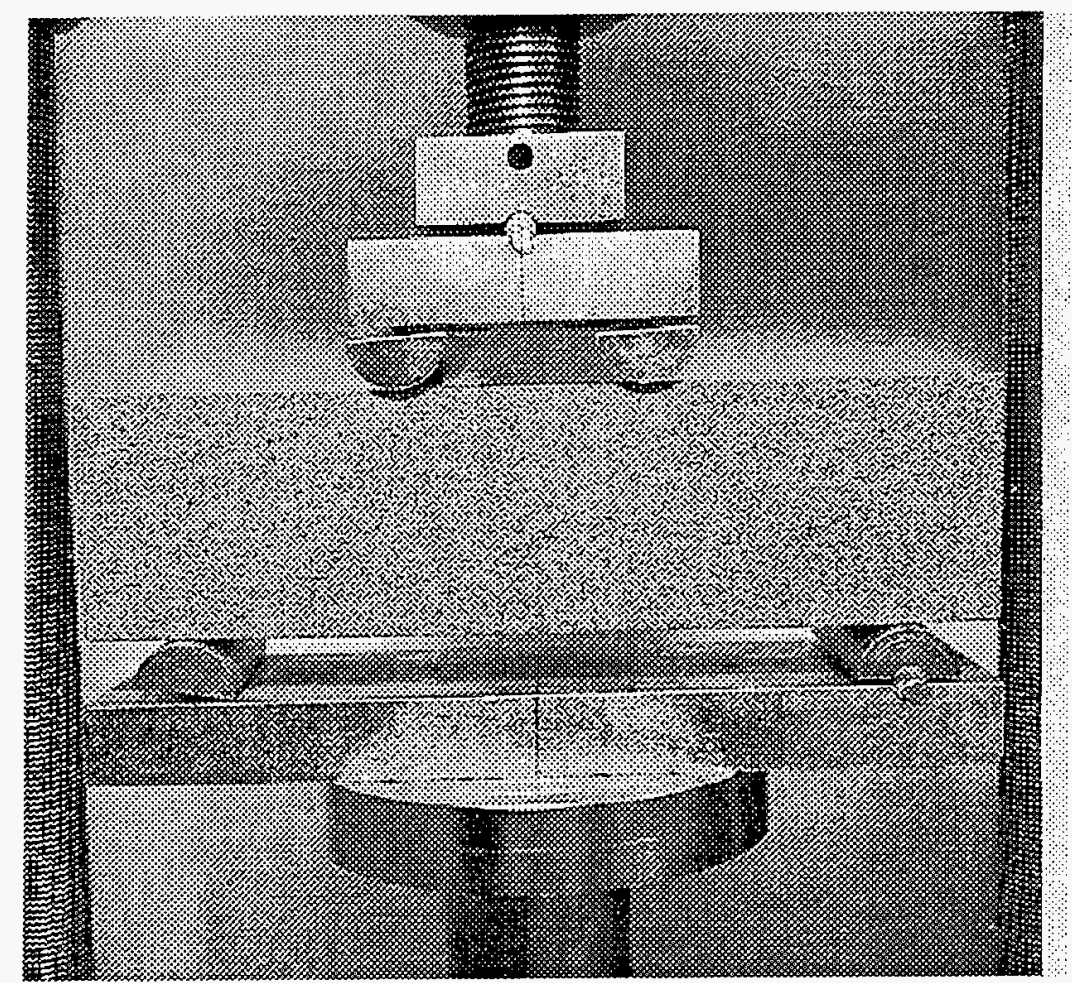

Figure 5.20 Apparatus for Flexural Strength Testing

\subsubsection{Immersion test of cores}

It is expected that a subterranean containment barrier will be exposed to aqueous environments from either leakage of the supernatant contained in a UST, waste site container leakage, or percolate water. Exposure of barrier materials to aqueous solutions can result in swelling, cracking, or dissolution. Also the soils used as aggregate may also interact with the water through swelling (i.e., expansive clays) or dissolution of mineral components. Aggregate interactions can cause internal stresses with resultant cracking and strength losses in the barrier. Core samples were immersed in deionized water for a period of 90 days. The specimens nominally measured $44 \mathrm{~mm}$ diameter and $86 \mathrm{~mm}$ in length. The samples were inspected visually for cracking and swelling periodically during the course of the test. The samples were weighed, 
measured, conditioned at $100 \%$ relative humidity and destructively tested for compressive strength (ASTM C-39) at the end of the test period. There was minimal water uptake by the polymer composites (triplicate) with average weight changes of $1.1 \%$. No dimensional changes occurred and the compressive strength averaged $6.2 \pm 0.6 \mathrm{MPa}$ compared to $9.2 \pm 2.1 \mathrm{MPa}$ for the baseline cores. The decrease in strength can be attributed to the absorbed water. The grout was a lowmodulus polymer that becomes more pliable or plastic when fully saturated. It is expected that the strength of the immersed samples would have been greater if the post immersion conditioning was continued longer, allowing the sample to be unsaturated (but still at $100 \%$ relative humidity within the pore space). This was seen in past programs with some styrene based polymers.

For the cement samples (duplicates) weight changes averaged $9.8 \%$, there were no dimensional changes and the compressive strength averaged $18.6 \pm 0.7 \mathrm{MPa}$ compared to 20.1 $\pm 4.3 \mathrm{MPa}$ for the baselines.

\subsubsection{Wet-dry cycling of cores}

The Hanford site is located in a semi-arid region where the soil moisture content is low, ranging between 1 and $3 \%$ (by volume). Sometimes precipitation percolates the ground and recharges the aquifer. The barrier will be under saturated conditions during these times. Wet-dry cycling has a severe impact on construction materials such as hydraulic cements. Core samples taken from the polymer layer [triplicates] as well as the cement layer [duplicates] were subjected to wet-dry cycling adhering to ASTM D-4843. ${ }^{15}$ Test samples were cycled twelve times, from $60^{\circ} \mathrm{C}$ dry to $20^{\circ} \mathrm{C}$ wet. The ASTM test requires the evaporation of the water after each wet cycle, and the weighing of the residue left in the beaker. Due to the durable nature of the polymers it would be difficult to measure the very small residuals left after each wet cycle. To increase the accuracy in determining the residue, the samples were wet cycled in the same beaker, for all cycles while reusing the water (additional water was added to replenish loses from evaporation). After the final cycle the water was evaporated and the residue weight recorded at the end of the final cycle. The wet samples were towel dried and weighed after each cycle. The dry cycle samples were weighed directly. In addition, samples were compression tested (ASTM C-39) after the final cycle in order to determine mechanical integrity.

Neither the polymer nor cement core samples showed any visible degradation (i.e., cracking) after 12 cycles. Weight changes for the polymer soil mortars were minimal from beginning to end. Comparing the initial pretest weight to the final dry cycle weight, average weight change for the three field emplaced samples was $0.07 \%$, which compares to $0.20 \%$ for laboratory prepared samples. Looking at the first dry cycle weight and comparing it to the final dry cycle weight shows a change of $0.29 \%$, similar laboratory prepared samples had differences averaging $0.86 \%$. The average weight histories of the core samples are given in Figure 5.21. Note that one polymer sample shows higher weight fluctuations than the other two $(0.17 \%$ versus $0.49 \%$ ). The difference may be due to a lower binder to soil ratio in the area this core was taken or the soil stratification may have been such that a coarser sand existed near the bottom of the barrier where this core was taken. Figure 5.22 depicts the weight of the specimens after each dry cycle. Looking at the trend of this plot we see that the weights remain constant throughout the 


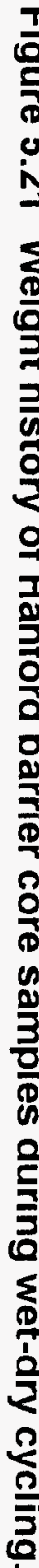

\section{Percent of Initial Weight}

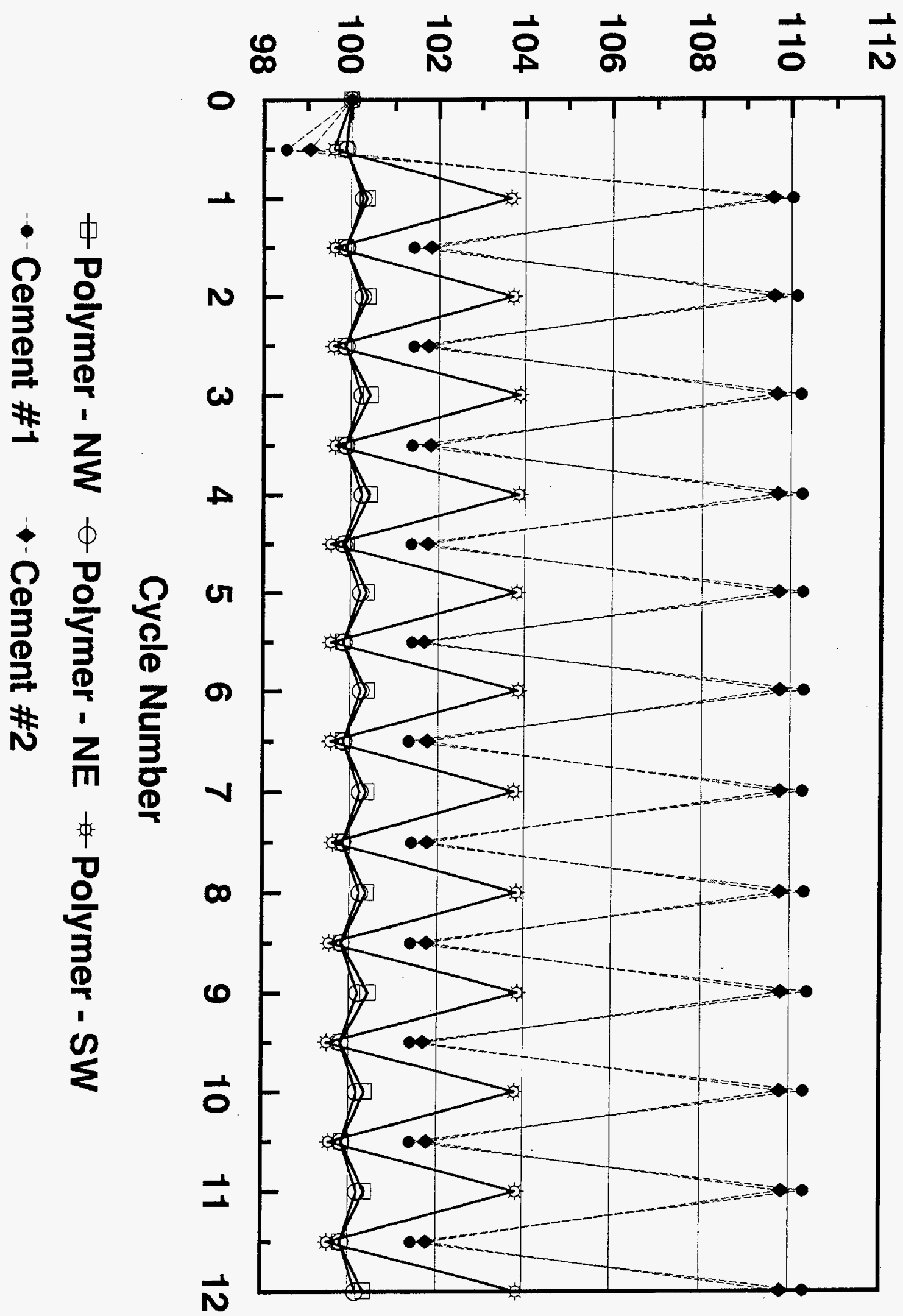




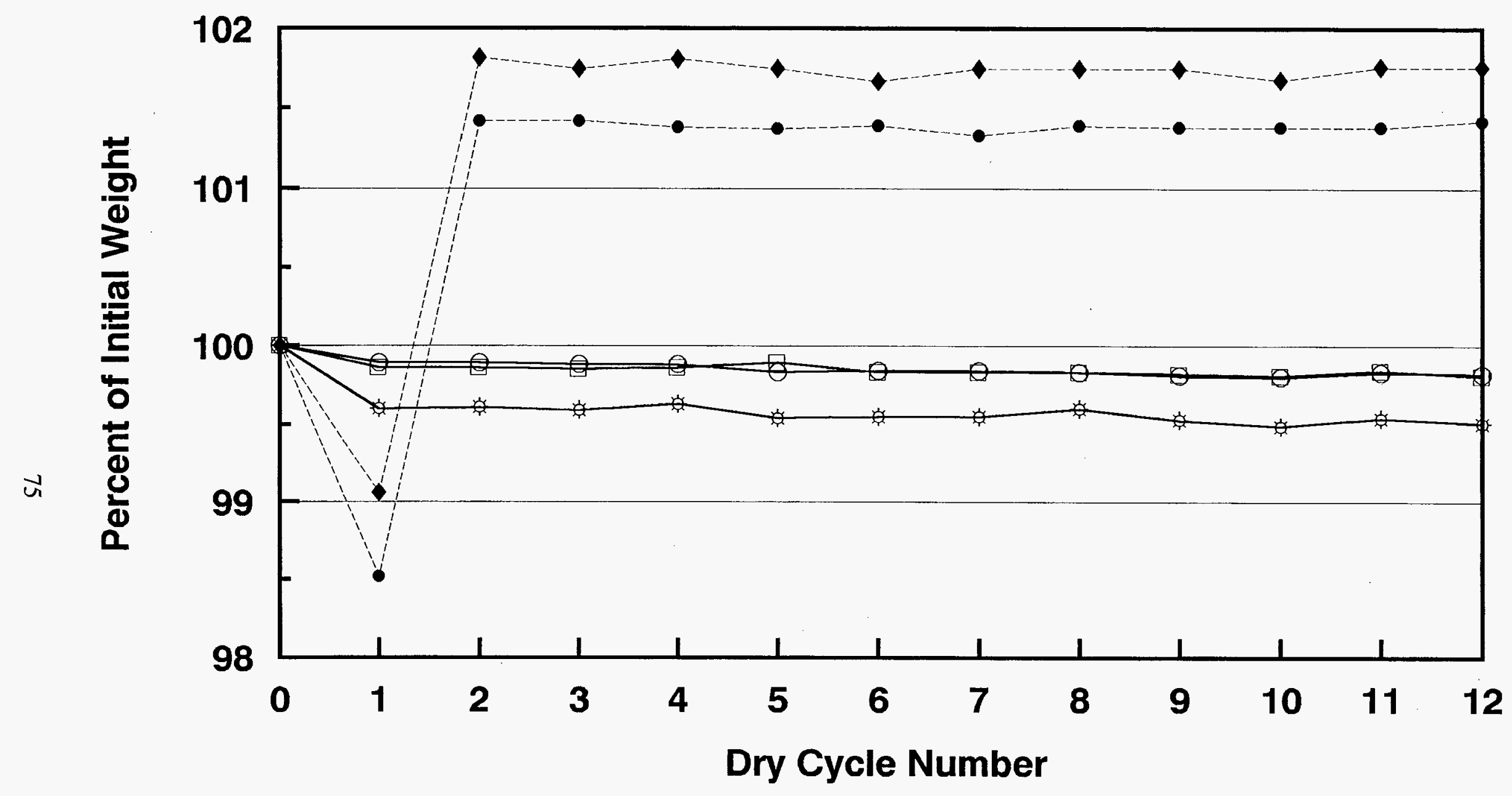

$\because$ Polymer-NW $\odot$ Polymer-NE Polymer-SW

- Cement \#1 - Cement \#2

Figure 5.22 Weight history of Hanford barrier core samples during dry cycling. 
cycling and there doesn't appear to be any slow degradation of the sample. The residue left after testing was minimal and averaged $0.07 \%(0.17 \mathrm{~g} \pm 0.08 \mathrm{~g}$, avg. sample wt. $=258.4 \mathrm{~g})$ compared to $0.08 \%(0.15 \mathrm{~g} \pm 0.03 \mathrm{~g}$, avg sample $w \mathrm{t} .=192.2 \mathrm{~g})$ for the laboratory prepared specimens. The field emplaced sample absorbed very little water during the wet cycling, averaging only $1.67 \%$. Laboratory samples behaved similarly absorbing an average of $2.23 \%$ water. Compressive strength of the samples after wet-dry cycling averaged $12.5 \mathrm{MPa}$, an increase in strength of $36 \%$ over the baseline $(9.2 \mathrm{MPa})$. Similar laboratory prepared specimens had strength increases after wet-dry cycling of $32 \%$. Again the performance of the field emplaced grout was well mirrored by the laboratory samples. [Note: The strength increases were attributed to increased polymerization of the grout due to the higher temperatures encountered in the dry cycle.] It should be noted that the sample from the SW bottom that shows higher water uptake than the NW and NE middle samples, also had the lowest strength. The compressive strength $(5.0 \mathrm{MPa})$ was a third of its counterparts (14.9 MPa and 17.6 MPa for NW and NE samples respectively). This is indicative of a lower binder to soil ratio or stratification within the sample. Visual inspection did not detect any stratification. Density of this sample was lowest of the three at $1.95 \mathrm{~g} / \mathrm{cm}^{3}$ versus $1.98 \mathrm{~g} / \mathrm{cm}^{3}$ and $2.06 \mathrm{~g} / \mathrm{cm}^{3}$ for the NW and NE samples respectively.

Weight changes for the cement soil mortars were higher than those for the polymer grout. Comparing the initial pretest weight to the final dry cycle weight, average weight change for the cement cores was $1.6 \%$. Looking at the first dry cycle weight and comparing it to the final dry cycle weight shows a change of $2.8 \%$. The average weight histories of the core samples are given in Figures 5.21. In figure 5.22, which compares the sample weight after each dry cycle, we see that the cement samples have an initial change in weight. The weight goes down after the first dry cycle but then rises to a value greater than its initial value. This is probably due to additional hydration reactions occurring while the sample is at the elevated temperature of the dry cycle. The additional hydration does not occur until the second dry cycle. This is most likely due to the fact that the test starts with a dry cycle. Specimens were at $100 \%$ relative humidity at room temperature prior to testing but would still be unsaturated. The small amount of moisture in the sample is evaporated off before the sample reaches $60^{\circ} \mathrm{C}$ and no further reactions take place. This is evidenced by the small weight loss after the first dry cycle. The sample is then wet cycled before the second dry cycle. The specimen becomes saturated with water and then is placed in the dry cycle. At the second dry cycle water remains in the sample long enough to see the elevated temperature. Once this additional reaction takes place there are no further unreacted materials available and the sample weight therefore stabilizes after the second dry cycle. The residue left after testing was minimal and averaged $0.11 \%$. Specimens absorbed a fair amount of water during the wet cycling, averaging $9.0 \%(22.3 \mathrm{~g}$ of $\mathrm{H} 2 \mathrm{O}$, avg sample $=248.4 \mathrm{~g})$. Compressive strength of the samples after wet-dry cycling averaged $24.6 \mathrm{MPa}$, compared to 20.1 Mpa for the baseline.

\subsubsection{Conclusions from laboratory testing of cores}

One of the difficulties in predicting long term behavior of grout barriers is the inconsistencies between field emplaced grout and laboratory prepared grouts. For hydraulic 
cements differences of two orders of magnitude in permeability are common. Initial physical testing shows the performance achievements of laboratory and field prepared polymer grouts to be identical. This gives greater confidence in accelerated laboratory durability testing to determine the long term behavior of the grout. It also highlights the "cleanliness" of polymer systems. They are not as prone to unpredictable incompatibilities or property changes (both local and gross) due to outside chemical interactions as cementitous grouts are. So long as a proper and thorough preinstallation compatibility determinations are made, polymer systems offer a very predictable product.

The field measured performance values for in situ placed grouts and laboratory measured (core specimen) performance values for field emplaced grouts had a remarkable consistency and agreement both among themselves and with the laboratory prepared grout/soil composites. The hydraulic conductivities measured for the polymer barrier, cores and lab specimens and the cement barrier and core samples exemplify this fact. This is evidence that well-planned, well-controlled procedures coupled with careful adherence to QA/QC protocols in both the laboratory and field can result in consistent values and produce a quality product.

\subsubsection{Evaluating the effect of barrier installation on the waste form}

Stresses on the waste form (tank) were monitored using four earth pressure cells, eight accelerometers, eight extensiometers and eight inclinometers to determine what if any effect the barrier placement had on the waste form. Cables from within the tank extended to a trailer outside for monitoring of the stresses. Due to concern that the cables would be damaged during construction the cables were disconnected during injection and monitoring of stresses was performed only before and after installation, providing a net change in stress on the tank. No change in the stresses on the tank were evidenced and it appears the grouting operation did not affect the waste form.

\subsection{Meeting the Objectives of the Demonstration}

The Hanford demonstration had to meet certain objectives prior to proceeding to full implementation at BNL. The objectives were defined earlier and all were successfully met. Compatibility of the grout materials with the emplacement equipment was demonstrated at the INEEL demonstration and convincingly confirmed at the Hanford demonstration. Use of dualwall drill pipe to inject two-fluid, thermosetting-polymer grouts was proven to be safe and reliable. The product formed via this technology is comparable to conventional single fluid jet grouting. This is the preferred method of installation for any grout that is subject to rapid polymerization or curing and can be delivered as two separate components.

Jet grouting was proven to be capable of installing a continuous barrier without affecting the waste form. No net change in the stresses on the waste form were observed. This was important going into implementation at BNLs glass pits since the waste form(s) consisted of glass bottles many of which were intact and contained hazardous materials. 
Laboratory measurements on core samples provided evidence that a durable barrier was emplaced and that the performance values obtained for field emplaced grouts were the same as those obtained for laboratory prepared samples. One of the difficulties in predicting long term behavior of grout barriers is the inconsistencies between field emplaced grout and laboratory prepared grouts. The identical behavior of laboratory and field samples gives greater confidence in the ability laboratory testing to determine the behavior of the barrier, a feature often lacking in cementitous grouts.

The demonstration also provided on a proof-of-concept level the ability to emplace a barrier integrity verification system at the site. The verification is described in the next section and was validated by physical inspection of the barrier. Excavation, visual inspection and a falling-head permeability test provided positive evidence that the barrier was indeed fault free.

The cost of installing the close-coupled barrier was documented and compared to the estimated costs of removing and treating soil and/or groundwater. DOE has about 3000 hazardous waste landfills, the representative site is approximately 2 acres. For the cases taken potential cost savings of close-coupled barrier technology range from a few million to tens of millions per representative 2 acre site.

Subsurface barrier costs vs. Remediation costs for a representative 2 acre site, $6 \mathrm{M}(20 \mathrm{ft})$ deep

Type of Corrective Action Estimated Project

Approximate Project Cost Cost in $\$$ cubic meter

Subsurface Barrier Systems Under Development

Close-coupled Polymer/

$\$ 24$

$\$ 1,700,000$

Cementitious Barrier**

Cryogenic Barrier ${ }^{16}$

$\$ 90$

$\$ 6,400,000$

Remediation of Organic Compound Contaminated Site

Thermally Enhanced Vapor

$\$ 150$

$\$ 10,700,000$

Extraction ${ }^{17}$

Excavate and Treat ${ }^{16}$

$\$ 590$

$\$ 41,900,000$

**Project cost data

These costs/savings will be site and problem specific and must be taken as such. For a site such as the BNL Chemical/Animal pits and Glass Holes where each pit is small and the waste treatable by BDAT methods, the installation of 51 separate barriers [ $9 \mathrm{M} 1 \times 9 \mathrm{M} \mathrm{w} \mathrm{x} 9 \mathrm{M} \mathrm{d}$ (30'1 
x 30'w x 30' d)] greatly affects the cost comparison over bulk excavation and treatment. For such a case close-coupled barrier installation is estimated to cost between $\$ 150 \mathrm{~K}$ and $\$ 300 \mathrm{~K}$ per unit or $\$ 7.65 \mathrm{M}$ to $\$ 15.3 \mathrm{M}$ for complete site remediation. An estimate for bulk excavation and off-site treatment and disposal was given as $\$ 8 \mathrm{M}^{18}$, although the estimated volume of waste that would have to be treated and the ultimate cost of this treatment are both considered to easily be off by $100 \%$ or more [exact waste type/quantity is unknown and was estimated from the excavation of one pit]. 


\subsection{VERIFICATION TECHNOLOGIES TO ACCESS THE INTEGRITY OF THE CLOSE-COUPLED BARRIER}

As the conceptualization of the project progressed it was plagued by the same old question all subsurface barriers are subject to; "How can you be certain there are no holes in the barrier?" To be most effective the barriers should be continuous and depending on use, have few or no breaches. A breach may be formed through numerous pathways including: discontinuous grout application, from joints between panels and from cracking due to grout curing or wet-dry cycling. No suitable method exists for the verification of an emplaced barrier's integrity. The large size and deep placement of subsurface barriers makes detection of leaks challenging. This becomes magnified if the permissible leakage from the site is low. Detection of small cracks (fractions of an inch) at depths of 100 feet or more has not been possible using existing surface geophysical techniques. Compounding the problem of locating flaws in a barrier is the fact that no placement technology can guarantee the completeness or integrity of the emplaced barrier.

\subsection{Proof-Of-Concept Demonstration of the Perfluorocarbon Tracer Verification Technology}

Tracer techniques involve emplacement or injection of a substance that will migrate to a collection point. Based on the rate of arrival at the monitoring well and the transport properties of the tracer and materials in the subsurface system, estimates of barrier integrity can be obtained. For subsurface soil systems, the tracer can be radioactive or non-radioactive liquids or gases. Radioactive tracers can be incorporated into the barrier grout and the radiation field can be monitored to ascertain the location of the grout. In this case, the migrating substance is the radiation particle. For barrier integrity studies in the unsaturated zone, gas phase tracers are needed. Liquid phase tracers will not have high enough mobility to be useful for determining barrier integrity on a short time scale. Gas phase tracers show promise to be able to detect fractures on the order of a few centimeters in size.

Gas phase tracers include perfluorocarbon tracers (PFT's) and chlorofluorocarbon tracers (CFC's). Both have been applied for leak detection in subsurface systems. BNL proposed using perfluorocarbon tracers (PFT) for subsurface barrier verification. PFTs which were originally utilized in atmospheric and oceanographic studies and have since been applied to a great variety of problems including; detecting leaks in buried natural gas pipelines, determining the rate of dioxin movement into a commercial building from surrounding contaminated soil, the rate of leaking dielectric fluid from subsurface electrical cables, the rate of leaking gasoline from underground storage tanks and locating radon ingress pathways in residential basements. ${ }^{19,20}$ Prior accomplishments in determining gas pathways in residential basements was readily applicable to barrier verification. The residential basements studied are essentially miniature "barriers" with vertical concrete walls and a horizontal concrete floor. Thus, PFT tracer technology should be directly applicable to barrier verification. 
PFT technology should allow locating and sizing of breaches at depth in a subsurface barrier. The technology has regulatory acceptance for other applications and is used commercially for non-waste management practices (e.g., detecting leaks in underground power cables). This technology has been used in a variety of soils and may be applicable to the entire DOE complex as well as commercial waste sites. PFTs will be to verify placement continuity of a freshly emplaced barrier, to re-check corrective actions that may be used to seal or repair a breach and periodically check a barrier to determine the long term integrity of the walls.

In this study, PFT's were chosen as the tracer. PFT's have the following advantages and characteristics as compared to other tracers:

- Negligible background concentrations. Consequently, only small quantities are needed;

- $\quad$ PFT's are nontoxic, nonreactive, nonflammable, environmentally safe (does not contain chlorine) and commercially available;

- PFT technology is the most sensitive of all non-radioactive tracer technologies. Concentrations in the range of 10 parts per quadrillion of air can be easily measured;

- $\quad$ PFT technology can simultaneously deploy, sample, and analyze up to six PFT's with the same instrumentation. This results in lower costs and flexibility in experimental design, testing and data interpretation; and

- $\quad$ PFT concentrations can be analyzed in a few minutes in the field or in the laboratory using gas chromatography.

The ability to use multiple tracers at a single site can help to improve the spatial resolution of the breach. Theoretically, the combination of monitoring data with numerical modeling of the movement of the PFT's can be used to locate hole size down to a few centimeters in size. Testing to determine the resolution that can be obtained in the field remains to be done.

The focus of this section is to describe the barrier verification tests conducted at the Hanford barrier using PFT's and analysis of the data from the tests. The objective of these tests were to demonstrate the proof-of-concept that PFT technology can be used to determine if breaches exist in the barrier and for estimating the effectiveness of the barrier in preventing migration of the gas tracer to the monitoring wells. This section describes the verification studies conducted at Hanford. The experimental results and the analysis of the data follows. Based on the findings of this study, conclusions are offered and suggestions for future work are presented. 


\subsubsection{Purpose}

The purpose of this work was to demonstrate on a proof-of-concept level that PFT technology can be used for subsurface barrier integrity verification. Existing tracer technology, in conjunction with vadose zone monitoring techniques and with the aid of computer modeling, were used to determine if breaches exist in the demonstration barrier, to estimate the size of the breach, and to estimate (order of magnitude) the diffusion coefficient of the barrier materials.

\subsubsection{Technology need}

Subsurface barriers are a remediation option for many of the DOE defense sites including: Sandia, Hanford, INEEL, ORNL, Fernald, and Rocky Flats. Barriers are also considered an important remediation option by the USEPA ${ }^{4}$. Several of the DOE Integrated Demonstrations (MWLID, BWID) and Programs (ISRIP) are investigating variations of permeation grouting and jet grouting to emplace grout barriers. Permeation grouting is plagued by short circuiting of the flow of grout which can leave large untreated areas. Jet grouting methods require straight boreholes and sufficient overlap of columns to maintain barrier continuity. Often the borehole wanders or the jet is partially obstructed by cobble or varying soil types, leaving a gap in the final barrier. Panel jet grouting may leave gaps between panels and or at the junctions of horizontal and vertical barrier walls. The ability to verify barrier integrity is valuable to the DOE, EPA, and commercial sector and will be required to gain full public acceptance of subsurface barriers as either primary or secondary confinement at waste sites.

It is recognized that no suitable method exists for the verification of an emplaced barrier's integrity. Because of the large size and deep placement of subsurface barriers, detection of leaks is challenging. This becomes magnified if the permissible leakage from the site is low. Detection of small cracks (fractions of an inch) at depths of 100 feet or more has not been possible using existing surface geophysical techniques. Compounding the problem of locating flaws in a barrier is the fact that no placement technology can guarantee the completeness or integrity of the emplaced barrier.

\subsubsection{Technology benefits}

PFT technology should allow locating and sizing of breaches on the order of fractions of an inch at depth in a subsurface barrier. The technology has regulatory acceptance for other uses and is used commercially for non-waste management practices (e.g. detecting leaks in underground power cables). This technology has been used in a variety of soils and locals and will be applicable to the entire DOE complex as well as commercial waste sites. The major use of tracers will be to verify placement continuity of a freshly emplaced barrier and to re-check corrective actions that may be used to seal or repair a breach. It will also be useful to periodically check a barrier to determine the long term integrity of the walls. This would certainly be beneficial if a cementitous grout (portland based) barrier were used. Cementitous grouts are prone to cracking from various degradation modes including wet-dry cycling which is prevalent at many 
of the DOE sites (e.g. Sandia and Hanford). Tracers would allow determination of losses in containment performance over the life of the barrier.

An additional use for PFTs may be in confirming integrity of waste disposal vaults. Many of the agreement states have regulated that low level waste will be disposed of in some form of an engineered vault. The technology developed for subsurface barriers should directly transfer to disposal vault validation. Since the predominant failure mode of vaults is some form of concrete cracking, tracers could be used for the entire lifetime of the vault to determine when and what performance loss occurs.

\subsubsection{Technology Description}

As a subtask to the barrier emplacement project, a method to verify continuity of the barrier using perfluorocarbon tracers (PFT) was developed. This method involves injection of the gas tracer inside the region contained by the barrier and measuring the time evolution in PFT concentration at a series of monitoring locations outside the barrier. Using a mathematical model for the transport of the tracer through the soil and barrier system, estimates of the barrier integrity can be obtained. If the barrier is intact, estimates of the transport rate through the barrier can be made. If the barrier has a breach, the location and size of the breach can be estimated through mathematical techniques. The demonstration provide a proof-of-concept for gaseous tracer verification of barrier integrity.

PFT technology consists of the tracers themselves, injection techniques, samplers and analyzers. As discussed in Section 6.1 PFTs have a number of advantages over conventional tracers. These include their low-background concentration, their nonreactive nature, the sensitivity of detection (ten parts per quadrillion can be detected), and the ability to use multiple tracers. The ability to detect extremely minute amounts permits injection of only small quantities of the gas. This minimizes disturbance to the system. The last feature, use of multiple tracers, can be beneficial in optimizing experimental design. Tracers at different locations can be injected to test the integrity of discrete regions in subsurface barriers. In addition, the flexibility afforded by having multiple tracers permits the system to be rechecked at later periods without interference from previous testing.

Typically, the PFTs are measured by a capillary adsorbent tracer sampler (CATS) which is a small cigarette sized glass tube containing a carbonaceous adsorbent specific for the PFTs. This sampler can be used dynamically (flowing a sample through the CATS) or passively (Opening only one end so as to allow the CATS to sample by diffusion). The passive mode allows a time integrated PFT concentration to be measured in a simple manner. The CATS are shipped back to the laboratory for PFT analysis. Several real-time PFT analyzers are available, one which detects four different PFTs per five minutes sample down to the ambient background of the PFTs in air. Another real time instrument can analyze PFT down to a part per trillion but cannot speciate the various PFTs. 
Low detection limits allow detection of very small breaches in the barrier. Breaches will be located by injecting a series of PFTs inside the barrier enclosure and monitoring for those tracers on the outside of the barrier enclosure. The injection and monitoring (through CATS) of the PFTs will be accomplished through vadose zone monitoring wells and/or multilevel monitoring ports. The amount and type of tracer detected on the monitoring side of the barrier will be used to determine the size and location of a breach. Multiple tracer types can be injected at different points along the barrier (both vertical and horizontal). Investigation of the spectra of tracers coming through a breach then gives a location relative to the various tracer injection points.

Some computer analysis will be required for experimental design and data analysis. Understanding mass transport through defects in a close-coupled barrier is central to evaluation of the performance of the barrier. To compliment the experimental program and enhance the understanding of the tracer movement, migration of the tracers will be analyzed using computer codes that predict the transport of the gas tracer through a porous soil and the close-coupled barrier. Existing computer codes, such as DUST, BLT, or TOUGH will be adapted as necessary for the problem.

\subsubsection{Scope}

The barrier was checked for breaches after the installation of the cement layer and again after the polymer layer installation. PFT technology locates flaws by injecting a perfluorocarbon tracer (PFT) on one side of a barrier wall and monitoring for that tracer on the other side. The injection and monitoring of the PFT was accomplished through vadose zone monitoring wells. The amount and location of tracer detected on the monitoring side of the barrier would determine the size and location of a breach. PFTs were measured by gas chromatograph and capillary adsorbent tracer samplers (CATS) which are small cigarette sized glass tubes containing a carbonaceous adsorbent specific for the PFT. The CATS were shipped back to BNL for PFT analysis. To compliment the experimental program and enhance the understanding of the tracer movement, migration of the tracers were to be analyzed using computer codes that predict the transport of the gas tracer through a porous soil and the close-coupled barrier. Existing computer codes, such as DUST, BLT, or TOUGH will be adapted as necessary for the problem.

\subsubsection{Performance objective}

The objective of the PFT technology task was to demonstrate on a proof-of-concept level that PFT technology is capable of verifying barrier integrity by determining if breaches exist in the demonstration barrier, to estimate the size of the breach, and to estimate (order of magnitude) the diffusion coefficient of the barrier materials. 


\subsubsection{Objective criteria}

To achieve the above objective the following criteria must be successfully demonstrated:

1) demonstrate that PFT technology can be used to determine the location and size of a breach in a subsurface barrier, and

2) determine if PFT technology is capable of being used to estimate transport properties, and thus the performance of a subsurface barrier.

\subsubsection{Demonstration parameters}

The specific parameters that will be measured to determine the successful completion of the objective criteria will be as follows:

1. Breach locations will be determined, and

2. Breach size will be estimated from the PFT data.

3. An estimate of the gaseous diffusion coefficient of the cement layer will be made.

\subsubsection{Criteria for success}

The criteria for successfully meeting the objectives of this demonstration will be as follows:

1) Successful detection, location, and sizing of a breach in a subsurface barrier by the PFTs,

2) Order of magnitude estimates of the diffusion coefficient of the cement layer.

Verification that the PFT technology was capable of meeting the above criteria was accomplished by the excavation of the barrier and subsequent comparison of the results found by the PFT technology.

\subsubsection{Experimental systems}

The demonstration of barrier integrity was conducted in two parts. In the first phase, the PFT perfluoromethylcylohexane, $\mathrm{PMCH}$, was injected into the system beneath the center of the simulated waste tank approximately three meters below grade prior to emplacement of the polymer grout.

During the first phase of the program, prior to installation of the cementitious grout liner monitoring wells were installed. The monitoring network consisted of seven wells located parallel to and approximately one meter outside the cement grout barrier. These wells were used to draw 
samples to measure the PFT concentration as a function of time. These wells are designated by their location as North, Northeast, East, Southeast, South, Southwest, and Northwest. An eighth well, located in the West position, was destroyed construction during the site preparation phase. These wells were composed of perforated casing. Two wells located in the interior of the cemented region were utilized for the first test. These wells are designated North and South and are located parallel to and one meter inside the barrier. These wells were used to measure the concentrations during the injection period of three days.

The injection started on October 18, 1995 and lasted for three days at a nominal rate of $15 \mathrm{~cm}^{3} / \mathrm{min}$ (measured rates varied between $12-15 \mathrm{~cm}^{3} / \mathrm{min}$ ) at a PMCH concentration of 373 $\mathrm{ppm}$. In the seven external monitoring wells, tracer concentration measurements were performed at the end of the injection period and beginning with the sixth day after the start of injection, measurements were made daily except on weekends for 17 days. The data permits evaluation of the cement grout as a barrier to releases and allows estimation of transport parameters in native soil and the cement grout.

After completing the tests and analyzing the data, the polymer grout was injected in December of 1995. In March of 1996, another PFT, ortho-cis-perfluorodimethylcyclohexane, ocPDCH, was injected into the subsurface at the center of the simulated waste tank as before. The injection started on March 3 and lasted for three days at a nominal rate of $15 \mathrm{~cm}^{3} / \mathrm{min}$ at an ocPDCH concentration of $30 \mathrm{ppm}$. In this case, the monitoring wells were re-constructed to permit sampling at different depths by inserting copper tubing of different lengths inside the well casing and backfilling with sand to affect discrete separation of the sampling zones. This is discussed further in Section 6.1.9.4.1.

The physical system at Hanford which is under study is displayed in Figure 6.1. The approximate dimensions of the system are $6.3 \mathrm{~m}$ deep and $12.5 \mathrm{~m}$ in diameter. The cementitious barrier wall was constructed by injecting two parallel rows of grout at an angle of $\pi / 4$ radians (45 degrees) to the ground surface. A schematic of the top view of the system is displayed in Figure 6.2. In this study, the barrier was covered by $60 \mathrm{~cm}$ of soil. The use of a sloping barrier wall forms an inverted cone. The second row of cement columns is used to fill in gaps/thins at the overlap of columns in the first row the grout barrier and help insure that large scale breaches in the barrier do not occur. The design basis thickness of the cementitious grout barrier is one meter (this is the thickness in the plane parallel to the barrier). Figure 6.3 shows the monitoring wells and the extension of the tank above the ground surface. The tank represents a simulated waste form and has dimensions of approximately $3 \mathrm{~m}$ in diameter and $2.4 \mathrm{~m}$ in height.

\subsubsection{Data collection and interpretation}

To support the PFT testing procedure, modeling of the subsurface movement of the PFT gas has been conducted for the Hanford soil/neat cement barrier. Modeling was used to estimate the rate at which the tracer will travel through the barrier and reach the monitoring wells, to demonstrate the effects of small holes $(1-10 \mathrm{~cm})$ on concentration at the well, and the effects of 


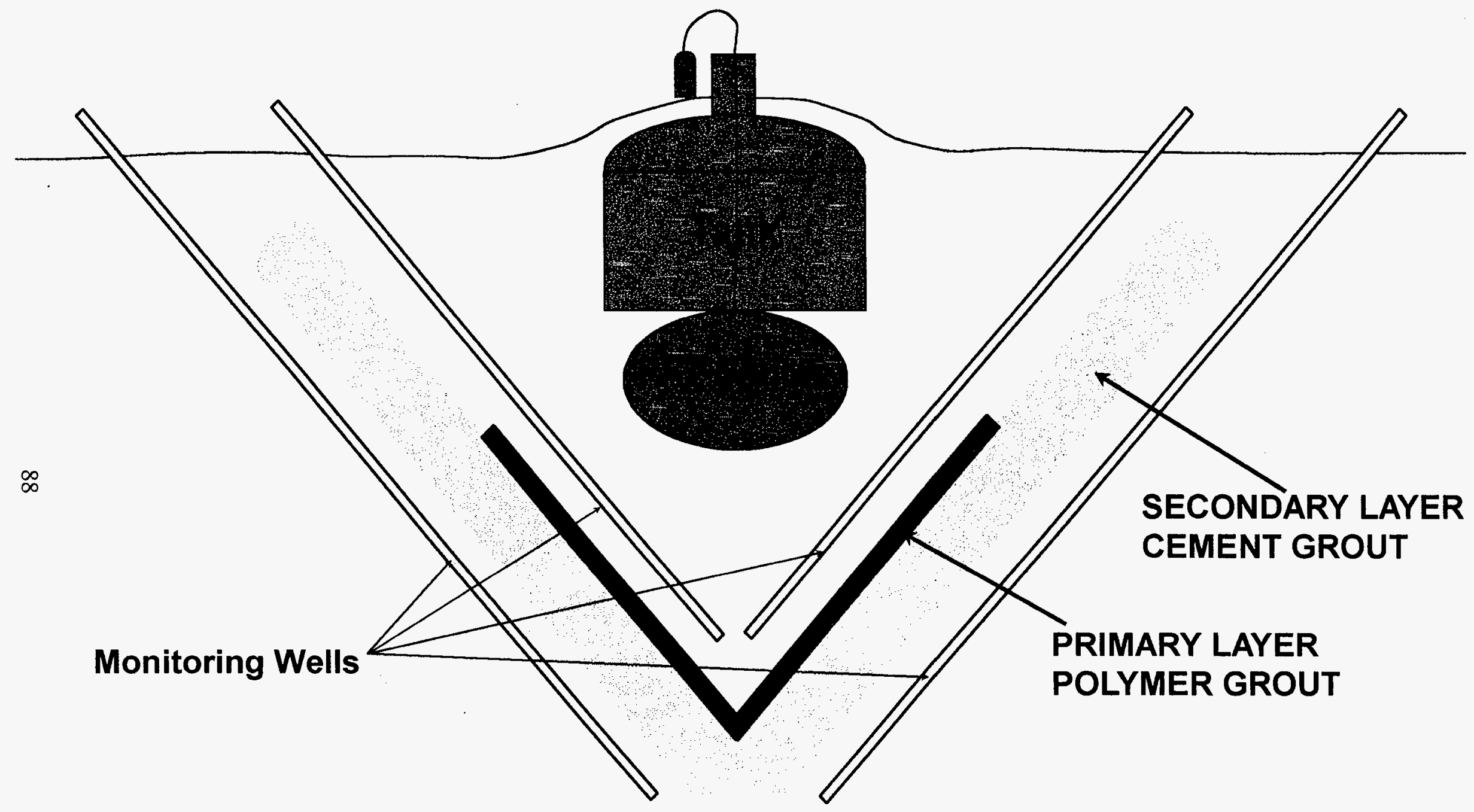

Figure 6.1 Layout of the barrier system used in modeling perfluorcarbon tracer transport. 


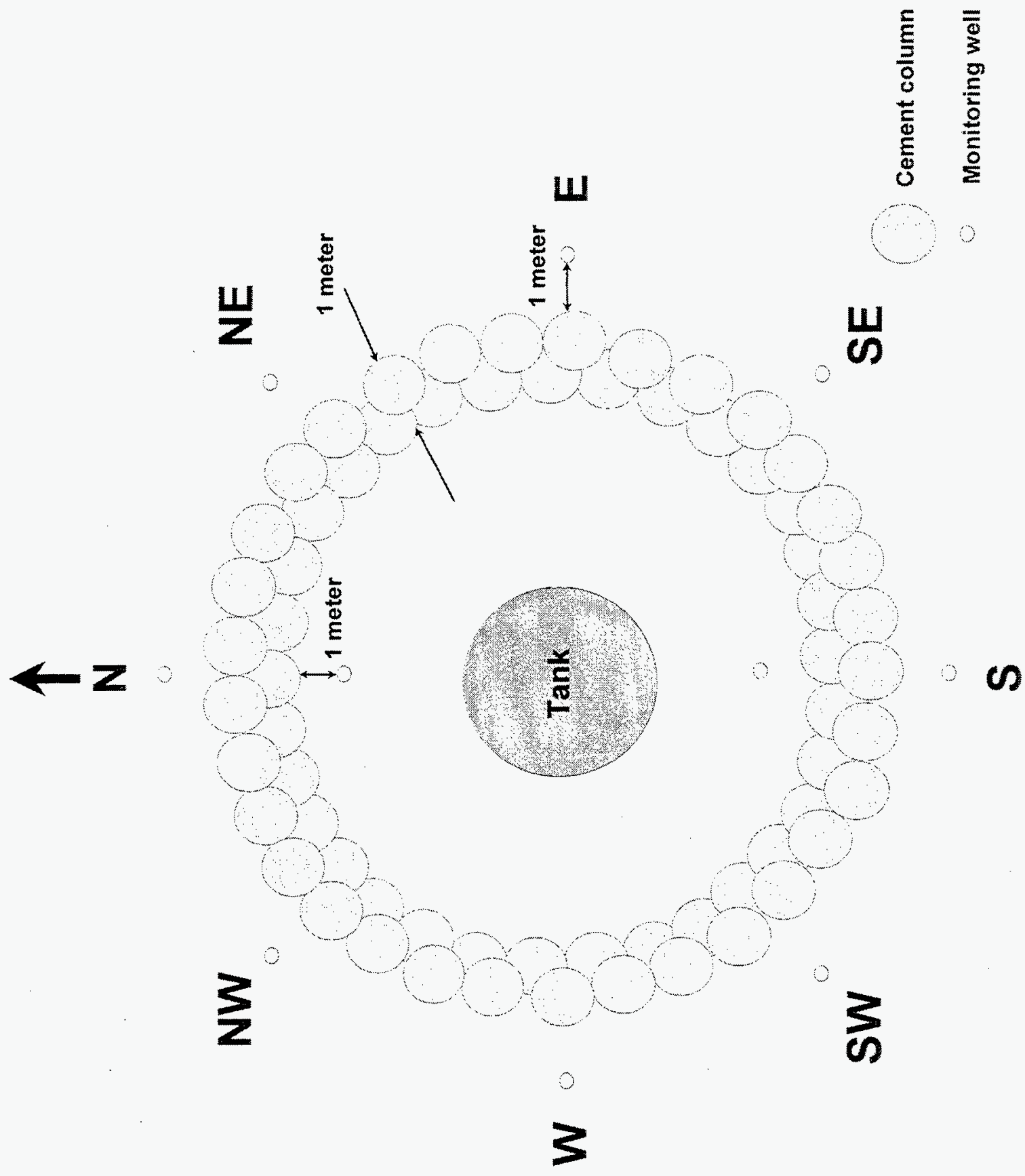

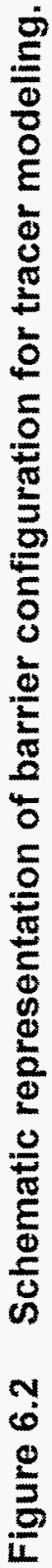




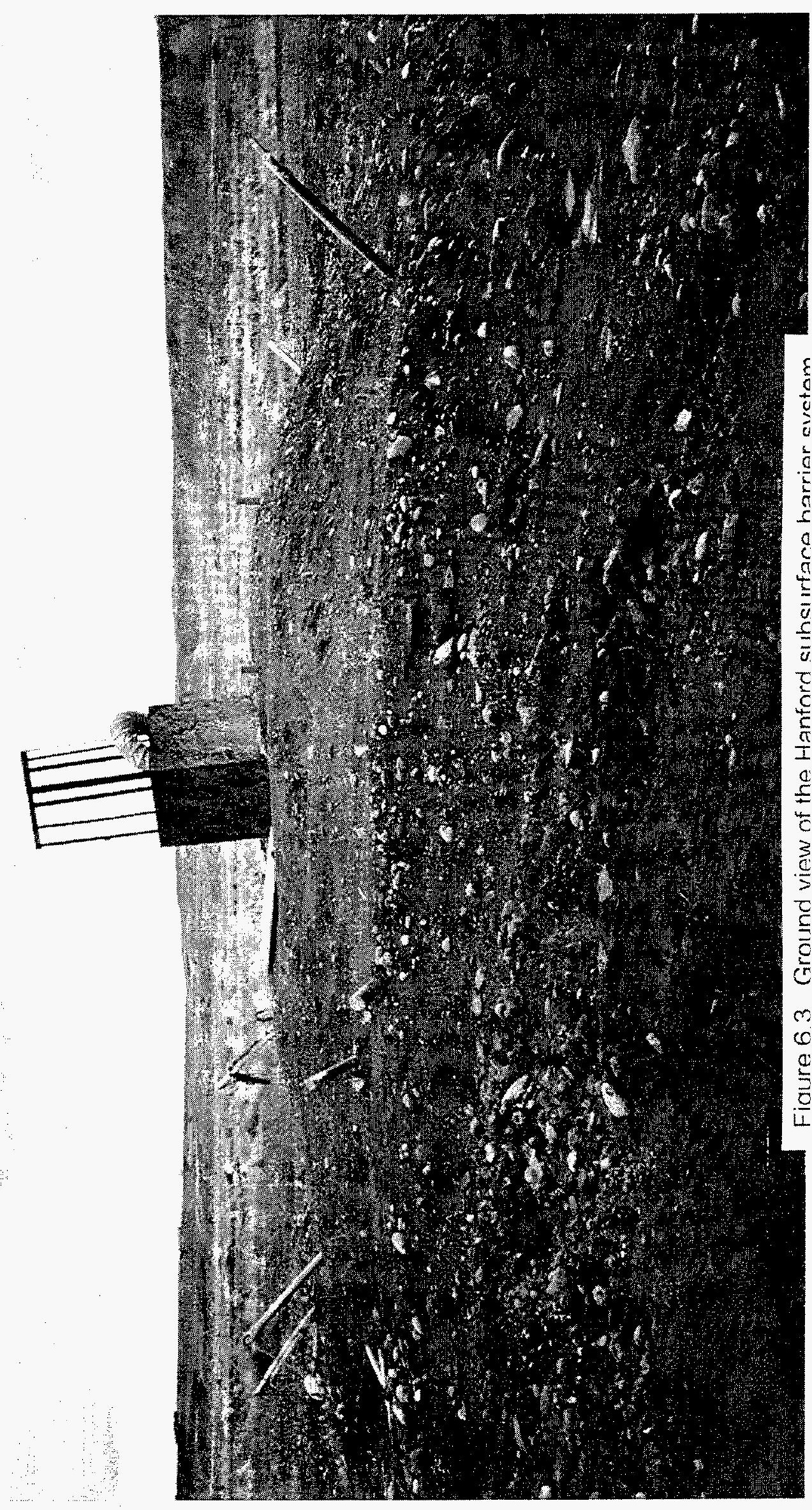


the waste tank on movement of the gas. This modeling information was used to assist in the determination of injection rates for PFT's into the subsurface system, the frequency and duration of sampling, and the time to flush the system prior to testing the close-coupled system.

\subsubsection{Conceptual model}

The problem involves transport of an injected gas tracer through an engineered barrier (soil/neat cement) to a monitoring well. To model this requires knowledge of the rate of tracer injection, location of injection, geometry of the system, location of the monitoring wells, and transport properties of the PFT through the soil and soil/neat cement barrier. The complicated geometry (e.g. sloping walls, potential for flow through a small hole, and simulated tank) and the non-uniform transport regions, i.e., the soil and the barrier, necessitate a numerical solution.

The diffusion equation with a time-dependent external source is used to solve for the movement of the tracer from the injection location throughout the modeled domain. The equation is:

$$
\frac{\partial C}{\partial t}=D \nabla^{2} C(x, z, t)+Q(x, z, t)
$$

where: $\quad C(x, z, t)$ is the tracer concentration

$\mathrm{D}$ is the diffusion/dispersion coefficient $\left(\mathrm{cm}^{2} / \mathrm{s}\right)$, and

$\mathrm{Q}(\mathrm{x}, z, t)$ is the rate of tracer injection into the system.

The dominant transport process for air in soil systems is believed to be diffusion ${ }^{21}$. Advection resulting from barometric pressure changes can facilitate the release of the tracers to the atmosphere and was considered in the initial phase of the modeling. The advection due to barometric pressure changes is expected to vary cyclically. These pressure changes will lead to times when the flow is into the soil and times when the flow is directed out of the soil. The preliminary modeling results indicated that for likely values of the cyclical advection velocity, diffusion would be the dominant transport process as expected and advection could be neglected ${ }^{22}$ Substantial differences between the predicted concentrations of the diffusion only and the diffusion with cyclical advection case occurred only in the top meter of the soil. However, since the permeability of the soil was not measured, advection can not be completely ruled out as a transport mechanism.

The measured diffusion coefficient for the PFT PMCH in air is $5 \times 10^{-2} \mathrm{~cm}^{2} / \mathrm{s}$. Measured values in the soil system at the Hanford test facility are not available. To account for tortuosity effects in the soil, the diffusion coefficient of PMCH in the soil has been estimated as $10^{-2} \mathrm{~cm}^{2} / \mathrm{s}$ for the base case. This value is similar to that for radon gas in dry soils ${ }^{23}$. Radon and the PFT's are inert gases with approximately similar molecular weights (e.g. Radon molecular weight $=226$ and PMCH molecular weight $=350$ ). Therefore, the diffusion coefficients of the two gases should be similar. The diffusion coefficient through the soil/neat cement was selected as $10^{-4}$ 
$\mathrm{cm}^{2} / \mathrm{s}$. The range of diffusion coefficients for radon gas through residential concretes is $10^{-4}-5$ $\mathrm{x} 10^{-3} \mathrm{~cm}^{2} / \mathrm{s}^{24}$. A value from the low end of the range was selected in the initial stages of modeling in an attempt to provide a lower estimate of release to the monitoring wells and to insure that sampling would be able to detect the PFT's.

Simulations with a completely intact barrier were performed as a baseline. Then the effects of having small imperfections (caused by imperfect grouting) were studied. In this analysis, the imperfections are represented as a hole through the entire wall. The range of hole sizes that were modeled was between one and ten $\mathrm{cm}$.

\subsubsection{Computational model for the Hanford test site}

At the Hanford test site the PFT's were injected into the center of the inverted cone directly beneath the waste tank. This permitted an assumption of cylindrical symmetry. Therefore, to simulate this physical system described in the previous section, Figure 6.1 , a twodimensional cylindrical slice through the center of the cone was taken. The tank (waste form) was represented as a no flow boundary. For simplicity and because of the lack of site-specific data, it is assumed that there are two distinct materials in the subsurface system, the soil and the soil/neat cement barrier. The subsurface barrier system at the Hanford test facility was modeled in cylindrical geometry using a two-dimensional finite-element transport code, BLT ${ }^{25}$.

This problem has two size scales. The first scale is that of the system itself. The height from the bottom of the subsurface barrier to the ground surface is $6.6 \mathrm{~m}$. The radius of the barrier was also approximately $6.6 \mathrm{~m}$ and a total distance of $12.8 \mathrm{~m}$ was simulated in the direction parallel to the ground surface. The second scale is that of the size of the potential breach which is on the order of a few centimeters. It would require nearly one million computational points to model the entire system on the scale of one centimeter. This is not computationally feasible. To account for the two scale sizes, variable mesh spacing was used. A fine mesh (order of one centimeter) was used in the region of the hypothetical breach. The mesh was increased in size as the distance away from the hypothetical breach increased. The slanting soil/neat cement barrier was modeled by defining the finite elements used to represent the barrier to also slant at a $\pi / 4$ radians (45 degree) angle. These two details led to a complicated finite-element mesh with three thousand computational points, Figure 6.4 .

Initially, the system is tracer free and, therefore, the initial condition is zero concentration at all locations. The boundary condition assumed zero flux at the centerline due to the assumed symmetry. Zero concentration boundary conditions were used at the top boundary, bottom boundary, and right-hand boundary defined in Figure 6.4. The right-hand boundary is located at a large enough distance such that the tracer does not reach the boundary during the simulation period of 0.1 years. The top boundary was selected to have zero concentration to represent PFT concentrations in the atmosphere which are assumed to be zero. Analysis performed with flow out of the ground surface and into the atmosphere indicated that the zero concentration boundary condition is an excellent approximation due to the higher transport rates in the atmosphere (higher diffusion and advection rates). 


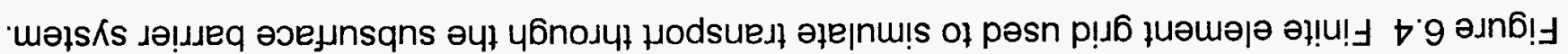

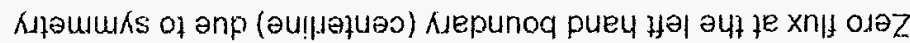

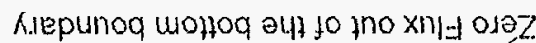

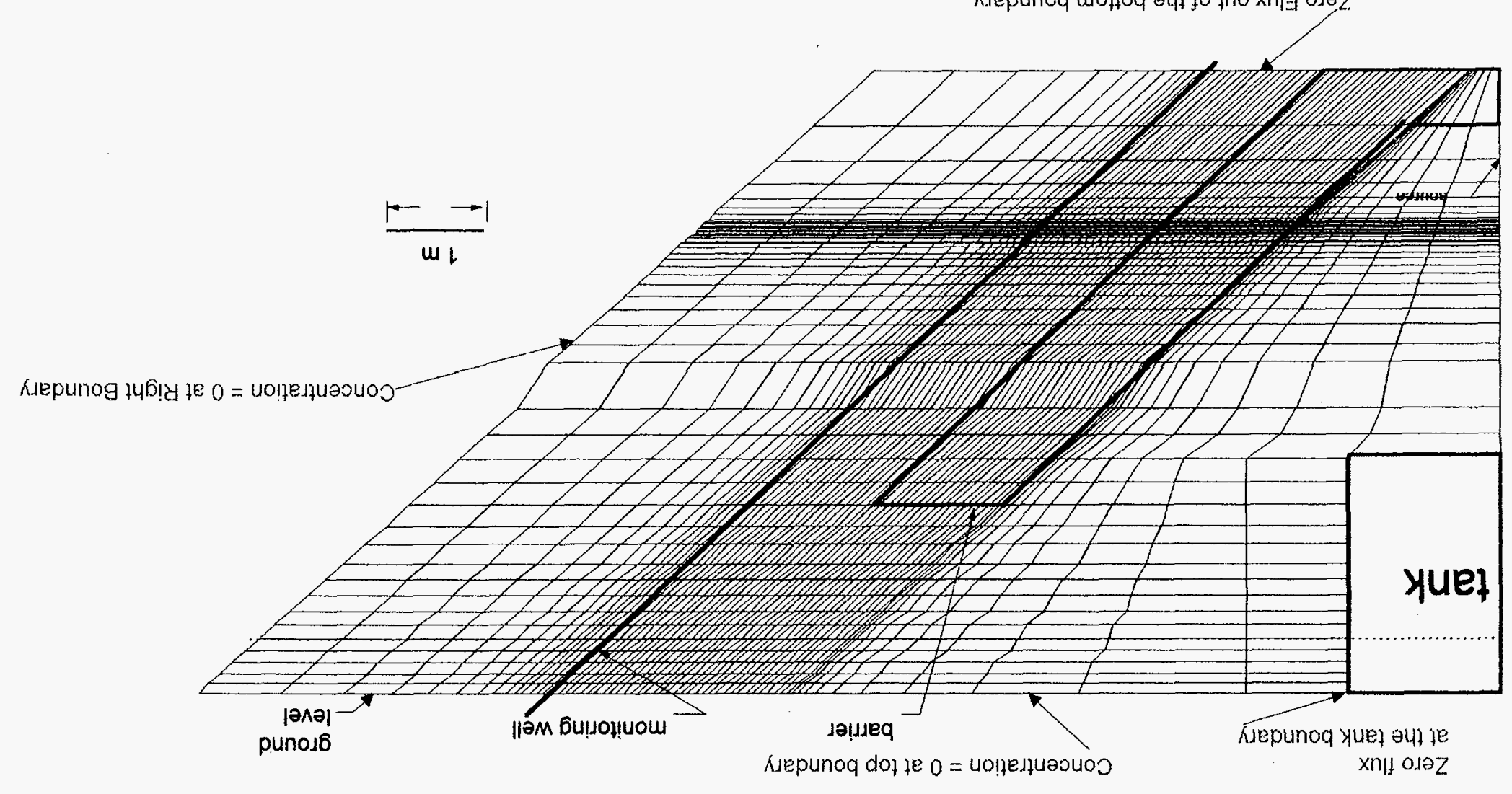


In the preliminary modeling exercise conducted prior to the experiment, the source was treated as a point source being injected at the centerline at an elevation of $97 \mathrm{~cm}$ above the bottom of the facility. Two injection scenarios were modeled: a 3.7 day pulse injection and continuous injection over the entire simulation period of 37 days. The air injection rate was assumed to be $30 \mathrm{~cm}^{3} / \mathrm{min}$ at a unit tracer concentration. This problem exhibits a linear response to the injection concentration. This property was used to normalize all of the simulation concentrations to the injection concentration.

PFT tracers are non-reactive in soil systems and can be detected at levels of one part in $10^{15}$. Typically, injection concentrations are on the order of one hundred parts per million. Therefore, the detection limit will be approximately $10^{-11}$ of the incoming concentration. One objective of the preliminary modeling work was to define the time at which the PFT's will first be detected at the monitoring wells and the time evolution of concentration at the monitoring wells. For the purposes of defining the experimental protocol, the minimum detection limit was multiplied by a factor of 10,000 for the design objective. This provides a design goal for the normalized concentration in the monitoring wells of $10^{-7}$ over the thirty-six day simulation time Due to the choice of diffusion coefficients in the low end of the expected range for the soil and soil/grout, it was expected that the predicted concentrations would provide a lower bound on the actual concentrations.

\subsubsection{Model results}

\subsection{Model projections prior to data collection}

The computer code $\mathrm{BLT}^{25}$ was used to solve the above equations for the tracer plume due to injection of the tracer. A wide range of cases was considered to assist in gaining an understanding of the system behavior. The objective of these simulations was to estimate the time evolution of tracer concentration at the monitoring well.

Model simulations of the tracer plume were followed for $3.15 \times 10^{6}$ seconds ( 36.5 days) using the base case parameters in Table 1 . In the base case it is assumed that the subsurface barrier wall is intact and no substantial breach occurs. In the simulation, tracer was injected for the entire simulation period. The results of this simulation $1.57 \times 10^{6} \mathrm{~s}(14.6$ days $)$ after the start of the experiment are presented in Figure 6.5. The contour plot color key is presented in Figure 6.6. All projected concentrations are normalized to the injection concentration.

In Figure 6.7, it is seen that for the base case parameters, the simulated soil/neat cement wall provides an effective barrier to migration of the PFT's. Concentrations at the well 14.6 days since the beginning of tracer injection are more than eight orders of magnitude (which is below the design objective of the experiments and is the lowest value represented on the contour plots) less than the injection concentration. Inspection of the output files indicates that the projected base line concentrations are nine orders of magnitude less than the injection concentration at this time. Concentrations at the monitoring well exceeded the design basis value of $10^{-7}$ after thirty days. 


\section{Concentrations at 14.6 days}

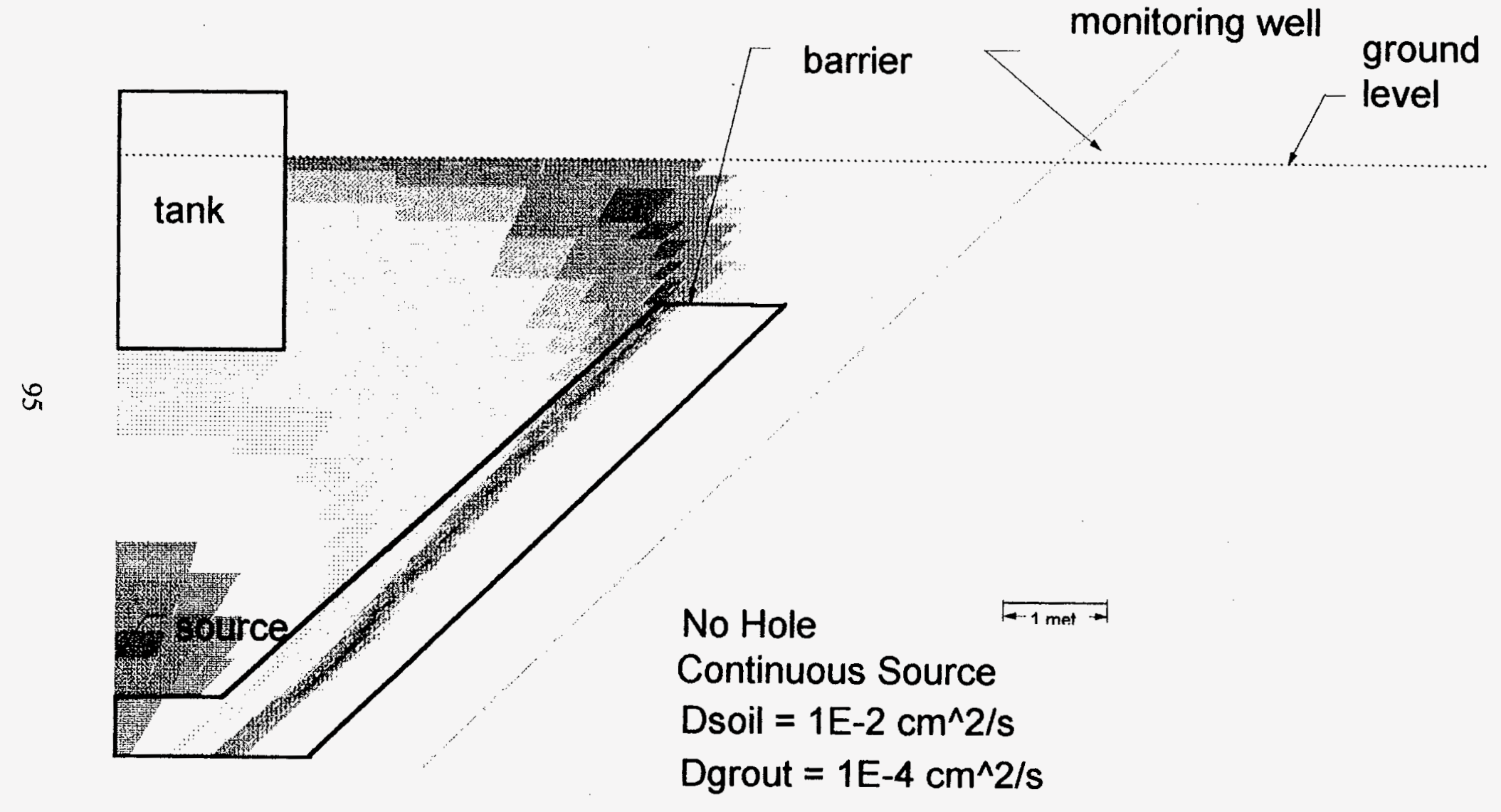

Figure 6.5 Concentrations at 14.6 days for an intact barrier with a soil diffusion coefficient of $10^{-2} \mathrm{~cm}^{2} / \mathrm{s}$ and a barrier diffusion coefficient of $10^{-4} \mathrm{~cm}^{2} / \mathrm{s}$. 
Contour Plot Color Key (Normalized Concentration)

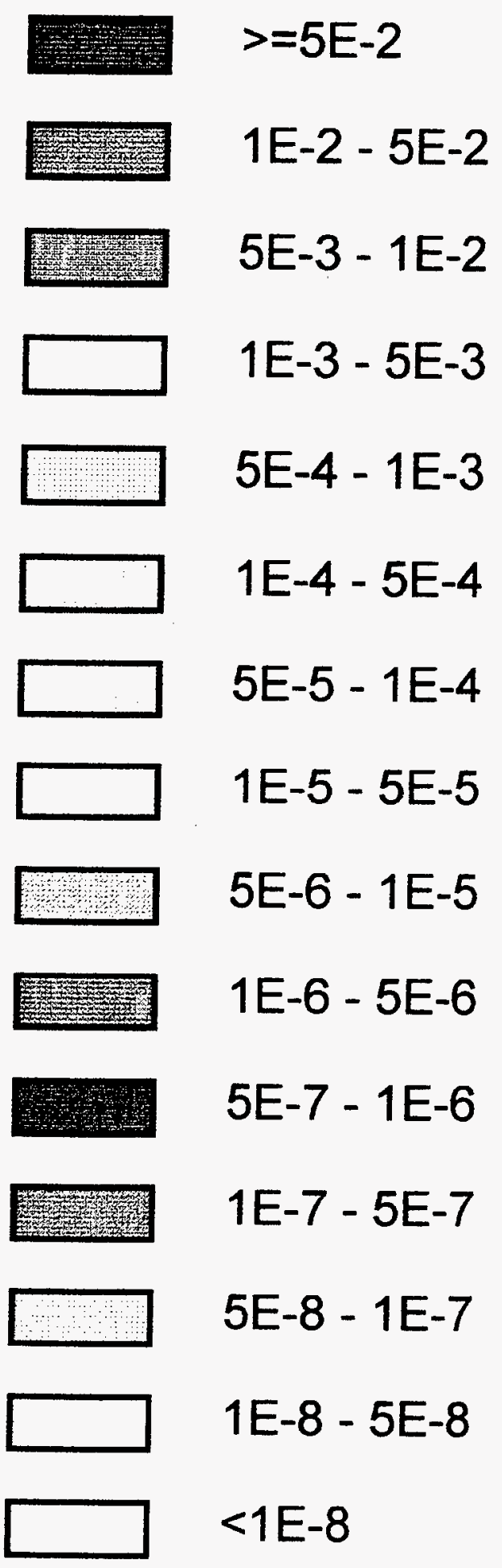

Figure 6.6 Contour plot color key (normalized concentration). 


\section{Concentrations at 14.6 days $w /$}

\section{$5 \mathrm{~cm}$ hole in the barrier}

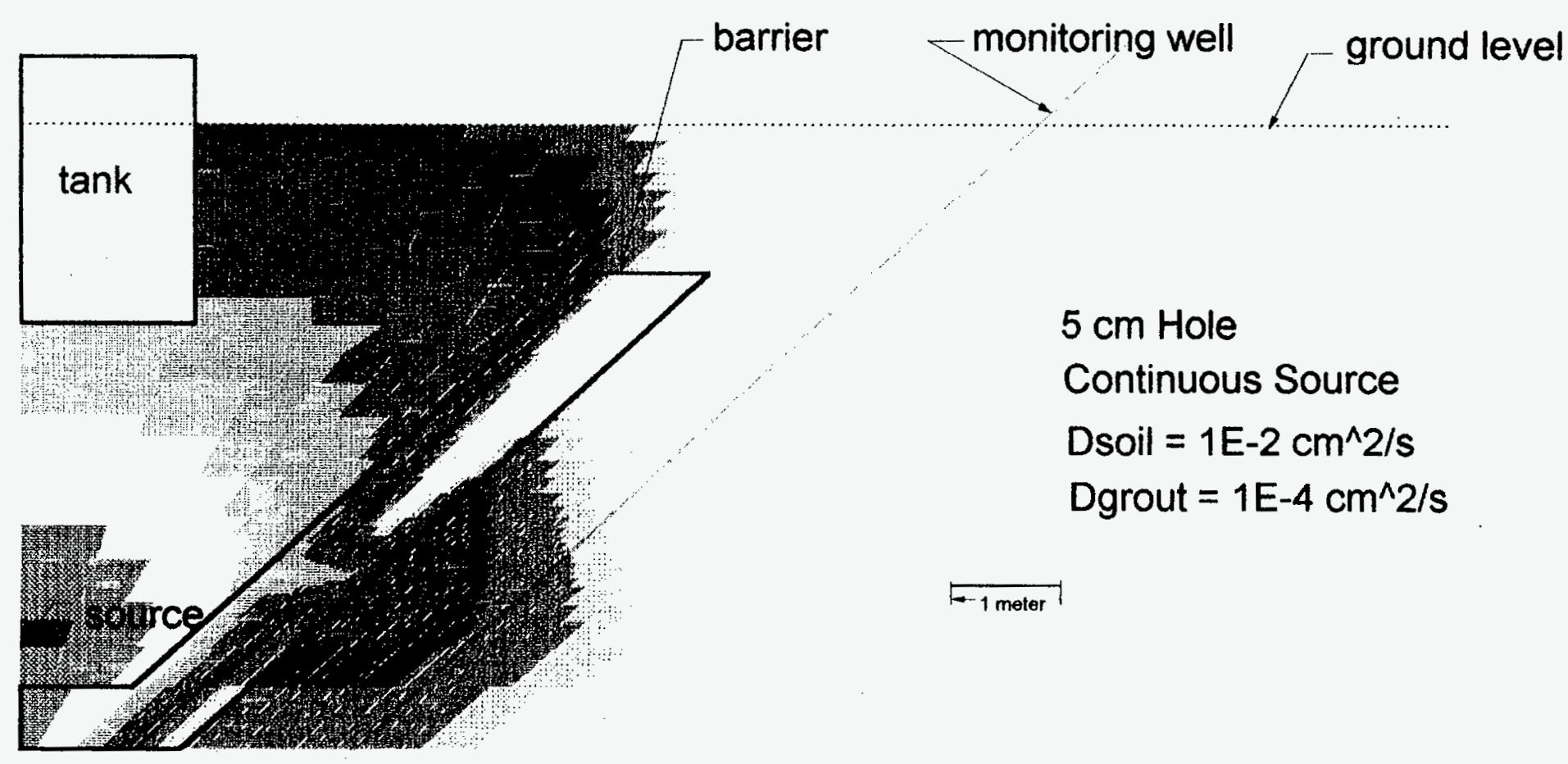

Figure 6.7 Concentrations at 14.6 days for a barrier with a $5 \mathrm{~cm}$ breach and a soil diffusion coefficient of $10^{-2} \mathrm{~cm}^{2} / \mathrm{s}$ and a barrier diffusion coefficient of $10^{-4} \mathrm{~cm}^{2} / \mathrm{s}$. 
Table 6.1 Transport Parameters for the base case

\begin{tabular}{|ll|l|}
\hline Parameter & Value \\
\hline Diffusion Coefficient: & Soil & $10^{-2} \mathrm{~cm}^{2} / \mathrm{s}$ \\
\hline & Soil/neat cement & $10^{-4} \mathrm{~cm}^{2} / \mathrm{s}$ \\
\hline
\end{tabular}

To determine the effect of the barrier diffusion coefficient on release, the base case was modified by increasing the barrier diffusion coefficient by a factor of 10 to $10^{-3} \mathrm{~cm}^{2} / \mathrm{s}$. This value is expected to be more representative of the soil/neat cement barrier It is in the middle of the range of measured radon diffusion coefficients through residential concretes ${ }^{24}$. In this case, predicted concentrations at the monitoring well at 14.6 days reached a maximum normalized concentration of $7 \times 10^{-6}$ and averaged more than $10^{-6}$. This exceeds the design basis concentration.

\subsection{Effect of a breach on projected release from the barrier}

To determine the effect of a small breach in the barrier a $5-\mathrm{cm}$ hole was simulated as having the same properties as the soil, diffusion coefficient of $10^{-2} \mathrm{~cm}^{2} / \mathrm{s}$. This hypothetical hole in the barrier was located at an elevation of $1.8 \mathrm{~m}$ from the bottom of the modeled domain, 0.8 $\mathrm{m}$ higher than the source. The total distance from the source to the edge of the hypothetical hole in the barrier is $1.8 \mathrm{~m}$. The results of this analysis at 14.6 days after the start of the injection, Figure 6.7, indicate that the breach has a pronounced effect on the tracer plume. Streaming through this $5-\mathrm{cm}$ breach is clearly evident. The peak normalized concentration at the well is 4 $\times 10^{-6}$. Average normalized concentrations along the lower section of the well are above $10^{-6}$, a three order of magnitude increase over the projected concentration for the intact wall. In fact, the projected concentrations at the monitoring well for the $5-\mathrm{cm}$ hole simulation was of the same order of magnitude as the case with the barrier diffusion coefficient increased an order of magnitude over the base case value.

In all three cases, the tracer plume within the region bounded by the subsurface barrier is almost identical. Average concentrations in this region are approximately $10^{-3}$, four orders of magnitude larger than at the monitoring well location for the case with a barrier breach. This indicates that only a small fraction of the tracer reaches the monitoring wells under the conditions simulated. In fact, after 14 days more than $99 \%$ of the tracer injected is retained in the subsurface barrier region.

The simulated hole size was varied from $1-10 \mathrm{~cm}$ and the results were similar. Even a $1 \mathrm{~cm}$. hole would permit the normalized concentration of PFT tracer that reaches monitoring well to exceed the base case (an intact barrier) value by $2-3$ orders of magnitude in the early stages (i.e. before diffusion through the barrier becomes an important source at the wells). The large increase in predicted release due to a small breach indicates that resolution of breaches on the order of a centimeter is theoretically possible. 
In the field experiment, a breach would be indicated if the measured concentrations in one of the external monitoring wells differed from the others by a several orders of magnitude . Relatively uniform concentrations at each of the monitoring wells indicates that a breach has not occurred.

\subsubsection{Comparison of experimental results with model predictions}

To test the concept of monitoring barrier performance with PFT's, PMCH was continually injected for three days into the area contained by the soil/neat cement barrier, just beneath the empty tank at the center of the region bounded by the cone. Seven monitoring wells were located parallel and approximately 1 meter outside of the barrier. The wells are designated by compass direction, i.e, $\mathrm{N}$ for North, NE for Northeast, etc. The eighth well at the location designated as West was unusable. Samples for PMCH were taken from each well beginning three days from the start of injection. Daily sampling occurred between 6 and 17 days except for Saturdays and Sundays.

PMCH concentrations within the region bounded by the barrier were measured during the three-day injection period The data showed a net drift toward one side of the barrier. Interior monitoring well $\mathrm{N}$ had measured concentrations approximately one order of magnitude greater than the interior well $\mathrm{S}$. If diffusion was the only transport mechanism, the concentrations at these two wells which are equidistant from the source, would be equal. Therefore, advection is occurring. The cause of this net drift is not known, however, it has been postulated that it is due to the injection flux $\left(0.2-0.25 \mathrm{~cm}^{3} / \mathrm{s}\right)$. The fact that there is a drift indicates that the exterior concentrations in wells near the north side, should exceed those on the south side by an order of magnitude provided the barrier is intact (i.e., no breach)

The time evolution of measured concentration normalized to the injection concentration at the seven monitoring wells is displayed in Figure 6.8. Each of the monitoring wells shows similar behavior over time. The spread in the measured concentrations is approximately one order of magnitude and this is consistent with the internal well monitoring data, (i.e., highest concentrations are measured on the North side of the facility). The drop in concentration between the inner and outer monitoring wells (i.e., across the barrier) was approximately four orders of magnitude at the end of the injection period of three days. There was no evidence of a substantial breach in any region.

The concentrations displayed in Figure 6.8 are all normalized to the initial injection concentration of $373 \mathrm{ppm}$. The actual measured PMCH concentrations are in the range of a hundred parts per trillion (normalized concentration of $3 \times 10^{-7}$ ) to parts per trillion (normalized concentration of $3 \times 10^{-9}$ ).

To estimate diffusion coefficients in the soil and the barrier, prospective model evaluations were performed. The computational model is similar to the one described to examine the influence of a breach in the barrier, Figure 6.3, with the exception that the dimensions were 
Tracer Experimentally Measured Normalized Concentrations versus Time

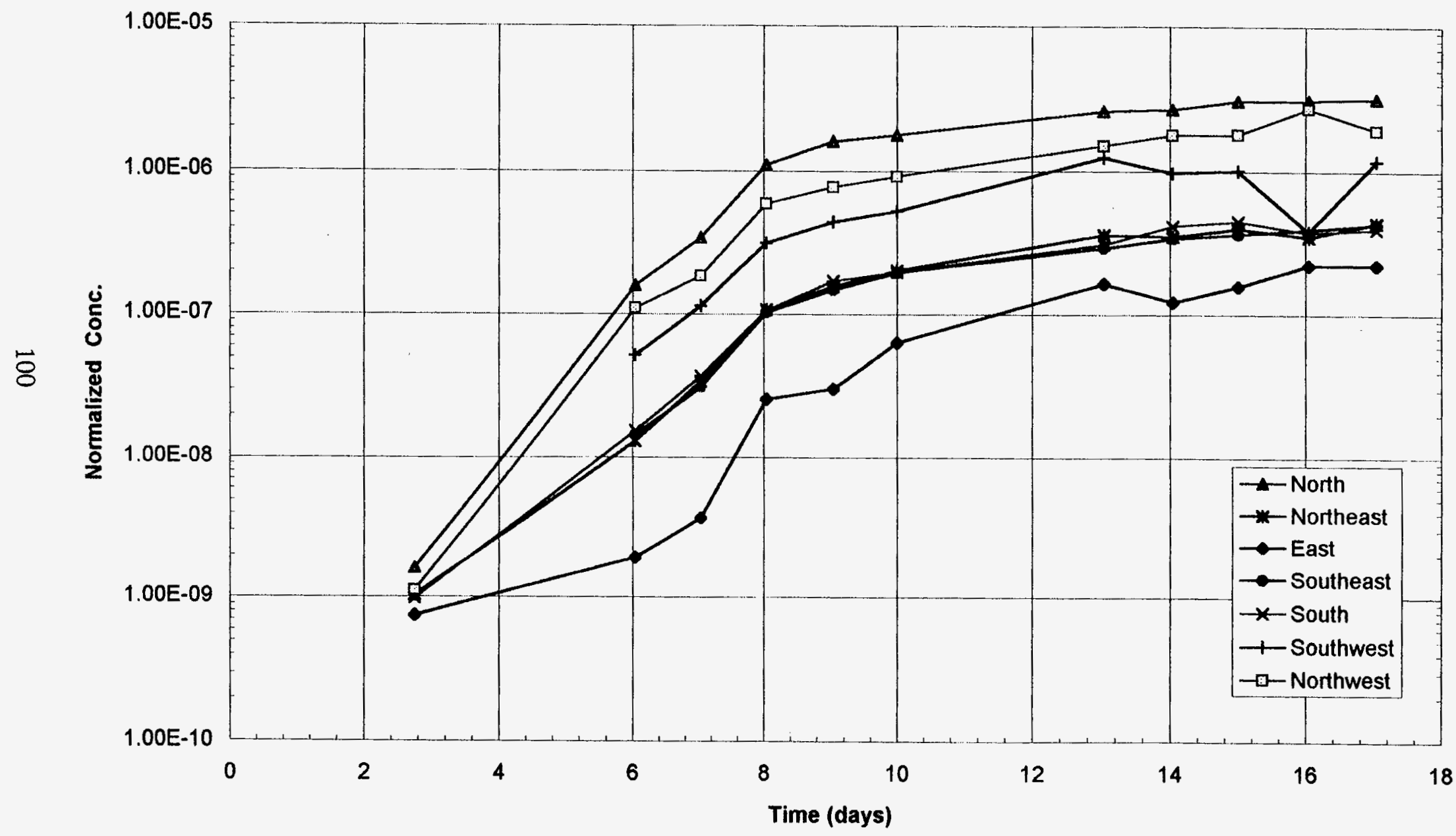

Figure 6.8 Time history of normalized PFT concentration in the seven exterior wells. 
changed to match the as-built dimensions and the source location was changed to reflect the experimental conditions. The major change in input involved increasing the barrier thickness to 1.15 meters and adjusting the location of the source to directly under the simulated waste tank.

The base case diffusion coefficient estimated values, $D_{\text {soil }}=10^{-2} \mathrm{~cm}^{2} / \mathrm{s}$ and $D_{\text {wall }}=10^{-4}$ $\mathrm{cm}^{2} / \mathrm{s}$, provided concentration estimates that were far lower than the measured value. This was expected because the base case values were chosen with the intent of under predicting the amount that would reach the wells to insure that detection would be possible.

A range of different values of the diffusion coefficients was simulated. The results have been compared to the measured average normalized concentration value of the seven monitoring wells and are displayed in Figure 6.9. From these evaluations, the soil diffusion coefficient for the PFT has been determined to lie between $1-5 \times 10^{-2} \mathrm{~cm}^{2} / \mathrm{s}$ under the test conditions. The diffusion coefficient for the soil/neat cement barrier has been determined to lie between $1-5 \mathrm{x}$ $10^{-3} \mathrm{~cm}^{2} / \mathrm{s}$. The best fit was obtained using a soil diffusion coefficient of $2 \times 10^{-2} \mathrm{~cm}^{2} / \mathrm{s}$ and a barrier diffusion coefficient of $2 \times 10^{-3} \mathrm{~cm}^{2} / \mathrm{s}$. Attempts to improve the fit by regression analysis or other statistical techniques have not been undertaken. At this time, it is felt that due to the net drift exhibited during injection, diffusion was not the only process leading to transport during the injection phase. Therefore, fine tuning the estimate would have little meaning within the limits of the data and its interpretation (i.e., diffusion controlled process).

\subsection{Modeling transport through the close-coupled system}

After completion of the $\mathrm{PMCH}$ tracer testing for the soil/neat cement barrier, a polymer grout liner was injected on the interior of the barrier to further reduce the potential for transport. Another set of tracer tests were conducted using ocPDCH. In this experiment ocPDCH tracer was injected beneath the buried tank for three days at an injection concentration of $30 \mathrm{ppm}$. The nominal injection rate was $15 \mathrm{~cm}^{3} / \mathrm{min}$.

Test data for the first seventeen days after injection of ocPDCH tracer has been collected and analyzed. The measured data for the first three days is substantially different than that found in the previous test (i.e., when the polymer liner was not present). The normalized internal well concentrations are two orders of magnitude lower (i.e. $10^{-4}$ as compared to $10^{-2}$ ) and external concentrations are approximately two orders of magnitude higher (i.e. $10^{-7}$ as compared to $10^{-9}$ ) when the liner is present. The low concentrations measured in the internal well are not consistent with mass balance calculations which indicate internal normalized concentrations should be around $10^{-2}$. The high concentrations at the external wells are not consistent with diffusion being the dominant transport mechanism.

The cause for this behavior is unknown but may be due to the monitoring techniques which differed between the first and second set of tests. In the first test, interior monitoring wells had a solid end and were slotted over a two foot range near the bottom of the pipe. In the second set of tests, the bottom of the pipe used for the monitoring well was open and it was speculated that 


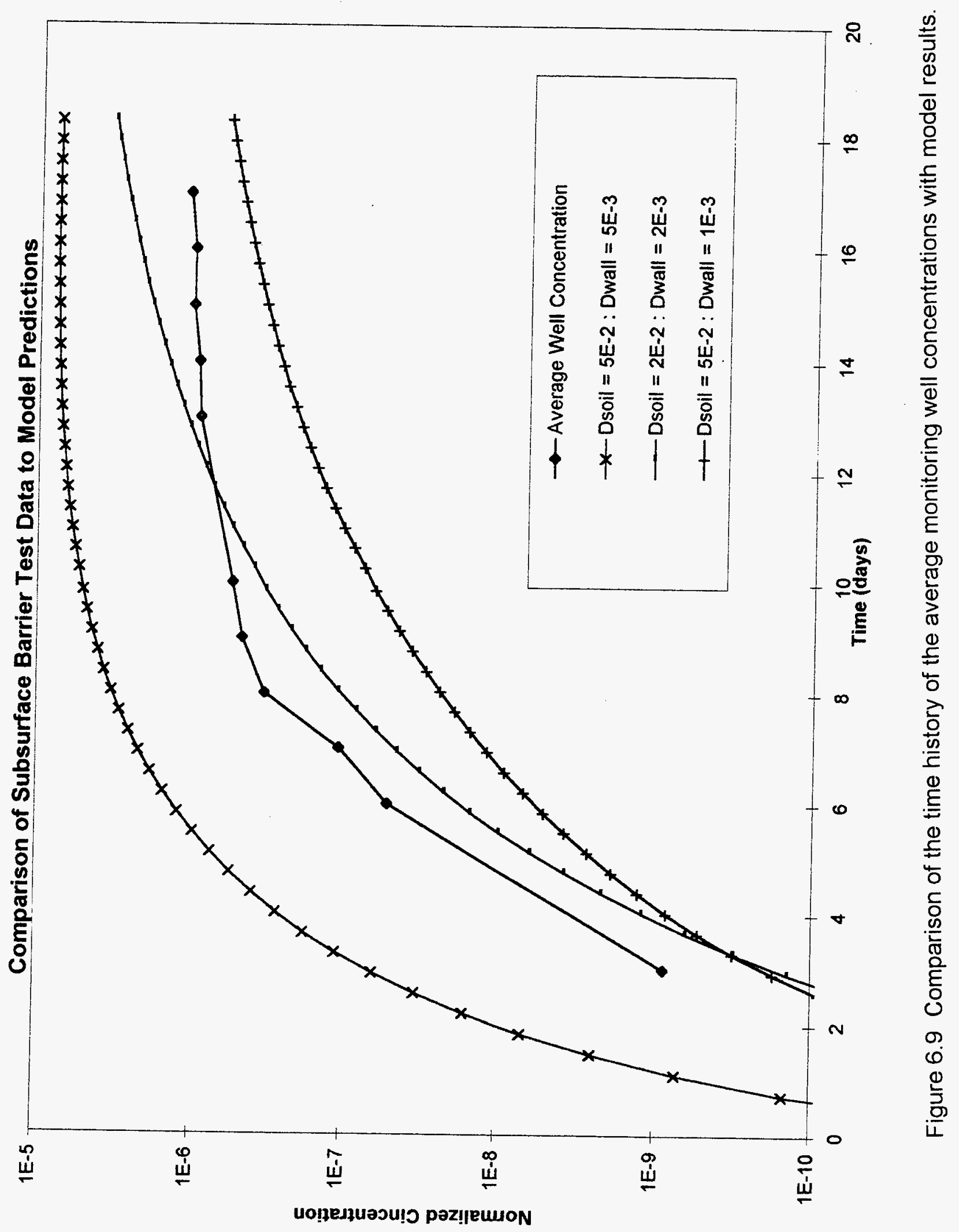


it may have been partially clogged during emplacement. This would lead to improper mixing in the pipe and lower concentrations. Other possibilities include improper sampling (i.e. neglecting to purge the lines prior to sampling, neglecting to purge the sample collectors, obtaining contaminated samples, or other experimental errors). However, after review of the sampling plan and discussion with the staff that conducted the sampling, it is believed that appropriate sampling procedures were followed.

In addition, sampling along the length of the external monitoring wells was accomplished by inserting a bundle of tubes of differing length inside of the monitoring well. Figure 6.10 shows the top of the bundle of copper sampling tubes inserted into the well. Figure 6.11 shows the addition of sand to fill the void space of the monitoring well and thereby isolating the different sampling tubes from each other. Vertical profiling of the external wells indicates relatively uniform concentrations in the north and northwest wells. While the concentrations in the other wells peak at the bottom of the wells ( $28 \mathrm{ft}$ depth in the plane parallel to the wells). Peak concentrations in the north and northwest wells are a factor of five greater than in the other wells.

A finite-element representation of the subsurface barrier system containing a soil/neat cement outer barrier and a polymer liner has been developed. Several geometries have been considered including:

a) the polymer liner as designed covering all but the top five feet of the soil/neat cement barrier, contact between the liner and the concrete barrier was assumed;

b) the polymer forming a cone at the bottom of the facility with the top of the polymer barrier $1 \frac{1 / 2}{\mathrm{ft}}$ beneath the tank, contact between the liner and the concrete barrier was assumed, and

c) the geometries in a and b with a four inch gap between the polymer liner and concrete barrier.

Model results based on the best fit diffusion coefficients for the soil and soil/neat cement region and an assumed polymer liner diffusion coefficient of $2 \times 10^{-4} \mathrm{~cm}^{2} / \mathrm{s}$ (a factor of 10 less than in the cement grout) were obtained. The results were unable to satisfactorily duplicate the measured data for the first three days. Model results were much higher (several orders of magnitude) in the region near the injection point, consistent with the mass balance. Model results were consistent with the results of the previous experiment. In the external monitoring wells, model results were generally at least an order of magnitude lower than measured results and the peak concentrations were located at the shortest distance between the source and monitoring wells in the middle region of the wells. Model predictions indicated a two order of magnitude variation in concentration along the length of the well as compared to the relatively uniform concentrations found experimentally. The fact that the measured concentrations were inconsistent with the previous test casts suspicions on the quality of the data. 


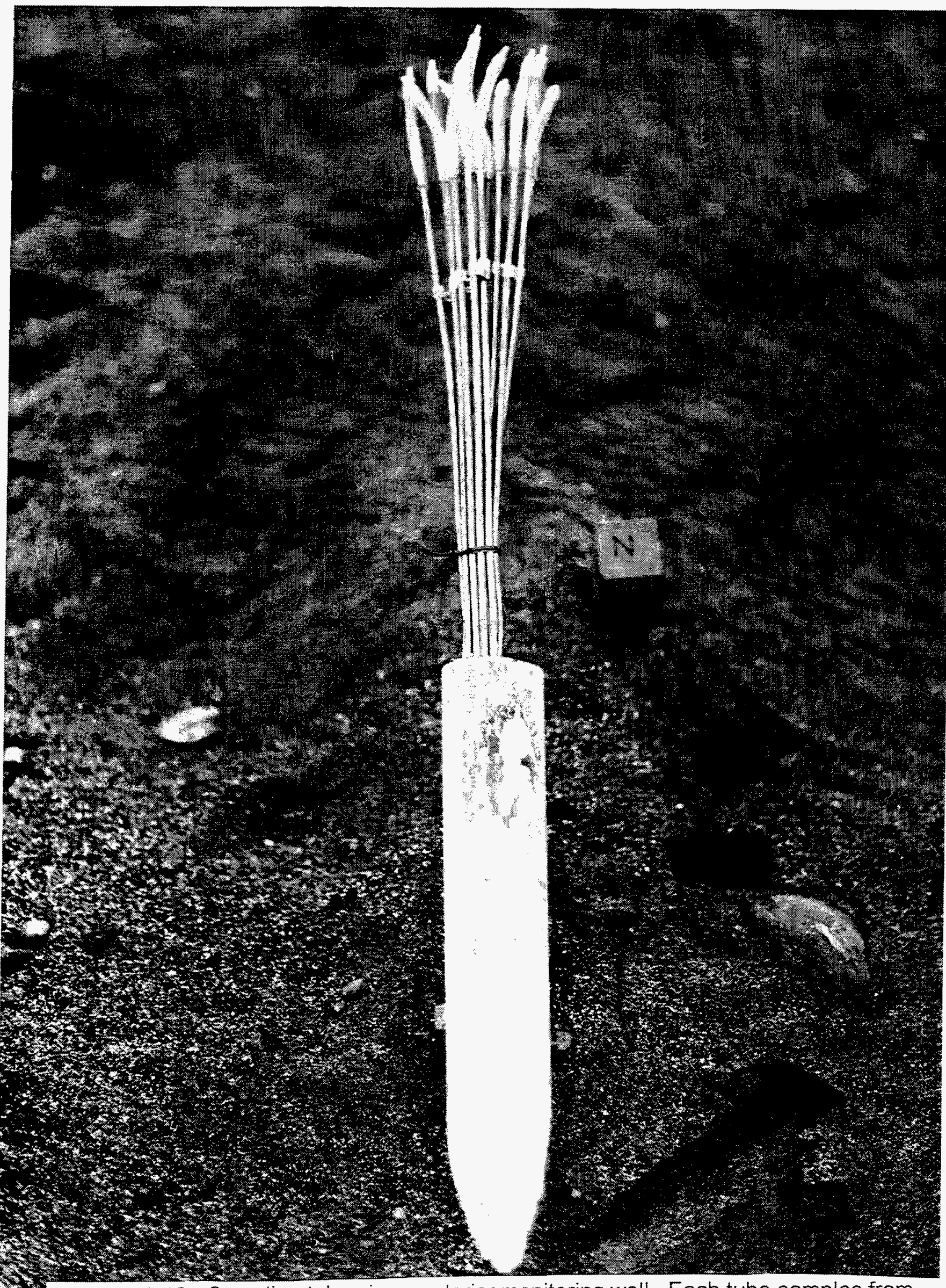

Figure 6.10 Sampling tubes in an exterior monitoring well. Each tube samples from a different depth. 


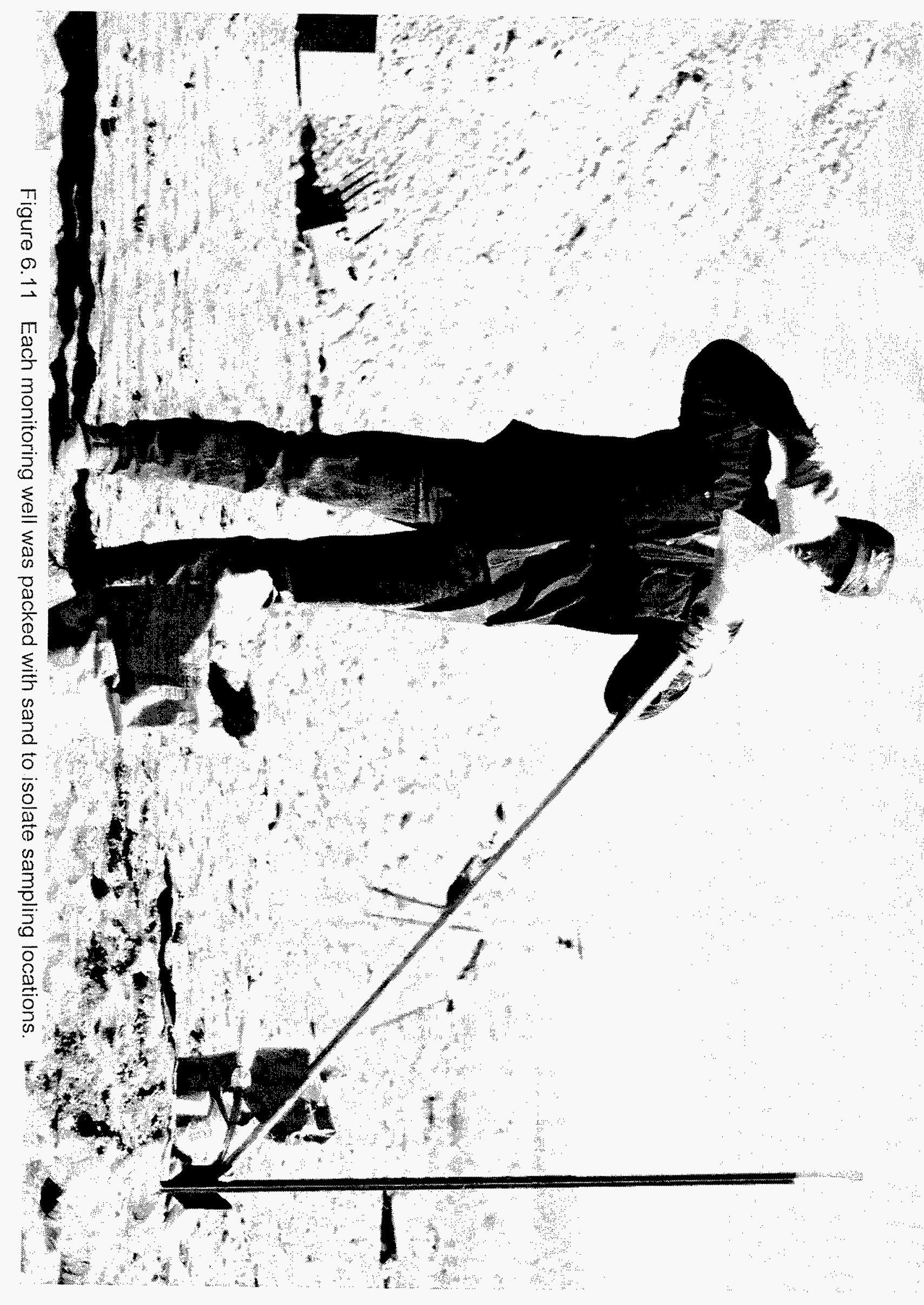


Data was collected nine and seventeen days after the start of the injection of ocPDCH. This data is more consistent with the previous data collected on the soil/neat cement barrier and modeling projections. At these times, the normalized concentrations at the exterior wells were one or two orders of magnitude lower when the polymer liner was present. This would be consistent with the liner providing an additional barrier to release. In addition, there was a net drift from east to west. The tracer ocPDCH was not detected after nine days in the east well, was detected at only one depth in the northeast well, and was detected at low normalized concentrations $\left(<10^{-8}\right)$ in the southeast well. Wells in the northwest, south and southwest had peak normalized concentrations near $2 \times 10^{-7}$. Peak normalized concentrations at all wells are displayed in Table 2. From this table it is clear that concentrations at the monitoring wells are increasing by one to two orders of magnitude over this time frame of nine to seventeen days after injection. This is consistent with model projections. Recall that the data after three days indicated external well concentrations on the order of $10^{-7}$. There is no readily explainable physical mechanism that would cause the concentration to raise to this level after three days, fall by one or two orders of magnitude by nine days and then increase by one or two orders of magnitude after 17 days. This casts further suspicion on the quality of the data collected during the first three days.

Due to the questionable quality of the data collected over the first three days, no attempt was made to compare model projections to measured concentrations over the seventeen day time period. The lack of interior well data causes problems in interpreting the long term data and the net drift towards the west indicated that advection was occurring.

Measurements for the PFT PMCH were also made. This tracer was injected in October. Two weeks after the start of the test (beginning of November) the normalized concentrations were $10^{-6}$ to $10^{-7}$. During March, PMCH was detected in all wells and the normalized concentrations had decreased by approximately two orders of magnitude to values near $10^{-8}$.

Data was taken at two foot intervals in each of the exterior sampling wells. These wells were installed parallel to the sloping grout barrier at an angle of 45 degrees relative to the ground surface. Therefore, the depth below grade can be obtained by multiplying the distance along the well by 0.707 ( $\cos (45))$. For instance, the 20 foot location is at a depth of 14.2 feet. No definite trends in the data with respect to depth were apparent. Concentrations would change by as much as a factor of five over a two foot change in location. In addition, low values would be adjacent to higher values. It appeared that higher concentrations were located near the bottom of the wells (22 - 26 foot range) and lower concentrations near the ground surface. However, this was not always the case. 
Table 6.2 Peak Normalized Concentrations of ocPDCH after the three day injection beginning on March 3

\begin{tabular}{|l|l|l|l|l|}
\hline Well Location & $\begin{array}{l}\text { Peak Normalized } \\
\text { Concentration 3/12 }\end{array}$ & $\begin{array}{l}\text { Distance along } \\
\text { the well }\end{array}$ & $\begin{array}{l}\text { Peak Normalized } \\
\text { Concentration 3/20 }\end{array}$ & $\begin{array}{l}\text { Distance } \\
\text { along the well }\end{array}$ \\
\hline East & BDL & & BDL & \\
\hline North & $6.1 \mathrm{E}-9$ & 28 & $4 \mathrm{E}-8,3.1 \mathrm{E}-8$ & 8,18 \&24 \\
\hline Northeast & BDL & & $2.8 \mathrm{E}-8$ & 20 \\
\hline Northwest & $3.15 \mathrm{E}-8$ & 20 & $2.1 \mathrm{E}-7$ & 26 \\
\hline South & $2.6 \mathrm{E}-9$ & 28 & $1.4 \mathrm{E}-7$ & 24 \\
\hline Southeast & $3.1 \mathrm{E}-9$ & 14 & $8.1 \mathrm{E}-9$ & 20 \\
\hline Southwest & $4.1 \mathrm{E}-8$ & 24 & $2.2 \mathrm{E}-7$ & 22 \\
\hline
\end{tabular}

Upon completion of the PFT injection tests for the close-coupled barrier system, the soil surrounding the barrier was excavated. Visual inspections of the close-coupled barrier confirmed that a breach did not occur in either the soil/neat cement or polymer components of the barrier . The soil/neat cement barrier had a relatively uniform thickness. Due to the emplacement techniques the polymer liner ranged from $15-30 \mathrm{~cm}$.

\subsubsection{Conclusions}

A successful proof-of-concept demonstration that PFT's can be used as a method for monitoring barrier performance was performed on a simulated waste pit at Hanford. Field scale experiments were conducted, the data collected and analyzed. The results support the feasibility of detecting tracers outside of the barrier on the time frame of a few days or weeks for intact barriers.

Modeling of transport of PFT tracers in a subsurface system consisting of soil and a soil/neat cement barrier has been conducted Numerical estimation of the movement of the gas tracer is required because of the complex geometry presented by sloping walls, the presence of wastes, the potential for small breaches, and the dissimilar transport properties in the different materials (soil, cement grout, and polymer). The simulations indicate that for the base case, a two order of magnitude difference in the PFT diffusion coefficient in the soil and barrier, small holes (on the order of $\mathrm{cm}$ ) should be easily detectable. As the difference in diffusion coefficients of the soil and barrier decreases, the ability to detect small holes also decreases.

Site-specific data on transport parameters were not available. Therefore, the model evaluations were compared to the experimental data and used to estimate the diffusion coefficient for the PFT through the soil and barrier. The best fit to the data indicates that the soil diffusion 
coefficient is approximately $2 \times 10^{-2} \mathrm{~cm}^{2} / \mathrm{s}$ and the barrier diffusion coefficient of $2 \times 10^{-3} \mathrm{~cm}^{2} / \mathrm{s}$. These values are in the range of expected values based on diffusion coefficients of other gases through soil systems.

The fact that the barrier emplacement was successful in that no large scale breaches were formed prevented field-scale demonstration of the accuracy of PFT's in defining a breach. Model evaluations indicate the feasibility of locating breaches down to a few $\mathrm{cm}$ in size. However, experimental verification of this concept is needed. It is recommended that tests be performed on subsurface barriers with pre-formed breaches of known location, size, and geometry. In addition, work should be done for partial breach failure (e.g. a region with half-the thickness of the barrier) to simulate improper grouting. These types of tests are needed to permit demonstration of the resolution that can be obtained by using PFT's and build confidence in the ability to understand, monitor, and predict the behavior of subsurface barriers.

More experience is needed in the application and development of simulation models used to estimate the size and location of potential small scale breaches or barrier imperfections for realistic geometries and on the field scale. Areas with unresolved issues include: transport parameter estimation, breach location and size determination, the role of advection on transport, estimation of spacing requirements between PFT monitoring locations that are needed to define a breach, inverse modeling to define a breach, the role of small scale heterogeneities and experimental uncertainties in influencing estimates of breach location and the role of simultaneous use of different PFT tracers to evaluate barrier performance.

\subsection{Using Ground Penetrating Radar to Access the Subsurface Barrier}

Allied Signal approached SNL and suggested using their ground penetrating radar (GPR) unit to map the barrier after installation. This section briefly describes the field test performed by Allied Signal at the Hanford barrier site.

\subsubsection{Purpose}

The purpose of this demonstration was to determine the effectiveness of GPR in mapping subsurface features for consideration in future barrier work.

\subsubsection{Technology Need}

GPR provides a technique for verifying the installation, location and ideally the continuity of an emplaced subsurface grout barrier. GPR is able to do this without disturbing the subsurface.

\subsubsection{Technology Benefits}

The expected benefits from GPR include: 1) a non-intrusive method of observing the subsurface, and 2) a 3-dimensional image of the grout form. 


\subsubsection{Technology Description}

GPR has been used to locate subsurface features such as old mine tunnels and buried waste $^{26}$. GPR involves towing a radar antenna across a site along a set of grid lines spaced about one half meter apart. The transmitted radar is reflected back to the surface where a receiver picks up the perturbed signal. The received signal is used to map the subsurface. Formation features including water, rock, soil, plants, and buried man-made items result in either reflections which are recorded by the receiving antenna or absorption of the radar signal which results in an weak reflection of the radar signal. These changes in radar signal are used to identify and map the subsurface. GPR is particularly prone to interference from metallic objects.

\subsubsection{Scope}

Allied Signal's Kirtland Operations would produce an image of the subsurface barrier using GPR after installation was completed. This would include;

- $\quad$ employing a GSSI Model SIR-10A GPR system with both 100 and $300 \mathrm{Mhz}$ antennas

- determining the 3-dimensional extent of the barrier, and

- Characterizing the integrity of the barrier

\subsubsection{Objectives}

The primary objective of the GPR demonstration is to determine the resolution limits of the technique. The following criteria would be used to determine demonstration success:

1) The technology should be able to assess appropriate locations and sizes of breaches or discontinuities in the barrier.

2) The technology must be capable of providing a 3-dimensional scaled image of the installed barrier.

\subsubsection{Results and Conclusions}

A letter report on the ground penetrating radar (GPR) survey of the Hanford site was prepared by Allied Signal Federal Manufacturing \& Technologies which details the survey and provides the data analysis ${ }^{27}$. The GPR unit used was from Geophysical Survey Systems, Inc. and was operated at 100 and $300 \mathrm{MHz}$. The Allied report includes one variable density plot of a section of GPR data collected over the outer portion of the barrier. They were unable to obtain data in the center of the barrier due to interference from the metal tank. The reports' authors concluded: 
"The data example clearly shows each individual grout injection. It clearly shows both layers of 21 injections."

The actual number of holes drilled was 120 ( 60 for each layer). The barrier is $12.5 \mathrm{M}$ (41ft) in diameter and the holes were placed at $6^{\circ}$ intervals $[0.6 \mathrm{M}(2 \mathrm{ft})$ on centers]. It is believed that Allied used 42 columns as the number originally given to them by the contractor. This corresponds to the number of columns that would be used for one pass, not two, if the columns were placed one meter ( $3 \mathrm{ft}$ ) on centers. The contractor originally hoped to use one meter which would save time, but as a precaution this was reduced to $0.6 \mathrm{M}$. Allied must have misinterpreted this to mean 42 columns total or 21 per layer. They appear to have fit the interpretation of the GPR data to fit the construction blue prints rather than try to reproduce the barrier shape from their data.

"The data, as presented in the Allied report, do not appear to be useful for verification and it is our belief that the individual columns were not clearly defined. The report lacked a discussion on the data processing and display format in addition to a detailed discussion on the features in the data. The test of GPR at the Hanford site was also made less than optimal by the large metal storage tank, which presumably would cause significant interference to or loss of the GPR signal. We do feel however, that GPR can be a useful tool to determine the horizontal extent of grout injections and may also be suited to finding gross deficiencies in a barrier (i.e., a missing column injection). This would allow some real time $\mathrm{QC}$ checking of the grouting process. The failure to produce useful information at the Hanford site serves only as a caution that GPR is a limited tool and should not preclude its use in subsurface barrier technology. It would be interesting to backfill the barrier and re-survey with GPR in the absence of interference from the steel storage tank. 


\subsection{IMPLEMENTATION OF CLOSE-COUPLED BARRIER TECHNOLOGY AT THE BROOKHAVEN NATIONAL LABORATORY CHEMICAL/GLASS WASTE PITS}

Following the successful demonstration at Hanford, full-scale implementation of closecoupled barrier technology was performed at BNLs Glass Hole Waste Site. This installation was performed following the same engineering principles as the Hanford barrier with the following alterations; the site is an actual remediation site; a V-trough shape was chosen to eliminate the excessive grout usage at the apex of the cone-shaped barrier; the barrier was designed for interim (3-5 years) containment which allowed the use of a shorter lifetime hence, more economical polymer grout for the primary layer; and following the barrier installation the pit contents were solidified using the same jet grouting equipment. These design modifications and additions are detailed later in this section.

During the 1960's through the early 1980's, an area designated as the AOC $2 \mathrm{C}$ glass pits was used for the disposal of laboratory wastes (contaminated glassware and laboratory chemicals). In response to detection of contaminants in the soil and groundwater below these pits, site evaluations and development/demonstration tasks are being conducted to determine safe and cost effective remediation technologies for closure of AOC $2 \mathrm{C}$. This project developed and demonstrated a technology capable of effective remediation of the glass pits: interim geotechnical isolation as a precursor to removal.

After successful demonstration of this isolation concept at the Brookhaven National Laboratory site, the technology is ready for immediate application by end users. This demonstration constitutes the requirements for commercialization of the technology. The majority of field actions will be completed by private industry collaboration.

The uncertainty of remediation and the cost of remediation is significantly reduced by using the stabilization and isolation technology demonstrated by this task. Additionally, closure operations have significantly higher safety performance as compared with alternative ex situ and in situ remediation actions.

The project was again a collaborative effort involving several participants. Funding was provided mainly by DOE EM-50 through TTPs CH36LF52 (Environmental \& Waste Technology Center, BNL) and AL27SS21 (Mixed Waste Landfill, SNL). EM-50 contributions provided for engineering, construction and evaluation/verification of the barrier and solidification of the pit waste. BNL's Office of Environmental Restoration provided funding for health physics support, on-site logistics and services (e.g., water tanker) and monitoring well installation (Geoprobe and crew). WHC provided the polymer grout in a mutually beneficial waste to resource transaction which is described later. Geochemical Corp. provided technical assistance in evaluating the polymer grout. AGEC, Inc. performed the grouting through a contract with SNL. This section describes the demonstration installation and verification and the solidification of the pit wastes via in-situ jet grouting. The latter was an addition to the project and was brought about by the collaborative demonstration with INEEL described earlier. 


\subsection{Purpose}

The primary objective of this project was to demonstrate at a field-scale, emplacement of a composite barrier technology capable of containing waste forms within their existing subsurface transport, disposal, or storage structures. The "Glass Pit Remediation Technology Demonstration" task activities provide a technically sound, commercially applicable, safe, and cost effective system, methodology and equipment, to safely contain solid waste disposal pits/trenches containing glass and laboratory reagents and other unknown waste materials. Upon successful completion of this project, the technology is now available for commercial use.

The secondary objective of this project was to provide a demonstration barrier for integrity verification technologies. The barrier may serve as a potential test site for verification studies (e.g., PFT technologies and geophysical survey techniques).

\subsection{Need}

Contaminated soils and buried waste, treated and untreated, pose a threat through contaminant transport to groundwater or back to the surface. Nearly every hazardous waste site contains buried waste constituents that, if left untreated, may eventually become mobile in the environment. In many instances this may result in unacceptable human health and environment exposures. Caps are used to prevent or minimize the percolation of atmospheric water into and through the vadose zone. These caps do not prevent migration of contaminants from the waste area. Volatile species can diffuse horizontally and it has been shown that soils beneath clay caps can have significant moisture content. The moisture increases soil diffusivity and may increase the migration of contaminants toward the boundary of the cap where percolating atmospheric water can transport the contaminants to the groundwater. Subsurface containment barriers will improve remediation performance by removing pathways for contaminant transport due to water infiltration, vapor- and gas-phase transport, transpiration, etc.

A subterranean barrier will increase the performance of the waste storage site and reduce the possibility of contaminant migration into local geologic media or groundwater. Failure to treat contamination in situ will also result in exorbitant restoration costs at a later date. In addition, the legal ramifications for not treating many of these waste sites could be detrimental to the responsible parties.

On May 14, 1996 a public meting of the Community Work Group was held at Brookhaven National Laboratory. Bill Gunther and Jim Brower from the BNL Office of Environmental Restoration presented remediation options being considered for the treatment of the Chemical/Glass Hole pits at BNL. John Heiser attended as a technical expert to answer specific questions on in-situ treatment technologies, including subsurface barriers and in-situ stabilization. The in-situ technologies were to be demonstrated and the performance of these technologies evaluated prior to making a final decision on treatment of the 50 pits. In-situ treatment technologies were presented as alternatives to excavation. The community appeared to welcome 
the additional choices of remediation. All members of the work group were invited to attend the demonstrations that summer.

Letters of interest in subsurface barrier technologies, and in particular interest in the goals of this and the previous related barrier demonstrations where obtained from INEEL, BNL and Sandia. These letters are reproduced in appendix A.

\subsection{Benefits}

The cement/polymer based composite barrier demonstrated by this task is applicable to final, interim, and emergency loss of confinement conditions. The technology is applicable to any buried or surface waste form that has the potential to release mobile contaminants. Unlike many other subsurface barrier technologies, composite barriers are applicable to a wide range of waste materials and geohydrologic conditions. This is extremely advantageous because nearly every waste site has site specific conditions that require the flexibility offered by this technology; more specifically this technology offers an ability to place barrier materials that are compatible with virtually any waste form in almost any geologic setting. This specific project utilizes an economical polymer grout that is designed for interim applications lasting up to five years. Extreme resistivity and low permeability are achieved using the polymer and this layer will last long enough for remediation activities. The barrier acts as a safety net to future remediation efforts (i.e., excavation of the pits).

End users for this technology include any DOE, state or commercial facility that has buried waste that may release contaminants to the environment at unacceptable levels. Specific end users have been identified and include Idaho National Engineering Laboratory (INEEL), Rocky Flats Plant (RFP), and the Hanford reservation. INEEL, and BNL are specifically interested in the full subsurface polymer/cement based composite barrier technology. Letters of support of the demonstration have been obtained from Lockheed Idaho for INEEL and the DOE area office for BNL. Hanford has expressed interest in the use of polymers to form a close-coupled barrier. A method of sealing leaking USTs at Hanford could be developed based on this technology.

\subsection{Technology Description}

The technology is essentially the same as that detailed in Section 5.4. Changes were made in the barrier shape to reduce the amount of redundant grouting that was placed at the apex of the cone-shaped barrier installed at Hanford. While the conic shape worked well enough, the internal volume was severely reduced by excess grout pumped into the apex by the convergence of 60 columns. For this installation a V-trough shape was chosen (see Figure 7.1). The trough was constructed with a cement grout using the column jet grouting technique described earlier. The internal surface of the trough was lined with an acrylate grout (AC-400, described later) forming a close-coupled multi-layered barrier. The polymer grout is an economical one, designed for interim applications lasting up to five years. Extreme chemical/contaminant resistance and low permeability are achieved using the polymer and this layer will last long enough for remediation 


\section{WASTE MATERIAL}

\section{(Glassware, reagent bottles, etc.)}

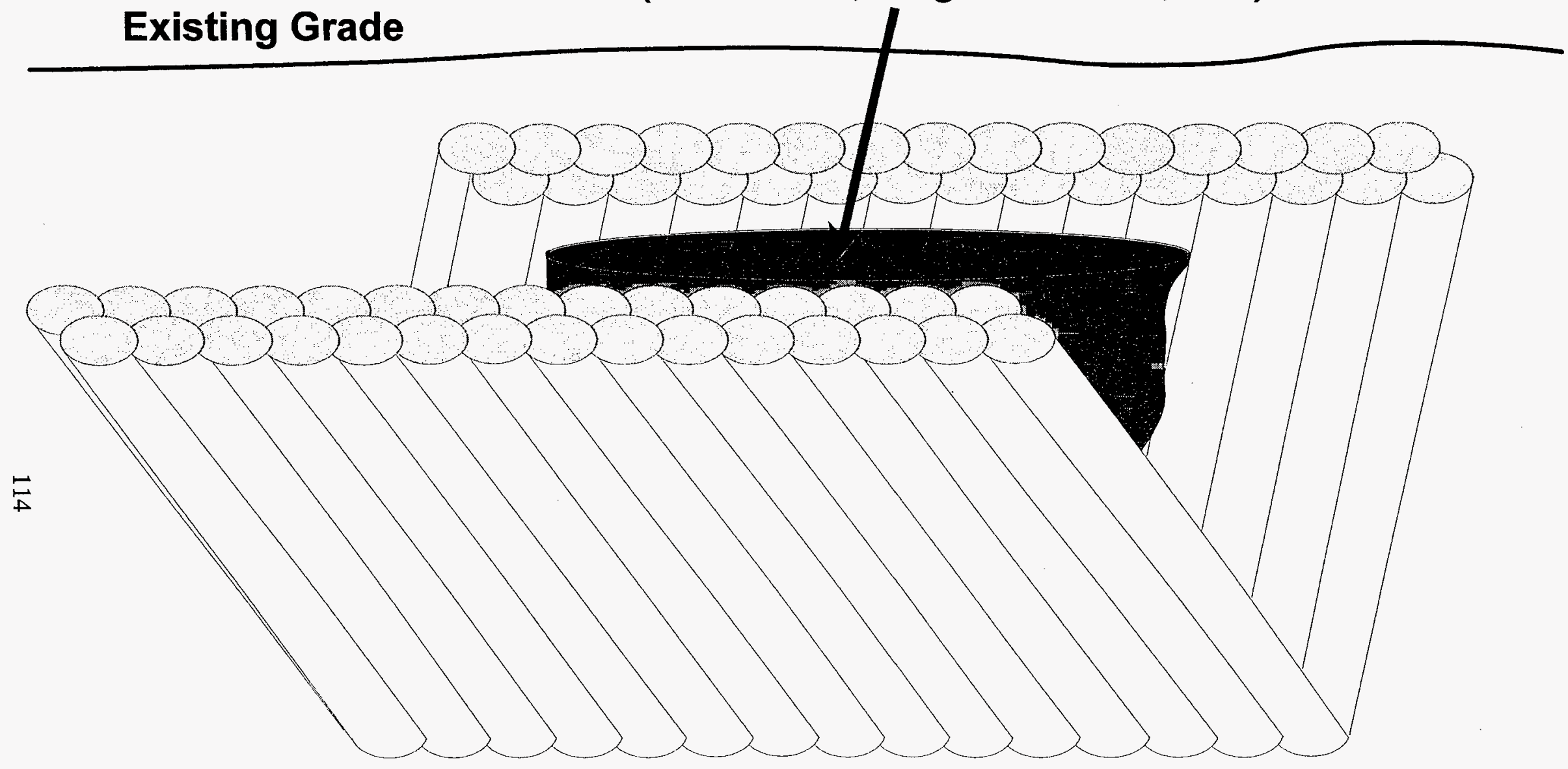

End sections left off for clarity

WATER

TABLE

Figure 7.1 Schematic of V-trough close-coupled barrier. 
activities. After remediation of the waste (assuming the treated waste is left buried in place), the longer-lived cementitous barrier will remain intact and may act as a safety net if the remediation proves faulty in the future.

The outside dimensions of the barrier are: $13 \mathrm{M}(42 \mathrm{ft})$ long, $9 \mathrm{M}(30 \mathrm{ft})$ wide, extends $8 \mathrm{M}(26 \mathrm{ft}$ ) below grade and is $\sim 1 \mathrm{M}(3 \mathrm{ft}$ ) thick (see Figures 7.2 - 7.4). The contained area is: $11 \mathrm{M}(36 \mathrm{ft})$ long, $7.3 \mathrm{M}(24 \mathrm{ft})$ wide, $5.5 \mathrm{M}(18 \mathrm{ft})$ deep. The north and south walls were installed at a 45 degree angle to level. The barrier lies $1.5 \mathrm{M}(5 \mathrm{ft})$ below grade. A layer of overlapping cement columns, having a diameter between 66 and $76 \mathrm{~cm}$ ( 26 and 30in), were placed $0.5 \mathrm{M}$ (21in) on centers with a redundant layer placed behind the first in the same triangular pitch used at Hanford. In a similar fashion vertical end walls were placed, east and west, to finish the trough. Following the cement trough installation a polymer liner was installed along the interior bottom portion of the trough using panel jet grouting. Overlapping panels were laid along the bottom six feet of the trough forming a very-low permeability, chemically resistant zone that had enough volume to contain the entire liquids content of the pit, should all the intact bottles break. The polymer was a two component system and was installed using the dual-fluid injection techniques proven at the INEEL and Hanford demonstrations. Before proceeding with the pit stabilization task the barrier integrity was checked using the PFT technology demonstrated at Hanford. This was a rudimentary check of the cement layer that was performed during the completion of the polymer layer (due to time constraints). The disturbance of the subsurface by the drilling activities limited this verification to determination of gross leakage and no attempt was made at estimating diffusion through the cement layer.

This task development and demonstration activity also prepared stabilized monoliths of mixed geologic media and waste materials. These cell monoliths were prepared for removal and eventual disposal by BNL personnel at a later date The panels were placed by trenching around the pit to a depth of $2 \mathrm{M}(6 \mathrm{ft})$. Plastic sheet pile sections were assembled in the trench and the trench was then backfilled. The internal area bounded by the sheet piling and containing the waste was then solidified using a cement grout applied with jet grouting. Spiral wound tubing (Dywidag) was inserted vertically into the grouted monolith prior to curing, such that the array of tubes outlined $\sim 1.3 \mathrm{M} \times 1.3 \mathrm{M}(4 \mathrm{ft} \times 4 \mathrm{ft})$ cells. The tubing was placed every $0.3 \mathrm{M}(1 \mathrm{ft})$ in the east to west direction and every $0.6 \mathrm{M}(2 \mathrm{ft})$ north to south. These tube would later be filled with a demolition grout to split the monolith into discrete cells. Picking eyes were also placed in each stabilization cell before the materials cured. Upon complete curing of all cells, final retrieval of solidified monoliths containing the stabilized contaminant materials is facilitated by vertical crane withdrawal using the picking eyes in each cell. Each cell monolith can then be containerized, transported and stored, disposed to other facilities, or other actions taken in accordance with Brookhaven National Laboratory closure plans. 
$9 \mathrm{M} / 30 \mathrm{ft}$

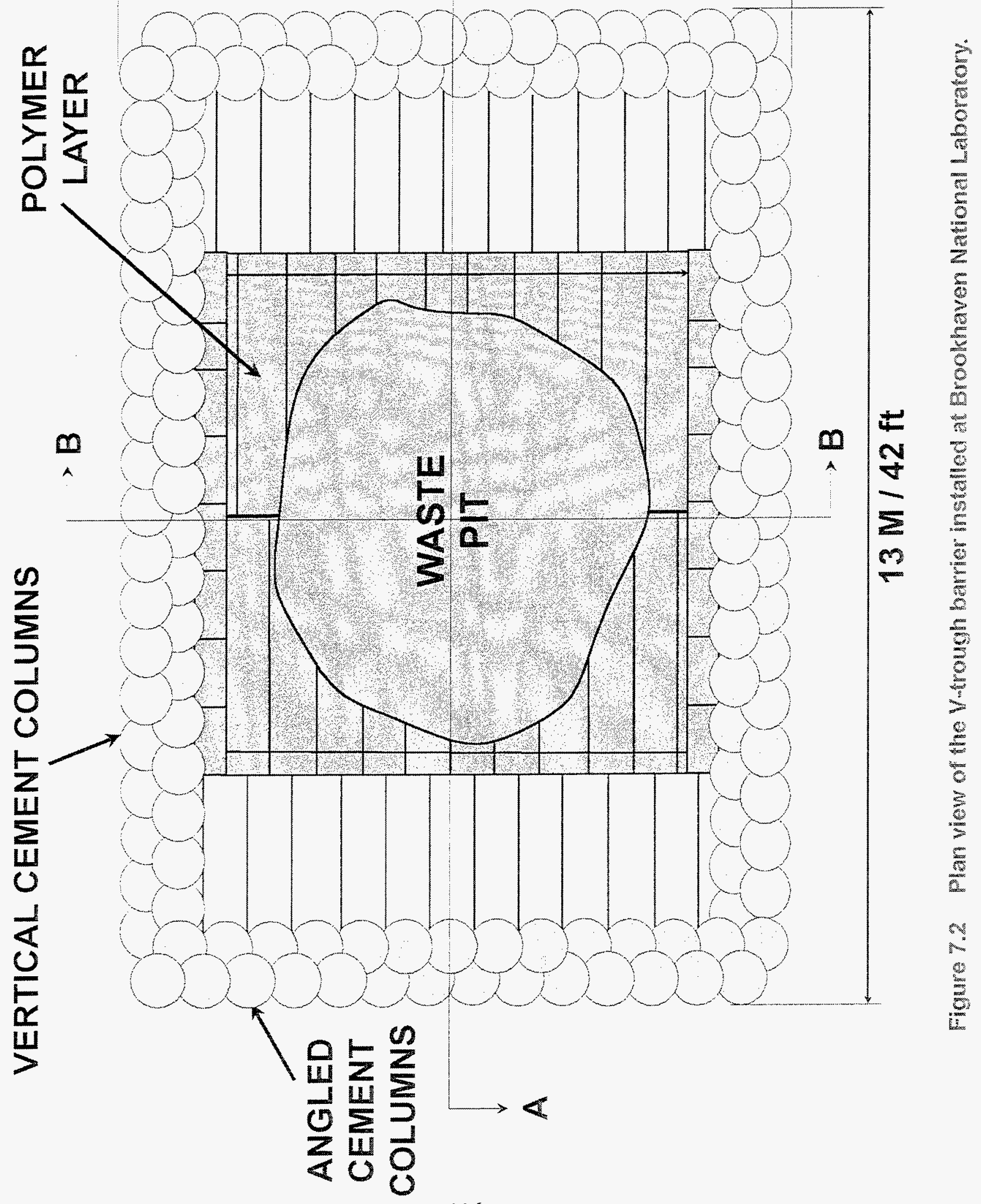



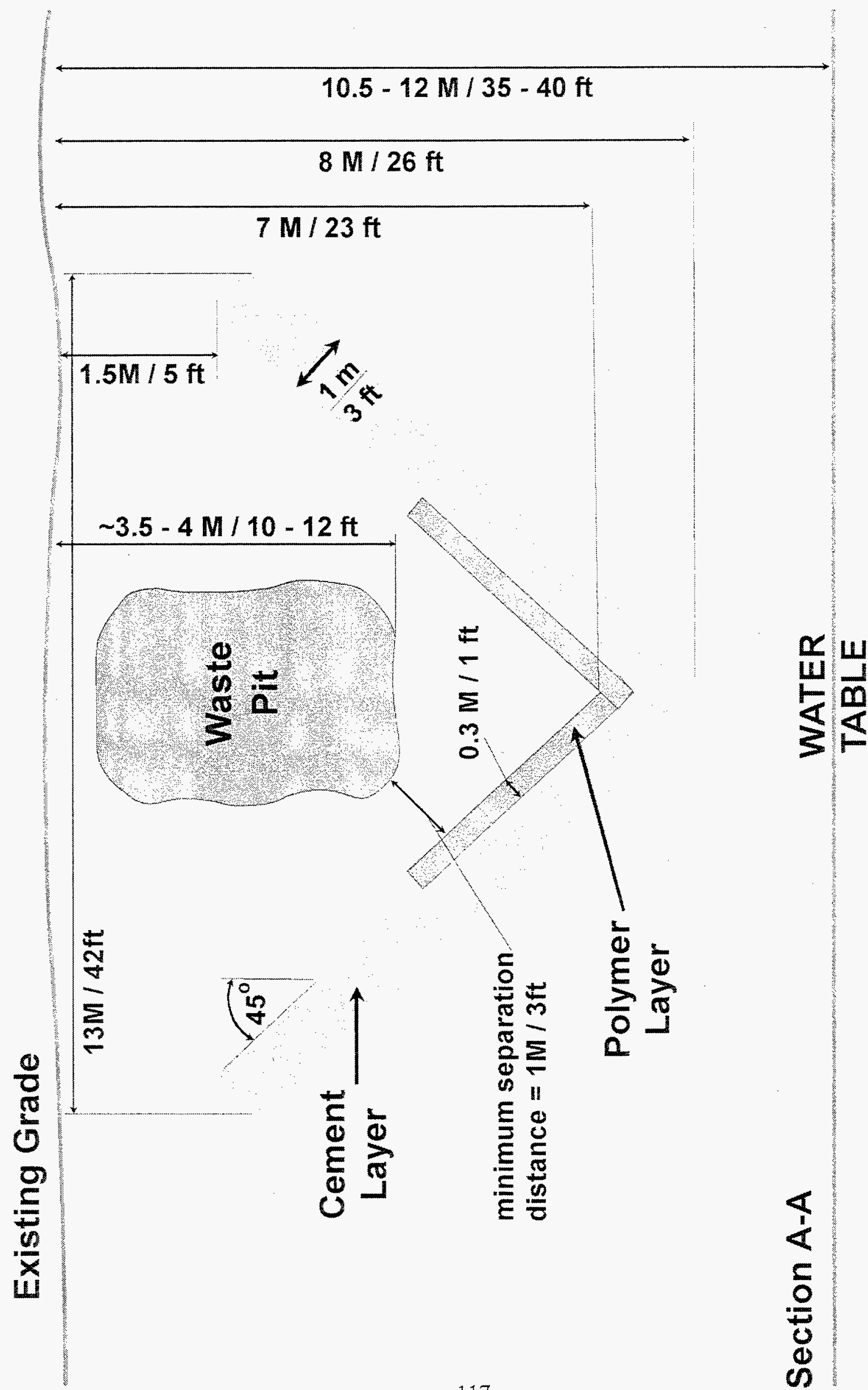


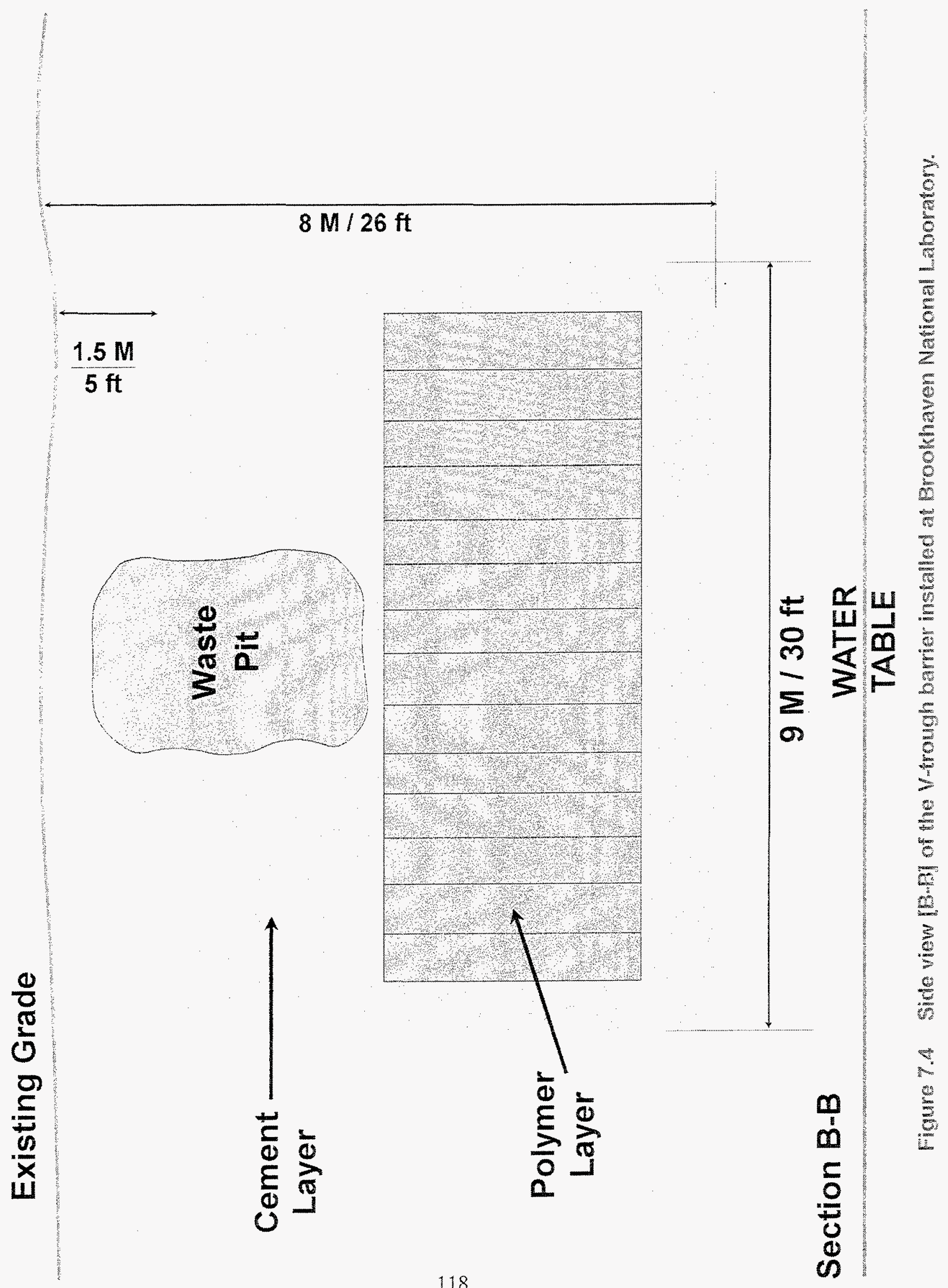




\subsection{Scope}

The scope of the project was to emplace a low-permeability interim containment barrier beneath Glass Bottle Pit G-11 without disturbing the waste pit or its contents. The containment is a multibarrier composed of a V-trough shaped cement grout "bath tub" that serves as a backdrop for a thin liner of a polymer grout. The V-trough barrier was installed by jet grouting conventional interconnected columns using a cementitous grout followed by panel grouting along the bottom half of the internal surface of the V-trough with a polymer grout. The thin (.3 meters) polymer layer, being very low permeability and chemically resistant, composes the primary barrier to contaminant mobility. The cementitous layer is thick ( $\sim 1$ meter) and serves as a secondary barrier to contaminant mobility. The composite barrier was engineered to act as an interim safety net, catching any liquid that might escape from the pit during solidification/remediation activities.

The barrier was checked for breaches after installation by injecting a series of PFTs on one side of a barrier wall and monitoring for those tracers on the other side. The injection and monitoring of the PFTs was accomplished through vadose zone wells.

Upon determination that the barrier was continuous and breach free, the contents of the pit were solidified in-situ using a cement grout. This portion of the project is experimental in nature and is designed to evaluate effectiveness of in-situ stabilization. The grout was delivered to the subsurface via jet grouting. Grouting was confined to a rectangular area confined by plastic sheet piling. This area encompassed the entire waste pit, the contents of which will end up solidified in a monolith defined by the sheet piling. Prior to the cement grout setting, lifting eyes and spiral wound tubing (dywidag) were inserted into the monolith. This facilitated splitting the monolith (using a demolition grout) into manageable pieces that can be removed (via the lifting eyes) by crane.

Composite barrier technology is applicable for final, interim, or emergency containment of subsurface waste forms. Consequently, when considering the diversity of technology application, the construction emplacement and material technology maturity, general site operational requirements, and regulatory compliance incentives, the composite barrier system provides an alternative for any hazardous or mixed waste remediation plan. Successful demonstration of this isolation concept at the Brookhaven National Laboratory site has shown that the technology is ready for application by end users.

\subsection{Objectives}

This project demonstrated a composite engineered subsurface barrier system for the containment of buried waste forms. The objective criteria were derived from the objectives statements of the demonstrations and from questions from potential end users. 


\subsubsection{Objective criteria}

The object of this project was to demonstrate a "Systems Approach" that integrates directional drilling, grout emplacement, multiple barrier material usage, and verification technologies. Questions by end users covered such topics as effect of grouting process on the waste form(s); barrier performance issues such as life expectancy, probable failure mechanisms, final properties, and reactions between barrier materials and targeted wastes; how barrier integrity will be verified; and cost versus performance values.

To achieve the above objective and provide answers to the questions posed by end users, the following criteria must be successfully demonstrated:

1. barrier materials are compatible with the placement equipment and the waste form;

2. install the barrier without disturbing the waste form;

3 . reduce the formation permeability to $10^{-7} \mathrm{~cm} / \mathrm{sec}$ or less;

4. deploy a barrier verification system to evaluate barrier integrity in a reasonable time frame; and

5. the installation cost of a composite barrier is offset by the cost savings of preventing further contamination of the subsurface either by inaction or cleanup activities.

\subsubsection{Demonstration parameters}

The parameters that used to measure or verify successful completion of the criteria for the composite grout barrier as defined above are as follows:

1. compatibility of the grout materials with the waste form and emplacement equipment;

2. precise monitoring of volume and pressure gauges to ensure uniform grout placement;

3. laboratory permeability measurements on core samples;

4. verify the integrity of the barrier; and

5. the cost of installing the composite will be documented and compared to the alternative remedial actions.

The sampling and analytical procedures were designed to provide data to measure and evaluate the effects of the above parameters on the objective criteria. Sampling procedures were in accordance with the appropriate quality assurance and quality control guidelines set forth by the DOE and EPA for demonstrations of this type.

1. Documented grout emplacement parameters are:

- injection pressure;

- extraction length (per step);

- step duration;

- diameter of nozzles; and

- withdrawal rate. 
2. Measurements of the hydraulic conductivity of the barrier will be performed. Measurements will be made in accordance with ASTM D-5084 [3]. Full saturation will be determined by measuring the compression B value according to ASTM D-4767-(88) [4].

3. Measurements of the compressive strength will made for the cement layer. Triplicate samples will be taken from various locations along the barrier and measured according to ASTM C-39[5].

4. The cost of installing the barrier was recorded, this cost excludes additional costs that were accumulated in the additional testing of the barrier for the purposes of the demonstration. Costs have been compared to estimates of the cost of not remediating the site or additional costs associated with traditional cleanup technologies.

\subsubsection{Criteria for success}

Successful demonstration of technology for composite subsurface barriers was verified by strict operational monitoring of all pertinent instruments. During barrier placement, any problems were evaluated and fixed immediately, prior to continuing the demonstration.

Specific criterion for measuring technology success include:

- formation hydraulic conductivity reduction to $10^{-7} \mathrm{~cm} / \mathrm{sec}$ or greater than two orders of magnitude, which ever is lower;

- emplacement of primary and secondary barriers without compromising the integrity of the waste form as determined by post experiment evaluation;

- smooth integration of emplacement, barrier materials, and verification technologies, providing a comprehensive subsurface barrier program.

\subsection{Site}

Brookhaven National Laboratory is located in Upton, Long Island, New York, near the geographical center of Suffolk County (Figure 7.5). Suffolk County contains approximately 1.32 million people, with about 400,000 people residing in Brookhaven Township, which also contains BNL. The BNL facility occupies $21.3 \mathrm{Km}^{2}(5,265$ acres $)$ of land, most of which $(75 \%)$ is wooded. The terrain is gently rolling with elevations ranging between 13.4 and 36.6 meters (44 and 120 feet) above mean sea level. The property lies on the western rim of the shallow Peconic River watershed, with a principal tributary of the river in the north and west sections of BNL. 


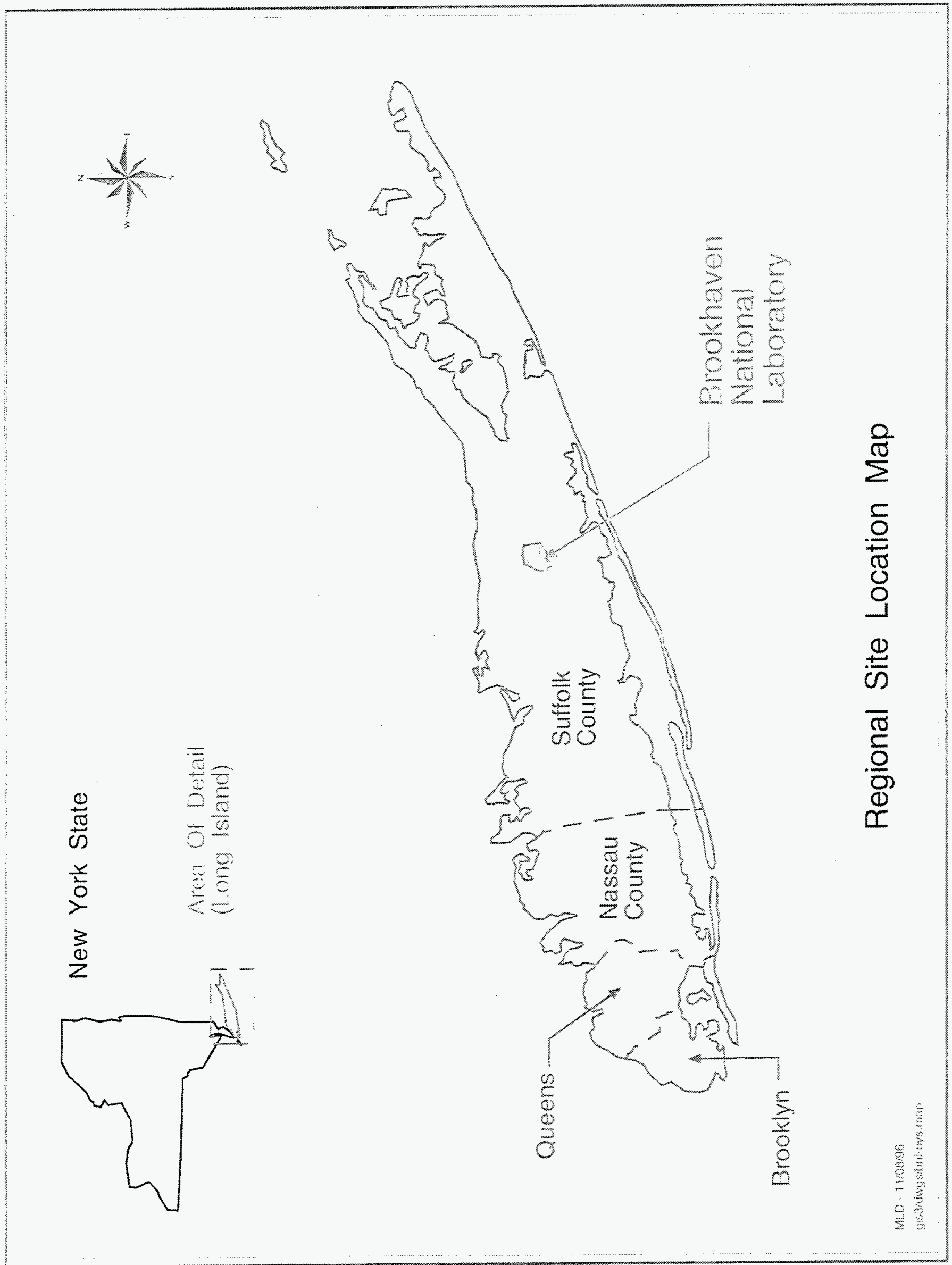


Originally constructed and used by the U.S. Army during World Wars I and II and by the Civilian Conservation Corps between the wars, the site was known as Camp Upton. In 1947, the ownership of the property was transferred to the Atomic Energy Commission for research on atomic energy and materials. In 1975, the site was transferred to the Energy Research and Development Administration, and finally to DOE in 1977. It is a multi-disciplinary scientific research center operated by Associated Universities Inc.

Meteorological records exist for the BNL site from 1948 to the present. The local climate is moderated significantly by the presence of the Long Island Sound, the Atlantic Ocean, and several bays along the southern shore of Long Island. Average annual temperature is $9.8^{\circ} \mathrm{C}$ $\left(49.6^{\circ} \mathrm{F}\right)$. The annual average precipitation is 1.23 meters ( 48.2 inches) which varies only slightly from month to month.

Long Island's hydro geologic system consists of three major aquifers, the Lloyd Sand Member of the Raritan, the Mongothy Formation, and the upper Pleistocene Glacial deposits separated by two confining units (the Raritan Clay between the Lloyd and the Mongothy aquifers, and the Gardiners Clay unit between the Mongothy and the upper glacial aquifer). Taken together, these aquifers and confining layers have been designated by the EPA as a Sole Source Aquifer System. The Mongothy aquifer is the principle public water supply aquifer beneath Long Island. The Upper Pleistocene Glacial Aquifer is an important aquifer for private and public water supplies.

In 1989 BNL was added to the EPA's National Priorities List. The site, depicted in Figure 7.6 is divided into seven operable units (OU). OU I includes the former landfill area. The field task site is noted as the AOC 2C Glass Holes location (Figure 7.7). It is located in close proximity to the Chemical/Animal Pits Area AOC 2B, the Former Landfill AOC 2A, and the Interim Landfill AOC 2D. Beginning in the 1960's and continuing into the 1980's, BNL disposed of laboratory waste (glassware, chemicals and animal carcasses) in numerous shallow pits. In the glass holes area, historical records indicate that there were 10 glass pits excavated, but further investigation has shown the presence of 17 glass pits. The glass pits were typically excavated with a clam-shell. Individual pits were approximately 3.0 to 4.6 meters (10 to 15 feet) in diameter and 3.0 to 4.6 meters (10 to 15 feet) deep. Waste materials and backfill were placed into the individual unlined pits in lifts with final backfill to grade. Record keeping on the number of pits, location and contents were poor by today's standards. This makes it difficult to fully assess the problem and to develop a remediation plan. The drivers for remediating the pits are; historical records that indicate hazardous materials may have been disposed of in the pits; ground water contamination down gradient of the pits; a test excavation of one of the glass holes that unearthed laboratory glass bottles with unidentified liquids still contained; and the fact that BNL rests atop an EPA designated sole-source aquifer.

The near surface geology at BNL is composed of Pleistocene glacial deposits composed primarily of fluvial outwash sediments. The majority of the geologic media located at or near the ground surface is composed of fine to coarse grained quartzose sand with lesser amounts of gravel. 


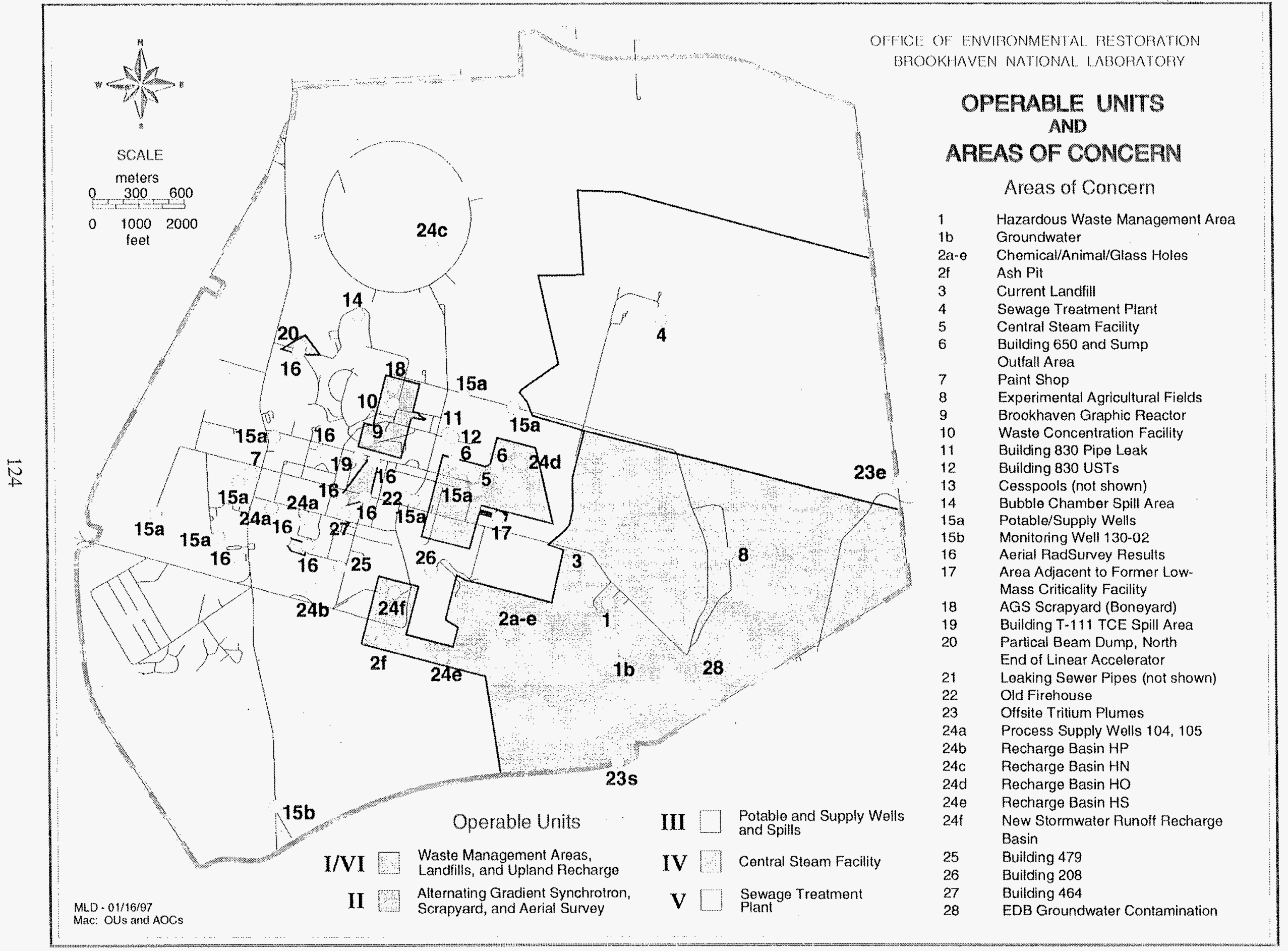




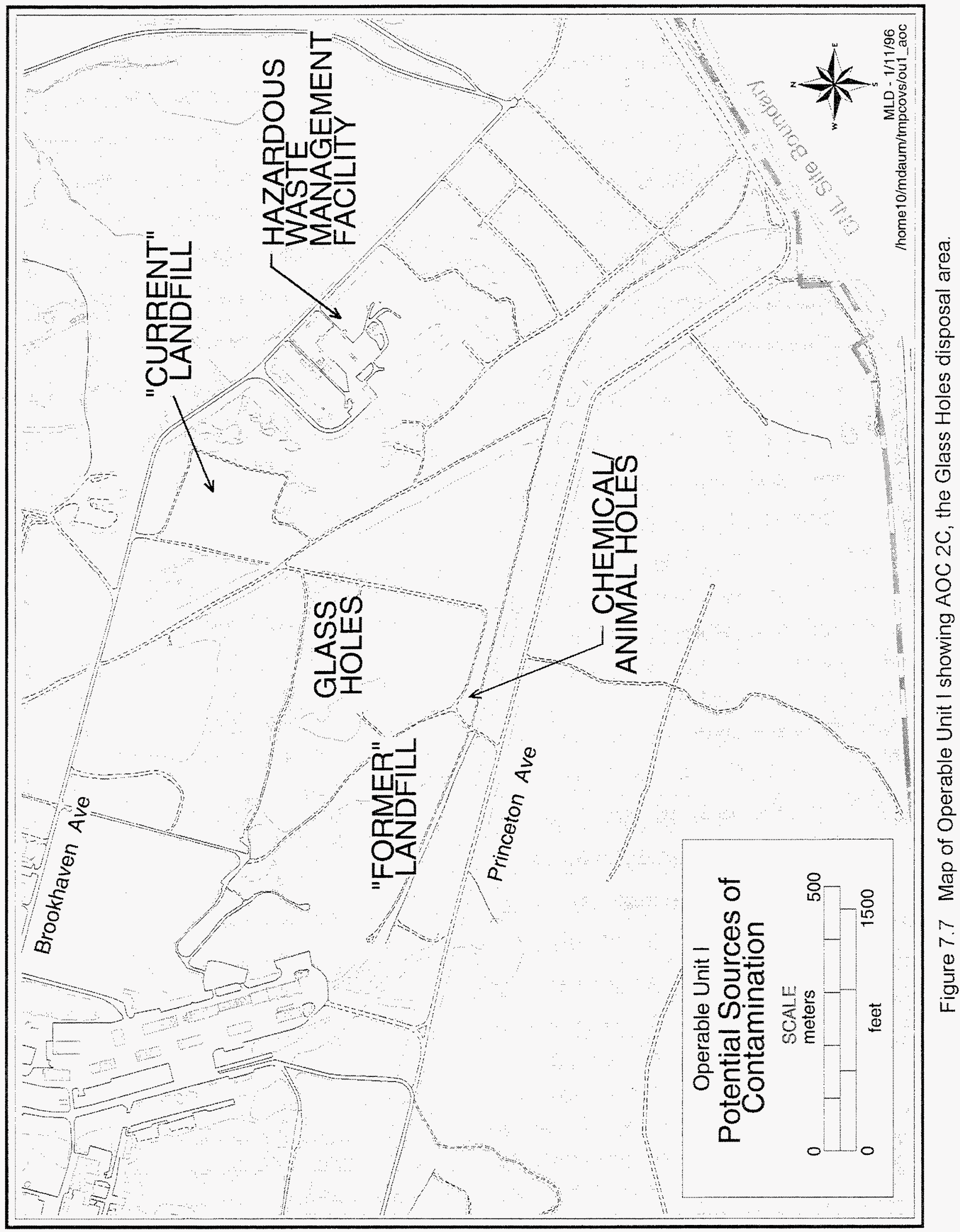


The thickness of the deposits varies from 40 to 76 meters (130 to 250 feet). The sediments are crudely stratified and highly permeable in both horizontal and vertical directions. The specific site chosen for this demonstration was pit G-11 of the glass holes (AOC-2C). The requirements that lead to choosing this pit were; a well characterized pit and a relatively isolated pit where our construction operations would not impact on adjacent pits. The glass holes area, including pit G11, was comprehensively surveyed using a suite of geophysical techniques (e.g., EM-31, EM-61, GPR) ${ }^{28}$ Pit G-11 was originally believed to be a doublet pit consisting of two nearly connected pits. Just prior to this demonstration (but after the pit selection process) the data was re-evaluated using better analysis methods, resulting in the pit being re-defined as a single pit. [The layout for grouting the barrier was re-set accordingly and the pit outline was staked out by BNL-OER personnel based on this evaluation]. In the area of concern the water table is approximately 13 meters (42ft) from the ground surface with a gradient from the north northwest to the south southeast. There is also a $0.3 \mathrm{M}(1 \mathrm{ft})$ thick cobble layer located approximately $1.5 \mathrm{M}(5 \mathrm{ft})$ below grade consisting of 2 to $8 \mathrm{~cm}$ ( 1 to $3 \mathrm{in}$ ) quartz stones. Groundwater sampling in the OU-I area has shown the presence of volatile organics, heavy metal(s), and fission product(s). There is some uncertainty as to the exact origin of contaminants within OU-I; for instance, is a specific contaminant from AOC $2 \mathrm{~A}$ or the Former Landfill and so on.

\subsection{Barrier Installation and In-Situ Stabilization Demonstration}

This section describes the construction phase of the Brookhaven National Laboratory Glass Pit implementation of a close-coupled subsurface barrier which took place between May 21, 1996 and June 25, 1996.

\subsubsection{Environmental, safety and health requirements}

There were no anticipated environmental problems associated with this demonstration nor were any encountered.

\subsubsection{National Environmental Policy Act}

Relevant National Environmental Policy Act (NEPA) applicability to this technology demonstration task is assurance that federal agencies and their contractors give appropriate consideration to environmental impacts in decision making relative to site activities in accordance with NEPA. This task emplaced a barrier and internal monolith materials in order to reembodied actual or potential releases of contaminants from the bottle pits to the groundwater. No significant environmental impacts were anticipated and only minor operational impacts occurred due to operation of diesel / hydraulic engines and equipment usage.

\subsubsection{Resource Conservation and Recovery Act}

Resource Conservation and Recovery Act (RCRA) Subtitle ' $C$ ' requirements apply to the generation, accumulation, treatment, storage, and disposal of hazardous or dangerous waste 
materials. Waste generated during the task activity will fall under a general Brookhaven National Laboratory permit as required by the Hazardous and Solid Waste -Amendments (HSWA) to RCRA for solid waste management units. Alternatively, the task activity may qualify as part of a RCRA corrective action since remedial benefits will result from the demonstration.

\subsubsection{Clean Air Act}

In situ stabilization and isolation of buried waste materials results in negligible release of gas to the atmosphere. Only very small quantities of gas were anticipated to be produced due to the displacement of soil gas with grout materials. An organic vapor analyzer was available to monitor for organic vapors greater than detection levels. No greater than detection levels were found during the entire demonstration.

\subsubsection{Emergency Planning and Community Right-to-Know}

Remediation of Glass pits required the use of geotechnical equipment and stabilization and isolation materials. Current material safety data sheets (MSDSs) for all materials used to support this action were available on site and reported in accordance with the Emergency Planning and Community Right-to-Know Act. No hazardous materials were used for this task.

\subsubsection{Safety}

Safe operations primarily followed regulations set forth by the Occupational Safety and Health Administration (OSHA). Of special concern was the operation of high pressure systems. Personnel working in the area of high pressure systems, high pressure piping systems, and grout delivery systems have special US Department of Energy training. Inspection of high pressure systems and components before use and during operations was mandated.

Industrial first aid or equivalent training by job site representatives was required. First aid materials were also required on the jobsite. Emergency equipment, e.g., fire extinguishers for each major geotechnical equipment unit, eyewash bottles, a cellular telephone and radio were available at the job site. A general corporate health and safety plan was also available for review, upon request.

\subsubsection{Training}

Occupational Safety and Health Administration (OSHA) training for personnel working at sites containing hazardous waste was required for personnel working within the project exclusion zones. Site and task specific training was also required for all personnel working within and around the work site. Hazardous Communication training was required for staff operating geotechnical equipment and support equipment. Safety training was required as delineated in the Activity Specific Health and Safety Plan. Training records were available on site. 


\subsubsection{Personnel}

Site personnel worked under corporate memoranda wherein work at a federal government site, i.e., Brookhaven National Laboratory, was commensurate with work at the US Department of Energy Hanford site. Applied Geotechnical Engineering and Construction, Incorporated [AGEC] were not in effect working in the state of New York, or for state of New York employers.

\subsubsection{Installation of the cement layer}

The same grout injection unit described earlier, was mobilized from Hanford to Brookhaven National Laboratory during the last week of May 1996. This included: a diesel/hydraulic crawler-mounted injector, and a diesel high-pressure, tri-plex slurry pump. The injector was modified to enhance mixing of glass and geologic media within vertical cells inside the glass pit. On arrival at the glass pit location, all systems were configured for operation, interfaced, and tested for systems performance before initiation of barrier and cell stabilization task demonstration activities.

Grouting was performed in the beginning of June 1996, by AGEC. The parameters chosen to install the cement were: $2.2 \mathrm{~mm}$ nozzle, 400 bars ( $6000 \mathrm{psi}$ ), 2 revolutions $/ \mathrm{step}, 5 \mathrm{~cm} / \mathrm{step}$, and $4.25 \mathrm{sec} / \mathrm{step}$ and were based on the Hanford installation. The vertical walls were installed first, starting with the east wall. Drilling was performed at $90^{\circ}$ to the horizon. One row of cement columns was grouted followed by a second row of columns behind and touching the first row in a triangular pitch. Columns were $~ 0.7 \mathrm{M}(26-30 \mathrm{in})$ in diameter and spaced $0.5 \mathrm{M}(21 \mathrm{in})$ on centers to allow for sufficient overlap of adjoining columns and assuring a gap free barrier. The cement grout was a standard Portland type I mix (w/c=1, by weight) specified by SNL. The grout was received as a ready mix supplied by a local vendor and trucked to the site in a cement mixer. The cement was delivered to a $210 \mathrm{~L}$ (55gal) surge tank fitted with a screen to remove coarse particulates that may have been in the ready-mix truck. From the surge tank the cement was transferred via a trash pump to the high pressure pump to be delivered to the drill stem at 400 bars $(6000 \mathrm{psi})$. The tractor-mounted drilling unit was positioned at the first hole, the drilling angle set at $45^{\circ}$ and the drill stem driven into the ground to the desired depth. The cement stream was activated and grouting proceeded as follows. While delivering the grout at 400 bars (6000psi) the drill stem was slowly revolved and withdrawn from the ground. The withdrawal was performed in discrete $5 \mathrm{~cm}$ steps at a rate of 4.25 seconds per step. Rotation occurred at two revolutions per step. The step rate was adjusted in the field to minimize spoils return. Spoils production was slightly higher than observed at the Hanford but still at an acceptable level. This sequence was repeated for each of the odd number holes in the first line of columns and then repeated on the even number holes. Alternating holes was performed to eliminate crosscommunication between columns. If the second column injection were to be performed immediately adjacent to the first, because of the overlap in column the high velocity grout would break through to the first grouted area. Any grout injected would/could short circuit into the first hole and be pumped via the drill hole to the surface as spoils rather than completing the second column. Allowing the first column to cure slightly eliminated such cross-communication. Once 
the first row of columns was completed a second row was grouted inside the first ( 21 " center to center separation). Each row required 17 holes, each wall 34. This same process was used to install the west wall.

The angled walls were installed next, grouting columns in an east to west direction. Drilling was completed at a $45^{\circ}$ angle to level. These walls met the vertical walls five feet below grade, forming the trough. Grouting followed the same triangular pitch and grouting parameters. The final cement barrier lies five feet below grade. The outside dimensions of the barrier are: 13 $\mathrm{M}(42 \mathrm{ft})$ long, $9 \mathrm{M}(30 \mathrm{ft})$ wide, extends $8 \mathrm{M}(26 \mathrm{ft})$ below grade and is $\sim 1 \mathrm{M}(3 \mathrm{ft})$ thick (see Figures 7.2 - 7.4). The contained area is: $11 \mathrm{M}(36 \mathrm{ft})$ long, $7.3 \mathrm{M}(24 \mathrm{ft})$ wide, $5.5 \mathrm{M}(18 \mathrm{ft})$ deep.

\subsubsection{Installation of the polymer layer}

Once the cement trough was in place the drilling unit was re-configured to the dual-wall drill stem to allow grouting with the two component polymer. The polymer layer was placed over a two day span, using panel jet-grouting following the same procedures detailed in Sections 4 (dual-fluid grouting) and 5 (panel jet-grouting). Overlapping panels were laid along the bottom two meters (6ft) of the trough forming a very-low permeability, chemically resistant zone (Figure 7.6) approximately $0.3 \mathrm{M}(12 ")$. This layer had enough volume to contain the entire liquids content of the pit, should all the intact bottles break. The polymer used was AC-400, an acrylate gel polymer that is described in Section 7.8.3.1 that follows. This polymer was chosen based on the barrier being needed for interim (3-5 years) use only. Grouting pressures were 70 bars (1000 psi) for both pumps and the withdrawal was kept constant and at a rate that kept spoils to a minimum. The grout injection rate was 210 - $250 \mathrm{Liters} / \mathrm{min}(55-65 \mathrm{gal} / \mathrm{min})$. Panels were placed every $0.5 \mathrm{M}(21 \mathrm{in})$ providing sufficient overlap between panels and a continuous liner. The angled walls were placed first followed by the vertical walls.

\subsubsection{AC-400 acrylic polymer grout}

The inner liner of the barrier was produced using a polyacrylate grout manufactured by Geochemical Corporation (Geochem). Polyacrylic acid, under the tradename AC-400 is among the most widely used hydraulic barrier materials for construction applications in the United States. This material, a magnesium acrylate, produces a soft gel rather than a hard solid with typical compressive strengths of $0.35 \mathrm{MPa}(50 \mathrm{psi})$. AC-400 is commonly used to seal sewer pipe leaks and to stop water infiltration at construction sites. Acrylate grouts have been shown to have low water permeabilities and to be resistant to a large number of chemicals. ${ }^{29}$ Acrylate grout gels typically contain $80-90 \%$ water and are extremely sensitive to wet-dry and freeze-thaw cycling. Such high water content gels work best in $100 \%$ humidity or water submerged conditions or for interim time periods (up to 5 years) in unsaturated zones. Acrylate grouts behave similarly to the acrylamide grouts and have quickly replaced the latter due to lower toxicities (1/100th of acrylamide grouts). Polymerization occurs using triethanolamine (TEA) catalyst and ammonium persulfate (AP) initiator. Gel time is variable from 5 seconds to 1 hour and can be adjusted by adding potassium ferricyanide $\left(\mathrm{KFe}[\mathrm{CN}]_{6}\right)$, an inhibiting agent. 
To purchase this grout for the demonstration would have cost approximately $\$ 18,000$. From past cooperative efforts between SNL and WHC some $900+$ gallons (3400 L) of AC-400 grout was left over from a SNL project two years prior. The materials were considered hazardous waste by Hanford and were slated for disposal. Assuming a disposal cost of $\$ 165 / \mathrm{ft}^{3}$, the $\sim 475 \mathrm{ft}^{3}$ of waste would cost Hanford $\$ 78,000$. The manufacturer stated that the grout could still be used if it had not yet polymerized. Hanford personnel investigated and found the grout to still be liquid. A decision was made to use this material and take advantage of the $\$ 96 \mathrm{~K}$ in cost savings to DOE and the waste minimization. The only problem facing the use of this material was obtaining it in a timely fashion from Hanford. With diligent assistance from Gail Penny at the BNL DOE office and Elizabeth Bowers of the Hanford DOE office the normally lengthy paperwork process was fulfilled quickly and the grout arrived at BNL in time to be used for the demonstration.

Besides the savings and waste minimization the use of this excess grout resulted in a third benefit; William Clarke, President of Geochem came to BNL and inspected the grout and set up formulations for using this grout at the demonstration. This industrial partnership helped assure successful application of the grout and helped to build on the contractor knowledge base for two part chemical grouting. The gel time was set to 30 minutes to avoid run-out in the coarse sand and injections proceeded smoothly.

\subsection{Verification of the Barrier Continuity}

After placement, the integrity of the composite V-trough barrier was checked using the PFT technology described earlier. The results of the tracer testing indicated that the barrier was intact and breach free and that we could continue with in-situ stabilization of the pit contents.

In this test, the objective was to demonstrate that a large scale breach in the barrier did not occur. This was needed in order to satisfy regulatory issues. The demonstration was achieved by injecting $30 \mathrm{ppm}$ of PFT ocPDCH at a nominal flow rate of $15 \mathrm{~cm}^{3} / \mathrm{min}$ inside of the cement grout barrier and monitoring on both the inside and outside regions of the barrier, Figure 7.8. The monitoring wells were installed parallel to the barrier walls. Placement was accomplished using a truck-mounted Geoprobe unit (Figure 7.9) and frost augers. Two inch diameter holes were bored to depth, sampling lines inserted every two feet and the borehole was backfilled with fine quartz sand. The experiment was conducted during construction of the containing wall for the stabilization task and therefore, was not a well controlled experiment. The injection lasted approximately one day until the polymer solidified around the injection point. During curing of the polymer, it is likely that thermally driven advective flow patterns may have arisen to bring the PFT to the surface and be released to the atmosphere.

For all of the above reasons, detailed modeling was not performed. Modeling was limited to simple scoping calculations to estimate the expected concentration drop through the barrier that would occur if no breach occurred. This estimate was used as a basis for determining if a breach had occurred. 


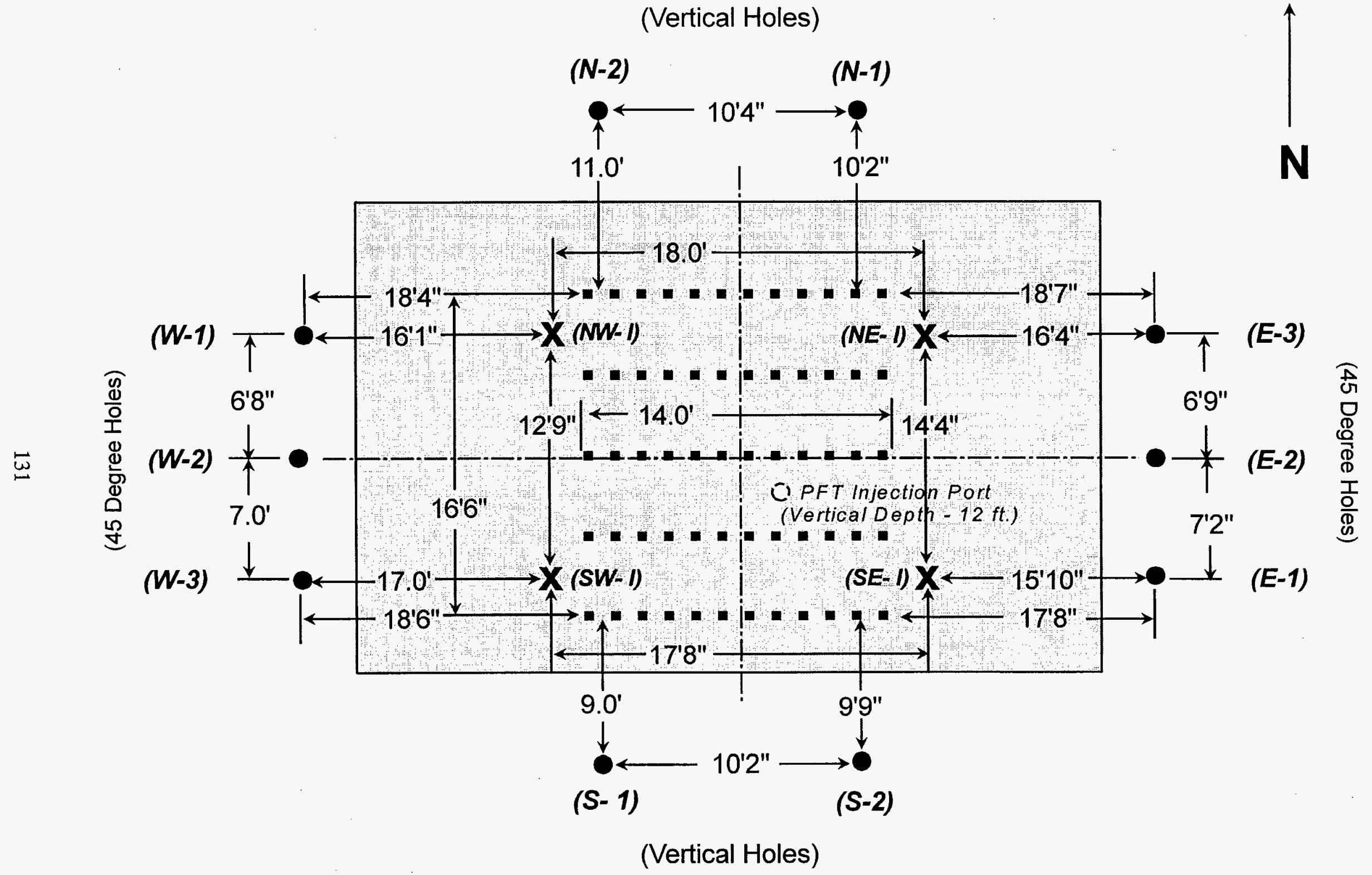

Figure 7.8 Layout of monitoring and injection wells at the G-11 waste pit barrier. 


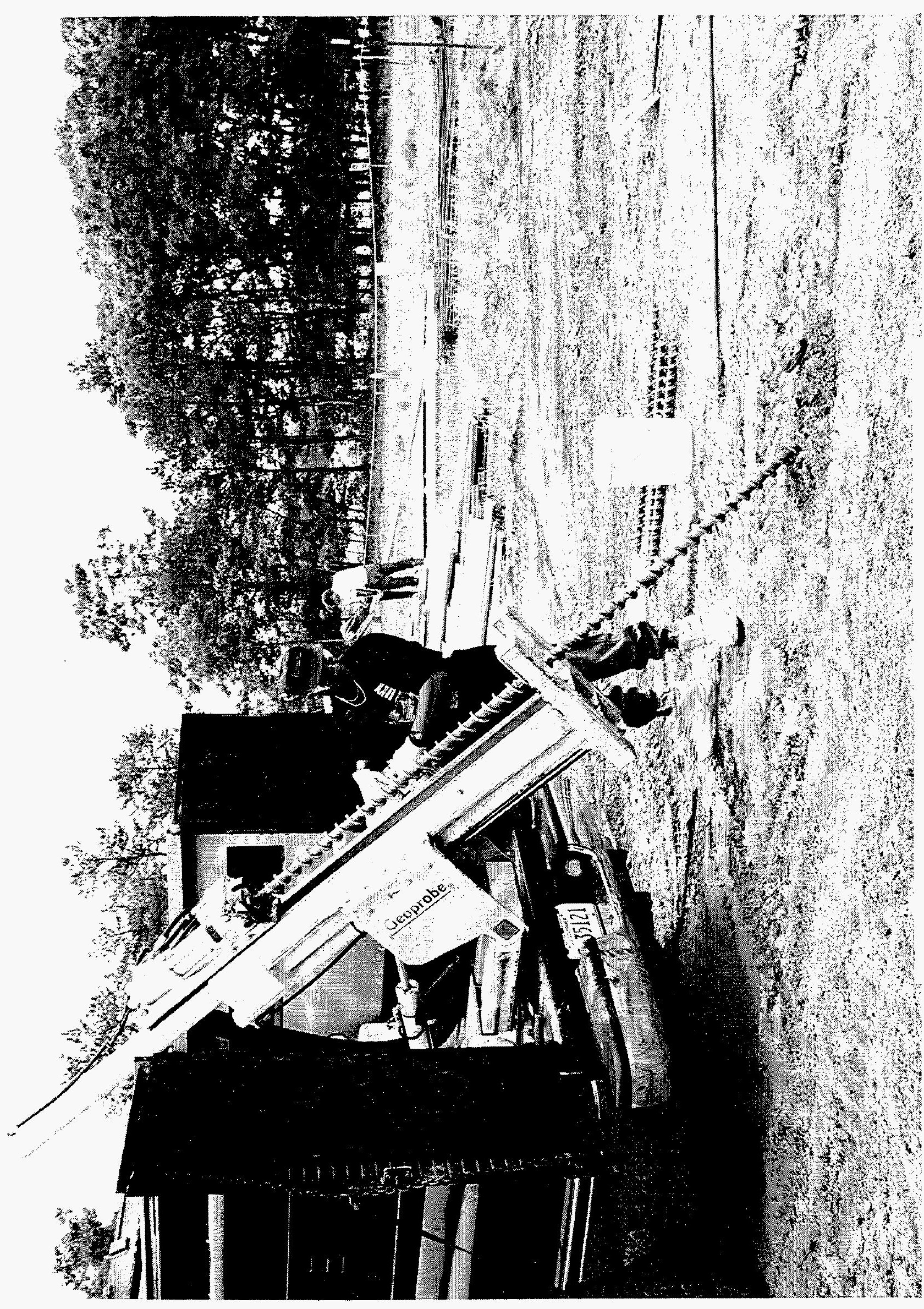


Scoping analysis indicated that concentrations should peak near the bottom of the facility due to the location of the injection points and the distance to the sampling points. Concentrations should decrease as the ground surface is approached. If the barrier was intact, normalized concentration seven days after injection should be three orders of magnitude lower outside as compared to inside the barrier. Data was consistent with these predictions. At the four interior wells, the normalized ocPDCH concentrations, Figure 7.10, were between $1-6 \times 10^{-8}$ after the injection and dropped to $0.5-1.5 \times 10^{-8}$ one week after the injection was completed. This indicates relatively uniform mixing within the barrier region after one week. At the eight exterior wells, the normalized concentrations ran between $10^{-12}$ and $10^{-9}$. Of approximately 120 exterior samples, about $10 \%$ had normalized concentrations above $10^{-10}$. Most concentrations were below $10^{-11}$. The normalized concentrations from the well designated as E-1, Figure 7.8, at the 20 feet location is presented in Figure 7.11. This well was typical of the other wells. The highest external concentrations were located in the wells closest to the SE interior well which exhibited the highest internal concentrations. The concentrations in the exterior wells were approximately the same order of magnitude. The absence of a region of relatively high concentration in the exterior monitoring wells supports the notion that a large scale breach in the barrier did not exist.

The sensitivity of the measurement technique to the PFT ocPDCH is quite good. Normalized concentrations of $10^{-10}$ are representative of actual concentrations of $3 \times 10^{-15}$. In the initial measurement of the gas samples, background concentration samples of VOC's in the parts per trillion range were measured. The presence of VOC's was taken into account when determining PFT concentrations.

During the summer of 1997, the Glass Pits area was remediated by excavating the waste pits. At the same time pit G-11 was also excavated. During the excavation and removal of the monolith and barrier (described later) a limited visual inspection was performed. No large scale breaches were observed further confirming the pft verification results.

\subsection{In-Situ Stabilization of the Pit Waste}

The contents of the waste pit were stabilized in-situ via jet grouting using a cement grout. Grouting took place over a two day period. Later the single large rectangular monolith was subdivided into $1.3 \mathrm{M}$ by $1.3 \mathrm{M}$ ( $4 \mathrm{ft}$ by $4 \mathrm{ft}$ ) cells using a demolition grout. These cell monoliths were prepared for removal and eventual disposal by BNL personnel at a later date. Figures 7.12 to 7.14 show the pit stabilization in plan and cross-sectional views.

Using plastic sheet piling a large cell was constructed around the waste pit, internal to the V-trough, forming a vertical rectangular wall around the pit contents (see Figure 7.15). The panels were placed by trenching around the pit to a depth of six feet. Plastic sheet pile sections were assembled in the trench and the trench was then backfilled. The internal area bounded by the sheet piling and containing the waste was then solidified using a cement grout applied with jet grouting. Columns were placed on $0.5 \mathrm{M}(21 \mathrm{in})$ centers and the entire interior of the sheet piling confines was grouted. Spiral wound tubing (Figure 7.16) was inserted vertically through the 


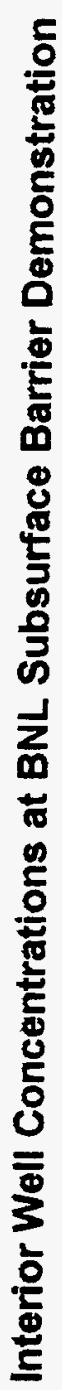

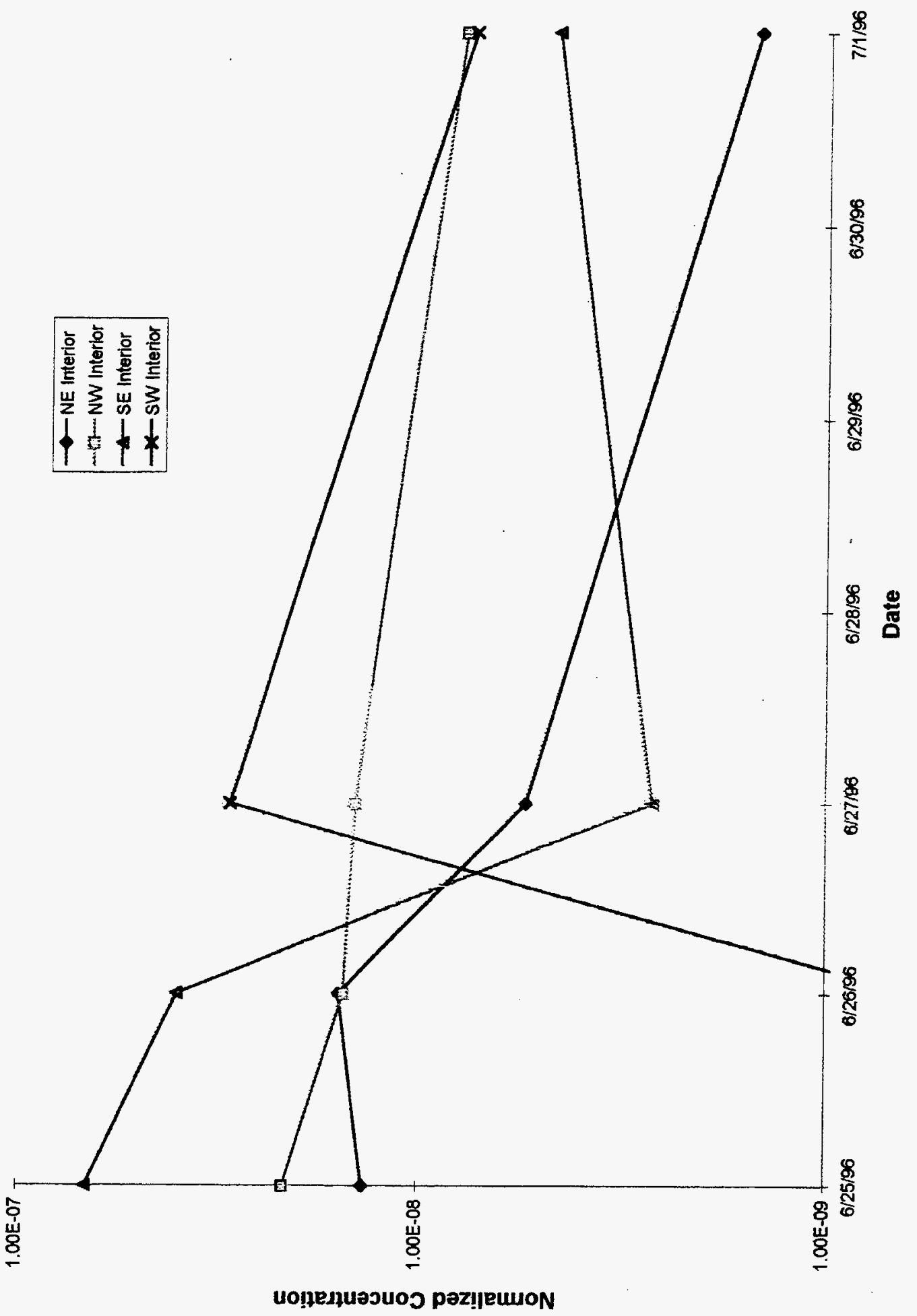

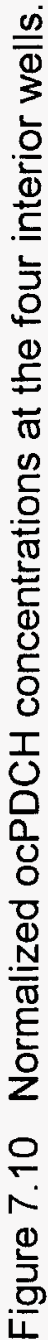




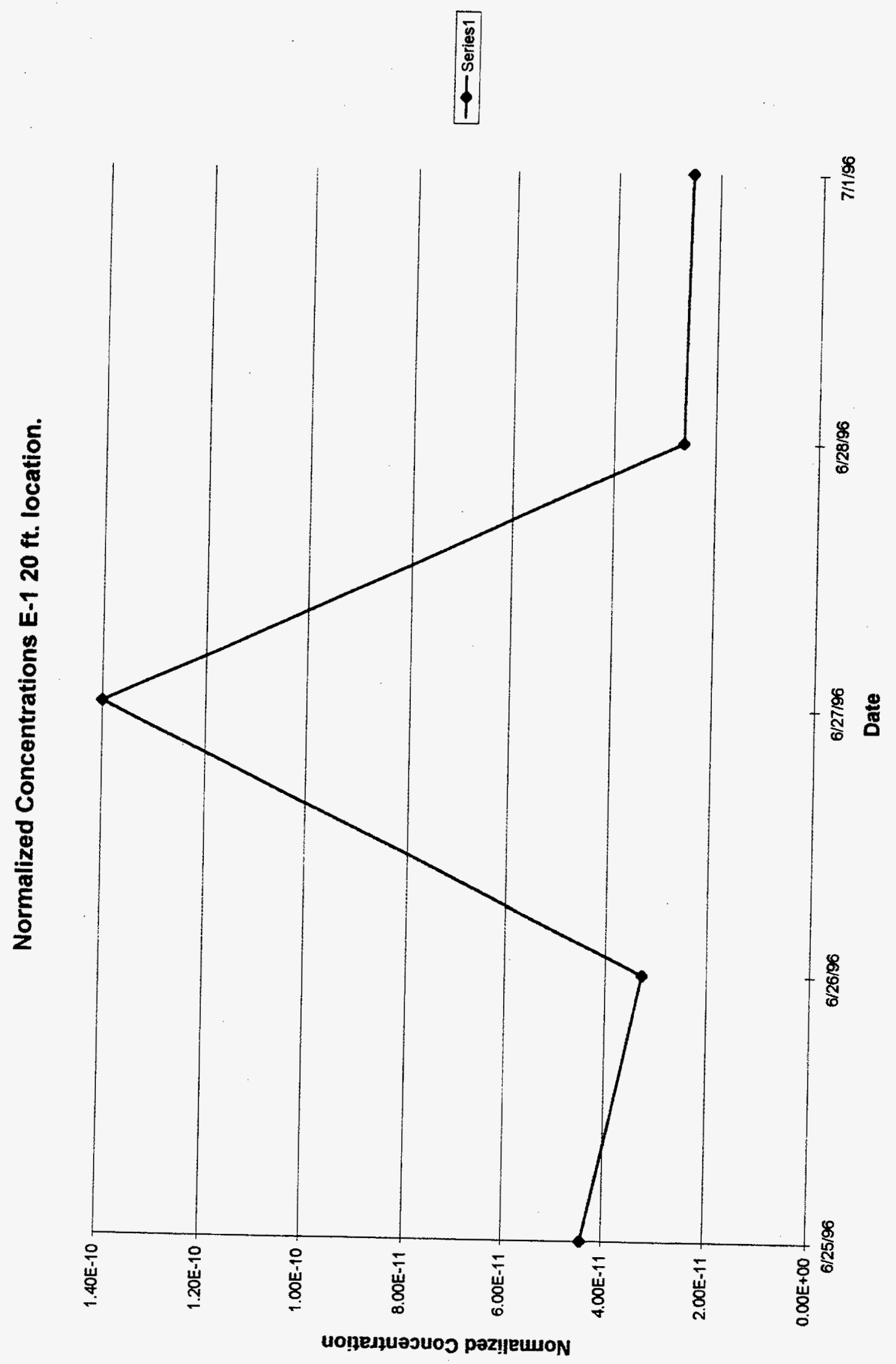

음 


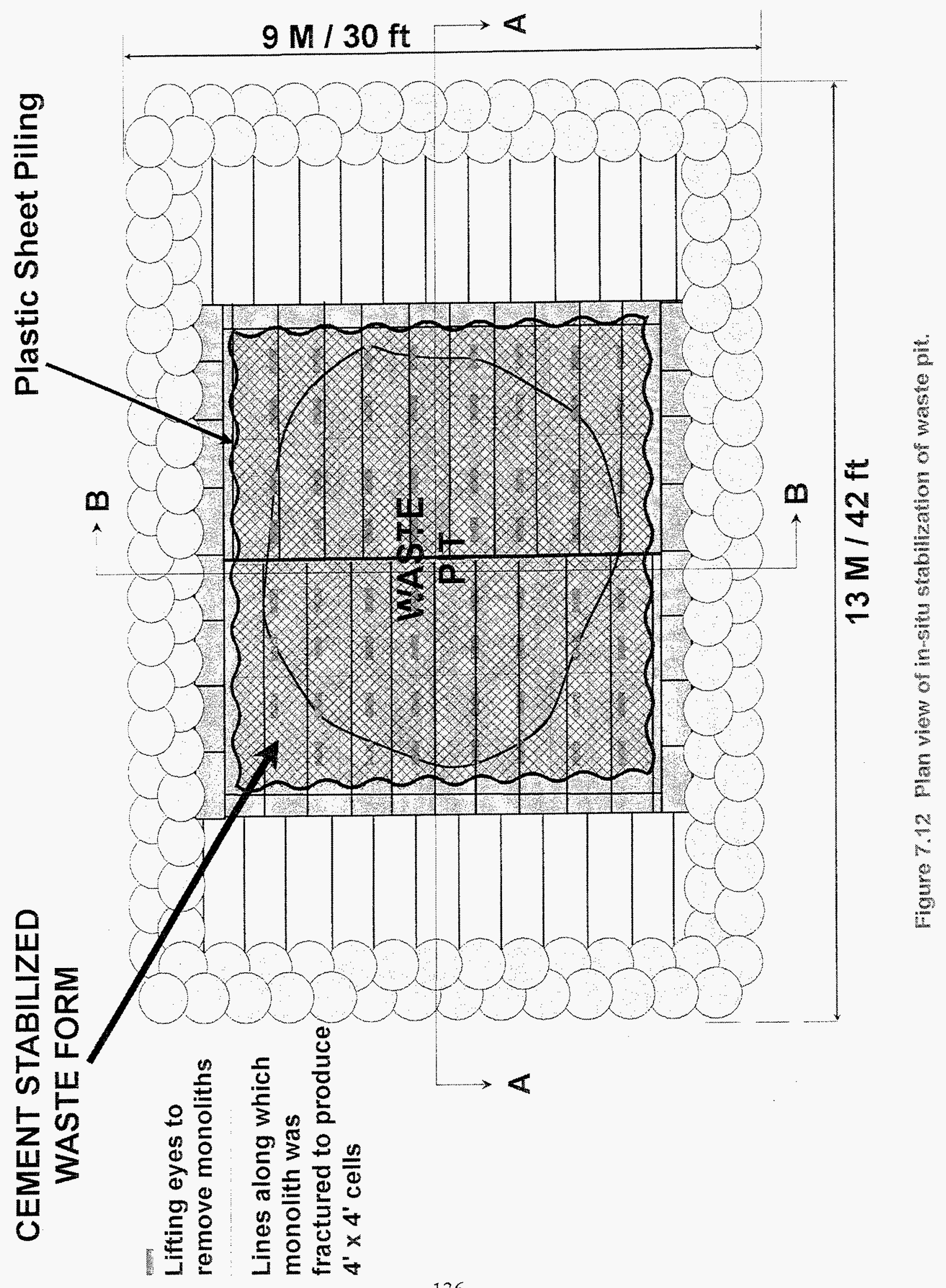




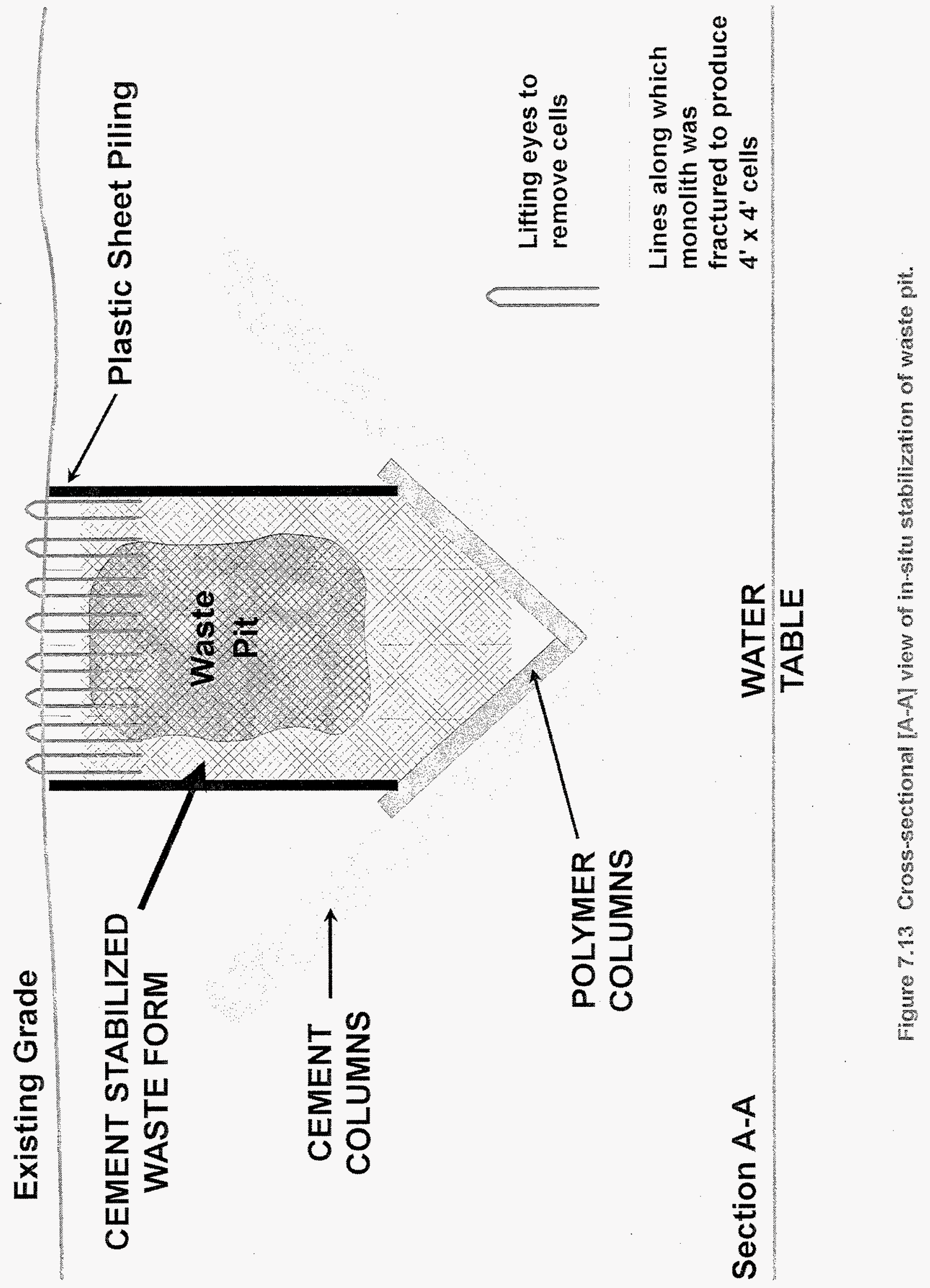




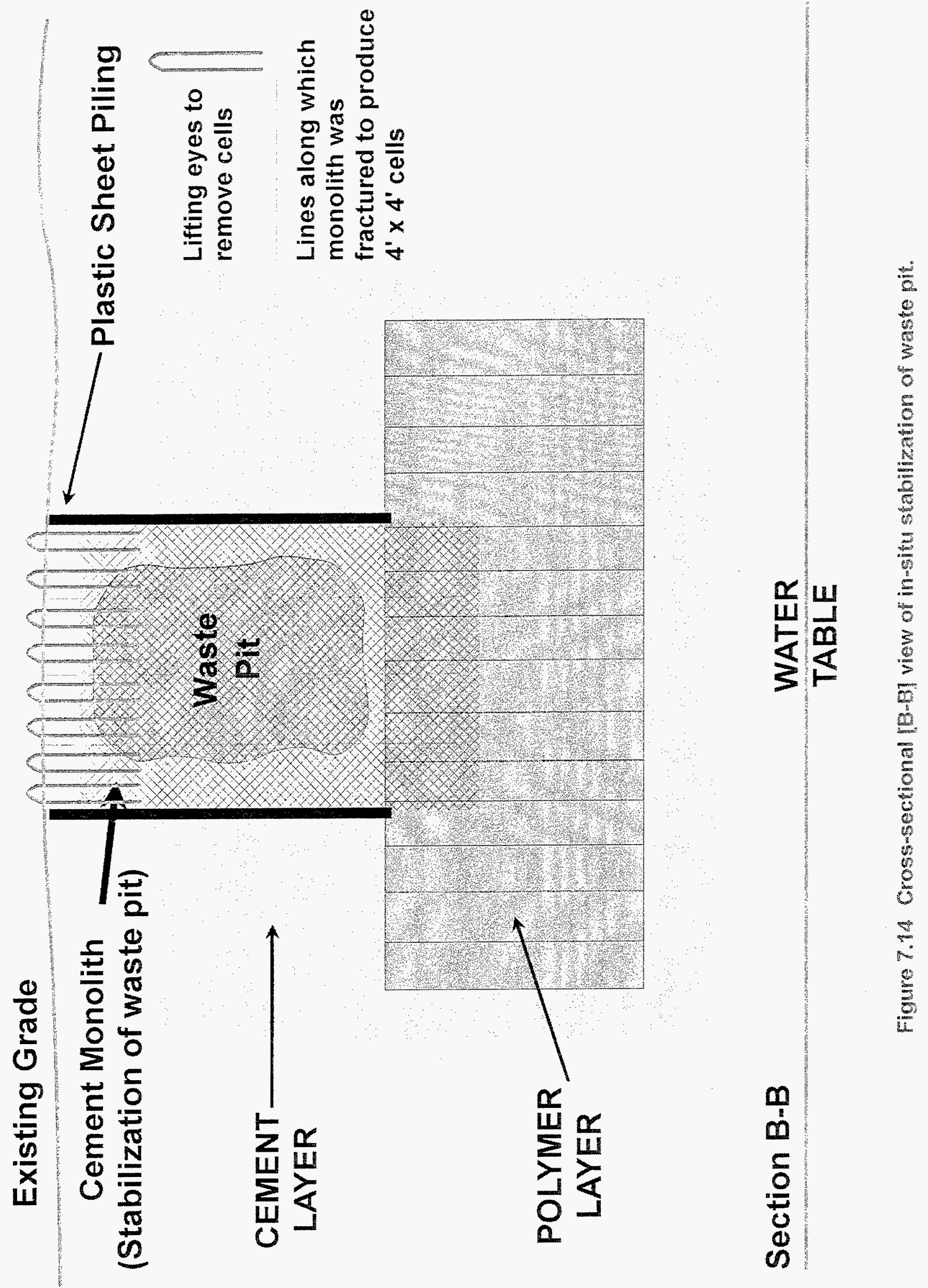




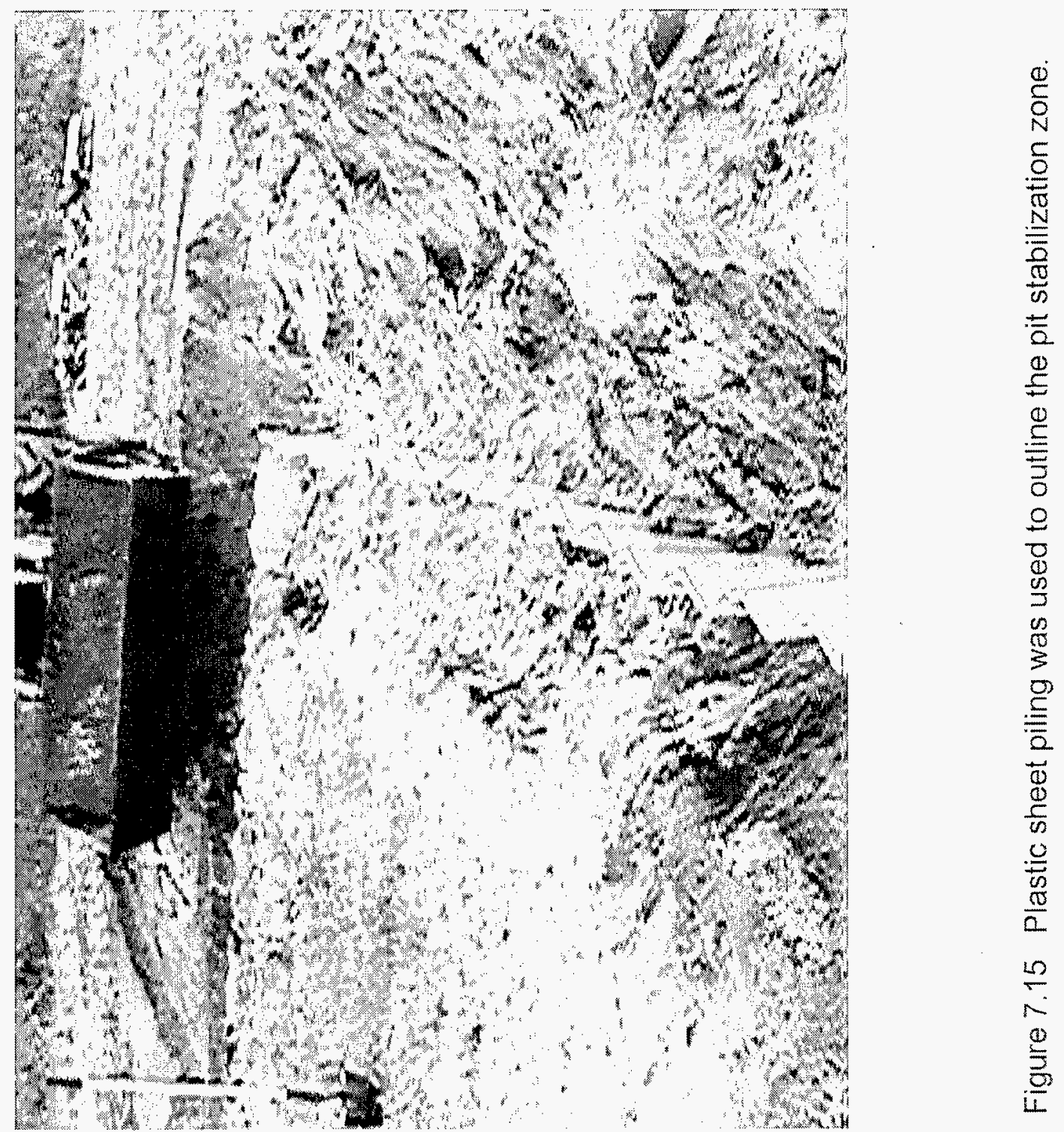




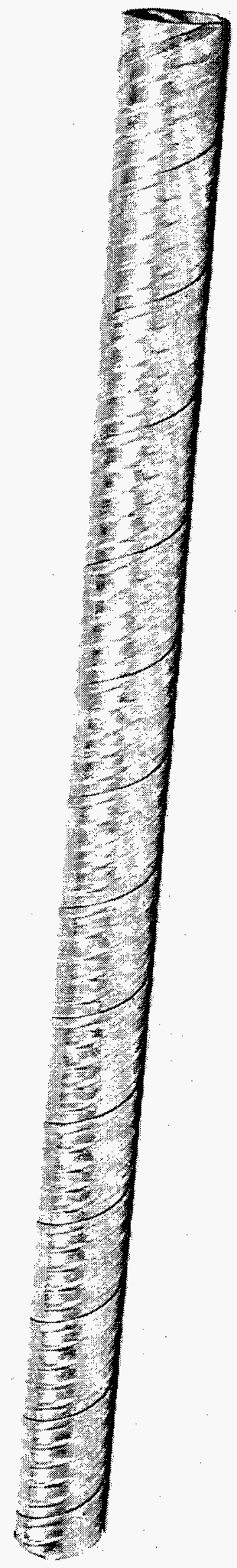




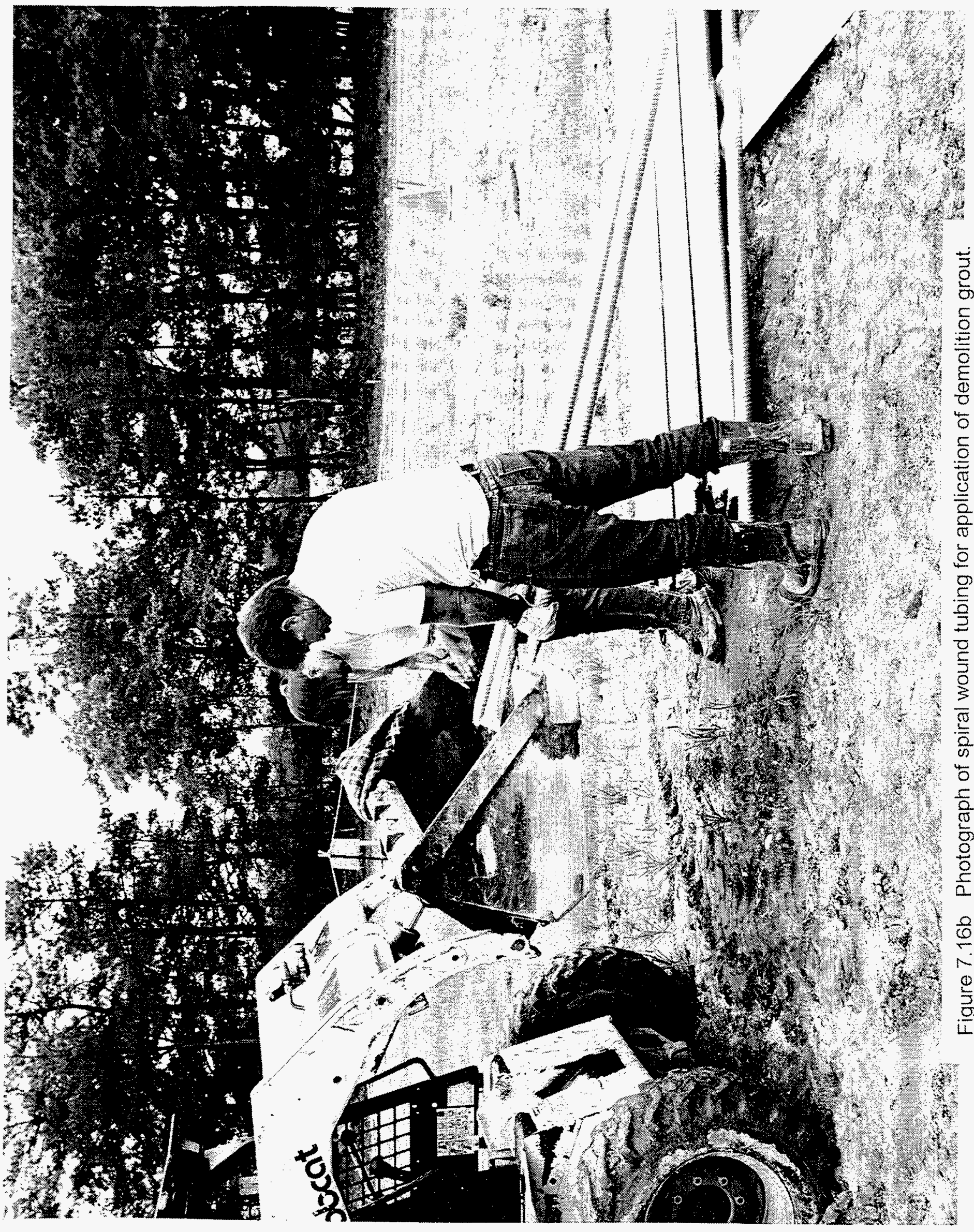


entire height of the grouted monolith such that the array of tubes outlined $1.3 \mathrm{M}$ by $1.3 \mathrm{M}$ (4ft by $4 \mathrm{ft}$ ) cells. On plan view, the tubing was placed every foot in the east to west direction and every two feet north to south (see Figure 7.17). Retrieval picking eyes were also placed in each stabilization cell before the materials cured. Grouting was completed June $25^{\text {th }}$, 1996 . Upon complete curing of all cells, final retrieval of solidified monoliths containing the stabilized contaminant materials would be facilitated by vertical crane withdrawal using the picking eyes in each cell. Each cell monolith could then be containerized, transported and stored, disposed to other facilities, or other actions taken in accordance with Brookhaven National Laboratory closure plans.

The monolith was allowed to cure for several months. On September 4, 1996 personnel from AGEC returned to BNL to apply the Bristar demolition grout. This is a fast curing expansive grout that is commonly used to fracture rock and concrete structures. Representatives from Bristar accompanied AGEC and mixed and placed the grout in the dywidag spiral wound tubes. The grout was mixed in a 5 gallon $(19 \mathrm{~L})$ bucket and poured into the dywidag. The $0.3 \mathrm{M}$ (1ft) spacing break lines were treated first and after filling all these tubes the grout was allowed to cure and expand for 24 hours. The grout sets rapidly with high heat generation. As the grout cures it expands greatly putting pressure on the tubing. The tubing, being spiral wound, tends to "un-wind" and puts tensile loads on the cement monolith. This pressure should cause the monolith to crack preferentially along the line of spiral tubes. At the end of 24 hours the destructive nature of the demolition grout was evidenced by cracks in the ground along the tubing line (see Figure 7.18). Demolition grout was then applied to the $0.6 \mathrm{M}(2 \mathrm{ft})$ spacing tubes and after another 24 hours the slabs should have been divided into $1.3 \mathrm{M}$ by $1.3 \mathrm{M}$ ( $4 \mathrm{ft}$ by $4 \mathrm{ft}$ ) cells. Each cell has four lifting eyes formed from re-bar (Figure 7.19).

\subsection{Excavation of the barrier and in-situ stabilized waste form}

The monolithic cells were left in place until the summer of 1997 when the Glass Pits remediation project was initiated. The remediation consisted of excavating the pit waste and disposing of it off site. The pit contents of G-11 were removed at this time. In the initial attempt to remove the monoliths, a backhoe was used to unearth the top of the monoliths and to remove the dirt from the inside of the south portion of the barrier (adjacent to the monolith). At this time no cracking of the cement waste form was noticeable. A chain was attached to the four picking eyes of one of the 4 foot square "monoliths" and a tractor was used to pull on the monolith. Pulling was away from the waste pit area but did not succeed in separating the monolith from the large waste form. In fact, the pulling eventually led to failure of the re-bar picking eye. The Bristar demolition grout and dywidag tubing had failed to crack the cement monolith as predicted and observed at other installations. It is possible the waste acted as an aggregate or reinforcing fiber or that the glass pieces prevalent in the waste form stopped the crack propagation process initiated by the Bristar grout. In any case the demolition process had no noticeable effect on the cement matrix and is not recommended for future use in waste form resizing. 


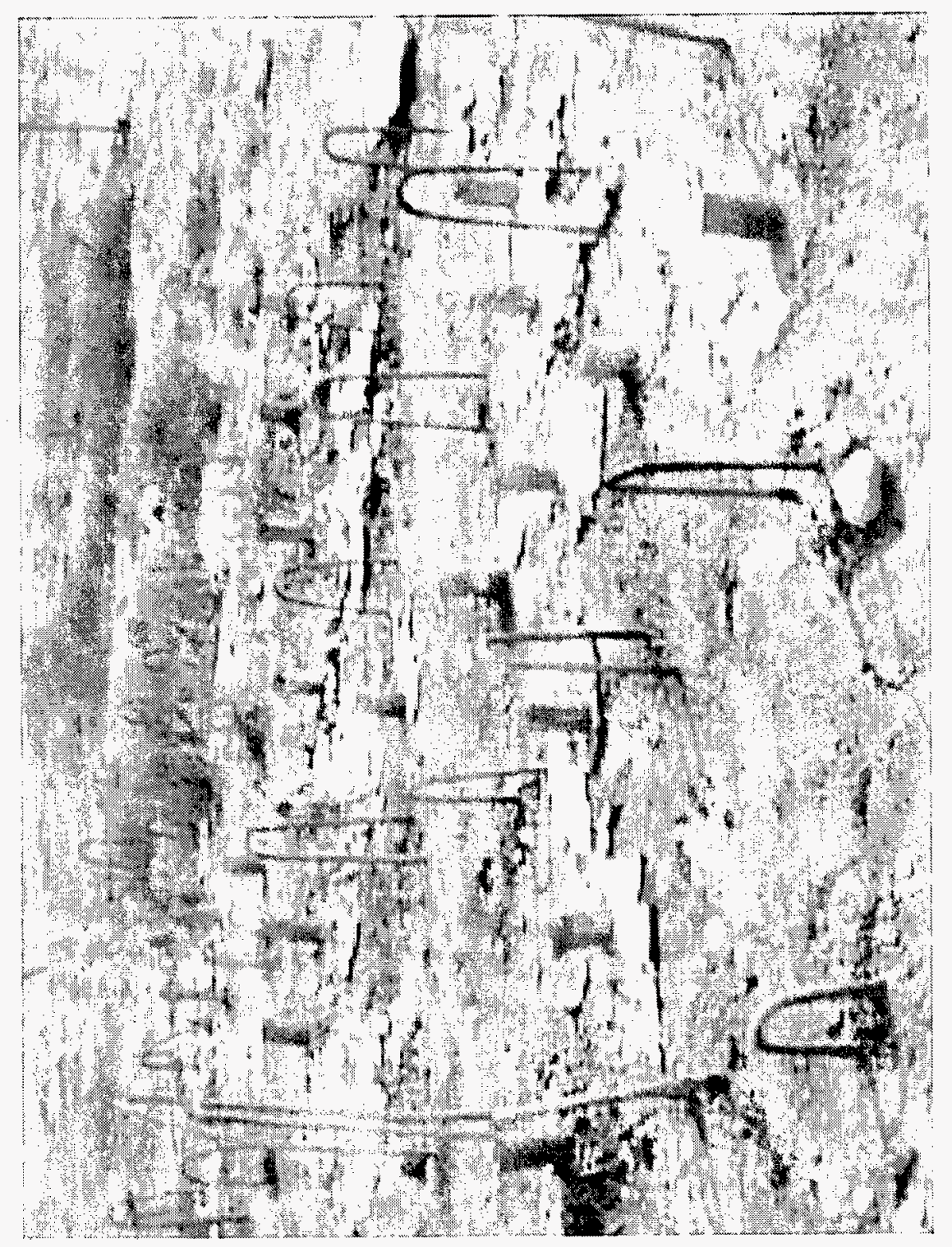

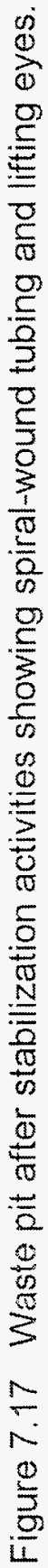




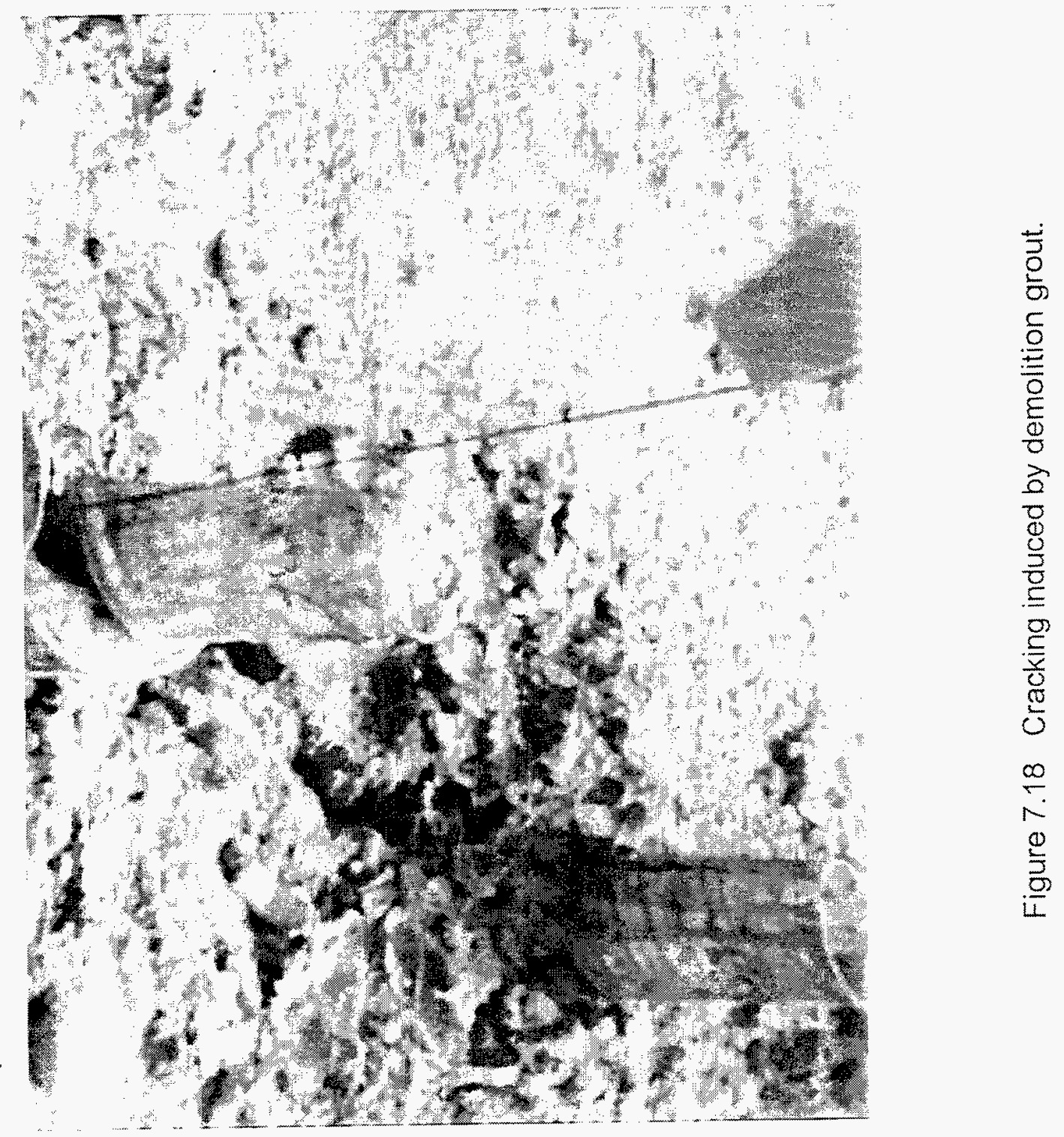




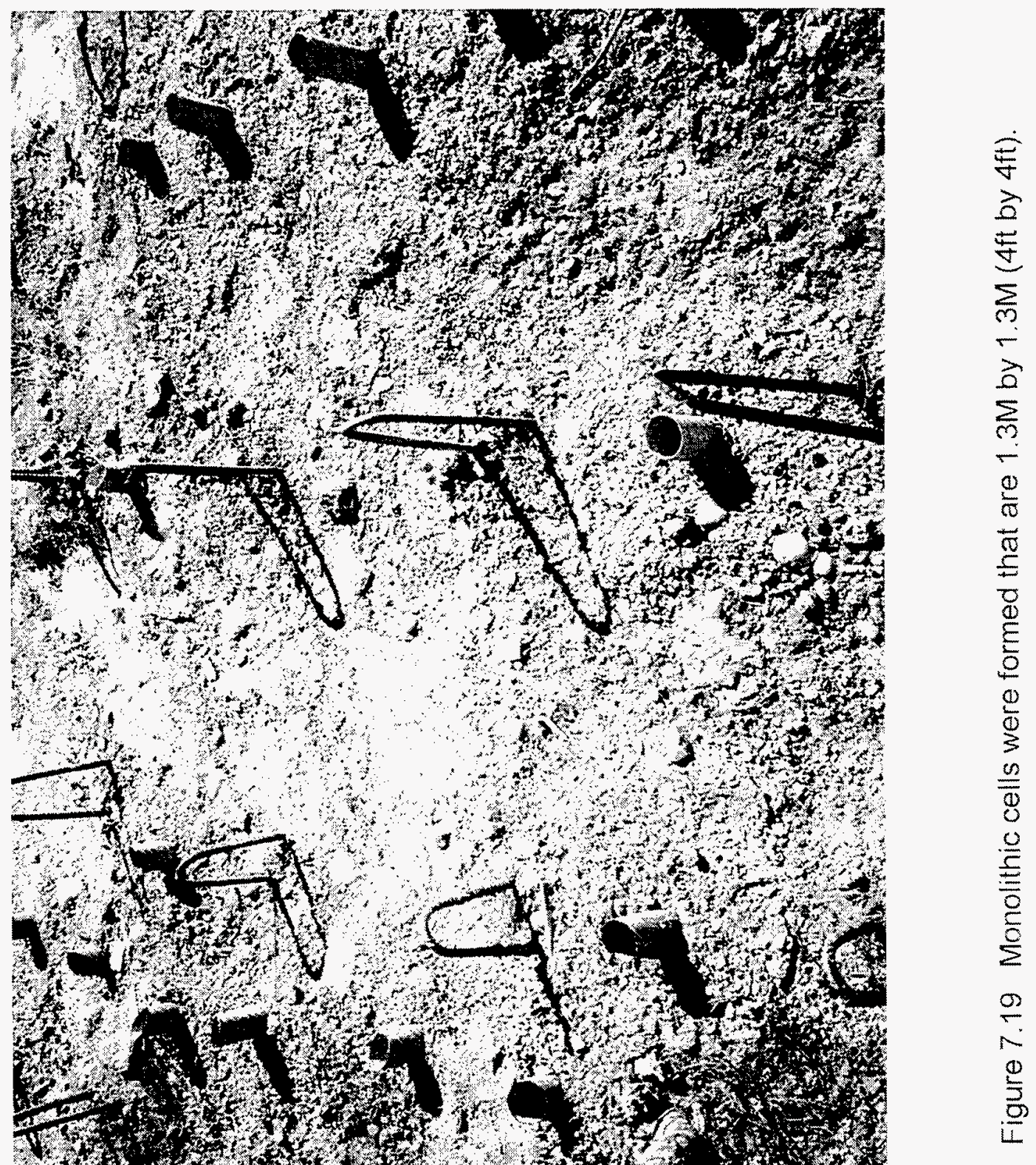


After the failure of the monolith to separate, a backhoe was used to physically break the cement waste form into smaller pieces. The pieces obtained in this manner were irregular in size and shape and more difficult to handle due to lack of lifting eyes (or balanced lifting) and nonconformity to one another. [Several of these pieces are being stored for coring and tested (e.g., density, homogeneity, TCLP) to determine homogeneity and stabilization effectiveness.] The monolith was slowly broken into many smaller pieces and the excavation continued to the bottom of the barrier.

During the excavation a small amount of debris was unearthed outside the stabilization boundaries but within the barrier confines. Excavation of the initial few glass pits that were unstabilized determined that the areal extent of some pits had been severely underestimated. The geophysics surveys that predicted pit depths of 3.5 to 4.5 meters (12-15 feet) were found to be off by 3 to 4 meters. This was also the case for pit G-11, waste was found down to the 9 meter ( 30 feet) level. This required the removal of the barrier as the bottom of the barrier contained solidified waste. It was hoped that the barrier could be kept intact as a test facility for verification technologies but this mis-characterization in the pit depths precluded leaving the barrier in place. Several large metal waste pieces were discovered in this pit, including a 55 gallon drum and several gas cylinders (see Figures 7.20 And 7.21). These waste types could have caused interference or shadowing of the geophysics signals.

For the most part the bottles and glassware in the pit were broken up by the energy of the jet (Figures 7.22 and 7.23), however in many cases bottles (but no laboratory glassware) appear to be relatively intact (Figures 7.24 and 7.25). The degree of consolidation was very good, the cement grout kept the waste together for easier removal. Small pieces of waste such as syringes were encapsulated by the grout (see Figure 7.26). Had the separation process (Bristar demolition grout) been successful the removal process would have been far simpler. Further investigation is planned for the monolith remnants to gain a truer picture of the success of the stabilization. Coring of a representative number of the large pieces will be performed to evaluate homogeneity and TCLP characteristics. If the waste forms pass TCLP requirements then the stabilization effort will have been doubly successful; the pit contents was consolidated for easier handing and the pit contents would not be classified as waste with resultant savings in disposal/treatment costs. Final analysis of the cores will be completed in FY98.

As the excavation progressed, a small amount of waste was found outside the stabilization area. The pit was slightly wider than predicted, but not to a great extent. It was only when the monolith was removed and the bottom of the barrier exposed that it became readily apparent that the depth of the pit had been greatly underestimated. There was waste incorporated into the barrier walls. This required the removal of the barrier portions that contained any waste as the presumption was that the stabilized waste form would be dealt with as hazardous waste. After removing the bottom of the barrier, waste was found to exist to two feet below the barrier or to a depth of 9 meters ( 30 feet). 


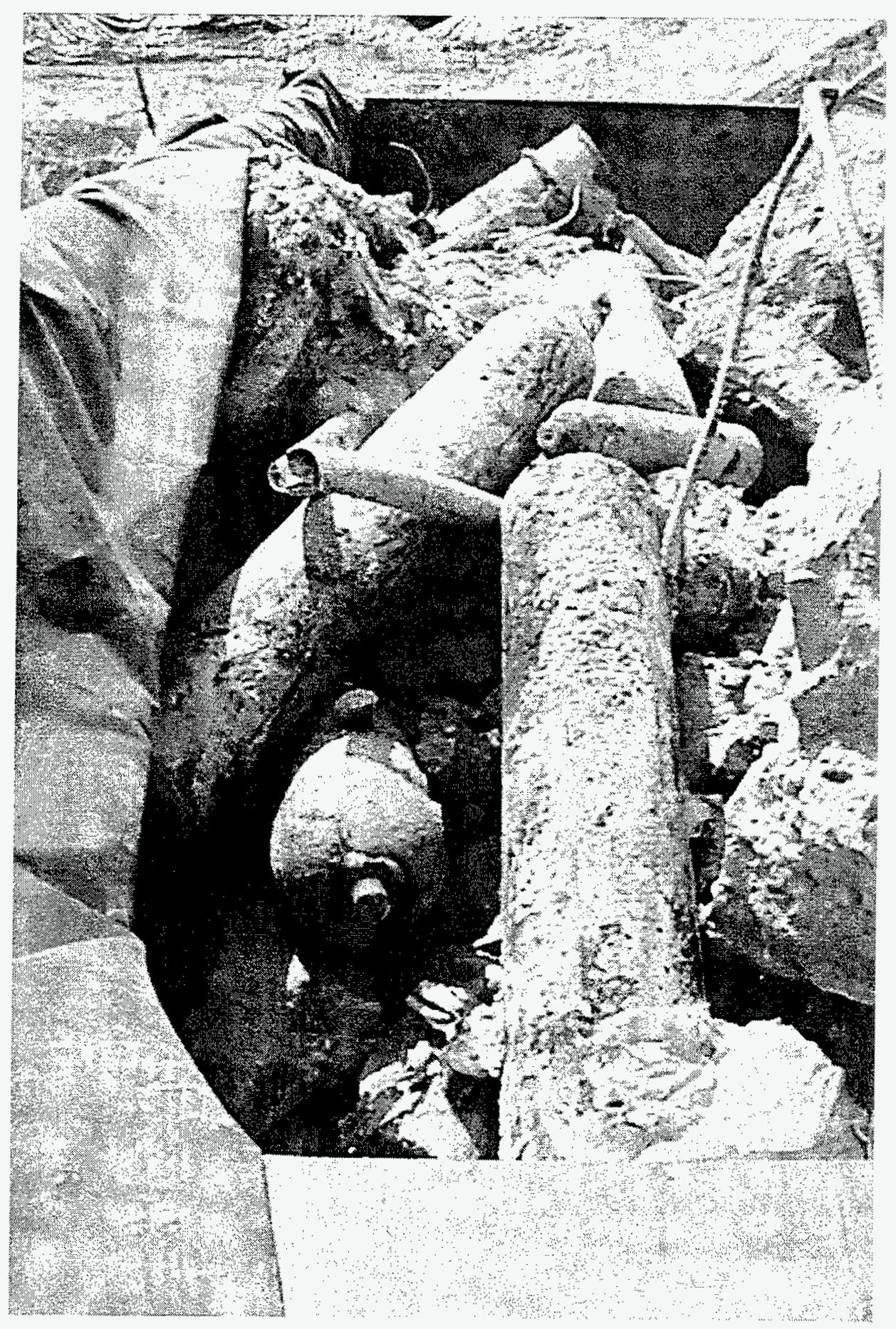

Figure 7.20 Gas cylinders disposed of in pit G-11. 


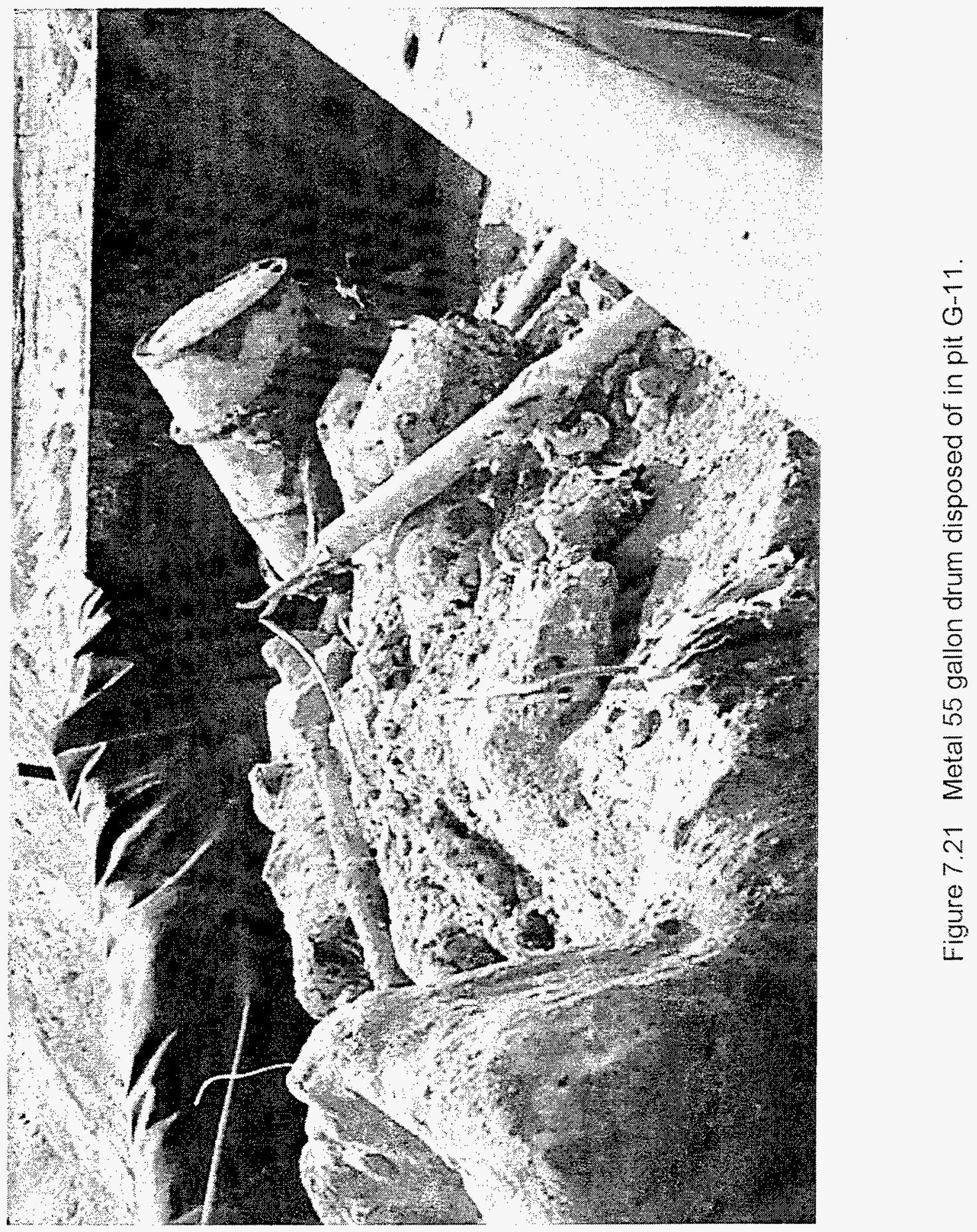




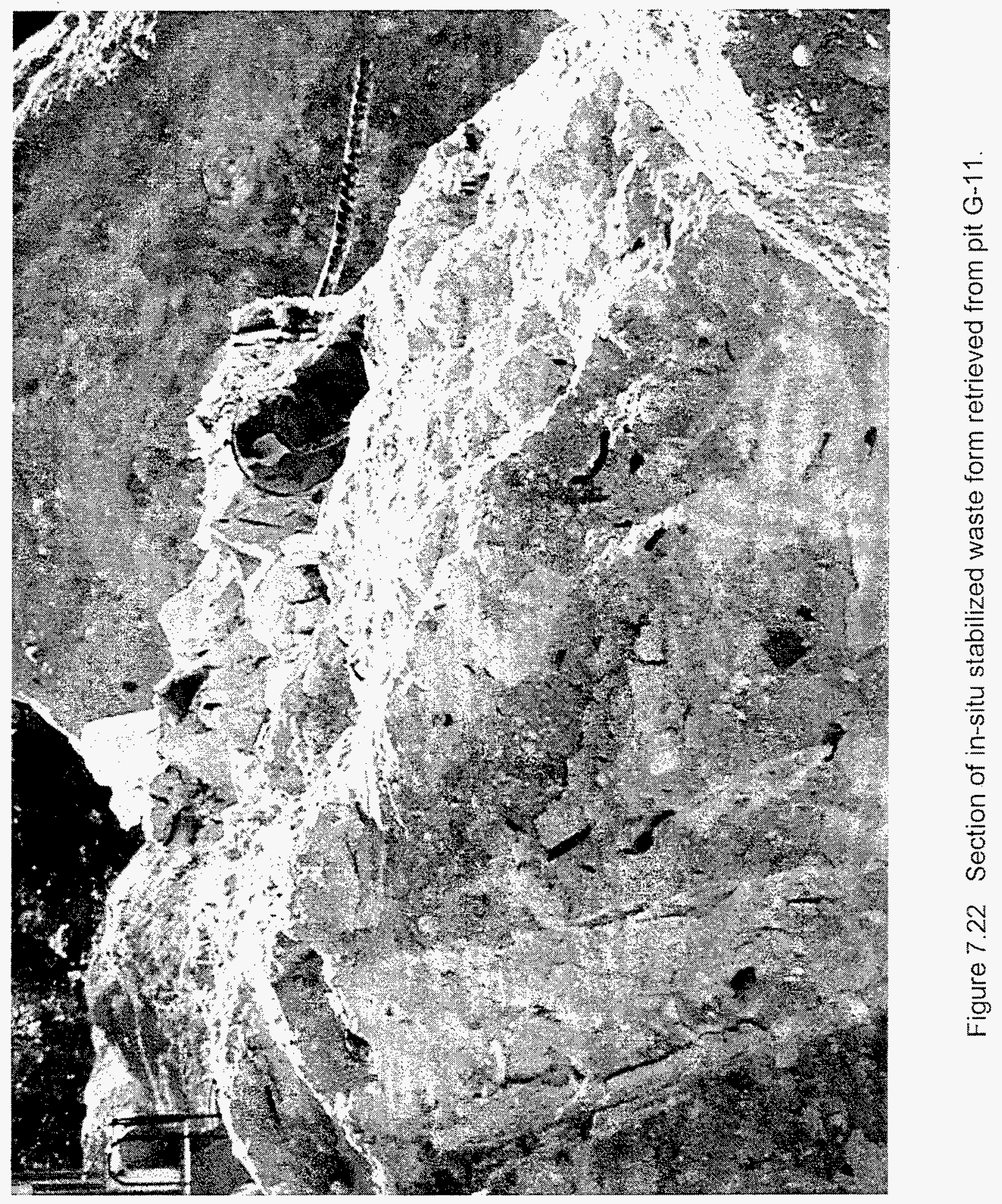




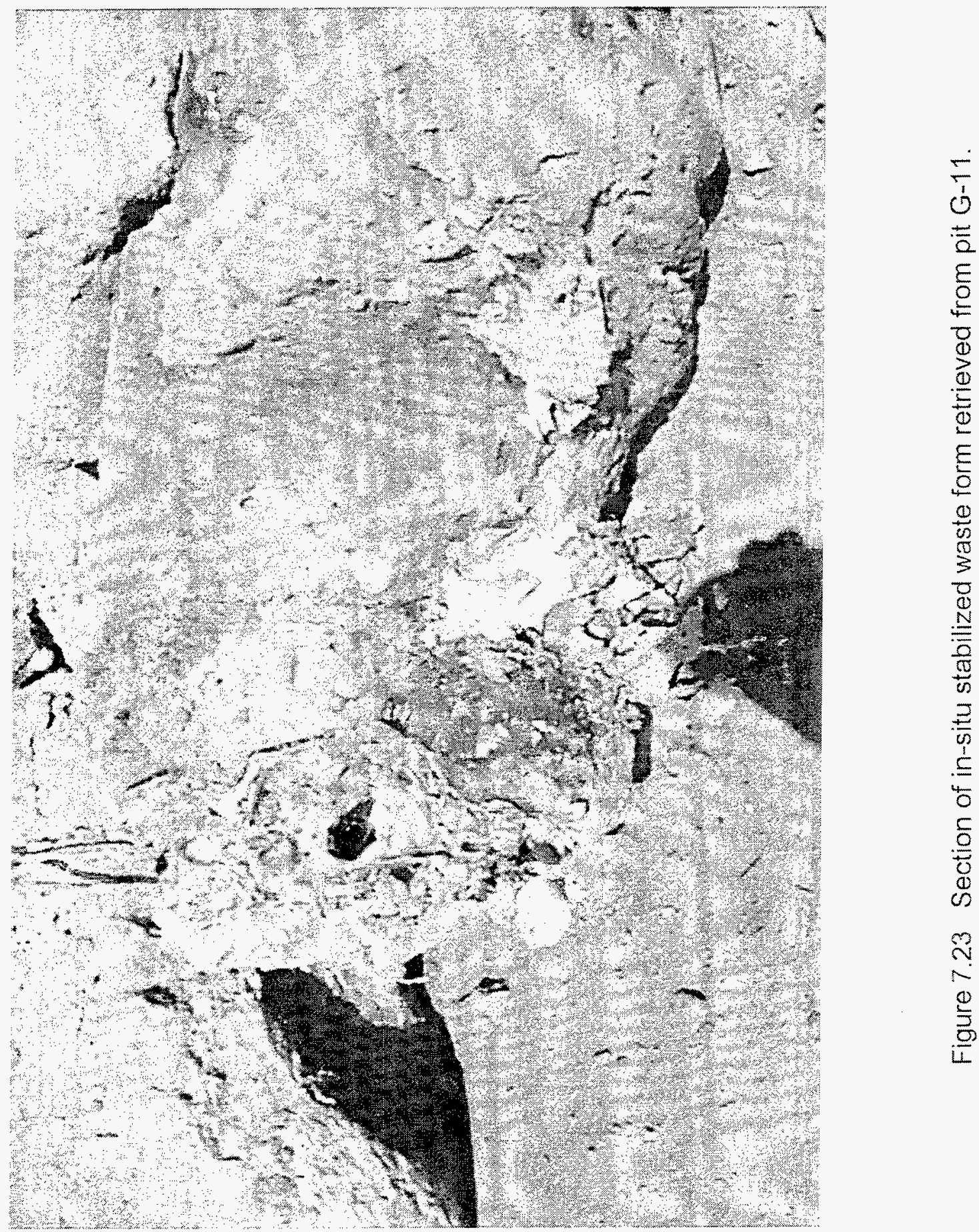




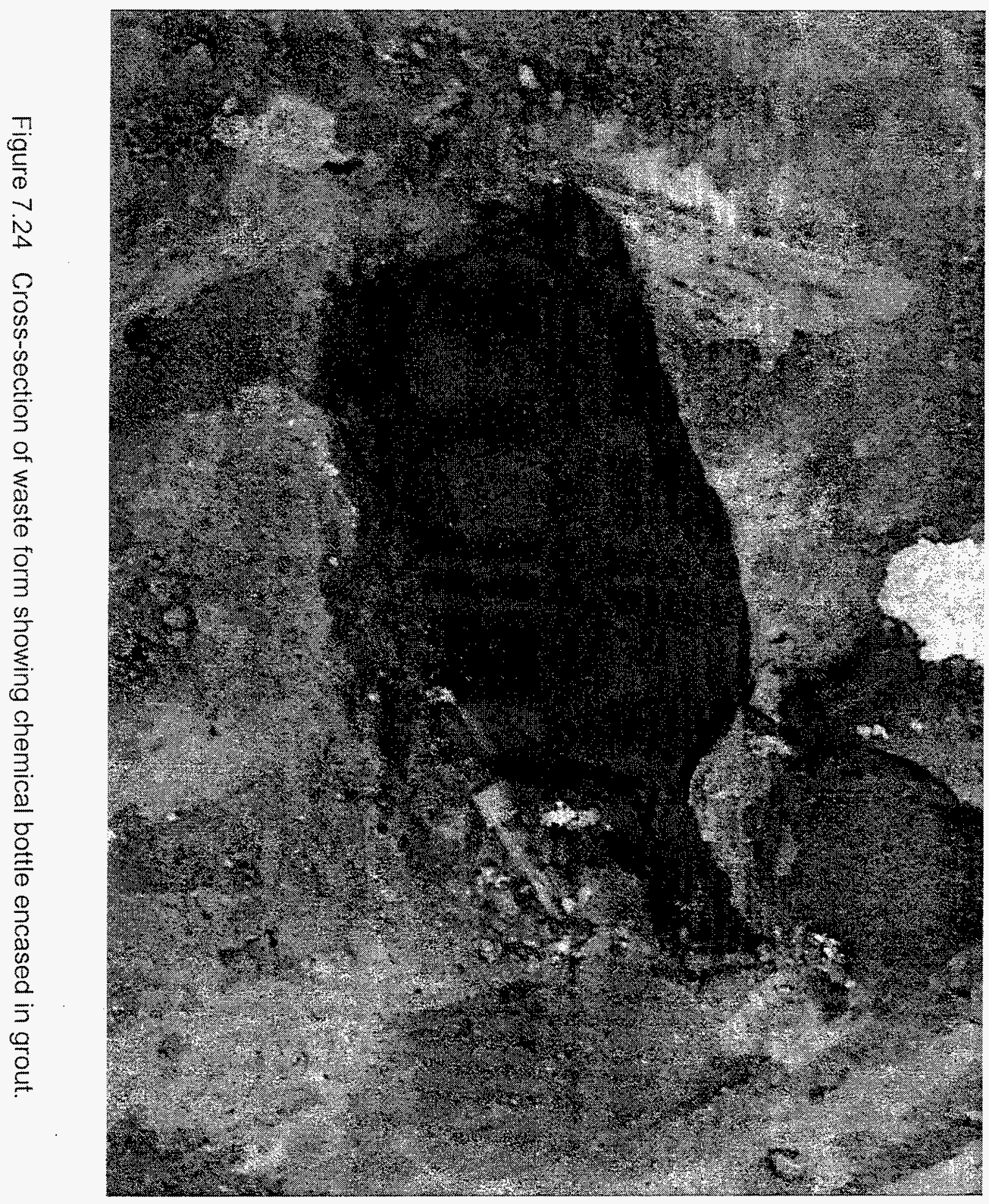




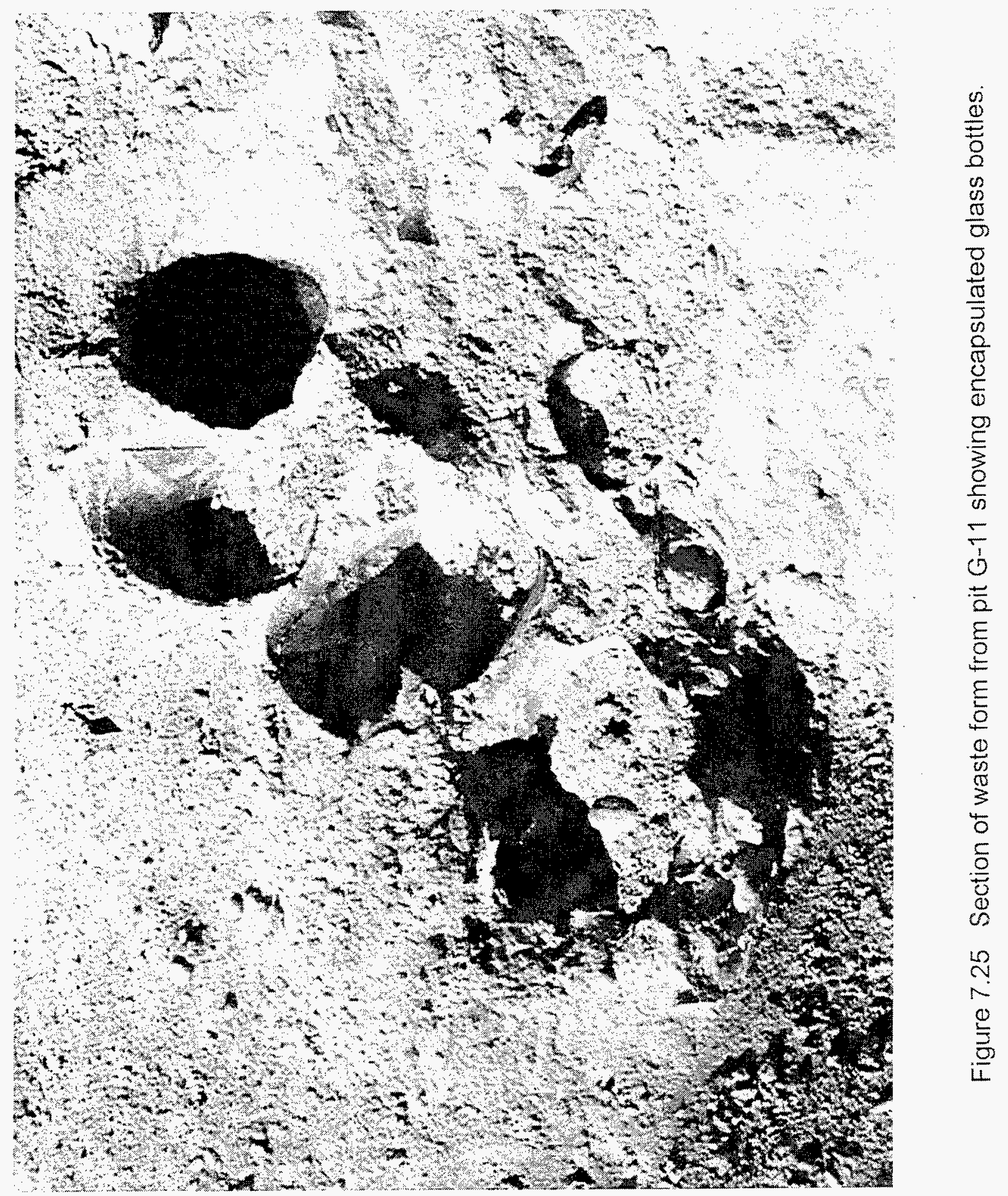




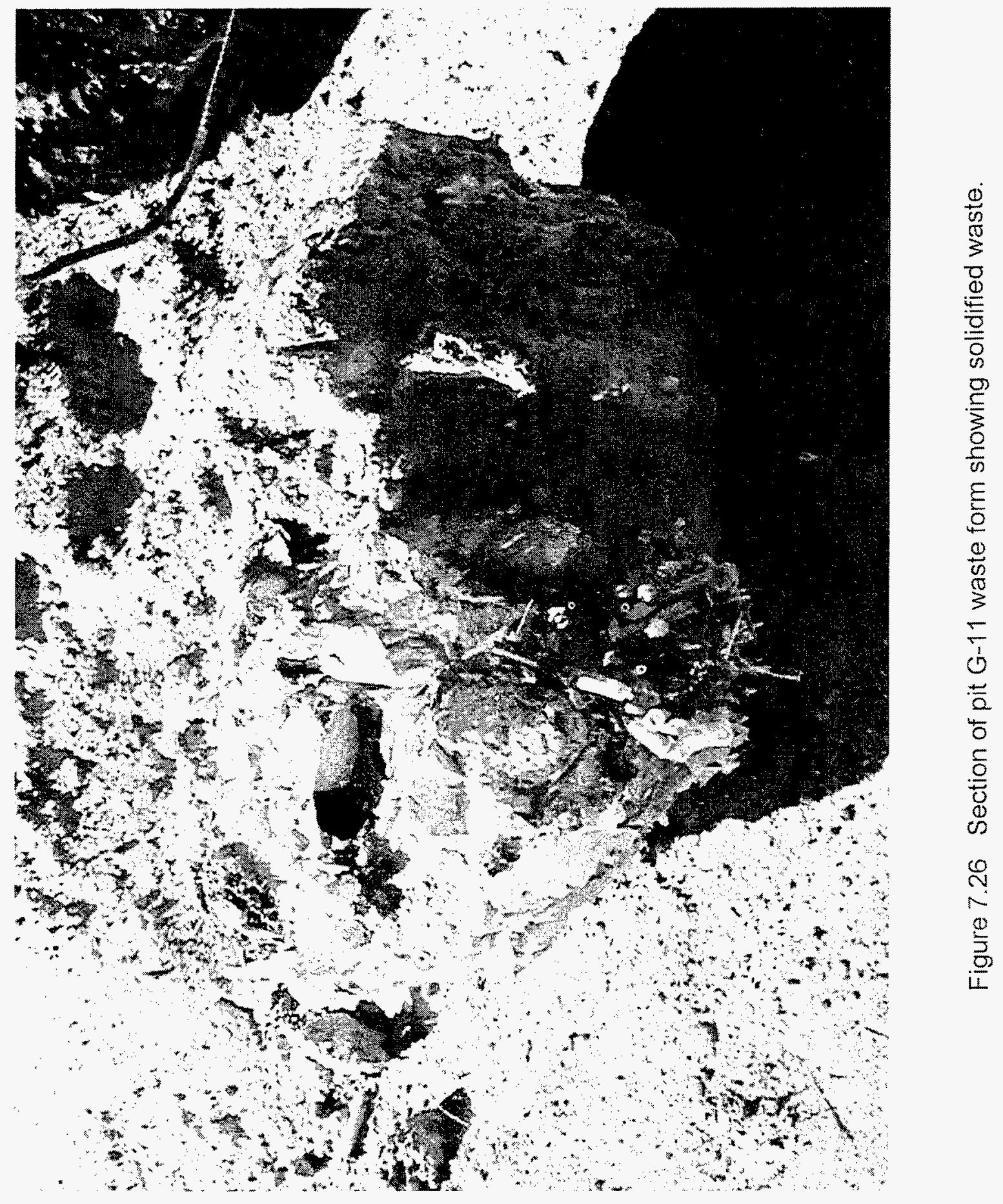


Since the bottom of all four walls was removed the remaining portions of the barrier were also removed. The walls all appeared intact and no major breaches were observed prior to demolition by the backhoe. It was difficult to see fine detail during the excavation/remediation process since loose dirt covered parts of the walls. As each large piece of wall was removed and placed above ground, inspection showed good overlap between columns, uniformity in the column diameters along their lengths and no small holes were observed (Figures 7.27 to 7.30 ). In all, the cement barrier construction appeared to be high quality and continuous.

\subsection{Laboratory Evaluation of the Barrier}

This barrier was employed at a remediation site and had to be left reasonably undisturbed until the waste forms were removed from the site. We could not extensively core holes or excavate the barrier without compromising the integrity of the containment until after the monolithic waste forms were removed. At this time limited data are available on the compressive strength, density and hydraulic conductivity of the cement portion of the close-coupled barrier. A section of the upper portion of the cement layer was recovered during the initial uncovering of the monolith and barrier. This approximately 1 meter long column section was then cored using a diamond tipped coring bit and a coring drill with water lubrication. Cores were taken radially through the section. Two sizes were cored $4.4 \mathrm{~cm}$ (1.75 inches) and $9.5 \mathrm{~cm}$ ( 3.75 inches). The cores were then cut to specific lengths using a wet diamond-blade cutoff saw.

Densities were measured for the core samples by weighing the samples and calculating the sample volume from measurements taken using a vernier caliper. Measurements were taken at three heights along the cylinder and at roughly equidistant locations along the diameter and average values were used for the volume calculations. The density of the cement core samples averaged $1.84 \mathrm{~g} / \mathrm{cm}^{3} \pm 0.10 \mathrm{~g} / \mathrm{cm}^{3}$. This compares to 1.93 to $2.01 \pm 0.03 \mathrm{~g} / \mathrm{cm}^{3}$ measured for the Hanford barrier. Inspection of the density data showed two distinct ranges of density. By subdividing the data into two categories; outside samples and inside samples a better understanding of the data may be obtained. The inside samples had densities averaging $1.93 \pm 0.05 \mathrm{~g} / \mathrm{cm}^{3}$ and the outside samples averaged $1.75 \pm 0.04 \mathrm{~g} / \mathrm{cm}^{3}$. The scatter in each of these groups is considerably lower than the combined group. The difference from outside to inside most likely is attributable to grout to soil ratio differences. The outside area of a column represents the furthest penetration of the jet and hence should receive less grout that the inner regions. Such difference in grout/soil ratios may also explain the lower strength and higher permeability seen for the BNL cement layer versus the Hanford cement layer.

For compressive strength measurements the samples were sized to meet the 2:1 length to diameter ratio specified in the ASTM standard. This resulted in nine cylinders $4.4 \mathrm{~cm}$ in diameter by $8.8 \mathrm{~cm}$ in length and three cylinders $9.5 \mathrm{~cm}$ in diameter by $19 \mathrm{~cm}$ in length. Compressive strength was measured following ASTM C-39, results are given in table 7.1. The smaller cylinders averaged $6.8 \pm 1.2 \mathrm{MPa}$ and the large cylinders averaged $5.1 \pm 0.1 \mathrm{Mpa}$. As might be expected the scatter in the larger samples is considerably less. Inhomogeneities such as aggregate (pebbles, stones, etc.) size have a greater effect on the smaller (less representative) 


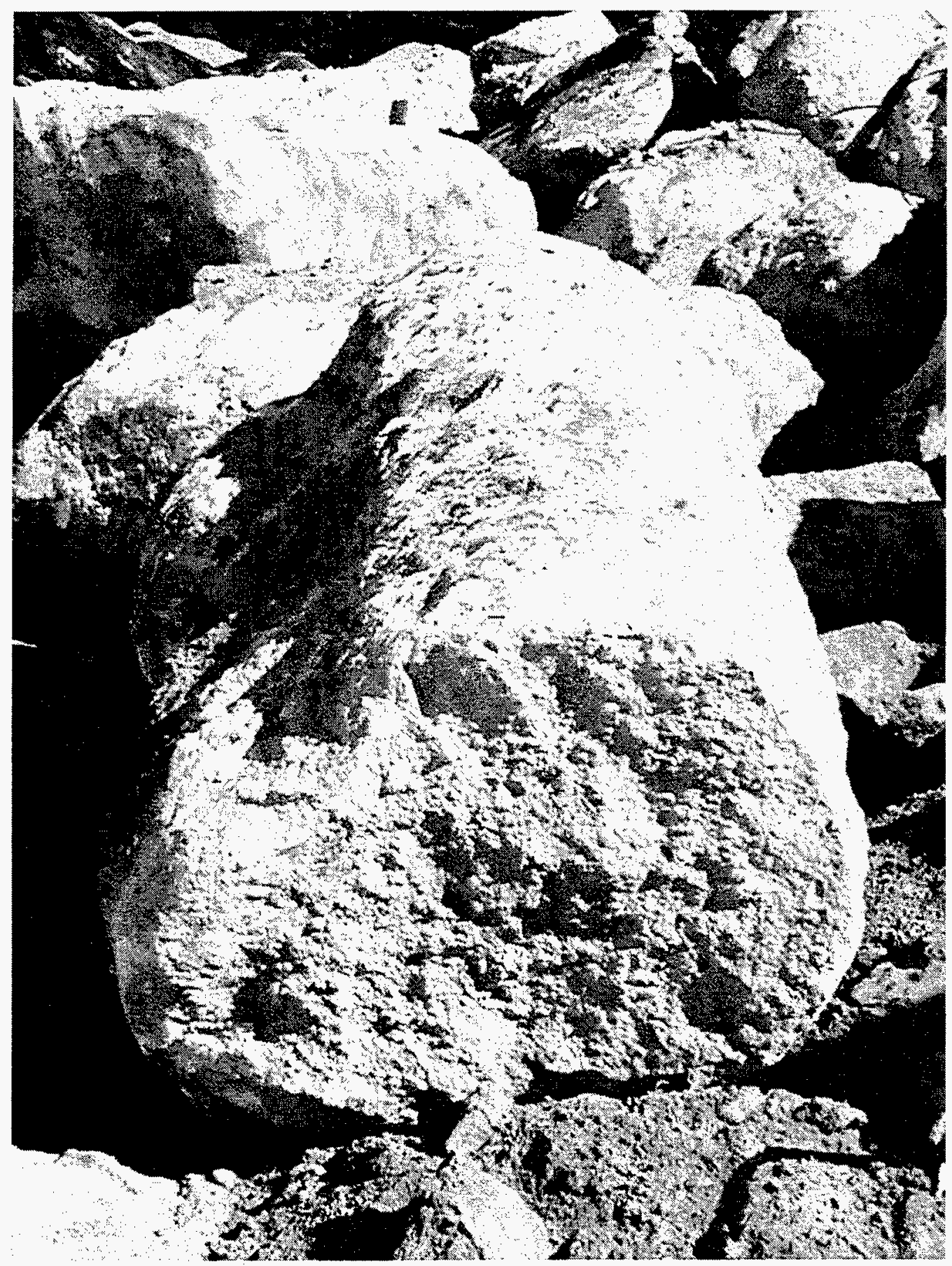

Figure 7.27 Section of the cement layer of the BNL close-coupled barrier showing adjacent columns 


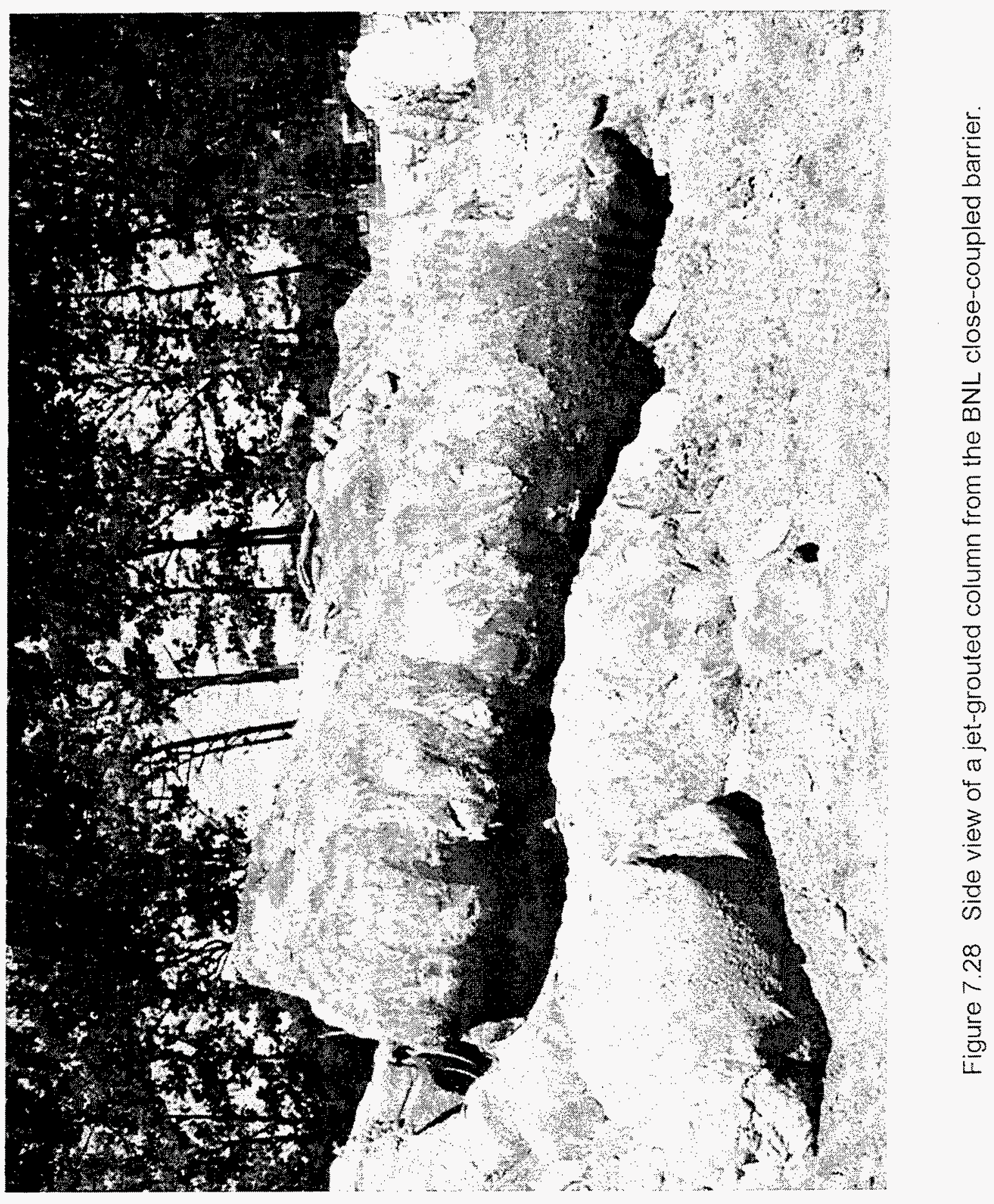




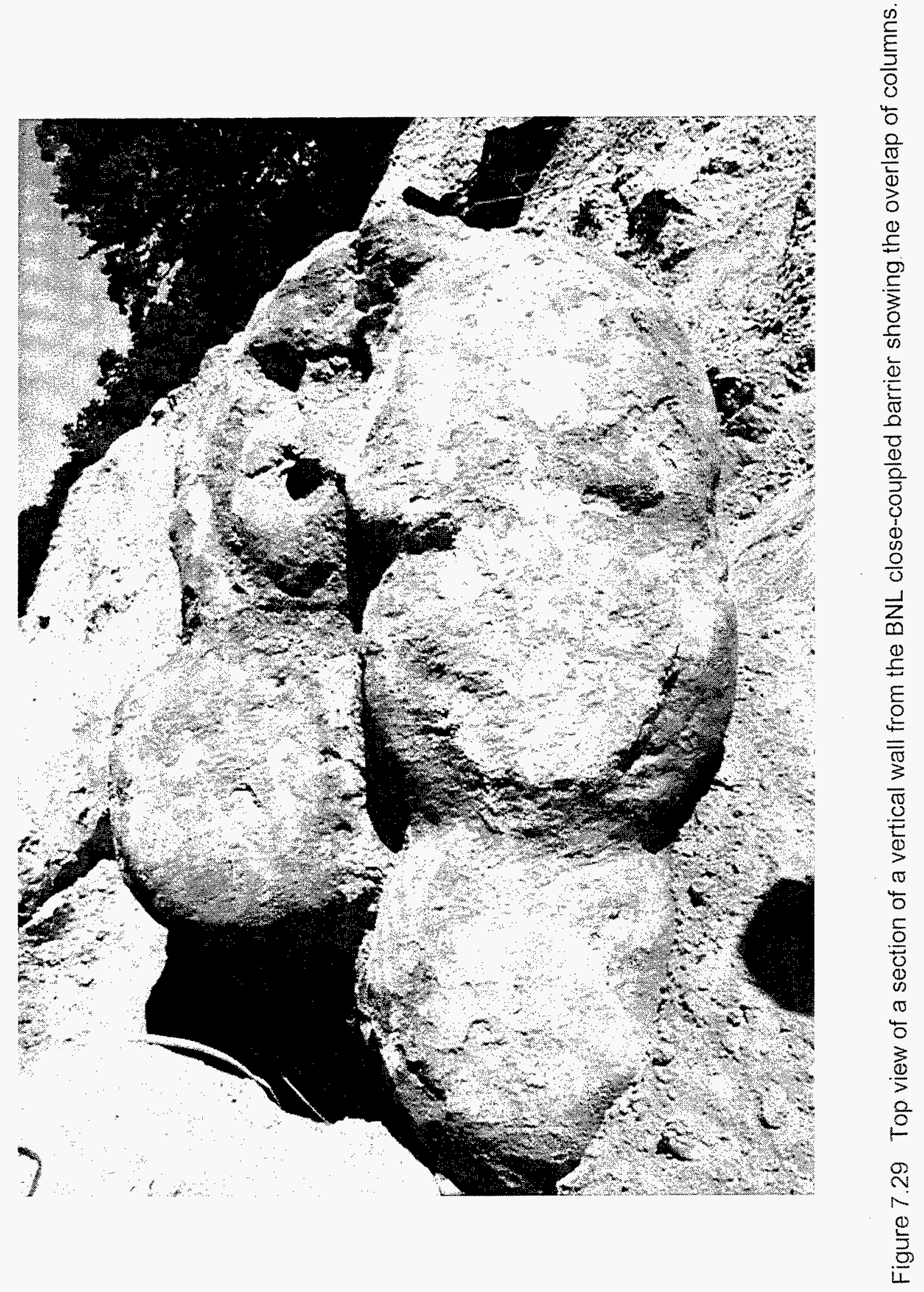




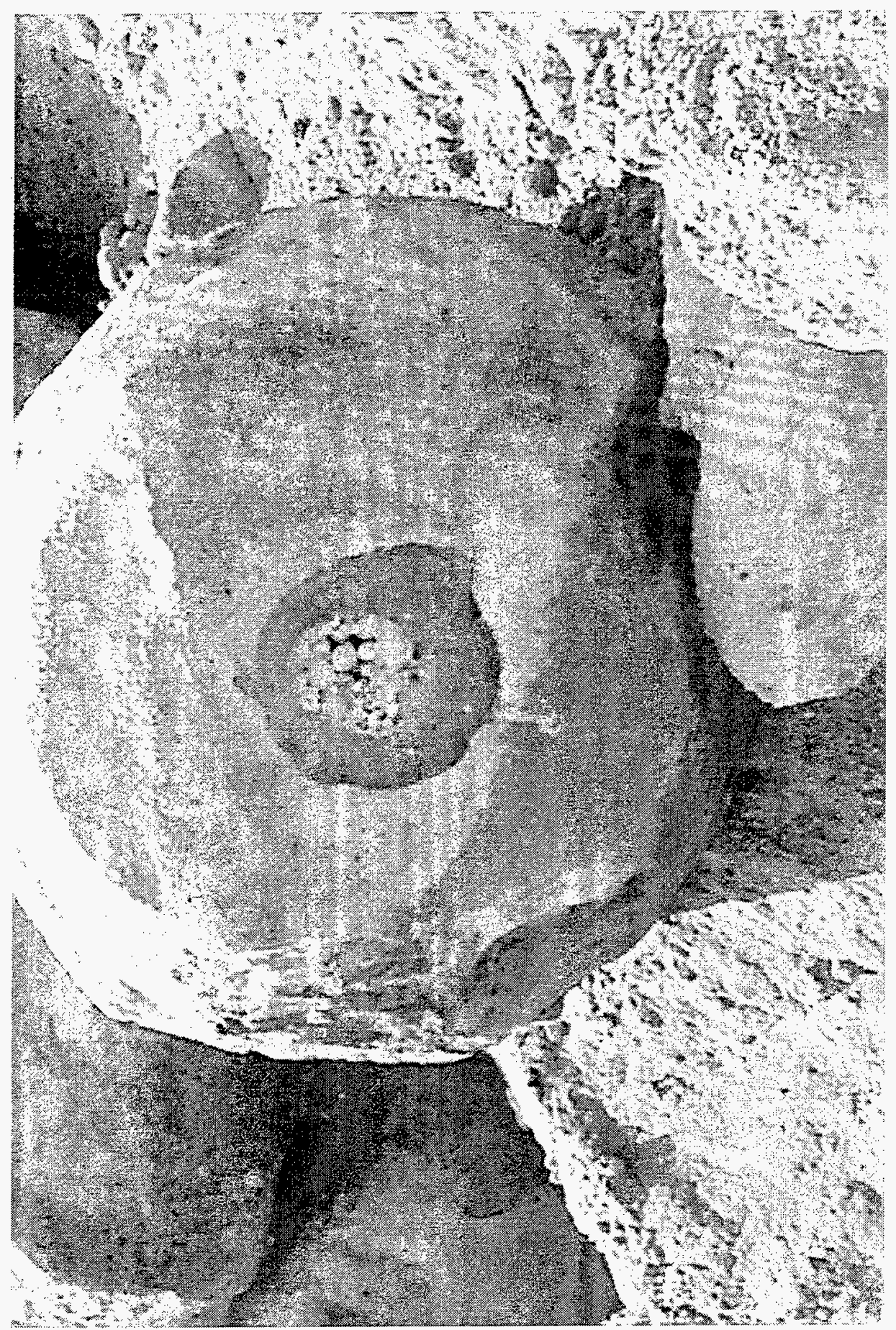

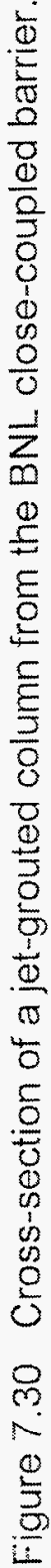


cylinders than they do on the larger (greater sampling volume) cylinders. The values obtained for the BNL cement layer are much lower than values obtained for the cement layer at the Hanford barrier $(20.1 \pm 4.3 \mathrm{MPa})$. This may be due to differences in soil (aggregate) particle size or some differences in curing or grout/soil ratios.

Table 7.1 Compressive strength of core samples taken from the cement layer of the BNL close-coupled barrier at pit G-11

\begin{tabular}{|rrrrrrr|}
\hline & \multicolumn{2}{l}{ LOAD (lbs) } & \multicolumn{2}{c|}{ Strength (psi) } & \multicolumn{2}{c|}{ Strength (MPa) } \\
sample size & $4.4 \mathrm{~cm}$ & $9.5 \mathrm{~cm}$ & $4.4 \mathrm{~cm}$ & $9.5 \mathrm{~cm}$ & $4.4 \mathrm{~cm}$ & $9.5 \mathrm{~cm}$ \\
\hline & 2820 & 8220 & 1172 & 744 & 8.1 & 5.1 \\
& 2360 & 8080 & 981 & 732 & 6.8 & 5.0 \\
& 2500 & 7980 & 1039 & 723 & 7.2 & 5.0 \\
& 2280 & & 948 & & 6.5 & \\
& 3200 & & 1330 & & 9.2 & \\
& 1920 & & 798 & & 5.5 & \\
& 2120 & & 881 & & 6.1 & \\
& 2420 & & 1006 & & 6.9 & \\
Average & $\mathbf{2 3 8 2}$ & $\mathbf{8 0 9 3}$ & $\mathbf{9 9 0}$ & $\mathbf{7 3 3}$ & $\mathbf{6 . 8}$ & $\mathbf{5 . 1}$ \\
Stand. Dev. & $\mathbf{4 0 6}$ & $\mathbf{9 8}$ & $\mathbf{1 6 9}$ & $\mathbf{9}$ & $\mathbf{1 . 2}$ & $\mathbf{0 . 1}$ \\
\hline
\end{tabular}

Four samples, $4.4 \mathrm{~cm}\left(1.75^{\prime \prime}\right)$ diameter, were measured for hydraulic conductivity, the lengths ranged from 3.5 to $4.0 \mathrm{~cm}$. The hydraulic conductivities were measured using a flexible wall permeameter following ASTM D-5084 (for details of methodology see section 5.9.3.1). Conductivities ranged from $1.1 \times 10^{-6} \mathrm{~cm} / \mathrm{sec}\left[1.1 \times 10^{-8} \mathrm{M} / \mathrm{s}\right]$ to $1.6 \times 10^{-8} \mathrm{~cm} / \mathrm{sec}\left[1.6 \times 10^{-10}\right.$ $\mathrm{M} / \mathrm{sec}$, averaging $3.4 \times 10^{-7} \mathrm{~cm} / \mathrm{sec}\left[3.4 \times 10^{-9} \mathrm{M} / \mathrm{sec}\right]$. The values for these samples are an order of magnitude higher than the hydraulic conductivities measured for the cement layer of the Hanford close-coupled barrier of $3.7 \times 10^{-8} \mathrm{~cm} / \mathrm{sec}\left[3.7 \times 10^{-10} \mathrm{M} / \mathrm{s}\right]$. This difference may be related to the differences seen in strength and density. Spoils (grout return to the surface) were slightly higher at the BNL barrier than at the Hanford barrier. This would imply lower grout to soil ratios at the BNL installation, since pressure, rotation and withdrawal/step rates where similar in both installations. Lower grout/soil ratios would result in a lower strength, more porous barrier.

\subsection{Meeting the Demonstration Objectives}

All of the project installation objectives were met for the BNL pit G-11 close-coupled barrier. A close-coupled barrier was successfully installed that achieved all of the performance requirements with no technical complications. The polymer materials were installed using the dual fluid injection procedures developed at the INEEL and Hanford demonstrations and performed flawlessly. The AC-400 acrylate grout was placed and polymerized as planned. The barrier layers could not be checked for hydraulic conductivity due to the site being a working remediation site. Late in FY97 after the remediation project was completed and the barrier confines excavated 
the barrier was seen to be breach free and uniform throughout. Coring was completed on the barrier walls and preliminary data show as expected results. More extensive testing to determine if the performance objectives for the monolith stabilization were met will be performed during FY98. These results will be published in a separate report.

We were able to install the barrier without disturbing the waste form. This was evidenced by a lack of contamination being brought to the surface either on the drill stem via the spoils, no earth movements in the pit area, no VOCs were detected at the surface during barrier emplacement and no reported increases in groundwater contaminant levels as routinely monitored by BNL-OER in the area of the glass pits.

Prior to stabilizing the waste pit, we successfully employed the perfluorocarbon tracer verification technology to ascertain the integrity of the barrier. The PFT verification indicated that the barrier was intact and breach free and we could therefore continue with the stabilization task. The pft technology still requires further refinement to determine resolution limitations and to accommodate other complex barrier configurations, but the proof-of-concept was demonstrated and the pft technology can at least be employed as a go/no-go integrity check. We must now move forward to determine the limitations and to perfect the locating ability of the technology. We have limited ourselves to a location by transport rate and well location, there is a great deal of improvement that can be accomplished by incorporating multiple tracers and by refining the modeling.

The cost of the barrier was somewhat less than the Hanford barrier due to the less expensive polymer grout used. This was a minor portion of the barrier costs and amounted to a difference of $\sim \$ 25 \mathrm{~K}$. Section 5.10 briefly discusses the economics of close-coupled barriers and finds them favorable compared to many remediation alternatives.

Close-coupled barriers have been proven to be an achievable, cost-effective remediation technology. The cost of installing a composite barrier is offset by the cost savings of preventing further contamination of the subsurface either by inaction or cleanup activities. Dual-fluid jetgrouting has been shown to be reliable and commercially feasible. A standard jet grouting rig set up for single fluid injections was modified for $\sim \$ 80 \mathrm{~K}$ and is now capable of injecting two component, thermosetting polymers without the fear of early gelation clogging the fluid pathways. This injection methodology has also proven useful for in-situ stabilization of buried waste and can be used in many other remediation needs such as temporary leak control from underground storage tanks or sewer/discharge lines. The demonstrated subsurface barrier technology has proven commercially viable and a no-cost cooperative agreement between AGEC, Inc. and Sandia National Laboratories was reached to further the commercial applicability of the developed technology (see appendix B).

In-situ stabilization appears to have produced a reasonably well homogenized waste form. Smaller components such as bottles, glassware, syringes, etc were either broken up by the jet 
energy or were fully encased in grout. Larger components such as 55 gallon drums and pressure cylinders were left intact by the jet and were simply macroencapsulated.

The large monolithic waste form constructed from the pit contents using jet grouting with cement grout had to be resized for removal and disposal. Bristar demolition grout had no noticeable effect on the cement matrix and is not recommended for future use in waste form resizing. 


\subsection{REFERENCES}

1. U.S. Environmental Protection Agency, "Engineering Bulletin - Slurry Walls," EPA/540/S-92/008, October 1992.

2. $\quad$ P. A. Spooner et al., "Slurry Trench Construction for Pollution Migration Control," EPA-540/2-84-001, February 1984.

3. Science Applications International Corporation, "HANDBOOK: Remedial Action at Waste Disposal Sites (Revised), " EPA/625/6-85/006, October 1985.

4. B. Siskind and J. Heiser, "Regulatory Issues and Assumptions Associated with Barriers in the Vadose Zone Surrounding Buried Waste", Environmental and Waste Technology Center, Brookhaven National Laboratory, Upton, NY, February 1993, BNL-48749.

5. J. H. Heiser and Colombo, P., "Polymer Containment Barriers for Underground Storage Tanks", Waste Management '94, February 28 - March 3, 1994, Tucson, AZ.

6. J.H. Heiser and L.W. Milian, "Laboratory Evaluation of Performance and Durability of Polymer Grouts for Subsurface Hydraulic/Diffusion Barriers", Brookhaven National Laboratory, Upton, NY, 1994, BNL-61292.

7. Loomis, G.G., Thompson, D.N., and Heiser, J.H., "Innovative Subsurface Stabilization of Transuranic Pits and Trenches", Idaho National Engineering Laboratory, Idaho Falls, Idaho, December 1995, INEEL-95/0632.

8. Heiser, J. and Dwyer, B., "Demonstration of Close-Coupled Barriers for Subsurface Containment of Buried Waste", Conceptual Test Plan, Revision 2.0, Brookhaven National Laboratory, Upton, New York, July 1995, BNL-62573.

9. Phillips, S.J., and Stewart, W.E., "Interim Subsurface Barriers for U.S. Department of Energy Underground Storage Tanks", in Proceedings of the Information Exchange Meeting on Retrieval, Treatment and Processing, U.S. Department of Energy, Washington, D.C., 1993.

10. S.J. Phillips and D.D. Fischer, Construction and Preliminary Description of a Geotechnical Test Facility at the Hanford Site, Richland, Washington, Rockwell Hanford Operations, 1982, SD-RE-TI-048.

11. American Society for Testing and Materials, "Measurement of Hydraulic Conductivity of Saturated Porous Materials Using A Flexible Wall Permeameter," Philadelphia, PA, ASTM D-5084 (90).

12. American Society for Testing and Materials, "Standard Test Method for Consolidated Undrained Triaxial Compression Test on Cohesive Soils, " Philadelphia, PA, ASTM D4767 (88). 
13. American Society for Testing and Materials, "Compressive Strength of Cylindrical Concrete Specimens, " Philadelphia, PA, ASTM C-39 (86).

14. American Society for Testing and Materials, "Flexural Strength of Soil-Cement Using Simple Beam with Third-Point Loading," Philadelphia, PA, ASTM D-1635 (79).

15. American Society for Testing and Materials, "Wetting and Drying of Solid Wastes," Philadelphia, PA, ASTM D-4843 (88) .

16. Chris Reno, "Cryogenically Created Barrier Keeps Contamination in Place,": Environmental Remediation Technology, December 15, 1993.

17. Mark Cummings, "Thermally Enhanced Vapor Extraction System, " Los Alamos National Laboratory Report (December 13, 1995).

18. CDM Federal Programs Corporation, Brookhaven National Laboratory Chemical/Animal Pits and Glass Holes, Draft Evaluation Report, p.4-32, March 1996.

19. D'Ottavio, T.W. and R.N. Dietz, "Radon Source Rate Measurements using Perfluorocarbon Tracers," Indoor Air '87, 4th International Conference on Indoor Air Quality and Climate, Berlin, Germany, 1987.

20. Horn, E.G., R.N. Dietz, R.M. Aldous, G. A. Leadon, L.J. Honan, and K.K. Seiffert, EPRI 1991 PCB Seminar, Baltimore, MD, 1991.

21. Hillel, D., Soil and Water, Physical Principles and Processes, Academic Press, p. 126, 1986.

22. Sullivan, T.M., A. Gard, and J. Heiser, (1996). "Modeling of Subsurface Barrier Performance," Waste Management '96, Tucson, AZ.

23. Nielson, K. K., and V.C. Rogers, "A Mathematical Model for Radon Diffusion in Earthen Materials," NUREG/CR-2765, U.S. Nuclear Regulatory Commission, Washington, D.C., 1982.

24. Rogers, V.C., K.K. Nielson, R.B. Holt, and R. Snoddy, "Radon Diffusion Coefficients for Residential Concretes," Health Physics, Vol. 67, No. 3, pp. 261 - 265., 1984.

25. Sullivan, T. M., and C.J. Suen, "Low-Level Waste Shallow Land Disposal Source Term Model: Data Input Guides, “ NUREG/CR-5387., 1989.

26. Davis, K., and Sandness, G., "Ground-Penetrating Radar for Remotely Controlled Site Characterization", paper 31, Proceedings of the Information Exchange meeting on Characterization, Sensors, and Monitoring Technologies, July 15-16, 1992, Dallas, Texas, CONF- 920791-draft. 
27. Baumgart, C., Pounds, T.Warthen, B. and Mathes, J., Characterization of Subsurface Barriers for Hazardous Waste Containment, Allied Federal Manufacturing Technologies, New Mexico, 1996.

28. Schneider, G.J. and Pfeifer, M.C., Final Report on Non-Intrusive Characterization of the Chemical/Animal Pits and Glass Hole Areas at Brookhaven National Laboratory, Idaho National Engineering Laboratory, September 1996.

29. Bodocsi, A. and Bowers, M.T., "Permeability of Acrylate, Urethane, and Silicate Grouted Sands with Chemicals", Journal of Geotechnical Engineering, Vol. 117, No. 8, Aug 1991, pp 1227-1244. 
APPENDIX A

A-1 
date:

to:
from: Jerry L. Peace $\quad$ Jy
MS 1148
Sandia National Laboratories
Albuquerque, NM 87185-1148
(505) 284-2472

subject: Geotechnical Isolation Needs at the Mixed Waste Landfill, Sandia National Laboratories

The Environmental Restoration Project at Sandia National Laboratories, New Mexico has just completed the Mixed Waste Landfill Phase 2 RCRA Facility Investigation Report and submitted the document to the New Mexico Environment Department in Santa Fe, New Mexico and EPA Region 6 in Dallas, Texas for review. The Environmental Restoration Project has been evaluating the Mixed Waste Landfill since 1992 to assess the nature and extent of contamination, contaminant source, the rate and direction of contaminant migration, potential contaminant transport mechanisms, and potential corrective measures. The report identifies tritium as the contaminant of primary concern. Tritium has migrated laterally beyond the fenced perimeter of the landfill. Investigators have identified the Mixed Waste Landfill as a candidate for application of an EM-50 technology, specifically, subsurface isolation of laterally migrating contaminants.

The Mixed Waste Landfill occupies 2.6 acres in the north-central portion of Technical Area 3. The landfill was established in 1959 as a disposal area for low-level radioactive and mixed wastes. The MWL accepted low-level radioactive waste and minor amounts of mixed waste from March 1959 through December 1988. Approximately $100,000 \mathrm{ft}^{3}$ of low-level radioactive and mixed waste containing approximately $6300 \mathrm{Ci}$ of activity (at the time of disposal) were disposed of at the MWL.

The Mixed Waste Landfill consists of two distinct disposal areas: the classified area, occupying 0.6 acres, and the unclassified area, occupying 2.0 acres. Wastes in the classified area were disposed of in a series of vertical, cylindrical pits. Once pits were filled with waste, they were backfilled with soil then capped with concrete. Wastes in the unclassified area were disposed of in a series of parallel, north-south excavated trenches. Trenches were backfilled with soil on a quarterly basis and, once filled with waste, capped with originally excavated soils which had been stockpiled locally. 
Historical records reveal that a total of $1,861 \mathrm{Ci}$ of tritium were disposed of at the Mixed Waste Landfill from March 1959 to January 1983. 1,451 Ci were disposed of in the classified area of the landfill. The remaining $410 \mathrm{Ci}$ of the tritium disposed of at the landfill were disposed of in unclassified area trenches. Tritium levels range from 1100 $\mathrm{pCi} / \mathrm{g}$ in surface soils to $20,600 \mathrm{pCi} / \mathrm{g}$ in subsurface soils in the classified area of the landfill. The highest tritium levels are found within $30 \mathrm{ft}$ of the surface in soils adjacent to and directly below classified area disposal pits. Below $30 \mathrm{ft}$ bgs, tritium levels fall off rapidly to a few $\mathrm{pCi} / \mathrm{g}$ of soil. Tritium has migrated through the vadose zone to $120 \mathrm{ft}$ below ground surface and laterally $100 \mathrm{ft}$ east of the classified area.

The Mixed Waste Landfill has been recommended for institutional control and continued environmental monitoring and maintenance. If the administrative funds for institutional control and environmental monitoring and maintenance are not available, the landfill will be capped.

In preparation for capping of the landfill, the EM-50 Technical Task Plan (TTP) No. AL27SS21 technology would provide an engineered technique for eliminating two very common problems in capped landfills: (1) surface subsidence; and (2) mitigation of downward and lateral movement of mobile contaminants away from the site. The technology appears to be capable of emplacing subsurface grout materials that are compatible with the various waste forms and local geology without disrupting the waste.

EM-40 is prepared to provide services in the following areas: scope of work and design/performance criteria development, regulatory compliance (permitting issues), and health physics, radiation protection, and technical field support.

The Environmental Restoration Project at Sandia National Labs supports the testing and development of all technologies that increase the effectiveness and efficiency of the DOE's Restoration Project. Integration of EM-40 and EM-50 activities provides an opportunity to benefit the DOE environmental cleanup mission in the areas of: (1) technology development; and (2) cost savings. 


\section{NO COST COOPERATIVE AGREEMENT}

This Agreement sets forth the terms and conditions of a collaborative project (hereafter "Project") between Sandia Corporation (hereafter "Sandia"), and Applied Geotechnical Engineering and Construction, Inc. (hereafter "AGEC").

WHEREAS, the work under this Agreement will provide a direct benefit to the DOE, DoD, and EPA government agencies that are involved in environmental protection through containment of hazardous materials;

WHEREAS, Sandia manages and operates a federally-owned facility known as Sandia National Laboratories for the DOE under Contract No. DE-AC04-94AL85000;

WHEREAS, it is agreed and understood that any work done or actions taken by Sandia must be in accordance with the terms and conditions of its contract with DOE for the operation of Sandia National Laboratories, and must be in accordance with any successor contracts for the operation of Sandia National Laboratories;

WHEREAS, Sandia, for its defense, energy, and environmental programs continues to develop expertise in laboratory, pilot, and field testing of unique concepts, methods, and techniques for environmental problems;

WHEREAS, AGEC has research and development equipment, and experienced engineering staff to facilitate work under this Agreement;

WHEREAS, it is an objective of the Project to develop, test and commercialize the methodology for geotechnical isolation of buried waste. This technology includes the testing of materials compatible with virtually any waste form, and equipment capable of handling all geologic conditions that material could be buried in. This methodology integrates barrier materials, subsurface access equipment, grout injection systems, and consequently considers verification and monitoring of the final product, i.e., the, subsurface barrier;

WHEREAS, Sandia identified five major U.S. owned jet grout injection contractors, including AGEC, spoke with representatives, became familiar with capabilities of each contractor to gain an understanding of the state-of-the-art capabilities of contractors in the subsurface grout injection arena;

WHEREAS, AGEC has the required equipment and personnel expertise to emplace subsurface barriers in accordance with DOE EM-50 needs, and is the only contractor expressing an interest in working with Sandia to further develop, test, and commercialize technological advances in the subsurface barrier field;

WHEREAS, through continued developmental research, cost effective use of equipment, and improved technology for addressing national environmental concerns, Sandia, AGEC, the DOE, and other government agencies, and the private sector can benefit from this work; and 
WHEREAS, Sandia and AGEC agree to the following terms and conditions under which the Project will be conducted:

1. The technical planning, direction, execution and reporting of the Project will be made jointly by Sandia and AGEC.

2. Sandia will be the primary interface with DOE. AGEC may participate at Sandia's or DOE's request in oral and written reviews of the Project with DOE.

3. Sandia shall receive DOE funds to support all Sandia costs associated with the Project. AGEC shall be contracted by Sandia to provide work per the scope of work. The benefit to Sandia and the DOE from this partnership with AGEC is a cost savings associated with the last three years worth of technology specific training, equipment modifications, and the use of government owned equipment at a fraction of private industry costs. More specifically AGEC personnel have:

(1) Q Clearances

(2) Hazardous Waste/ Radiation Worker Training

(3) OSHA 40 Hour Training

(4) Intellectual Property related to the project development

(5) High Pressure Training

(6) EPA approved test/demonstration facility for developmental work

(7) Specialized tolling/support modules

(8) Geotechnical and heavy equipment support vehicles/equipment

(9) Project specific parts inventory

(10) Safety systems and written protocols

(11) Operational protocols

(12) Radiological dose reduction engineering systems

(13) EM 40, and EM-50 past/ongoing task support activities

(14) Performance development and materials testing laboratory

(15) QA/QC systems and protocols

4. Both parties to this Agreement may purchase items or services from third parties and contribute these items or services for use in the Project, if necessary;

5. The development, testing and commercialization of subsurface barrier technology within a period of no more than two (2) years is a goal of this Project. Commercialization, as an ultimate goal, is extremely important to the government and private sector as well as to regulatory bodies;

6. Dissemination of information developed as part of the Project will benefit Sandia, AGEC, the DOE, other government agencies and the private sector. Thus, Sandia and AGEC, either separately or jointly, may publicly report the results from the Project. Such formal documentation, if prepared by one Project party, will be reviewed by the other party for release prior to public dissemination; 
7. In-kind contributions of services to the Project would be expected of both Sandia and AGEC. Examples of such services would be securing a technology demonstration test site, and developing a preliminary scope of work;

8. All information generated under this Agreement shall be deemed the property of Sandia and unless otherwise identified pursuant to a separate written nondisclosure agreement, shall be nonconfidential;

9. The development of intellectual property under the Project, including patents and copyrights, is possible as part of this Agreement, consequently the allocation of rights in such intellectual property is governed by federal statutes (42 USC 5908), DOE regulations (Chapter 9 or Title 48 CFR) and Sandia's contract with DOE;

10. It is recognized that Sandia and AGEC may wish to keep certain background information proprietary, such as subsurface barrier emplacement methodologies. Such background information is usually not required to achieve the objectives of the Project and its publication is prohibited without the written approval of the party contributing the background information. Right and Tile to background information contributed to the Project shall be retained by the contributing party.

11. Sandia and AGEC will enter into a nondisclosure agreement, if necessary, to allow Sandia access and AGEC access to proprietary background information of the other party that may assist in conducting Project activities.

12. Nothing is implied in this Agreement that will prohibit verbal progress and written project updates by Sandia to the DOE. These reports shall not contain background or proprietary information of AGEC.

13. AGEC may share information generated under this Agreement with any third party that has an interest in a joint venture in which AGEC has an ownership or equity or a production sharing arrangement, but only for the purposes associated with the joint venture.

14. Sandia and/or the DOE will be allowed to publicize the Project and the participation of $A G E C$ as an example of Doe-supported technology transfer. Information about the Project prepared for public release by either party via oral, printed or electronic media will be reviewed by both Sandia and AGEC.

15. Sandia and AGEC agree to provide properly trained personnel to conduct activities under the Project. Each party shall be responsible for the safety, training and compensation of its own workers.

16. Sandia and AGEC make no warranty, express or implied, as to the accuracy or utility of any information, or patent rights developed under this Agreement. Sandia and AGEC further make no warranty, express or implied, that the use of any Sandia or AGEC information, or patent rights made available under this Agreement will not infringe any United States or foreign patent, copyright or trade secret. Under this Agreement, Sandia or AGEC information, or Patent rights are made 
available to the Project on an "AS_IS" basis. EXCEPT FOR THE WARRANTIES EXPRESSLY PROVIDED" HEREIN, ALL WARRANTIES EXPRESS OR IMPLIED, INCLUDING BUT NOT LIMITED TO THE IMPLIED WARRANTIES OF MERCHANTABILITY AND FITNESS FOR A PARTICULAR PURPOSE, ARE EXCLUDED HEREUNDER.

17. Sandia and the DOE, and their agents, officers and employees shall not be liable for any loss, damage (including incidental, consequential and special), injury or other casualty of whatsoever kind, or by whomsoever caused, to the person or property of anyone, including AGEC and their Affiliates, arising out of or resulting from the licenses granted to AGEC herein, or the accuracy and validity of information generated by Sandia used, sold, leased or transferred by AGEC, and to the extent such loss, damage, injury or other casualty is the direct result of licenses granted to AGEC, AGEC agrees for themselves, their successors and assigns, to indemnify and hold Sandia and the Government, harmless from and against all claims, demands, liabilities, suits or actions (including all reasonable expenses and attorney's fees incurred by or imposed on AGEC in connection therewith) for such loss, damage (including incidental, consequential and special), injury or other casualty.

18. The term of the Agreement shall be two (2) years from the effective date of this Agreement. However, either party may terminate its participation in the Project by providing notice in writing to the other party at least sixty (60) days in advance. Likewise, either party may request that the period of the Agreement to extended with the other party's concurrence. Sandia's participation in this Agreement is subject to the availability of DOE funding, and Sandia shall incur no liability for its partial or total failure to perform under this Agreement in the event that said funding is reduced or terminated. In the event that Sandia does not receive funding to allow participation in the Project by December 1, 1996, this Agreement becomes null and void.

19. This Agreement contains all the agreements of the parties with respect to the matters contained herein and no prior agreement or understanding pertaining to any such matter, shall be effective for any purpose. No provisions of the Agreement may be amended or added to except by an additional agreement in writing signed by the parties hereto.

20. Nothing contained in this Agreement shall be construed as establishing any partnership not as establishing any joint obligations except those specifically set forth herein. Each party hereto retains the right to conduct its own business as it sees fit. Nothing contained herein shall be interpreted or construed as precluding any party from carrying out its own other research or participating in other research, even though the same may parallel or overlap the work done in connection with this project. Neither party shall have any rights, including but not limited to rights to or under any patents, in any such other research conducted by the other party. 
APPROVED AND ACCEPTED:

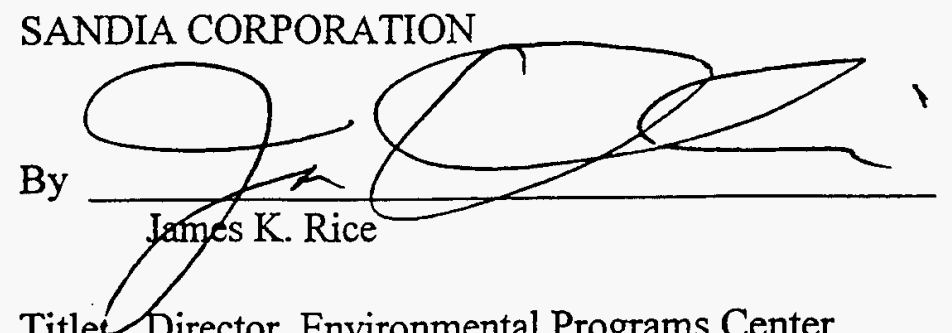

Title Director, Environmental Programs Center

Date: $11 / 13 / 96$

APPLIED GEOTECHNICAL ENGINEERING AND CONSTRUCTION, INC.

By:

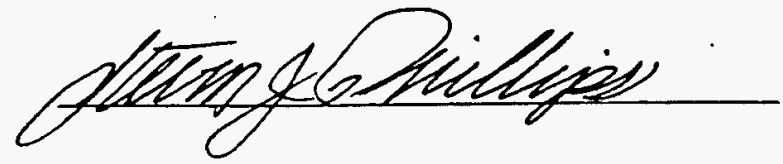

Title: President

Date: $11 / 26 / 96$ 


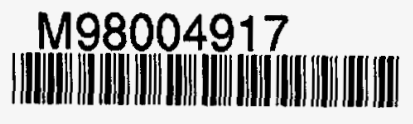

Report Number (14) BNL -52531

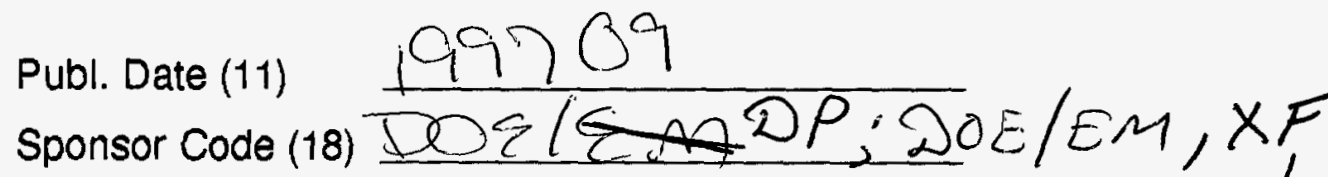
UC Category (19) UC-721; UC-2000, DOE/ER 